SERVIÇO DE PÓS-GRADUAÇÃO DO ICMC-USP

Data de Depósito:

Assinatura:

\title{
Personalização e adaptação de conteúdo baseadas em contexto para TV Interativa* $^{*}$
}

\author{
Rudinei Goularte
}

Orientador: Prof. Dr. Edson dos Santos Moreira

Tese apresentada ao Instituto de Ciências Matemáticas e de Computação - ICMC-USP, como parte dos requisitos para obtenção do título de Doutor em Ciências - Ciências de Computação e Matemática Computacional.

USP - São Carlos

Setembro de 2003

\footnotetext{
* Trabalho realizado com apoio FAPESP, processo número 98/15360-0.
} 
Dedico este trabalho a meus pais, João Raul Alves Goularte e Neusa Areco Goularte, que sempre me ofereceram seu carinho e apoio. 


\section{Agradecimentos}

Ao meu orientador, Professor Dr. Edson dos Santos Moreira, pela confiança, apoio e amizade.

À Flávia, pelo carinho, companheirismo, incentivo e pela compreensão com minhas ausências. Sem seu apoio tudo teria sido mais difícil.

À Professora Dra. Maria da Graça Campos Pimentel, pelo incentivo e pela rica troca de idéias com seu grupo de pesquisa.

Ao Professor PhD Gregory Abowd, por ter me recebido em seu grupo de pesquisa durante meu estágio no Georgia Institute of Technology.

Aos amigos Roberto Figueira Santos Filho, Renato de Freitas Bulcão Neto, Gustavo Blengini Faria e à Flávia, pela ajuda na revisão do texto e pelas sugestões.

À Gláucia Maria Saia Cristianini, pela revisão das referências.

Aos Amigos Francisco Gomes Milagres e Rodrigo Felício dos Santos, pela troca de idéias durante o desenvolvimento do trabalho.

Aos amigos do Intermídia, em especial ao Fernando Aires de Oliveira, pelo suporte técnico.

Aos amigos do ICMC, pelo companheirismo e incentivo.

Aos funcinários do ICMC, pela presteza e atenção com que sempre me atenderam.

Ao CCE-USP (Estúdio Multimeios) pelo suporte com as ferramentas MPEG-4 da Envivio.

À FAPESP, pelo apoio financeiro. 


\section{Sumário}

LISTA DE FIGURAS VII

LISTA DE TABELAS IX

LISTA DE SIGLAS $\mathbf{X}$

RESUMO XV

1.1 ANÁlise de TrabalHos RELACIONAdos 6

1.2 OBJETIVOS 9

1.3 Metodologia 9

1.4 ORGANIZAÇÃO DA TESE 11

$\underline{2}$ TV INTERATIVA 13

2.1 TELEVISÃo Digital 16

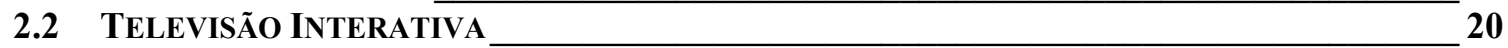

2.2.1 - TV EXPANDIDA

2.2.2 - TV PERSONALIZADA

2.3 MODELO DE REFERÊNCIA TV-ANYTIME

2.3.1 O MODELO FUNCIONAL DE REFERÊNCIA TV-ANYTIME

2.3.2 - O MODELO PARA METADADOS DO TV-ANYTIME —

2.4 OPORTUNIDADES E MODELOS DE NEGÓCIOS

2.4.1 - OPORTUNIDADES DE NEGÓCIOS

2.4.2 - CADEIA PRODUTIVA

2.4.3 - MOdELOS DE NEGÓCIOS DO TV-ANYTIME __ 36

2.5 CONSIDERAÇÕES FINAIS __ 39

$\underline{3}$ O PADRÃO MPEG-4 41

3.1 Visão Geral do PADRÃo MPEG-4 
3.1.1 - OBJETIVOS

3.1.2 - FUNCIONALIDADES 46

3.1.3 - ORGANIZAÇÃO DO PADRÃO MPEG-4_ 48

3.1 .4 - ARQUITETURA DE UM TERMINAL MPEG-4_51

3.2 DESCRITORES MPEG-4

3.2.1 - DESCRITOR DE OBJETO _ 55

3.2.2 - DESCRITOR DE FLUXO ELEMENTAR _ 58

3.3 CODIFICAÇÃO MPEG-4 60

3.3.1 -FUNCIONALIDADES DAS FERRAMENTAS DE CODIFICAÇÃO __ 60

3.3.2 -ESTRUTURA LÓGICA DO BITSTREAM MPEG-4_ 61

3.3.3 - COMPRESSÃO — 62

3.3.4 - ACESSO UNIVERSAL _ 63

3.4 DESCRIÇÃO DE CENAS_ 64

3.5 MPEG-J 67

3.6 PERFIS MPEG-4 70

3.7 Alternativas TeCnOlógicas aO Padrão MPEG-4_ $\mathbf{7 4}$

3.7.1 - X3D 74

3.7.2 - VETORES GRÁFICOS ESCALÁVEIS (SCALABLE VECTOR GRAPHICS - SVG) _ 74

3.7.3 - LINGUAGEM DE INTEGRAÇÃO MULTIMÍDIA SinCRONIZADA (SYNCHRONIZED MULTIMEDIA

INTEGRATION LANGUAGE - SMIL) _ 75

3.7.4 - FLASH _ 76

3.7.5 - Distribuição DE VÍDEO Digital - PlatAForma PARA MUlTimídia CASEIRA (DIGITAL

VIDEO BROADCASTING - MULTIMEDIA HOME PLATFORM - DVB-MHP) __ 76

3.8 CONSIDERAÇÕES FINAIS _ 76

$\underline{4}$ O PADRÃO MPEG-7 $\quad 79$

4.1 TERMinOLOGIA MPEG-7 82

4.2 AS PARTES DO PADRÃo MPEG-7 84

4.2.1 - PARTE 1 - SISTEMAS 85

4.2.2 - PARTE 2 - LINGUAGEM De DefiniçÃO DE DESCRIÇÕES __ 86

4.2 .3 - PARTE 3 - VISUAL _ 87

4.2.4 - PARTE 4 - ÁUDIO 88

4.2.5 - PARTE 5 - ESQUEMAS DE DESCRIÇÃO MULTIMÍDIA __ 88

4.2.6 - PARTE 6 - SOFTWARE DE REFERÊNCIA __ 89

4.2.7 - PARTE 7 - TESTES DE COMPATIBILIDADE_ 89

4.2.8 - PARTE 8 - EXTRAÇÃO E USO DE DESCRIÇÕES___ 90

4.3 OS ESQUEMAS DE DESCRIÇÃo MULTIMÍDIA__ 90

4.3.1 -FERRAMENTAS DE ESQUEMA ___ 93

4.3.2 - TIPOS BASE 94

4.3.3 - ELEMENTO RAIZ MPEG-7 95

4.3.4 - OS ELEMENTOS DE NÍVEL MAIS ALTO _ 96

4.4 OUTRAS ABORDAGENS PARA DESCRIÇÃO DE CONTEÚDO _ 98

4.4.1 - LINGUAGEM GENERALIZADA PADRÃO PARA MARCAÇÃO (STANDARD GENERALIZED
MARKUP LANGUAGE - SGML)

4.4.2 - LINGUAGEM DE ESTRUTURAÇÃO HIPERMÍDIA/BASEADA EM TEMPO (HYPERMIDIA/TIME-

BASED STRUCTURIG LANGUAGE - HYTIME) __ 99

4.4.3 - LinguageM DE MARCAÇÃo EXTENSÍVEL (EXTENSIBLE MARKUP LNAGUAGE - XML) _ 100

4.4.4 - ESQUEMA XML (XML SCHEMA) _ 101

4.5 CONSIDERAÇÕES FINAIS ___ 107 
5.1 DEFINIÇÃO DE CONTEXTO 113

5.2 DEFINIÇÃo de COMPUTAÇÃo CiENTE de CONTEXTO ___ 115

5.3 CLASSIFICAÇÃO DE CONTEXTO

5.4 REPRESENTAÇÃO DE CONTEXTO

5.5 CONSIDERAÇões FINAIS ___ 119

$\underline{6}$ REPRESENTACÃO DE CONTEXTO

6.1 Proposta para ClassificaÇão e OrganizaÇão de CONTEXTo _ 123

6.2 PROPOSTA PaRa REPRESENTAÇÃo De CONTEXTO

6.2.1 - ELEMENTO RAIZ _ 127

6.2.2 - CONJUNTO DE ESQUEMAS TIPOS DE CONTEXTO___ 128

6.2.3 - CONTEXTO PRIMÁRIO 132

6.2.4 - TIPOS PARA INFORMAÇÕES DE CONTEXTO 134

6.3 CONSIDERAÇÕES FINAIS _ 137

$7 \quad$ DESCRIC̃̃̃O DE OBJETOS DE MÍDIA $\quad 139$

7.1 RepresentaÇ̃̃o de Programas 143

7.2 REPRESENTAÇ̃̃o DE OBJETOS DE MídIA _ 145

7.2.1 - COMPOSIÇÃO DE OBJETOS

7.2.2 - DESCRIÇÕES DE MÍDIA E CONTEXTUAIS__ 150

7.2.3 - LIGAÇÕES E RELAÇÕES ENTRE OBJETOS 155

7.3 CONSIDERAÇÕES FINAIS

$\underline{8}$ PERSONALIZAÇÃO E ADAPTAČ̃̃O DE CONTEÚDO

8.1 O MOdElo Adotado _ 163

8.2 A INFRA-ESTRUTURA 166

8.2.1 - PRODUÇÃO DE CONTEÚDO _ _ 168

8.2.2 - DISTRIBUIÇÃO DE CONTEÚDO 170

8.2.3 - CONSUMO DE CONTEÚDO _ 172

8.3 Serviço de PERSONALIZaÇÃo _ 172

8.3.1 - EXEMPLOS DE PROGRAMAS PERSONALIZADOS 176

8.3.2 - ASSOCIAÇÃo DE DESCRIÇÕES A OBJETOS DE MÍdia __ 178

8.4 CONSIDERAÇÕES FINAIS _ 180

9 CONCLUSÕES 183

9.1 CONTRIBUIÇÕES

9.2 LIMITAÇÕES

9.3 Trabalhos DeCORRENTES DeSTa PeSQUiSa __ 188

9.4 SUGESTÕES PARA TRABALHOS FUTUROS 188

\begin{tabular}{lr} 
ANEXO A & 191 \\
\hline
\end{tabular} 
\begin{tabular}{lr} 
ANEXOC & 205 \\
\hline
\end{tabular}

REFERÊNCIAS $\quad 209$

APÊNDICE A

APÊNDICE B

APÊNDICE C

GLOSSÁRIO - 19 - 


\section{Lista de Figuras}

Figura 2.1 - Modelo de referência ITU para televisão digital (ANATEL, 2001).

Figura 2.2- Exemplo de um programa interativo (Microsoft, 2003b): (a) icone " $i$ " indicando presença de informação extra, (b) informação extra sendo exibida.

Figura 2.3 - (a) Exemplo de um PDR TiVo (Tivo, 2003). (b) Exemplo de um EPG usado para selecionar conteúdo armazenado no PDR (Tivo, 2003).

Figura 2.4 - O modelo funcional de referência do TV-Anytime (TV-Anytime, 2003).

Figura 2.5 - Modelo para fluxo de metadados (TV-Anytime, 2002). 27

Figura 2.6 - Diagrama hierárquico do esquema que implementa os metadados TV-Anytime. __ 30

Figura 2.7 - Diagrama da organização da cadeia produtiva em TV Interativa.

Figura 3.1 - Imagem não retangular (Ebrahimi \& Horne, 2000). —— 45

Figura 3.2 - Composição de uma cena audiovisual interativa (Avaro et al., 2000). _ 46

Figura 3.3 - Arquitetura de um terminal MPEG-4 (Avaro et al., 2000). 51

Figura 3.4 - Principais componentes do descritor de objeto (Herpel, 2002). 56

Figura 3.5 - Identificação de um fluxo através de um Descritor ES referenciado por um nó da cena (Herpel,

2002). 257

Figura 3.6-Referência a múltiplos descritores ES através de um OD (Herpel, 2002). __ 57

Figura 3.7 - Descritor de Objeto Inicial como referência para os fluxos descrição da cena e descritores de

objetos (Herpel \& Eleftheriadis, 2000). _ 58

Figura 3.8 - Fluxos descrição da cena e OD para uma cena hierárquica (Herpel \& Eleftheriadis, 2000). 58

Figura 3.9 - Principais componentes de um descritor de fluxo elementar (Herpel, 2002). 59

Figura 3.10 - Exemplo da estrutura lógica de um bitstream de vídeo MPEG-4 (Wollborn et al., 2002). _ 61

Figura 3.11 - Arquitetura de um terminal MPEG-4 equipado com o mecanismo MPEG-J (Swaminathan et al., 2002).

Figura 3.12 -Representação UML das APIs do terminal (Swaminathan et al., 2002).

Figura 3.13 - Relacionamentos entre XMT, SMIL, SVG e X3D (Avaro et al., 2002).

Figura 4.1 - Representação das relações entre descritores e esquemas de descrição (Nack \& Lindsay, 1999).

Figura 4.2 - Arquitetura de um Terminal MPEG-7 (Avaro \& Salembier, 2001). __ 85

Figura 4.3 - Organização do MDS MPEG-7 (Salembier \& Smith, 2001).

Figura 4.4 - Organização hierárquica dos tipos base MPEG-7 (ISO, 2001). _ 94

Figura 4.5 - Composição do elemento raiz MPEG-7 (ISO, 2001). _ 95

Figura 4.6 - Organização hierárquica dos tipos de mais alto nível (ISO, 2001). __ 97

Figura 4.7 - Exemplo de instância do elemento raiz MPEG-7.

Figura 4.8 - Exemplo de atributos do invólucro do esquema XML._ 102

Figura 4.9 - Exemplo de definição de um elemento. __ 103

Figura 4.10 - Exemplo de declaração, definição, e de instanciação de um atributo. __ 103

Figura 4.11 - Exemplo de definição de um tipo complexo. 105

Figura 4.12 - (a) Tipo derivado com extensão via simpleContent. (b) Tipo derivado com extensão via complexContent.

Figura 4.13 - Exemplo de tipo anônimo. 106

Figura 4.14 - Exemplo de grupo de atributos.

Figura 6.1 - Componentes do contexto do sistema. 124

Figura 6.2 - Diagrama hierárquico do elemento raiz e sua relação com os elementos de contexto.__ 127

Figura 6.3 - Diagrama de classes UML para o tipo ContextType. __ 128

Figura 6.4 - Diagrama de Classes UML para o contexto da Infra-Estrutura (InfrastructureType).__ 129 
Figura 6.5 - (a) Tipo LapTopType representando um novo dispositivo. (b) Instância de um dispositivo do tipo LapTopType.

Figura 6.6 - Diagrama de Classes UML para os contextos da Aplicação (ApplicationsType) e do Usuário (UsersType).

Figura 6.7 - Diagrama de classes UML para o contexto do Sistema (SystemType).

Figura 6.8 - Diagrama de classes UML representando o contexto Primario (PrimaryContextType). 133

Figura 6.9- Instância válida para o tipo LapTopType.

Figura 6.10 - Exemplos de tipos representando informações de contexto, (a) um tipo simples e (b) um tipo composto.

Figura 6.11 - Exemplos de instâncias de tipos diferentes para um componente de contexto Primário, (a) fullNameType e (b) simpleNameType.

Figura 7.1 - Composição de perfis de programas.

Figura 7.2 - Diagrama UML do esquema ITV-Program.

Figura 7.3 - (a) Elemento <MediaObject> como extensão do MPEG-7. (b) Uma instância do esquema

MediaObject.

Figura 7.4 - Diagrama UML do esquema MediaObject. 146

Figura 7.5 - Segmentação de um objeto de mídia. _ _ 148

Figura 7.6 - Hierarquia de objetos.___ 149

Figura 7.7 - Objetos compondo um quadro de vídeo. 149

Figura 7.8 - Descrição das características de mídia de um objeto. _ـ 151

Figura 7.9 - Descrição das características contextuais de um objeto intraquadro (local). __ 152

Figura 7.10 - Associação ente um objeto e sua descrição.

Figura 7.11 - Exemplo de descrição em arquivo separado. 154

Figura 7.12 - Referência ao arquivo contendo as descrições contextuais do objeto ID004 (“João”). __ 155

Figura 7.13 - Exemplo de relação entre dois objetos. 157

Figura 7.14 - Exemplo de ligação entre a descrição de um objeto e a de um programa._L 158

Figura 7.15 - Exemplo de ligação entre um programa e seus objetos. 159

Figura 8.1 - Infra-estrutura para produção, distribuição e consumo de programas de TV Interativa. __ 167

Figura 8.2 - Representação esquemática do serviço de personalização. 173

Figura 8.3 - Exemplos de descrições: (a) preferências de gênero de programas do usuário e (b) descrição do gênero de um objeto de mídia. __ 174

Figura 8.4 - Exemplo de acesso a um segmento de um programa interativo (Comentário). (a) Modo normal.

(b) Em "tela cheia".

Figura 8.5 - Exemplo de recuperação de informação de contexto associada a um objeto intraquadro. _ 177

Figura 8. 6-Exemplo de um programa personalizado e adaptado para acesso via PDA.___ 178 


\section{Lista de Tabelas}

Tabela 2.1 - Formatos e resoluções para TV digital (ANATEL, 2001). 18

Tabela 2.2 - Funcionalidades previstas para os novos serviços em TV Interativa. __ 32

Tabela 3.1 - Ferramentas MPEG-4.

Tabela 3.2 - Perfis para vídeo natural e tipos de objeto MPEG-4 (Koenen \& Pereira, 2002).___ 72

Tabela 3.3 - Niveis para os perfis Simple e Core (Koenen \& Pereira, 2002). __ 73

Tabela 4.1 - Lista de ferramentas para descrição e gerenciamento de conteúdo (ISO, 2002a). __ 92

Tabela 4.2 - Ferramentas de esquema MPEG-7 (ISO, 2001). __ 93

Tabela 6.1 - Funcionalidades dos elementos da biblioteca. _ـ 127

Tabela 6.2 - MPEG-7 e representações de informações de contexto.__ 136

Tabela 6.3 - Exemplos de tipos de informações contextuais presentes na biblioteca. _ 137

Tabela 7.1 - Esquemas de descrição MPEG-7 utilizados pelo elemento MediaFeatures. __ 150

Tabela 8.1 - Mapeamento das características do modelo para os elementos da infra-estrutura. __ 167

Tabela A1 - Características do modelo bidirecional em banda larga especificado pelo TV-Anytime Forum. 


\section{Lista de Siglas}

ABERT - Associação Brasileira de Emissoras de Rádio e Televisão.

ABNT - Associação Brasileira de Normas Técnicas.

ACE - Advanced Coding Efficiency (Eficiência Avançada de Codificação).

ANATEL - Agência Nacional de Telecomunicações.

API - Application Programming Interface (Interface para Programação de Aplicação).

ARTS - Advanced Real-Time Simple (Simples com Tempo Real Avançado).

ATM - Asynchronous Transfer Mode (Modo de Transferência Assíncrono).

ATSC - Advanced Television Systems Committee (Comitê para Sistemas Avançados de Televisão).

ATVEF - Advanced Television Enhancement Forum (Fórum para Melhoria de Televisão Avançada).

AVI - Audio Video Interleaved (Áudio e Vídeo Entrelaçados).

BIFS - Binary Format for Scenes (Formato Binário para Cenas).

BiM - Binary Format for MPEG-7 (Formato Binário para MPEG-7).

BST-OFDM - Band Segmented Transmission - Orthogonal Frequency Division

Multiplexing (Transmissão de Banda Segmentada - Multiplexação por Divisão de Freqüências Ortogonais).

B-VOP - Bidirectional Video Object Plane (Plano de Objeto de Vídeo Bidirecional).

CC/PP - Composite Capability/Preference Profiles (Capacidade de Composição/Pefis de Preferência).

CIF - Common Intermediate Format (Formato Intermediário Comum).

COFDM - Coded OFDM (OFDM Codificado).

CRID - Content Reference Identifier (Identificador de Referência de Conteúdo).

CS - Camada de Sincronização.

D-Descriptor (Descritor). 
DAB - Digital Audio Broadcast (Difusão de Áudio Digital).

DDL - Description Definition Language (Linguagem de Definição de Descrição).

DEMUX - Demultiplexer (Demultiplexador).

DMIF - Delivery Multimedia Integration Framework (Arcabouço de Integração para Distribuição Multimídia).

DOM - Document Object Model (Documento do Modelo do Objeto).

DS - Description Scheme (Esquema de Descrição).

DTD - Document Type Definition (Definição de Tipo de Documento).

DVB - Digital Video Broadcasting (Distribuição de Vídeo Digital).

DVD - Digital Video Disc (Disco de Vídeo Digital).

DVR - Digital Video Recorder (Gravador de Vídeo Digital).

EBS - Envivio Broadcast Studio (ver glossário).

e-commerce - eletronic commerce (comércio eletrônico).

ECT - Envivio Coding Tools (ver glossário).

EDTV - Enhanced Definition Television (Televisão com Definição Melhorada).

EES - Envivio Encoding Station (ver glossário).

ELB - Envivio Live Broadcaster (ver glossário).

EPG - Electronic Program Guide (Guia de Programação Eletrônico).

ES - Elementary Stream (Fluxo Elementar).

ES Descriptor - Elementary Stream Descriptor (Descritor de Fluxo Elementar).

FGS - Fine Granularity Scalability (Escalabilidade de Granulosidade Fina).

FlexMux - Flexible Multiplexer (Multiplexador Flexível).

FTP - File Transfer Protocol (Protocolo para transferência de arquivo).

GOV - Group of Video Object Planes (Grupo de Planos de Objetos de Vídeo).

HDR - Hard Disk Recorder (Gravador em Disco Rígido).

HDTV - High Definition Television (Televisão de Alta Definição).

HTML - Hypertext Markup Language (Linguagem para Marcação de Hipertexto).

HTTP - Hypertext Transfer Protocol (Protocolo para Transferência de Hipertexto).

HyTime - Hypermidia/Time-based Structurig Language (Linguagem de Estruturação Hipermídia/Baseada em Tempo).

ICMC - Instituto de Ciências Matemáticas e Computacionais. 
IEC - International Engineering Consortium (Consórcio Internacional de Engenharia).

IEEE - Institute of Electrical and Electronics Engineers (Instituto dos Engenheiros Elétricos e Eletrônicos).

IETF - Internet Engineering Task Force (Força-tarefa de Engenharia Internet).

IOD - Initial Object Descriptor (Descritor Inicial de Objeto).

IP - Internet Protocol (Protocolo Internet).

IPI - Intelectual Property Identification (Identificação de Propriedade Intelectual).

IPMP - Intellectual Property Management and Protection (Gerenciamento e Proteção de Propriedade Intelectual).

ISBN - International Standard Book Number (Padrão Internacional para Número de Livro).

ISDB - Integrated Service Digital Broadcast (Serviço Integrado para Difusão Digital).

ISMN - International Standard Music Number (Padrão Internacinal para Número de Música).

ISO - International Organization for Standardization (Organização Internacional de Padronização).

ITU - International Telecommunication Union (União Internacional de Telecomunicações).

ITU-T - ITU Technology sector (Setor de Tecnologia do ITU).

I-VOP - Intracoded VOP (VOP Intracodificado).

JDBC - Java Database Connectivity (Conectividade com Bases de Dados em Java).

JDK - Java Development Kit (Kit para Desenvolvimento em Java).

JPEG - Joint Picture Experts Group (Grupo de Especialistas em Imagens).

LAN - Local Area Network (Rede Local).

LDTV - Low Definition Television (Televisão de Baixa Definição).

MDS - Multimedia Description Schemes (Esquemas de Descrição Multimídia).

MHP - Multimedia Home Platform (Plataforma para Multimídia Caseira).

MPEG - Moving Pictures Experts Group (Grupo de Especialistas em Imagens Moventes).

MPEG-J - MPEG Java.

NDR - Network Digital Recorder (Gravador Digital de Rede). 
NTSC - National Television Systems Committee (Comitê Nacional para Sistemas de Televisão).

OCI - Object Content Information (Informação de Conteúdo do Objeto).

OD - Object Descriptor (Descritor do Objeto).

PAL - Phase Alternating Line (Linha de Alternância de Fase).

PDA - Personal Digital Assistant (Assistente Pessoal Digital).

PDR - Personal Digital Recorder (Gravador Digital Pessoal).

P-VOP - Previous VOP (VOP Anterior).

QCIF - Quarter CIF (Um quarto de CIF).

QoS - Quality of Service (Qualidade de Serviço).

RAM - Random Access Memory (Memória de Acesso Aleatório).

RDF - Resource Description Framework (Arcabouço para Descrição de Recurso).

RTP - Real-Time Transfer Protocol (Protocolo de Transferência em Tempo Real).

RVLC - Reversible Variable Length Codes (Códigos de Tamanho Variável Reversíveis).

SDM - Servidor de Descrições Multimídia.

SDTV - Standard Definition Television (Televisão com Definição Padrão).

SECAM - Sequential Couleur Avec Memoire (Colorização Seqüencial com Memória).

SET - Sociedade Brasileira de Engenharia de TV.

SGDB - Sistema Gerenciador de Banco de Dados.

SGML - Standard Generalized Markup Language (Linguagem Generalizada Padrão para Marcação).

SMIL - Synchronized Multimedia Integration Language (Linguagem de Integração Multimídia Sincronizada).

SNHC - Synthetic and Natual Hybrid Coding (Codificação Híbrida Sintética e Natural).

SQL - Structured Query Language (Linguagem Estruturada para Consultas).

SVG - Scalable Vector Graphics (Vetores Gráficos Escaláveis).

t-commerce - television-based commerce (comércio baseado em televisão).

TV-I - TV Interativa.

UDP - User Datagram Protocol (Protocolo do Datagrama do Usuário).

UHTTP - Unidirecional Hypertext Transfer Protocol (Protocolo para Transferência Unidirecional de Hipertexto). 
UML - Universal Modeling Language (Linguagem de Modelagem Universal).

URD - Unidade Receptora-Decodificadora.

URI - Uniform Resource Identifier (Identificador Uniforme de Recursos).

USP - Universidade de São Paulo.

VBI - Vertical Blanking Interval (Intervalo Vertical em Branco)

VHDL - Very High-speed Integrated Circuit Hardware Description Language

(Linguagem de Descrição para Circuitos Integrtados de Hardwre com Velocidade muito Alta).

VO - Video Object (Objeto de Vídeo).

VOL - Video Object Layer (Camada de Objeto de Vídeo).

VOP - Video Object Plane (Planos do Objeto de Vídeo).

VRML - Virtual Reality Modeling Language (Linguagem de Modelagem para Realidade Virtual).

VS - Visual Object Sequence (Seqüência de Objetos Visuais).

W3C - World Wide Web Consortium (Consórcio WWW).

XDB - XML Database (Banco de Dados XML).

XM - Experimentation Model (Modelo de Experimentação).

XML - Extensible Markup Language (Linguagem de Marcação Extensível).

XMT - Extensible MPEG-4 Textual Format (Formato Textual MPEG-4 Extensível). 


\section{Resumo}

O trabalho apresentado nesta tese trata do desenvolvimento de técnicas com suporte à ciência de contexto, baseadas nos padrões MPEG-4 e MPEG-7, para personalizar e adaptar conteúdo em TV Interativa. Um dos desafios dessa área é desenvolvimento de programas personalizados com rico conteúdo multimídia, com alta interatividade e que, além disso, sejam acessíveis a partir de uma variedade de dispositivos (fixos ou móveis), atendendo às expectativas de interação e de acesso dos usuários. Grande parte do problema está no fato de que os modos encontrados na literatura para representar, descrever e compor programas de TV Interativa não oferecem suporte a contexto, não permitem a separação entre descrições de programas e descrições de objetos e possuem baixa granulosidade de segmentação. Essas características dificultam e, em alguns casos, impedem o desenvolvimento de aplicações avançadas em TV Interativa. As técnicas desenvolvidas neste trabalho são baseadas em esquemas de descrição, compatíveis com o padrão MPEG7, e na segmentação de programas em objetos MPEG-4. Os esquemas são utilizados para descrever a estrutura, a composição e a semântica de programas e de seus objetos componentes. Também foi definida e implantada uma infra-estrutura para produção, distribuição e consumo de programas. A utilização conjunta da infra-estrutura e das técnicas permite o desenvolvimento de aplicações avançadas em TV Interativa. Como um exemplo dessas aplicações, foi desenvolvido um serviço automático para personalizar e adaptar programas de TV Interativa, permitindo que um usuário possa acessar, sob demanda, programas especialmente produzidos para ele, contendo apenas assuntos de seu interesse e permitindo que o acesso possa ser realizado por dispositivos fixos ou móveis.

Palavras-chave: TV Interativa, MPEG-4, MPEG-7, personalização, adaptação de conteúdo. 


\section{Abstract}

The work presented in this thesis developed techniques with context-awareness support, based on the MPEG-4 and MPEG-7 standards, in order to personalize and to adapt Interactive $T V$ content. One of the challenges in this area is the development of personalized programs with rich multimedia content, high interactivity and accessibility through a variety of devices (mobile and non-mobile). Most part of the problem is that the approaches found in literature do not provide context support, do not allow separation between programs and objects descriptions and have low level of segmentation granularity. These features make difficult or impossible, in some cases, the development of Interactive TV applications. The techniques developed in this work are based on MPEG-7 compliant schemes and on programs segmentation into MPEG-4 objects. The schemes are used to describe structure, composition and semantics of programs and component objects. An infra-structure to creation, delivery and consumption of Interactive TV programs was also defined. The joint utilization of infra-structure and techniques allows for the development of Interactive TV advanced applications. As an example of these applications, this work developed an automatic Interactive TV personalization and adaptation service. This service allows a user to access, on-demand, a program specially designed to match his interests and allowing content access through devices with mobile and non-mobile features.

Keywords: Interactive TV, MPEG-4, MPEG-7, personalization, content adaptation. 
Capítulo

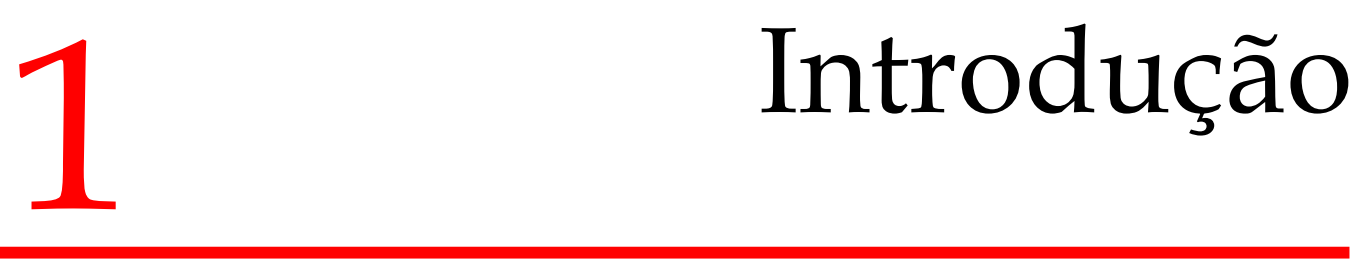


MODELO convencional da televisão tem dominado a comunicação audiovisual por anos. Esse modelo, largamente utilizado pelos sistemas de televisão aberta, possui características que limitam a interatividade: a linearidade dos programas, transmissão analógica por difusão, ausência de um canal de retorno e sincronismo entre transmissão e recepção. Essas características impedem ações como parar, retroceder e avançar programas durante sua exibição (incluindo programas ao vivo), obter informações sobre objetos aparecendo em uma cena simplesmente apontando para eles ou comprar produtos sendo anunciados do modo como é feito via Internet. Contudo, durante as últimas duas décadas, os avanços na tecnologia digital estão provocando uma evolução em termos de como o conteúdo audiovisual é produzido, distribuído e consumido.

O sucesso da WWW (World Wide Web) e a aceitação do seu modo interativo de operar têm claramente mostrado que o paradigma tradicional de televisão não irá continuar sendo suficiente para comportar serviços audiovisuais interativos. Usuários desejam ter acesso a áudio e vídeo do mesmo modo como eles têm acesso aos textos e gráficos da Web. Isso requer vídeo e áudio com qualidade razoável, com capacidade de serem transmitidos a baixas taxas de bits e com características de interatividade com conteúdo similares às da $W e b$ (paradigma $W e b$ ). Essa convergência entre televisão, multimídia e $W e b$ tem fomentado o desenvolvimento de um grande número de aplicações que visam fornecer: serviços personalizados, interação e busca baseadas em objetos, entrega e recepção independentes de dispositivo, entre outros.

Muitas aplicações utilizam multimídia como um elemento motivador à interatividade com o usuário. Porém, a diversidade de tipos de aplicações possíveis aliada ao fato de que cada uma impõe um conjunto diferente de especificações, tornam a representação e codificação de dados audiovisuais um grande problema. Além da representação, é necessário também permitir a interpretação do significado das informações contidas nos dados audiovisuais, de modo que as mesmas possam ser recuperadas com eficiência. A dificuldade está em associar informação semântica ao conteúdo dos dados audiovisuais, isto é, em como dar significado ao conteúdo (bits) de imagens e sons. 
A diversidade de aplicações, a necessidade de interconexão (na maioria dessas aplicações) e o desejo de trocar informações de modo transparente levaram a discussão sobre padronização na área de multimídia. A necessidade para qualquer padrão vem de um requisito essencial, relevante para qualquer aplicação envolvendo comunicação entre duas ou mais partes: interoperabilidade. Diversos esforços têm sido feitos em direção à padronização da representação de informações audiovisuais (Dublin Core, 2003; Apple, 2001; ISO, 1999). Dentre esses esforços se destaca o trabalho realizado pelo grupo MPEG (Moving Picture Experts Group) (ISO, 2003).

O grupo MPEG, desde 1980, vem trabalhando com padronização e codificação de dados audiovisuais, tendo produzido uma família de padrões. O padrão MPEG-1 (número ISO/IEC 11172) especifica a codificação de áudio e vídeo para entrega à taxa de 1,5 Mbps, para aplicações em CD-ROM e desktop. O padrão MPEG-2 (número ISO/IEC 13818) especifica a codificação genérica de sinais de vídeo, incluindo TV digital. Esses dois padrões estão intimamente ligados ao sucesso de produtos e serviços comerciais largamente adotados, como gravadores e reprodutores para Video-CD, DVD, difusão de áudio digital (Digital Audio Broadcasting - DAB) e MP3 (MPEG-1 Audio Layer 3). O padrão MPEG-3 tinha como objetivo a padronização de HDTV, mas foi cancelado e suas funcionalidades foram incorporadas ao padrão MPEG-2.

Diferente de seus antecessores, que trabalham codificando quadros (de áudio ou de vídeo), o padrão MPEG-4 (número ISO/IEC 14496) trata da codificação genérica de dados audiovisuais como objetos, os quais podem ser compostos para formar uma cena. Depois da definição do padrão MPEG-4 muita expectativa foi criada a respeito do nome do próximo padrão MPEG. A expectativa girava em torno dos nomes MPEG-5 (pois 5 é o sucessor de 4) e MPEG-8 (definindo um padrão exponencial de base binária - 1, 2, 4, 8, ...). Contudo, contrariando as expectativas, o grupo MPEG decidiu que o próximo padrão seria o MPEG7 (número ISO/IEC 15938), cujo objetivo é padronizar o modo de descrever conteúdo audiovisual. Dessa forma, os padrões MPEG-5 e MPEG-6, assim como o MPEG-3, não foram definidos. O padrão mais recente da família MPEG é o MPEG-21 (número ISO/IEC 21000, anteriormente ISO/IEC 18034) que tem como objetivo definir um arcabouço multimídia para habilitar o uso transparente e melhorado de recursos multimídia sobre uma 
variedade de redes e dispositivos em diferentes comunidades. Esse padrão ainda está em desenvolvimento.

A experiência adquirida pelo grupo atuante no laboratório Intermídia desde 1993, na pesquisa e desenvolvimento de sistemas multimídia e hipermídia distribuídos baseados em padrões, notadamente MPEG e W3C (World Wide Web Consortium) ${ }^{1}$, somada à experiência no desenvolvimento de aplicações que utilizam vídeo, tem motivado investigações sobre a utilização da tecnologia de vídeo interativo na construção de um protótipo de TV Interativa (TV-I).

A motivação para o desenvolvimento de sistemas para TV Interativa encontra eco ao redor do mundo. O desenvolvimento de padrões e o grande interesse da indústria eletrônica, operadoras de TV a cabo, companhias de telecomunicações e empresas de software e hardware têm impulsionado o desenvolvimento da TV Interativa como uma das principais aplicações da tecnologia de vídeo interativo. O maior benefício da TV-I para os usuários é a capacidade da cadeia geradora e distribuidora de vídeo em processar a informação digital para construir novos paradigmas de interação. Em particular, é esperada a construção de programas de TV personalizados especialmente projetados para atender às necessidades de cada usuário (Srivastava, 2002). Em uma situação ideal, cada usuário deve estar apto a assistir um programa de TV em um momento de sua escolha, com a duração que corresponda ao tempo que esse usuário tem disponível e com conteúdo que especificamente atenda aos interesses desse usuário (Merialdo et al., 1999; Srivastava, 2002).

Paralelamente ao desenvolvimento da TV-I, a computação está se tornando cada vez mais ubíqua, impulsionada pela proliferação de dispositivos móveis com acesso à Internet (como telefones celulares e computadores de mão). Esse fato, aliado à popularidade da Web, cria nos usuários expectativas de interagir com serviços e aplicações em qualquer lugar. Deseja-se que a interação ocorra a qualquer momento, independentemente do dispositivo utilizado e de modo a interferir minimamente no cotidiano do usuário. Contudo, dispositivos móveis impõem restrições no acesso a conteúdo devido ao seu tamanho reduzido, baixo poder de processamento, capacidade e tamanho de suas baterias e limitações de banda das redes utilizadas. A Computação Ubíqua, através da subárea Ciência

\footnotetext{
${ }^{1}$ www.w3.org. Acesso em 31 ago. 2003.
} 
de Contexto, explora a comunicação usuário-computador tirando vantagem da informação contextual inerente às interações para fornecer melhores serviços ao usuário (Abowd et al., 2002; Dey, 2001; Truong et al., 2001). Portanto, esse tipo de informação tem potencial para auxiliar o desenvolvimento de serviços avançados de TV Interativa, fornecendo conteúdo de acordo com o interesse do usuário ou capacidades dos dispositivos (Lum \& Lau, 2002).

Nesse cenário, torna-se um desafio o desenvolvimento de programas personalizados de TV Interativa com rico conteúdo multimídia, com alta interatividade e, além disso, que sejam acessíveis a partir de uma variedade de dispositivos (fixos ou móveis), atendendo às expectativas de interação e de acesso dos usuários. Esses tipos de serviços e aplicações necessitam que objetos multimídia (como vídeo) possam ser segmentados e possam ser compostos por subobjetos (Merialdo et al., 1999; Hjelsvold et al., 2001; Cosmas et al., 1999). Também necessitam de documentos descrevendo o programa e os objetos que o compõem (Hjelsvold et al., 2001; Lum \& Lau, 2002, Goularte \& Moreira, 2003). Essas descrições incluem: a composição dos programas e objetos, características de mídia dos objetos (como tamanho e tipo de codificação), informações de índice (como autor e data de criação), ligações e relacionamentos entre objetos e informações de contexto (como quem está na cena e qual o local onde a cena acontece ou quem é o usuário recebendo o conteúdo e onde ele está).

\section{1}

\section{Análise de Trabalhos Relacionados}

A segmentação de programas em aplicações de TV Interativa tem sido feita até o nível de seqüências, como em Hjelsvold et al. (2001) e Merialdo et al. (1999), limitando a interatividade a esse nível. O desenvolvimento de aplicações com interatividade baseada em objetos necessita que os segmentos sejam objetos e que os mesmos possam ser compostos por subobjetos. Além disso, devido ao conceito de objetos, espera-se que a segmentação possa ocorrer até o nível de regiões dentro de um quadro (objetos intraquadro). Essas características são completamente suportadas pelo padrão MPEG-4 (ISO, 2002). Contudo, por ser um padrão recente, suas características de segmentação têm sido pouco exploradas em aplicações de TV Interativa. Cosmas et al. (1999), apesar de utilizarem MPEG-4, realizam segmentação apenas até o nível de cenas. 
A maioria dos resultados de trabalhos anteriores em descrição de objetos de mídia, como em Benitez et al. (2000), Dublin Core (2003) e Lagoze \& Hunter (2001), foram absorvidos pelo padrão MPEG-7 (ISO, 2002a). Apesar de ser um padrão completo para descrever mídias, a utilização direta dos esquemas de descrição MPEG-7 gera instâncias desnecessariamente complexas. Outro aspecto a ser observado é que MPEG-7 não foi projetado para descrever programas de TV Interativa. Esquemas de descrição específicos para TV Interativa podem, contudo, aproveitar esquemas MPEG-7 para descrever as mídias que compõem os programas.

O problema de como produzir documentos específicos para TV Interativa foi abordado por vários trabalhos anteriores (Boll et al., 1999; Cosmas et al., 1999; Merialdo et al., 1999; Hjelsvold et al., 2001; Tsinaraki et al., 2001; Chorianopoulos et al., 2003). Esses trabalhos, contudo, não fornecem uma combinação adequada das representações estruturais e de metadados para programas e objetos de mídia. Uma exceção importante é o trabalho sendo desenvolvido pelo TV-Anytime Forum (TV-Anytime, 2000), o qual tem por objetivo produzir especificações para a área de TV Interativa, incluindo uma específica para descrição de programas (TV-Anytime, 2002). As especificações de programas TV-Anytime não fornecem suporte estruturado para informações de contexto e não fornecem os meios para produzir descrições de objetos de mídia separadas das descrições de programas, dificultando o reuso dessas descrições. Um outro problema das especificações do TVAnytime é o modo com que os esquemas MPEG-7 são utilizados para descrever os objetos de mídia: não é possível descrever objetos intraquadro.

A utilização de informações de contexto em aplicações de TV Interativa foi explorada em trabalhos anteriores do grupo. Em um desses trabalhos, Santos Júnior (2002) construiu uma modelagem sugerindo que informações de contexto podem ser usadas para auxiliar no gerenciamento de ambientes interativos. Questões pertinentes incluem: como caracterizar um ambiente, como saber quais serviços estão disponíveis em determinado ambiente, qual a forma mais adequada de se oferecer serviços tendo em vista os dispositivos disponíveis e as preferências do usuário. Para tratar essas questões existe a necessidade de se conhecer, além do contexto do usuário, a situação das aplicações, da rede e a situação das possíveis interações entre as aplicações e o sistema. Além disso, é necessário que as aplicações possam trocar tais informações (Santos Júnior et al., 2001). 
Contudo, trabalhos anteriores em ciência de contexto não relatam a definição de um modelo abrangente e flexível para representar informações de contexto de modo a permitir a troca homogênea dessas informações entre as aplicações (Abowd et al., 2002).

Em outro trabalho do grupo, Faria (2001) utiliza algumas especificações do TVAnytime Forum (TV-Anytime, 2002) para estruturar um programa de TV Interativa de modo a contemplar o uso de perfis de programas. As representações desenvolvidas permitem associar características de contexto, como as preferências de um usuário, aos perfis de programas. Os trabalhos de Santos Júnior (2002) e de Faria (2001) não abordam a representação de objetos de mídia, fornecem suporte a contexto pouco estruturado e representam segmentação de objetos somente até o nível das cenas.

A personalização e adaptação de informações em TV Interativa de acordo com as necessidades e interesses dos usuários é uma área de pesquisa muito ativa. Porém, poucos trabalhos têm investigado a personalização do conteúdo multimídia em si, e menos ainda usando computação ciente de contexto. Merialdo et al. (1999) descrevem um sistema de personalização para telejornais que otimiza o valor do conteúdo para um usuário específico. Cosmas et al. (1999) descrevem o projeto CustomTV, onde conteúdo MPEG-4 é usado para produzir programas, MPEG-7 é usado para auxiliar a personalização baseada nas preferências do usuário e as informações (conteúdo e metadados) são transmitidos via satélite em fluxos MPEG-2. Hjelsvold et al. (2001) discutem o desenvolvimento de uma aplicação, baseada em Web, que personaliza conteúdo de acordo com as preferências do usuário. Lum e Lau (2002) descrevem o desenvolvimento de uma estratégia, baseada em contexto, para adaptar o conteúdo de arquivos PDF em formatos mais adequados à recepção e visualização via dispositivos móveis. Esses trabalhos, de um modo geral, apresentam:

- Baixa granulosidade na segmentação de conteúdo, operando somente até o nível de cenas.

- Ausência ou carência de estruturação e flexibilidade na representação de informações de contexto e na separação entre descrições de programas e de objetos de mídia.

- Carência de interatividade baseada em objetos. 
- Carência de investigações sobre a adaptação de conteúdo baseado em vídeo para acesso via diferentes dispositivos.

\section{2}

Objetivos

Um dos objetivos desta tese é a definição de uma infra-estrutura para produção, distribuição e consumo de programas de TV Interativa, auxiliando o grupo rumo ao desenvolvimento de um protótipo de TV Interativa.

Outro objetivo deste trabalho é o desenvolvimento de um serviço, que opere usando a infra-estrutura definida, para gerar de modo automático programas personalizados de TV Interativa com rico conteúdo multimídia, com alta interatividade e que possam ser acessados a partir de diferentes dispositivos, fixos ou móveis.

Visando viabilizar o desenvolvimento do serviço de personalização e adaptação de conteúdo, outro objetivo deste trabalho é o desenvolvimento de técnicas que supram as carências de trabalhos anteriores apontadas na seção 1.1.

\section{3}

\section{Metodologia}

Para alcançar os objetivos a infra-estrutura foi definida seguindo o modelo de referência TV-Anytime para sistemas de TV Interativa (TV-Anytime, 2003). Foram analisadas as funcionalidades especificadas pelo TV-Anytime comparando-as com outras propostas encontradas na literatura. Como resultado chegou-se a um subconjunto de funcionalidades que servirão de base para as primeiras fases do desenvolvimento do protótipo de TV Interativa.

A infra-estrutura foi planejada para utilizar os padrões MPEG-4 na produção de conteúdo e MPEG-7 na descrição de conteúdo. Desse modo, os dois padrões foram analisados em detalhes, identificando-se métodos e softwares para produzir, segmentar e codificar conteúdo, no caso do MPEG-4, e métodos para criar esquemas de descrição compatíveis com o padrão MPEG-7. Os resultados dos estudos foram utilizados na implementação das técnicas e do serviço de personalização e adaptação de conteúdo. 
As técnicas desenvolvidas estão baseadas na composição de programas por subobjetos de mídia e em esquemas de descrição. Tais esquemas estruturam e organizam os documentos que descrevem os programas e os objetos de mídia componentes dos programas. Os esquemas desenvolvidos são mais flexíveis que outros métodos encontrados em trabalhos relacionados, permitindo a representação de informações de contexto, a separação entre descrições de programas e descrições de mídia, a descrição de objetos intraquadro, a descrição de relações entre objetos e a ligação entre objetos e suas descrições.

O desenvolvimento das técnicas previa a utilização de informações de contexto nas descrições de programas e objetos. Assim, foi realizado um estudo sobre a área de ciência de contexto, constatando-se a necessidade de se desenvolver modos de representar informação contextual. Essa representação foi também desenvolvida na forma de um esquema de descrição. Os esquemas para programas, objetos de mídia e contexto foram desenvolvidos em XML Schema (W3C, 2001d), uma vez que essa abordagem permitiu a integração dos mesmos com os esquemas MPEG-7.

O serviço de personalização foi desenvolvido em Java, devido à facilidade de execução em diferentes plataformas oferecida por essa linguagem e devido ao padrão MPEG-4 especificar uma API em Java: a MPEG-J (Swaminathan et al., 2002). O serviço utiliza as descrições dos programas e dos objetos de mídia, comparando-as com as preferências do usuário, para selecionar objetos de interesse e compor um programa personalizado. O serviço também usa tais informações para, se necessário, adaptar o conteúdo (recodificar objetos) de acordo com as capacidades do dispositivo sendo utilizado para acesso. A definição do novo programa é transformada em uma representação textual MPEG-4 (Kim \& Wood, 2002) por meio de uma ferramenta da infra-estrutura. O serviço utiliza então uma outra ferramenta da infra-estrutura para codificar a representação textual em uma apresentação MPEG-4 em formato binário, a qual pode ser transmitida ao usuário via a ferramenta de streaming da infra-estrutura.

O serviço contempla ainda interatividade baseada em objetos. Utilizando-se a API MPEG-J programas em Java podem ser associados aos objetos MPEG-4, permitindo fazer uso das descrições para potencializar o comportamento interativo. Por exemplo, ao clicar sobre a imagem de uma pessoa em um vídeo é possível apresentar ao usuário informações 
como: quem é e onde está essa pessoa ou uma lista de outros vídeos onde a mesma pessoa apareça.

\section{$\underline{1.4}$}

\section{Organização da Tese}

Esta tese está estruturada em nove capítulos, três anexos e três apêndices. O capítulo um apresenta esta introdução. Os capítulos de dois a cinco apresentam revisões da literatura em aspectos importantes para o desenvolvimento do projeto. Os capítulos de seis a oito apresentam o desenvolvimento e as contribuições do trabalho. O capítulo nove apresenta as conclusões e os trabalhos futuros.

O capítulo dois apresenta o estado da arte em TV Interativa, discutindo os principais conceitos e as classificações existentes. Também são apresentados os padrões existentes e os modelos de referência que serviram de base para a estruturação da infra-estrutura e para delimitar os serviços que se pretende explorar dentro do grupo.

O capítulo três fornece uma visão geral do padrão MPEG-4 e ao mesmo tempo detalha algumas de suas partes, as mais importantes no contexto deste trabalho. São apresentados seus objetivos, funcionalidades e organização. São detalhados os processos de codificação e de descrição de cenas, assim como a API MPEG-J, a qual permite associar programas Java aos objetos MPEG-4. Também é apresentada uma comparação entre o padrão MPEG-4 com outras alternativas para a produção de conteúdo multimídia.

O capítulo quatro apresenta uma visão geral do padrão MPEG-7, discutindo os principais conceitos e a organização do padrão. A parte do padrão relativa aos esquemas multimídia é detalhada, uma vez que esta parte é utilizada nos esquemas propostos nesta tese. Também é feita uma comparação entre o padrão MPEG-7 e outros padrões para a descrição de conteúdo, dando especial atenção à linguagem XML Schema, a qual é utilizada pelo padrão MPEG-7 e no desenvolvimento deste trabalho.

O capítulo cinco apresenta uma revisão sobre computação ubíqua, dando enfoque à subárea ciência de contexto. Nesse capítulo são apresentadas as definições e classificações de contexto e de computação ciente de contexto. Também é apresentada uma revisão demonstrando a carência de formas de representação de contexto homogêneas e flexíveis. 
O capítulo seis toma como base as definições e constatações apresentadas no capítulo cinco e apresenta uma proposta de representação de contexto. Tal proposta visa permitir que descrições de informação de contexto sejam inseridas de um modo padrão nas descrições de programas e de objetos de mídia, além de permitir o intercâmbio homogêneo desse tipo de informação.

O capítulo sete apresenta os esquemas desenvolvidos para a representação dos objetos de mídia e dos programas de TV Interativa. Tais esquemas utilizam as técnicas de representação de contexto apresentadas no capítulo seis para, em conjunto com as características de interatividade oferecidas pelo padrão MPEG-4, potencializar o desenvolvimento de serviços avançados em TV Interativa.

O capítulo oito apresenta a definição da infra-estrutura para produção, distribuição e consumo de programas de TV Interativa. As características da infra-estrutura foram definidas com base nos modelos de referência para TV Interativa apresentados no capítulo dois. Esse capítulo detalha os aspectos de implementação da infra-estrutura, assim como os meios pelos quais as instâncias dos esquemas propostos nos capítulos seis e sete são utilizadas pelo serviço de personalização de conteúdo para gerar conteúdo de acordo com os interesses do usuário ou das capacidades dos dispositivos.

O capítulo nove apresenta as conclusões do trabalho, discutindo as contribuições e limitações e sugerindo trabalhos futuros. O Anexo de A apresenta as características de um dos modelos para TV Interativa apresentados no capítulo dois. O Anexo B apresenta uma lista padronizada para classificação de programas de TV Interativa. O Anexo C apresenta os artigos publicados durante o desenvolvimento do trabalho. Por fim, Os Apêndices de A a C apresentam o código dos esquemas gerados neste trabalho. 
Capítulo

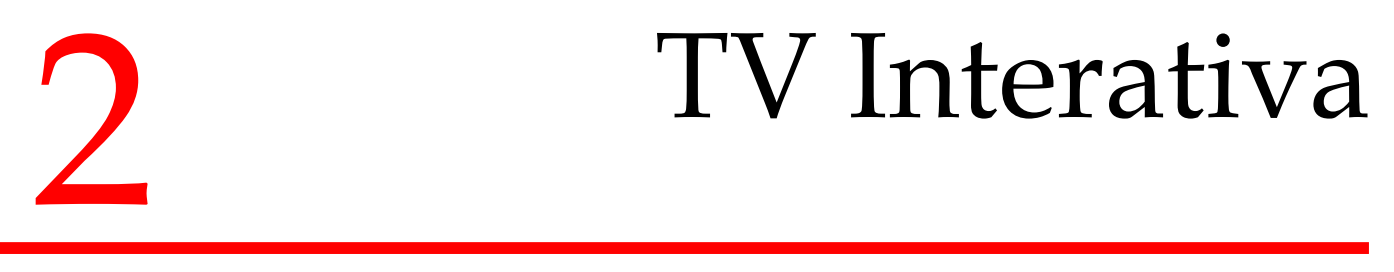


IDÉIA de usar interação na TV não é nova. Por exemplo, nos anos 50 um programa infantil da rede americana CBS, chamado Winky Dinky and You (1953-1957), já utilizava esse conceito. As crianças compravam folhas plásticas transparentes em lojas e livrarias para utilizar sobre a tela da TV. Durante o programa, as crianças eram convidadas a auxiliar Winky Dink em situações adversas, por exemplo, desenhando uma ponte para ajudá-lo a atravessar um rio (Srivastava, 2002). Desde então as emissoras têm tentado utilizar interação em seus programas através de carta, telefone e e-mail.

O surgimento do vídeo digital e os recentes avanços nas técnicas de codificação e de compressão têm aberto novas possibilidades. Aliado a esse fato, a tendência de convergência entre as áreas de telecomunicação, TV/entretenimento e Web têm criado nos usuários a expectativa de interagir com os programas e serviços da mesma forma que interagem na Web, criando uma demanda por novos serviços interativos. Tentando atender a essa demanda surgiram companhias, como Worldgate (2003), WebTV (Microsoft, 2003), OpenTV (Liberty, 2003) e Liberate (2003), fornecendo interatividade por meio do envio de um URI junto com o sinal de vídeo (operando em modo analógico ou digital). No modo analógico o envio do URI utiliza o VBI 21 (Vertical Blanking Interval 21) para enviar a informação extra, que é o mesmo método utilizado para transmitir closed caption.

Nenhum desses novos serviços, por enquanto, obteve sucesso no mercado de consumo. Segundo Srivastava (2002), tais esforços falharam por não oferecerem serviços melhores dos que os usuários já recebiam, além de compartilharem erros comuns e críticos:

- Estão concentrados no que o provedor de serviço deseja vender, e não no que o consumidor deseja comprar.

- Tratam interatividade como um objetivo, e não como uma maneira de atingir o objetivo.

- Tratam os potenciais consumidores como parte de um mercado de massa e não como indivíduos.

Ainda segundo Srivastava (2002), interatividade, por si só, não é desejável. Ela requer que o usuário faça um esforço para receber conteúdo ou serviços. Se a interação dá 
ao usuário resultados mais próximos das suas necessidade ou desejos, então o usuário é compelido a fazer o esforço. Caso contrário, a interação está fadada ao fracasso. Produtos e serviços na TV Interativa devem satisfazer a necessidades e interesses únicos, fornecendo benefícios aos usuários ${ }^{2}$ a um preço acessível.

Os avanços necessários para impulsionar a indústria da TV Interativa incluem o desenvolvimento da TV digital, de serviços interativos e de novos modelos de negócios (Srivastava, 2002; O’Driscoll, 2000; Swann, 2000). Desse modo, este capítulo apresenta um panorama atualizado do estado de desenvolvimento da TV Interativa. A seção 2.1 apresenta um resumo sobre TV digital. A seção 2.2 classifica os tipos existentes de TV Interativa. A seção 2.3 apresenta os modelos de referência, para TV Interativa, utilizados neste trabalho. A seção 2.4 discute algumas oportunidades de negócios que podem surgir com o desenvolvimento da TV Interativa e, a seção 2.5, apresenta algumas considerações finais sobre os modelos e serviços discutidos neste capítulo.

\section{1}

\section{Televisão Digital}

A televisão digital é baseada em conceitos similares àqueles empregados em telefonia digital móvel. Os sinais de televisão são transmitidos como dados digitais comprimidos em vez de sinais analógicos. Dados digitais comprimidos requerem menos banda que sinais analógicos equivalentes. Isto habilita a transmissão de um número maior de canais dentro da mesma banda utilizada pelos atuais sistemas de transmissão, os quais usam métodos analógicos (Srivastava, 2002). Além disso, a televisão digital oferece a oportunidade de suporte a desenvolvimento tecnológico adicional, incluindo alta resolução, formato widescreen e guias eletrônicos de programação (Electronic Program Guides - EPGs).

Segundo Faria (2001), a mudança da televisão analógica para a digital vem sendo discutida há duas décadas e a televisão digital não está difundida devido aos custos e investimentos envolvidos. Contudo, as barreiras econômicas vêm sendo vencidas gradativamente. Isso pode ser notado pela penetração de sistemas digitais na produção e armazenamento de programas, na transmissão de sinais digitais até o usuário final

\footnotetext{
${ }^{2} \mathrm{O}$ termo telespectador não faz sentido em televisão interativa uma vez que as pessoas deixam de ser uma entidade passiva diante dos programas.
} 
(broadcast) e na recepção de sinais digitais pelo usuário. Na parte da produção, muitos estúdios já utilizam equipamentos digitais de filmagem com os padrões Betacam digital, D1 e D2, por exemplo, além de ilhas de edição não-linear. Na parte da recepção do sinal, é cada vez maior a presença de aparelhos digitais como Unidades ReceptorasDecodificadoras (URDs) da TV por assinatura, aparelhos de TV com filtros e entradas digitais e gravadores digitais pessoais (Personal Digital Recorders - PDRs) (Faria, 2001; Srivastava, 2002).

O foco da discussão atualmente é a transmissão, que, na maioria dos sistemas abertos, ainda é analógica. Do mesmo modo que ocorreu uma disputa entre os padrões para a transmissão de cores no sinal analógico (NTSC, PAL e SECAM), existe uma disputa entre padrões da TV digital. Tentando minimizar os efeitos da disputa, em prol da padronização, a União Internacional de Telecomunicações (International Telecommunication Union - ITU) criou um modelo de referência para a televisão digital, o qual é utilizado pelos três padrões públicos existentes: o ATSC (Advanced Television Systems Committee), o DVB (Digital Video Broadcast) e o ISDB (Integrated Service Digital Broadcast).

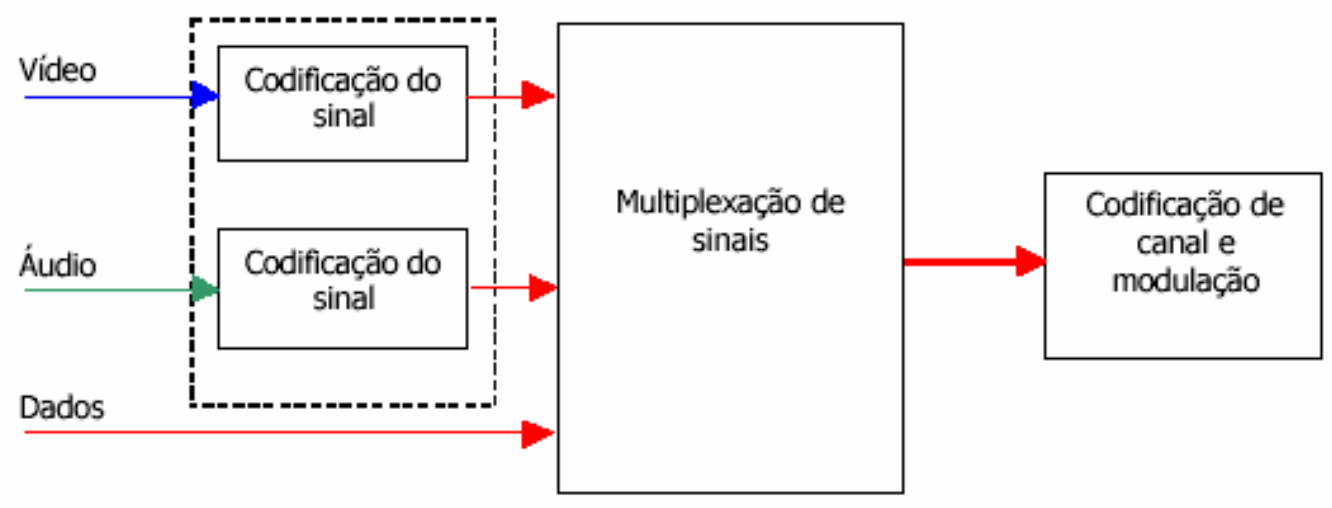

Figura 2.1 - Modelo de referência ITU para televisão digital (ANATEL, 2001).

A Figura 2.1 apresenta o modelo de referência da ITU para a televisão digital, que divide a transmissão em três blocos principais:

- Codificação do sinal. Responsável pela codificação e compressão dos sinais de áudio e vídeo analógicos em um formato digital, chamado de fluxo elementar. 
- Multiplexação de sinais. Responsável pela multiplexação dos fluxos elementares (de vídeo, áudio ou dados), de modo a formar somente um fluxo de dados.

- Codificação de canal e modulação. Responsável por converter o fluxo de dados em sinais que possam ser transmitidos por um meio físico, como ar ou cabos de cobre.

Existe consenso na adoção dos formatos para resolução de imagens, os quais são apresentados na Tabela 2.1. O formato LDTV (Low Definition Television) é o mais indicado para aplicações móveis e portáteis. O formato SDTV (Standard Definition Television) é o similar digital para a atual televisão analógica, com a vantagem de possuir imagens mais nítidas e razão de aspecto 16:9. O formato EDTV (Enhanced Definition Television) possui 480 linhas, assim como o SDTV, porém possui 720 pixels por linha. O formato HDTV (High Definition Television) possui dois tipos de resolução: um com 720 linhas em modo progressivo e outro com 1080 linhas em modo entrelaçado.

Tabela 2.1 - Formatos e resoluções para TV digital (ANATEL, 2001).

\begin{tabular}{|c|c|c|c|c|}
\hline & \multicolumn{2}{|c|}{ Resolução } & \multirow{2}{*}{$\begin{array}{c}\text { Razão } \\
\text { de aspecto }\end{array}$} & $\begin{array}{c}\text { Taxa Média de } \\
\text { bits } \\
\text { (estimativa) } \\
\text { (Mbit/s) }\end{array}$ \\
\hline \hline Formato & $\begin{array}{c}\text { Espacial (linhas } \\
\text { e pixels/linha) }\end{array}$ & Temporal & & $19(12-32)$ \\
\hline \hline HDTV & $1080 \times 1920$ & $60 \mathrm{c} / \mathrm{s}, \mathrm{e}$ & $16: 9$ & $14(8-20)$ \\
\cline { 2 - 3 } & $720 \times 1280$ & $30 \mathrm{q} / \mathrm{s}, \mathrm{p}$ & & $6(4-8)$ \\
\hline EDTV & $480 \times 720$ & $30 \mathrm{q} / \mathrm{s}, \mathrm{p}$ & $16: 9$ & $4,8(3-8)$ \\
\hline SDTV & $480 \times 640$ & $60 \mathrm{c} / \mathrm{s}, \mathrm{e}$ & $16: 9$ & $4(2,5-6)$ \\
\cline { 5 - 5 } & $240 \times 320$ & $30 \mathrm{q} / \mathrm{s}, \mathrm{p}$ & $4: 3$ & $1,1(0,5-1,2)$ \\
\hline
\end{tabular}

Legenda:

c/s - campos por segundo.

q/s - quadros por segundo.

e - entrelaçado.

$\mathrm{p}$ - progressivo.

Também existe consenso para a codificação do sinal de vídeo e para a multiplexação dos sinais, ambos utilizando o padrão MPEG-2 (Watkinson, 1998). Contudo, na última etapa (codificação de canal e modulação), cada padrão adota uma solução diferente:

- ATSC. O padrão ATSC (ATS, 2001), desenvolvido nos EUA, tem como principal objetivo dar suporte à televisão de alta definição (HDTV), embora sistemas ATSC também operem com os outros formatos. Esse padrão 
especifica a utilização de compressão MPEG-2 para vídeo e compressão de áudio no padrão Dolby Digital (AC-3) (ATS, 1995). A transmissão terrestre utiliza o padrão 8-VSB (Vestigial Side Band com oito níveis discretos de amplitude). Os maiores problemas do 8-VSB são o ruído e o mau desempenho em transmissão móvel (ABERT, 2001).

- DVB. É um consórcio europeu que desenvolveu uma família de padrões para a transmissão de TV digital: DVB-S para transmissão via satélite; DVB-C para transmissão via cabo; DVB-T para transmissão terrestre; DVBMC e DVB-MS para transmissão por micro ondas. O DVB-T (DVB, 1999) foi o desenvolvido para ser o padrão para a transmissão de TV Digital na Europa. O DVB-T especifica a utilização de modulação COFDM (Coded Orthogonal Frequency Division Multiplexing), que é menos suscetível a ruídos que a modulação 8-VSB e permite a recepção móvel (ABERT, 2001). A compressão de vídeo é MPEG-2 Main Profile at High Level, (MP@HL) e a de áudio é MPEG-2-Layer II. Contudo, o DVB também especifica o uso opcional do padrão AC-3 para áudio de 5.1 canais (ATS, 1995).

- ISDB. É o padrão japonês para transmissão de TV digital. Dentre os três padrões apresentados é o mais ambicioso, especificando também transmissão móvel e de informações multimídia, ao contrário dos padrões americano e europeu. O ISDB, assim como o DVB e o ATSC, é uma família de padrões, tendo diferentes especificações para transmissão terrestre (ISDB-T), via cabo (ISDB-C) e via satélite (ISDB-S) (Srivastava, 2002; ARIB, 1998). Sistemas ISDB utilizam modulação BST-OFDM (Band Segmented Transmission-OFDM) uma variação do COFDM utilizado em sistemas DVB-T (ARIB, 1998). A vantagem do BST-OFDM em relação ao COFDM é a utilização de um segundo embaralhamento de freqüências, diminuindo a suscetibilidade a ruídos durante a transmissão (ARIB, 1998). A codificação de vídeo é MPEG-2 e a de áudio é MPEG-2 AAC (Watkinson, 1998).

A ANATEL (Agência Nacional de Telecomunicações) realizou uma consulta pública (número 291) para avaliar comparativamente os sistemas de transmissão terrestre 
especificados pelos três padrões. Entre os relatórios recebidos em resposta à consulta, é considerado o mais completo o relatório contendo o resultado dos testes realizados pela Associação Brasileira de Emissoras de Rádio e Televisão (ABERT) em conjunto com a Sociedade Brasileira de Engenharia de TV (SET). O relatório ABERT/SET (ABERT, 2001) considerou o padrão ISDB como o melhor, em termos técnicos, tendo como pontos fortes a recepção móvel e a flexibilidade para novos modelos de negócios. O relatório também elogia o padrão DVB-T, mas não recomenda o padrão ATSC. Atualmente o governo do Brasil, através do ministério das comunicações, está promovendo uma série de debates e medidas visando à criação de um sistema brasileiro de televisão digital.

\section{2}

\section{Televisão Interativa}

Com o desenvolvimento da TV digital, a interatividade vem sendo explorada de diferentes modos por diferentes companhias. Isso gerou uma série de nomenclaturas para TV Interativa. Alguns autores (Faria, 2001; Srivastava, 2002; van Vilet \& van Stelten, 2001) classificam TV Interativa de acordo com os tipos de serviços oferecidos:

- Enhanced $\boldsymbol{T V}$. Oferece informações adicionais, como textos e gráficos, durante a programação convencional. A informação adicional está embutida nos programas, podendo ser acessada a qualquer momento via ícones e ligações, não necessitando de canal de retorno.

- Internet $\boldsymbol{T V}$. Permite acesso à Internet e todas as suas funcionalidades (incluindo navegação e correio eletrônico) através da TV. Esse serviço necessita de canal de retorno.

- TV sob Demand (On-Demand TV). A programação é oferecida sob demanda. Um servidor de vídeo responde a uma requisição por conteúdo em um sistema digital bidirecional.

- TV Individualizada (Individualized TV). Oferece ao usuário múltiplos ângulos de câmera, opções de áudio, opções de linguagem e replay de programas ao vivo. Também é possível responder questões de múltipla escolha em programas de perguntas e respostas. 
- TV Pessoal (Personal TV). Oferece as funcionalidades de um videocassete para programas ao vivo. Durante a exibição, os programas vão sendo gravados em um dispositivo, permitindo pausas, avanços e retrocessos. É possível agendar a gravação de programas específicos, os quais podem ser selecionados através de um menu. Oferece suporte a vídeo sob demanda, existindo, nesse caso, a necessidade de um canal de retorno.

Utilizando como critério de classificação a complexidade do dispositivo utilizado para oferecer o serviço, ou então o grau de interatividade com a programação, obtêm-se dois grupos. O primeiro, utiliza unidades receptoras-decodificadoras para oferecer os serviços Enhanced $T V$ e/ou Internet $T V$. De fato, algumas empresas como WebTV (Microsoft, 2003) e Liberate (2003) já oferecem ambos os serviços como um só produto. O segundo, utiliza uma versão mais elabora de URD, o PDR, para oferecer serviços de TV sob demanda, TV individualizada e TV pessoal. Existe uma forte relação entre esses serviços, de modo que TV sob demanda e TV individualizada podem ser vistas como subserviços de TV pessoal. Os dois grupos, de agora em diante chamados, respectivamente, de TV expandida e TV personalizada, serão detalhados nas subseções 2.2.1 e 2.2.2.

\subsection{1 - TV Expandida}

Os serviços de TV expandida possuem implementações tanto para a TV digital quanto para a TV analógica. No primeiro caso, as URDs são utilizadas para processar as interações entre o usuário e o programa, realizadas por meio de controle remoto ou teclado. No segundo, além de processar interações, as URDs são responsáveis por transformar informação digital (como textos e gráficos) em informação analógica, de forma que as mesmas possam ser apresentadas na TV.

A interatividade nos serviços de TV expandida está limitada ao acesso à Internet $\mathrm{e}$ ao acesso às informações extras contida no programa. Não é oferecida a possibilidade de mudanças de câmeras ou idiomas (apesar desse tipo de serviço ser possível através de transmissão digital).

$\mathrm{Na}$ tentativa de padronizar o desenvolvimento de conteúdo e a forma de entrega de conteúdo para TV expandida foi criado o fórum Advanced Television Enhancement Forum (ATVEF). As especificações do ATVEF são baseadas em tecnologia HTML, e incluem a 
criação de um URI (“tv:") para integração TV-WWW, além do protocolo UHTTP (Unidirecional Hypertext Transfer Protocol), específico para o transporte de dados por difusão (Srivastava, 2002).

Como exemplo de TV expandida pode-se citar a WebTV (Microsoft, 2003), que surgiu em 1995 oferecendo serviço de acesso à Internet via TV. Sua solução é composta por uma URD com saídas para TV, entrada RJ-11 (telefone) e um teclado com joystick. Hoje a WebTV pertence à Microsoft, com o nome de MSN TV. A Microsoft possui um outro produto chamado Interactive $T V$, no qual a interação só está disponível em determinados momentos de determinados programas. $\mathrm{O}$ usuário fica sabendo da possibilidade de interação devido à presença de um ícone "i”" na tela (Figura 2.2 (a)). Um clique nesse ícone torna visível a informação extra, conforme ilustrado na Figura 2.2 (b). As soluções WebTV e Interactive TV seguem a especificação 1.1 do ATVEF (ATVEF, 2000) (a Microsoft é membro do ATVEF). Outros exemplos incluem Worldgate (2003), OpenTV (Liberty, 2003) e Liberate (2003).

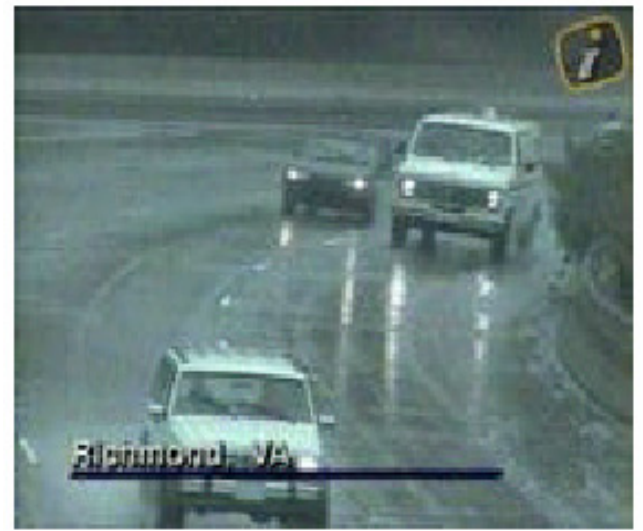

(a)

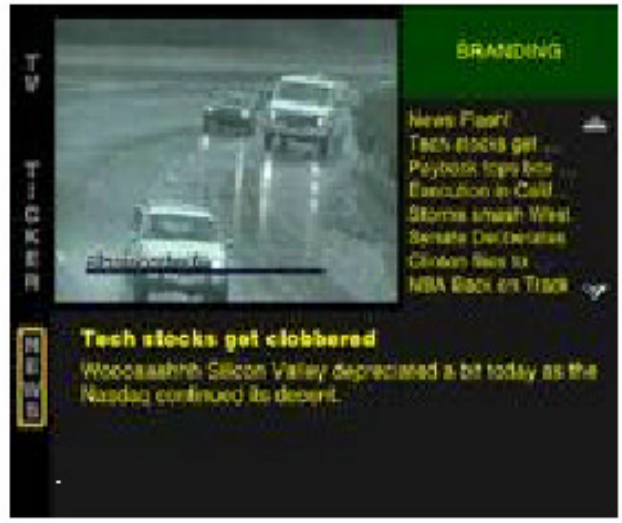

(b)

Figura 2.2- Exemplo de um programa interativo (Microsoft, 2003b): (a) ícone "ij" indicando presença de informação extra, (b) informação extra sendo exibida.

\subsection{2 - TV Personalizada}

As soluções atualmente disponíveis para TV personalizada utilizam um PDR (também chamado de DVR - Digital Video Recorder) como elemento central no fornecimento dos serviços. O PDR pode ser considerado o sucessor do videocassete, uma vez que tem como principal funcionalidade a gravação de programas de televisão. Porém possui diversas características que o tornam bastante atraente para o consumidor. Um PDR é composto por 
uma placa de captura de vídeo, permitindo transformar um vídeo analógico em digital (MPEG-2), e por um disco rígido que pode variar de tamanho de acordo com o modelo. Um PDR pode gravar com diversos níveis de compressão, permitindo armazenar até 80 horas de programas. Durante a exibição de programas ao vivo, os mesmos são armazenados temporariamente no disco local, permitindo pausas, avanços e retrocessos. Diversas empresas investem na comercialização de PDRs, entre elas TiVo (2003), ReplayTV (Digital, 2003), Philips (Royal, 2003) (com o nome de Hard Disk Recorder - HDR), Sony (2003) (Digital Video Recorder) e Panasonic (Matsushita, 2003) (Personal Video Recorder).

O acesso ao conteúdo gravado nos PDRs é realizado por meio de guias de programação eletrônicos (Electronic Program Guides - EPGs). Os EPGs possuem funções avançadas permitindo, por exemplo, gravação sem comerciais, programação instantânea (gravação a partir da chamada comercial de um programa) e criação de canais virtuais personalizados (armazenando somente filmes de Spielberg, por exemplo).

A Figura 2.3 (a) ilustra um exemplo de PDR, comercializado pela TiVo (2003), que oferece o serviço de TV pessoal. O PDR é conectado à TV (como um videocassete) e operado via controle remoto. A Figura 2.3 (b) ilustra um exemplo de EPG. Nesse exemplo o usuário havia solicitado a gravação de filmes sobre "James Bond" e "Sean Connery", assim como os jogos dos "Giants". Para assistir aos programas gravados basta selecionar um item do menu.

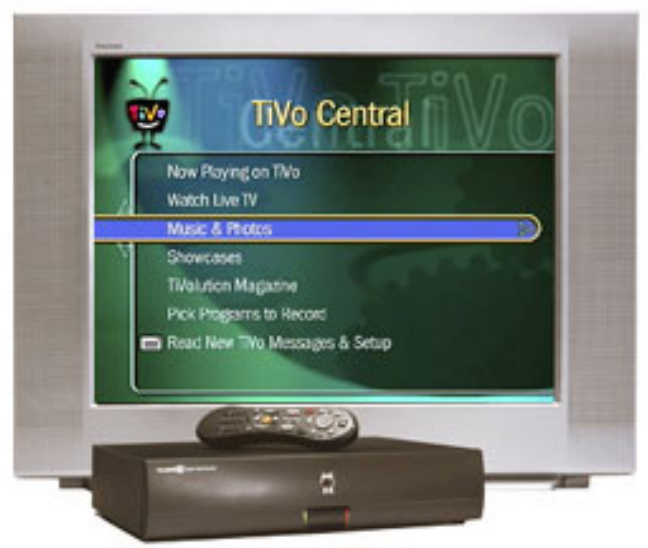

(a)

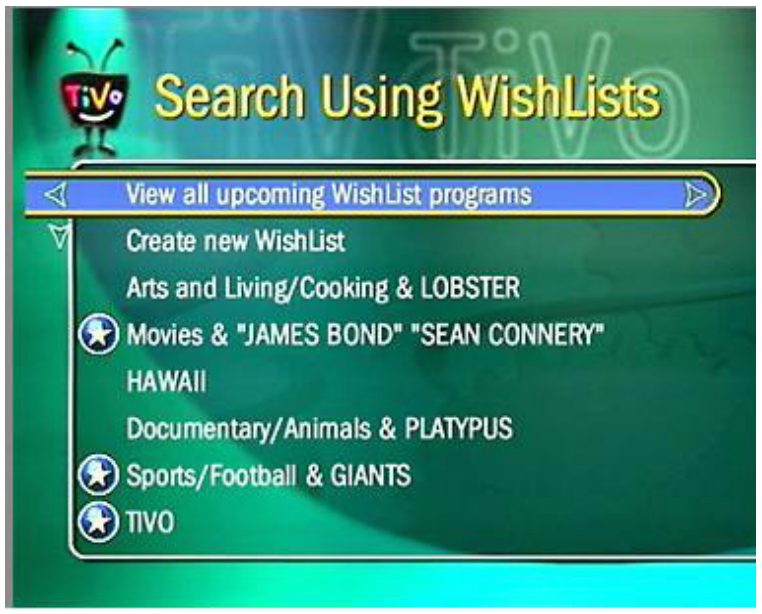

(b)

Figura 2.3 - (a) Exemplo de um PDR TiVo (Tivo, 2003). (b) Exemplo de um EPG usado para selecionar conteúdo armazenado no PDR (Tivo, 2003). 
Dentre as iniciativas para o desenvolvimento de padrões para TV personalizada destaca-se o TV-Anytime Forum. O destaque se deve ao grande número de organizações participantes (mais de 55) e à participação de importantes empresas como: British Telecommunications, Danish Bradcasting Corporation, France Telecom, Fuji, LG, Matsushita, Microsoft, Mitsubishi, Motorola, NEC, Nokia, Philips, Samsung, Sony, entre outras. Esse fórum tem como objetivo desenvolver especificações abertas que permitam, a diversos segmentos da indústria (como fabricantes de eletrônicos, produtores de conteúdo, provedores de serviços e provedores de acesso), explorar alto volume de armazenamento digital em plataformas consumidoras. Com essas especificações espera-se encorajar o desenvolvimento de serviços de TV Interativa e serviços multimídia relacionados, baseados no uso de PDRs, independente do modo de distribuição (TV-Anytime, 2003).

A TV Interativa que se espera para o futuro é um misto entre a TV expandida e a TV personalizada. Atualmente existem no mercado algumas iniciativas, como a Ultimate $T V$ da Microsoft (2003a), que oferecem os serviços de Internet TV e de TV pessoal em um só produto. Contudo, as possibilidades abertas pela tecnologia digital dos PDRs e os avanços nos modos de transmissão apontam para o surgimento de serviços cada vez mais elaborados. É este o cenário explorado neste trabalho, a convergência entre TV expandida e TV personalizada, denominada daqui por diante de TV Interativa, gerando novos e melhores serviços. O modelo de TV Interativa do TV-Anytime, a ser apresentado na seção 2.3, apresenta características bastante interessantes para o cenário em questão.

\section{3}

\section{Modelo de Referência TV-Anytime}

O TV-Anytime produziu quatro tipos de especificações: para o sistema, para metadados, para referência a conteúdo e para gerenciamento de direitos autorais (TV-Anytime, 2003). As duas primeiras envolvem, respectivamente, um modelo funcional de referência para o sistema e um modelo para metadados. Esses modelos, a serem apresentados nesta seção, foram utilizados para direcionar o desenvolvimento do projeto de protótipo de TV Interativa no qual este trabalho está inserido. 


\subsection{1 - O Modelo Funcional de Referência TV-Anytime}

O modelo funcional de referência especificado pelo TV-Anytime Forum está ilustrado na Figura 2.4. Cada retângulo representa uma função do sistema TV-Anytime e pode ser implementado de diferentes maneiras por diferentes provedores de serviço. A função de acesso está ilustrada como uma nuvem, simbolizando a conectividade entre as unidades funcionais. A conectividade pode variar desde fios dentro de um PDR até uma complexa rede em banda larga. O TV-Anytime especifica também um sistema de gerenciamento de direitos e segurança, o qual está ilustrado como um retângulo cinza envolvendo todos os aspectos do modelo.

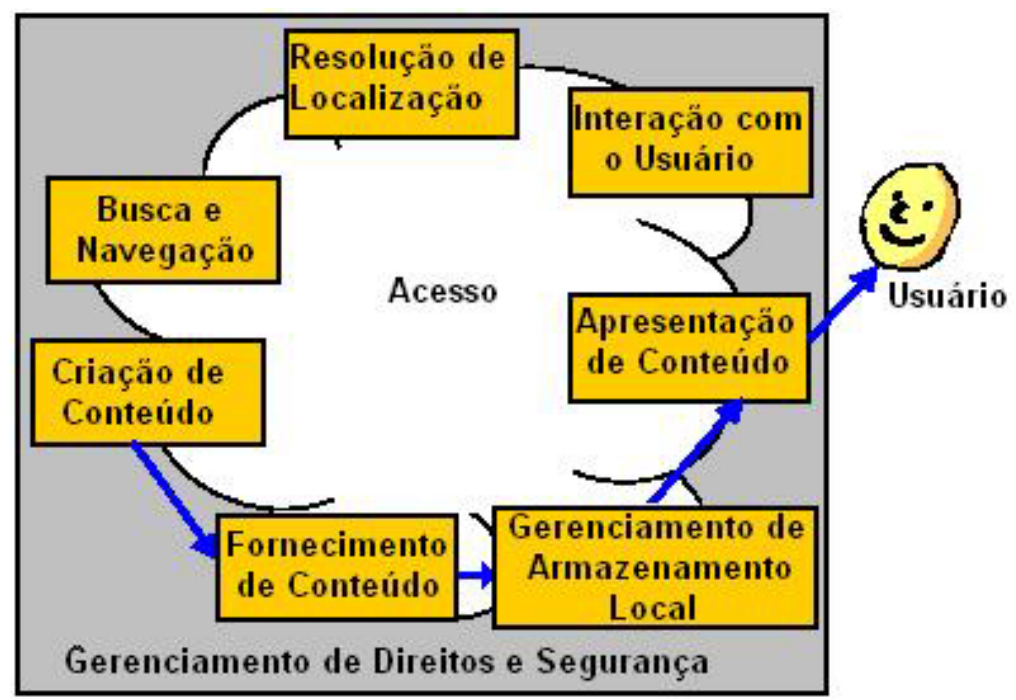

Figura 2.4 - O modelo funcional de referência do TV-Anytime (TV-Anytime, 2003).

O fluxo básico do conteúdo no modelo ilustrado na Figura 2.4 é indicado pelas setas. O conteúdo flui do criador de conteúdo (que possui ou administra os direitos do conteúdo), para o provedor de serviço (que cria pacotes de conteúdo), e então para o gerenciamento de armazenamento local. Do armazenamento local o conteúdo é entregue à unidade funcional de apresentação de conteúdo, a qual decodifica e exibe o conteúdo para o usuário. As unidades funcionais do TV-Anytime podem ser descritas como segue:

- Criação de Conteúdo. O criador de conteúdo produz apresentações e metadados diretamente relacionados a um conteúdo em particular. Por exemplo, uma produtora de vídeo, responsável pela criação de um programa de televisão, pode ser um produtor de conteúdo. Os metadados relacionados ao conteúdo 
fornecidos pelo criador de conteúdo podem incluir: dados sobre título, codificação, tipo de conteúdo, gênero da produção, segmentação, etc.

- Fornecimento de Conteúdo. O fornecimento de conteúdo é feito pelo provedor de conteúdo, o qual agrega conteúdo de várias fontes produtoras. O provedor de conteúdo utiliza um ou mais provedores de acesso para transferir o conteúdo (incluindo metadados e informações de propriedade intelectual) para os usuários. Por exemplo, uma rede de TV pode ser um provedor de conteúdo e usar os meios de transmissão convencionais de TV (broadcast network) para o acesso. Um provedor de conteúdo irá adicionar metadados relevantes para os seus serviços como edição, preço, informações para busca e navegação, horários da programação, etc.

- Gerenciamento de Armazenamento Local. Essa unidade funcional permite gravar, exibir e apagar conteúdo e metadados relacionados.

- Apresentação de Conteúdo. Essa unidade funcional decodifica e apresenta o conteúdo para o usuário.

- Interação com o Usuário. É a interface entre o usuário e os componentes que realizam busca e aquisição de conteúdo, incluindo resolução de localização.

- Resolução de Localização. Utiliza um CRID (Content Reference Identifier) (TV-Anytime, 2003) como entrada e produz uma lista de localizações a partir das quais o conteúdo pode ser acessado. Essas localizações podem ser: um canal de TV, um endereço URI na Internet ou um ponteiro para armazenamento local.

- Busca e Navegação. É um serviço disponível para o usuário, ou um agente executando em nome do usuário, para buscar e selecionar o conteúdo desejado. Essa unidade funcional utiliza informação do maior número de fontes possível (tais como provedores de conteúdo). O serviço/agente utiliza essas informações como entrada durante a fase de busca, produzindo como saída um CRID a ser usado na resolução de localização.

- Acesso. Fornece a conexão que permite informações e conteúdo serem transferidos de uma unidade funcional para outra, o que inclui qualquer tipo de sistema de transmissão. 
- Gerenciamento de Direitos e Segurança. É responsável pela proteção e manutenção do controle sobre o consumo de conteúdo, particularmente em casos onde a duplicação de material digital pode ser usada para criar ou burlar novos modelos de negócios. Isso inclui gerenciamento e proteção dos direitos sobre o conteúdo, políticas de distribuição e privacidade.

\subsection{2 - O Modelo para Metadados do TV-Anytime}

O TV-Anytime reconhece a importância da utilização de metadados em sistemas de TV Interativa, tendo produzido especificações que incluem elementos descritivos para auxiliar o processo de busca, assim como os processos de aquisição, captura e apresentação de conteúdo. Os metadados permitem ao usuário encontrar, navegar e gerenciar conteúdo a partir de uma variedade de fontes internas e externas incluindo, por exemplo, enhanced TV, TV personalizada, Internet e armazenamento local. O sistema deve estar apto a utilizar essas informações, manual ou automaticamente, através, por exemplo, de perfis e preferências de usuários.

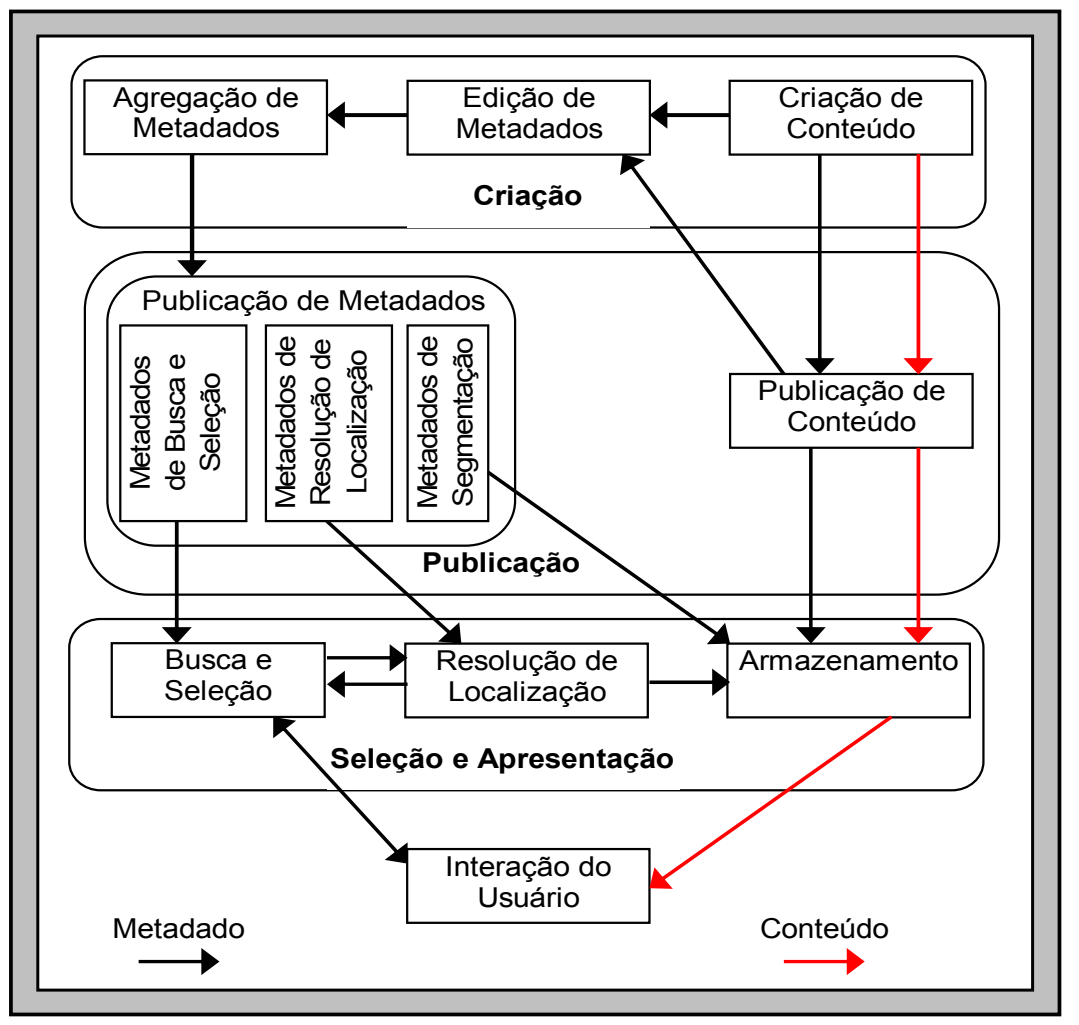

Figura 2.5 - Modelo para fluxo de metadados (TV-Anytime, 2002). 
O processo de criação e evolução dos metadados para um conteúdo em particular pode envolver várias organizações dentro da cadeia de criação, distribuição e entrega. Assim, existe a necessidade de definir um modo comum de representar os metadados para maximizar a interoperabilidade.

À luz do modelo funcional de referência, o TV-Anytime especificou um modelo para o fluxo de metadados, ilustrado na Figura 2.5. Esse modelo identifica claramente a separação entre o processamento dos metadados e do conteúdo e, ao mesmo tempo, ilustra o paralelismo entre tais processamentos. O paralelismo ocorre em três fases distintas: criação, publicação e seleção e apresentação. Essas fases são equivalentes às unidades funcionais: criação de conteúdo; fornecimento de conteúdo; busca e navegação, resolução de localização, gerenciamento de armazenamento e apresentação de conteúdo.

Com base no ciclo de vida do fluxo de metadados, o TV-Anytime identifica as entidades responsáveis pela criação de metadados ao longo do caminho entre a criação e o consumo de conteúdo (TV-Anytime, 2002):

- Produtor de Conteúdo. O criador original do conteúdo é a entidade mais apropriada para adicionar certos tipos de informações sobre o conteúdo. Alguns tipos de metadados podem, também, ser gerados automaticamente em tempo de criação: data e hora, localização, configurações de câmera, direitos autorais, etc.

- Provedor de Conteúdo. O provedor de conteúdo adiciona metadados tais como descrições adicionais, formato, informações sobre versões, informações adicionais de direitos autorais, etc.

- Provedor de Serviço. O provedor de serviços pode adicionar informações sobre aplicações relacionadas ou adicionais (jogos, por exemplo) e informações para EPGs. Também podem ser adicionadas informações sobre como o conteúdo deve ser gerenciado no PDR do usuário.

- Provedor de Acesso. O provedor de acesso abastece o usuário com informações de gerenciamento de serviço, tais como serviços disponíveis para assinatura ou informações sobre pagamento. Também é responsável por informações sobre autenticação e segurança.

- PDR. O PDR em si fornece metadados usados para gerenciamento de direitos autorais (tais como transferência de direitos para outra entidade), 
armazenamento e informação sobre cobrança (pagamento direto via cartão de crédito, etc.).

- Usuário. O usuário pode adicionar metadados pessoais ao conteúdo, tais como anotações. As preferências do usuário podem ser editadas manualmente ou obtidas automaticamente por meio dos padrões de uso. O PDR também gerencia um histórico de uso.

A arquitetura TV-Anytime permite, mas não requer, um canal de retorno para o envio de metadados. Informações sobre pagamentos, respostas interativas e perfis de usuários são de interesse de provedores de acesso e de serviço. Por exemplo, com a autorização do usuário, perfis podem ser enviados ao provedor de serviço para permitir a criação de listas de programas personalizados, comerciais direcionados e revistas eletrônicas, produzidos a partir de uma série de diferentes fontes. Um usuário pode desejar compartilhar com outros usuários metadados como comentários, bookmarks e perfis, e a forma de compartilhar essas informações pode ser um serviço oferecido pelo provedor de acesso.

Por questões de interoperabilidade, o TV-Anytime Forum adotou XML (Extensible Markup Language) (W3C, 2000) como formato para representação de metadados. Segundo o TV-Anytime, XML foi escolhida devido às suas vantagens em: permitir extensões, dar suporte à separação entre dados e aplicação, ser largamente utilizada e por existirem diversas ferramentas disponíveis.

A definição formal da estrutura e da sintaxe dos metadados é dada por meio de um esquema XML, o qual é desenvolvido com a linguagem XML Schema (W3C, 2001d) (capítulo quatro, subseção 4.4.4). O esquema desenvolvido pelo TV-Anytime utiliza alguns esquemas especificados no padrão MPEG-7 (ISO, 2002a) (capítulo quatro), principalmente no que se refere à descrição de mídias. A distinção entre qual elemento descritivo pertence ao TV-Anytime e qual pertence ao MPEG-7 é feita através do conceito XML de espaço de nomes (W3C, 2001d) (capítulo quatro, subseção 4.4.4.1). O espaço de nomes do TVAnytime é definido como: http://www.tv-anytime.org/2001/04/metadata (TV-Anytime, 2002).

O TV-Anytime fez um levantamento de requisitos identificando os conceitos que devem ser possíveis de serem representados através do esquema (TV-Anytime, 2002). Tais conceitos são: 
- Um programa simples como um filme.

- Um programa com diferentes versões. Por exemplo, com edições para sexo/violência/linguagem, cortes do diretor, etc.

- Um programa que tenha sido dividido em várias partes para publicação. Por exemplo, um programa de três horas apresentado em duas partes em dias diferentes.

- Séries de programas.

- Coleções de programas (e séries) que tenham um mesmo conceito. Por exemplo, programas sobre "cães".

- Programas que tenham atributos de publicação diferentes. Por exemplo, diferentes sinopses.

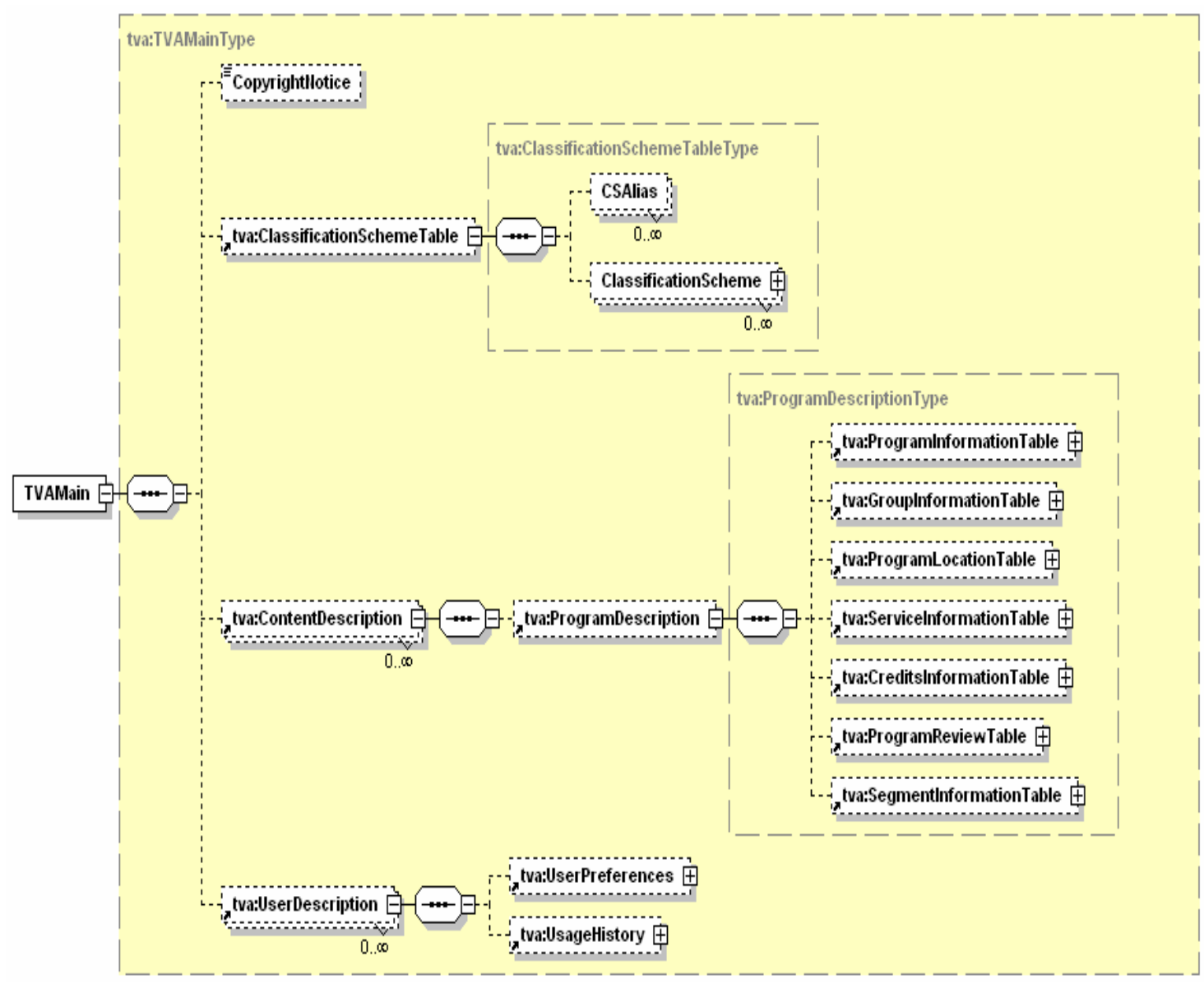

Figura 2.6 - Diagrama hierárquico do esquema que implementa os metadados TV-Anytime. 
A Figura 2.6 ilustra os elementos de mais alto nível na hierarquia do esquema TVAnytime para metadados. De acordo com esse esquema, as informações que descrevem qualquer um dos conceitos, chamados genericamente de programas, podem ser divididas em: informações de direitos autorais (elemento <CopyrightNotice>), classificação do programa (elemento <ClassificationSchemeTable>), descrição de conteúdo (elemento <ContentDescription>) e descrição do usuário (elemento <UserDescription>).

$\mathrm{O}$ esquema proposto pelo TV-Anytime gera instâncias que contém, em um mesmo arquivo, descrições sobre o programa, sobre as mídias que compõem o programa (normalmente apenas um vídeo) e sobre o usuário. Essa abordagem é uma desvantagem durante o processo de edição de conteúdo, pois dificulta o reuso de descrições.

\section{4}

\section{Oportunidades e Modelos de Negócios}

Da mesma forma que os atuais PDRs podem ser categorizados como de primeira geração, pode-se dizer que as atuais implementações de serviços em TV Interativa também são de primeira geração (van Vilet \& van Stelten, 2001). Existe uma expectativa de rápida evolução de novos serviços, uma vez que diferentes entidades vêem oportunidades de negócios (Markus et al., 2000): anunciantes vêem o aumento do direcionamento de propagandas, provedores de serviço vêem o aumento da renda por assinante, emissoras de televisão desejam trazer interatividade para a TV de modo a transformar telespectadores em usuários, consumidores (usuários) desejam ter mais controle da programação e provedores de infra-estrutura desejam vender mais hardware e serviços de acesso.

\subsection{1 - Oportunidades de Negócios}

As funcionalidades oferecidas pelos novos serviços são o ponto de partida para a criação de produtos diferenciados e de vantagens competitivas. Por outro lado, o usuário é quem vai direcionar as oportunidades de negócios. Dessa forma, as funcionalidades devem ser centradas no usuário. A literatura (O’Driscoll, 2000; Swann, 2000; van Vilet \& van Stelten, 2001; Srivastava, 2003) traz uma série de previsões sobre quais seriam essas funcionalidades (baseadas no uso de PDRs avançados), resumidas na Tabela 2.2. 
Tabela 2.2 - Funcionalidades previstas para os novos serviços em TV Interativa.

\begin{tabular}{|c|c|}
\hline Funcionalidade & Descrição \\
\hline Geral & $\begin{array}{l}\text { - Alta qualidade de vídeo e áudio. } \\
\text { - Acesso a centenas de canais. } \\
\text { - Gravar programas digitalmente. } \\
\text { - Acesso a novos serviços. } \\
\text { - Suporte a conteúdo não audiovisual (aplicações, páginas } \\
\text { Web, etc.). }\end{array}$ \\
\hline $\begin{array}{c}\text { Funcionalidades de Gravação } \\
\text { e Reprodução }\end{array}$ & $\begin{array}{l}\text { - Gravar programas ao vivo, desde o início, a qualquer } \\
\text { momento durante a transmissão do programa. } \\
\text { - Continuar gravando mesmo durante mudanças de canal. } \\
\text { - Gravar programas com base em segmento e/ou grupos de } \\
\text { segmentos: somente as manchetes, os próximos " } n \text { " } \\
\text { episódios, etc. } \\
\text { - Pausa, avanço e retrocesso em tempo real para eventos ao } \\
\text { vivo. } \\
\text { - Gravação e reprodução simultâneas. }\end{array}$ \\
\hline Busca e Recuperação & $\begin{array}{l}\text { - Pesquisas através de EPGs. } \\
\text { - Buscas por material relacionado. } \\
\text { - Buscas indexadas por gênero, autor, ator, etc. } \\
\text { - Ter um ambiente integrado para buscas na Internet, no PDR } \\
\text { local, no provedor de conteúdo e na TV aberta (broadcast). }\end{array}$ \\
\hline EPGs & $\begin{array}{l}\text { - Acesso fácil ao conteúdo de PDRs. } \\
\text { - Opções de listas de conteúdo por gênero, título, data, canal, } \\
\text { ou preferências do usuário. } \\
\text { - Opções de modo de visualização: textual, tabular, gráfico. } \\
\text { - Fornecer lembretes ao usuário quando um de seus } \\
\text { programas favoritos estiver para começar. }\end{array}$ \\
\hline Personalização & $\begin{array}{l}\text { - Gravação baseada em: canal, tipo de mídia, período, } \\
\text { assunto, atributos específicos (áudio digital 5.1, legenda em } \\
\text { português, etc.), características descritivas (somente para } \\
\text { maiores, indicado pela crítica, etc.). } \\
\text { - Sistema de sugestão de conteúdo. Gravação automática de } \\
\text { conteúdo baseada nas preferências do usuário. } \\
\text { - Perfis baseados no comportamento do usuário, em } \\
\text { interesses explicitamente indicados e em listas de } \\
\text { preferências. } \\
\text { - Possibilidade de dar notas aos programas. As notas podem } \\
\text { ser levadas em consideração para dar sugestões de } \\
\text { conteúdo. } \\
\text { - Possibilidade de escolher conteúdo a partir de perfis pré- } \\
\text { definidos (esportes, natureza, infantil, etc.). }\end{array}$ \\
\hline $\begin{array}{l}\text { Gerenciamento de } \\
\text { armazenamento }\end{array}$ & $\begin{array}{l}\text { - Lista de gravações antigas para remoção imediata. } \\
\text { - Oferecer um meio de prevenir conteúdo de ser apagado ou } \\
\text { atualizado, até mesmo pelos provedores. } \\
\text { - Configurar a qualidade da captura. } \\
\text { - Capacidade de dividir o disco em pastas pessoais e } \\
\text { compartilhadas. } \\
\text { - Capacidade de configurar o espaço máximo disponível para } \\
\text { conteúdo enviado por anunciantes e provedores. } \\
\text { - Transferir conteúdo para dispositivos externos. }\end{array}$ \\
\hline
\end{tabular}


Tabela 2.2 - (Continuação).

\begin{tabular}{|c|l|}
\hline Funcionalidade & \multicolumn{1}{c|}{ Descrição } \\
\hline \hline \multirow{3}{*}{$\begin{array}{c}\text { Compartilhamento de } \\
\text { conteúdo e comunicação }\end{array}$} & $\begin{array}{l}\text { - Enviar conteúdo para outros PDRs e receber conteúdo de } \\
\text { outros PDRs. }\end{array}$ \\
& - Trocar programas, listas de favoritos e índices. \\
& - Consciência de que outro usuário está on-line assistindo a \\
& um programa específico. \\
\hline Portabilidade & - Permitir importar e exportar preferências para que o usuário \\
& possa transportá-las (em dispositivos móveis ou cartões de \\
& memória, por exemplo) para outros PDRs. \\
& - Permitir comunicação do PDR com outros dispositivos. \\
\hline \multirow{2}{*}{ Navegação } & - Avançar através de segmentos: capítulos, seções, \\
& momentos chave (gols, por exemplo), etc. \\
& - Marcar partes de um programa para exibição posterior. \\
\hline
\end{tabular}

Os serviços interativos representam, para as emissoras operadoras de TV, novas oportunidades de gerar fluxos de renda adicionais. Os serviços personalizados abrem as portas para companhias de software introduzir novos conceitos e implementações. $\mathrm{O}$ acesso à Internet significa possibilidade de comércio eletrônico (e-commerce). Da convergência entre TV Interativa e comércio eletrônico surge um novo modelo de negócios - o comércio através da TV - também chamado de t-commerce (television-based commerce). $\mathrm{O}$ entusiasmo da indústria em relação ao t-commerce é justificado pelo potencial que esse mercado representa. Segundo Srivastava (2002), a televisão já provou sua capacidade para auxiliar vendas de produtos, assim como a Internet já provou sua capacidade em conduzir compras instantaneamente. A união entre essas duas tecnologias representa um bilhão e meio $^{3}$ de potenciais consumidores com capacidade de realizar compras por impulso instantaneamente. A seguir são apresentadas algumas das características do t-commerce (van Vilet \& van Stelten, 2001):

- É um novo modo para consumidores adquirirem produtos por meio de dispositivos já conhecidos (TV e controle remoto).

- É baseado no comportamento do consumidor.

- Está pronto para o mercado de massa.

- É escalável.

\footnotetext{
${ }^{3}$ Segundo estimativas (Srivastava, 2002), existem no mundo um bilhão e meio de aparelhos televisores.
} 
- É compatível com tecnologia de transmissão digital terrestre, por cabo ou via satélite.

- Permite o desenvolvimento de avançados perfis e bases de dados sobre consumo e consumidores.

- Pode oferecer transações completas, desde escolher a cor e o tamanho de um produto até a efetivação do pagamento.

- Permite que produtores e anunciantes decidam quais ofertas desejam fazer durante quais programas.

\subsection{2 - Cadeia Produtiva}

As funcionalidades e serviços previstos para a TV Interativa serão implementados por diferentes entidades, com diferentes papéis, dentro da cadeia criadora, distribuidora e consumidora de programas, chamada também de cadeia produtiva (van Vilet \& van Stelten, 2001; Srivastava, 2003). Cada entidade pode, eventualmente, desempenhar mais de um papel.

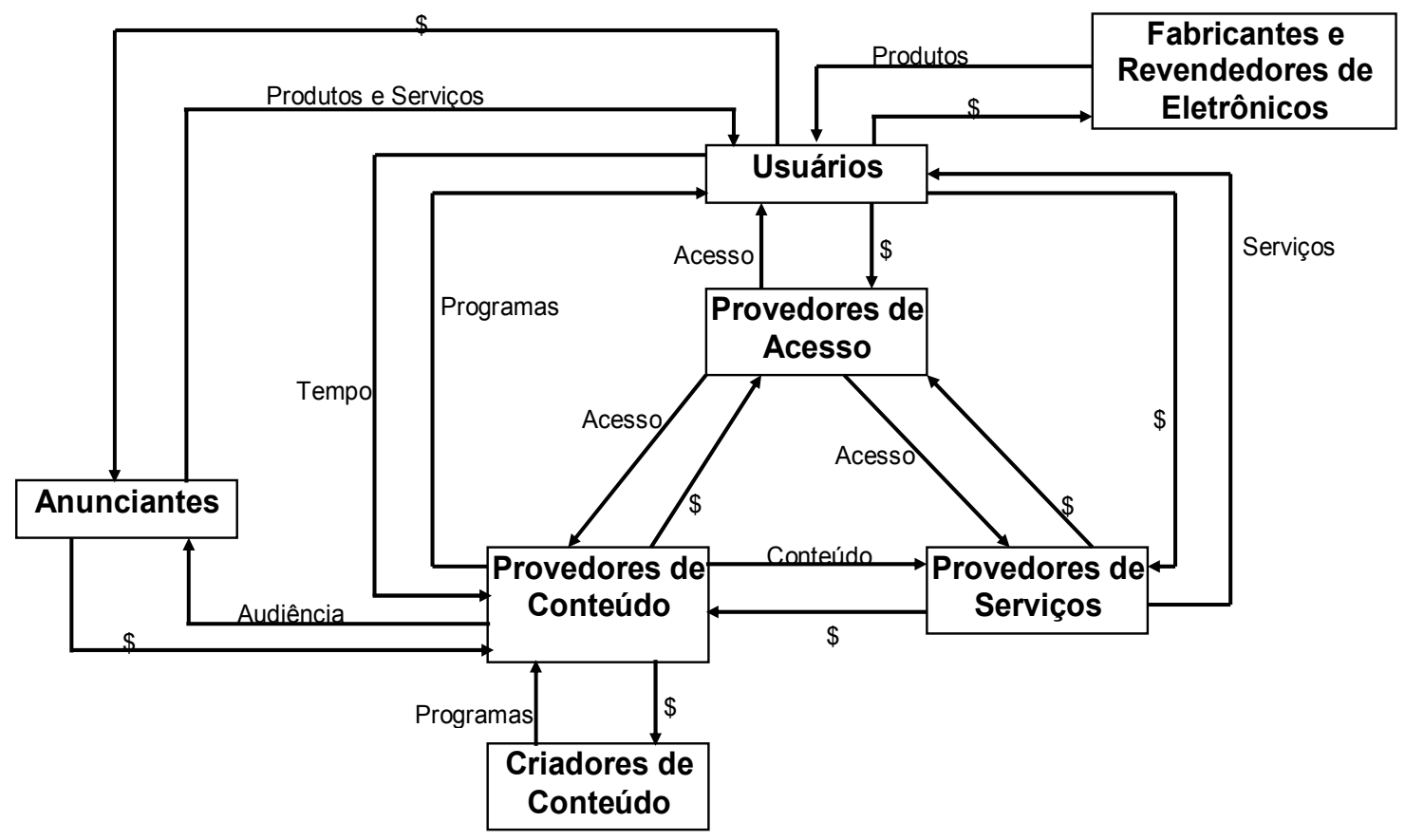

Figura 2.7 - Diagrama da organização da cadeia produtiva em TV Interativa. 
De acordo com a literatura (Swann, 2000; van Vilet \& van Stelten, 2001; Srivastava, 2003; TV-Anytime, 2000) essas entidades são representadas pelos seguintes segmentos da indústria, cujos inter-relacionamentos estão ilustrados na Figura 2.7:

- Criadores de conteúdo. São emissoras de rádio e televisão, produtoras de vídeo, portais da Internet e organizações similares que produzem conteúdo. Vendem conteúdo e direitos autorais aos provedores de conteúdo.

- Provedores de conteúdo. Coletam o conteúdo fornecido por diversos criadores de conteúdo criando séries e pacotes de programas, assim como conteúdo personalizado que atenda a parâmetros especificados pelos provedores de serviço. Para isso, devem segmentar o conteúdo original e acrescentar metadados que descrevam o novo formato dos programas. Oferecem conteúdo aos usuários que, por sua vez, investem tempo assistindo aos programas. Oferecem a audiência aos anunciantes, que pagam para terem propagandas de seus produtos e serviços incluídos nos programas. Para transmitir os programas utilizam os serviços dos provedores de acesso.

- Provedores de serviço. Fornece aos usuários serviços de busca e personalização de conteúdo. Gerenciam os perfis e preferências dos usuários de forma a fornecer conteúdo compatível. Tal conteúdo é providenciado pelos provedores de conteúdo, que podem produzir versões sob demanda de programas, baseados nas preferências e parâmetros estipulados pelo provedor de serviço. O provedor de serviços pode receber ou o conteúdo personalizado ou o endereço para acessar o conteúdo, repassando essa informação ao usuário (ou gravando essa informação no PDR do usuário).

- Anunciantes. Empresas e organizações que desejam anunciar seus produtos e serviços através de propagandas. Pagam aos provedores de conteúdo para ter seus anúncios incluídos na programação.

- Provedores de acesso. Fornecem os meios para que o usuário possa acessar conteúdo e serviços e, para que provedores de conteúdo e de serviços possam se comunicar com o usuário.

- Fabricantes e revendedores de eletrônicos. Fornecem os equipamentos necessários para o usuário receber, decodificar, assistir, gravar e interagir com 
conteúdo. Exemplos de equipamentos são: TVs, URDs, PDRs, controlesremotos, etc.

- Usuários. Investem tempo assistindo programas, gerando audiência. Investem dinheiro na contratação de serviços dos provedores de acesso, provedores de serviços e dos anunciantes, assim como na compra de produtos e equipamentos dos anunciantes e dos fabricantes e revendedores de eletrônicos.

\subsection{3 - Modelos de Negócios do TV-Anytime}

O TV-Anytime Forum desenvolveu três modelos de negócios que definem as funcionalidades do sistema (TV-Anytime, 2000; TV-Anytime, 2003a). O modelo um, o mais simples, é direcionado para sistemas onde a entrega de conteúdo é unidirecional, sem canal de retorno (transmissão terrestre de sinais de TV). O modelo dois mantém as capacidades do modelo um e acrescenta novas características, supondo a utilização de canal de retorno limitado (satélite). O modelo três acrescenta novas características às dos modelos um e dois, sendo direcionado para sistemas que possuam canal de retorno através de conexões permanentes (redes de banda larga). Esses modelos estão baseados no modelo funcional de referência do TV-Anytime, apresentado na seção 2.3, e suas unidades funcionais.

Dentre os três modelos, o último é o mais adequado para suportar as características de TV Interativa que se pretende explorar dentro do grupo de pesquisa. Além disso, esse modelo abrange a maioria das funcionalidades para serviços em TV Interativa apresentadas na subseção 2.4.1 podendo ser facilmente inserido na cadeia produtiva apresentada na subseção 2.4.2.

O modelo 3, também chamado de modelo bidirecional em banda larga, é baseado na integração entre múltiplos provedores de conteúdo, provedores de serviço e Internet. Nesse cenário, múltiplos provedores de conteúdo abastecem provedores de serviço com base nos requisitos estabelecidos nos perfis dos usuários, dando suporte também ao comércio eletrônico e ao chamado t-commerce, tudo em tempo real.

Os benefícios desse modelo para usuários, provedores de conteúdo e de serviço, provedores de acesso e anunciantes são descritos a seguir: 


\section{- Usuários:}

- Ver e armazenar conteúdo de modo totalmente independente da fonte, do método e do tempo de entrega.

- Personalização do modo de assistir um programa por meio de definições de preferências pessoais, levando à criação de canais virtuais pessoais. Incluindo no contexto de múltiplos membros de uma casa.

- Serviços personalizados.

○ Gravação digital de conteúdo permitindo: acesso aleatório a conteúdo, controle detalhado do modo de exibição, controle tipo videocassete de programas ao vivo, sumarização, indexação, arquivamento de programas e segmentos.

- Acesso a informações adicionais tais como comentários, conteúdo audiovisual extra e páginas Web fornecidos pelos provedores e anunciantes, as quais podem ser descarregadas fora dos horários de pico para exibição off-line ou obtidas sob demanda.

\section{- Provedores de Conteúdo e de Serviço:}

- O modelo aberto encoraja a competição, a colaboração e a oportunidade de desenvolver novos produtos e novas fontes de renda.

- A personalização de conteúdo e de serviços encoraja a fidelidade dos clientes (usuários).

- A distribuição de conteúdo pode ser mais eficiente e efetiva. Provedores de conteúdo podem usar segmentação para oferecer distribuição mais eficiente de programas e de serviços interativos, entregando noticiários ou programas de esportes, por exemplo, para usuários que não desejam assistir o pacote completo da programação.

- Monitoramento de uso de conteúdo. Mecanismos de relatórios de uso podem auxiliar os provedores de conteúdo a agregar conteúdo, direcionando a programação para uma audiência maior. Relatórios individualizados podem permitir aos proprietários do conteúdo gerar pacotes especializados para grupos de usuários (ou mesmo para um único usuário). 


\section{- Anunciantes:}

- Comerciais direcionados. Durante a exibição de um programa, os comerciais padrões podem ser substituídos por anúncios armazenados no PDR local, os quais foram selecionados baseados nas preferências do usuário. Outros parâmetros, como hora do dia ou localização, podem também ser utilizados.

- Fazer uso das respostas dos usuários. Se um canal de retorno está disponível, é possível transmitir informações de volta aos anunciantes descrevendo as ações dos usuários. O usuário pode ter opção para reagir ao comercial, incluindo assistir passivamente, responder, pedir por mais informações ou até mesmo comprar. Uma base de dados pode então conter uma visão atualizada do comportamento de consumo do usuário.

- A análise do comportamento do usuário pode indicar oportunidades de compra por impulso.

- Aumentar a fidelidade do usuário como resultado de uma compilação das preferências e da qualidade dos serviços personalizados entregue a ele.

- Redução de custos. Os comerciais direcionados só atingem o público interessado e podem ser armazenados no PDR fora do horário nobre.

- Novos modelos de negócios podem ser introduzidos (por exemplo, o hardware/serviço de armazenamento pode ser subsidiado pela indústria de propaganda).

\section{- Provedores de Acesso:}

- A possibilidade de gerenciar o PDR remotamente cria novas oportunidades de fontes de renda para os provedores de acesso.

- Uso mais eficiente da banda. Fora dos horários de pico os provedores podem enviar conteúdo para o dispositivo local do usuário. Essa abordagem economiza banda nos horários de pico (particularmente durante eventos ao vivo). 
- A habilidade de combinar material audiovisual com outros tipos de mídia cria novas possibilidades de serviços, aumentando o número de potenciais clientes.

O Anexo A traz uma lista das características previstas para o modelo 3, relacionando as mesmas às unidades do modelo funcional de referência.

\section{5}

Considerações Finais

Devido ao grande interesse das indústrias de telecomunicação, de entretenimento e televisiva, diversos esforços estão sendo feitos em direção à padronização da TV Interativa. Dentre esses esforços destaca-se o TV-Anytime Forum. Este projeto usa o modelo de referência do TV-Anytime para identificar as entidades da cadeia produtora, distribuidora e consumidora de conteúdo assim como os serviços, auxiliando no projeto de uma infraestrutura para produção e distribuição de conteúdo e serviços em TV Interativa (ver capítulo oito).

Um dos objetivos do projeto de protótipo de TV Interativa é explorar ambientes interativos, onde, além das interações entre o usuário e a aplicação, também sejam trabalhadas as interações entre aplicações e o sistema. Para que isso seja possível é necessário ter acesso à metadados sobre conteúdo, usuário e ambiente, entre outros tipos de informações de contexto. O TV-Anytime Forum reconhece a importância dos metadados na TV Interativa, tendo produzido uma especificação sobre o assunto. Contudo, tal especificação não prevê uso explícito da computação ciente de contexto como um meio para facilitar os novos tipos de interações desejados. Do mesmo modo, não fornecem meios para produzir descrições de objetos de mídia independentes das descrições de programas, tornando difícil o reuso das descrições.

Outro problema é como fazer ligações entre descrições e conteúdo. A solução do TV-Anytime foi criar um URI que aponta para um objeto representando o programa. A ligação é feita colocando esse URI na descrição do programa e nos guias de programação eletrônicos. Nessa abordagem a segmentação de um programa em seqüências, cenas e quadros é feita apenas de modo lógico, por meio das descrições MPEG-7. Isso dificulta a reutilização de segmentos de programas e de suas descrições relacionadas. 
Capítulo

O Padrão MPEG-4 
A

TENDÊNCIA de convergência entre as áreas de computação, telecomunicação e TV/filme/entretenimento, que vem sendo experimentada durante a última década, tem inspirado o surgimento de novas aplicações, tais como: transmissão de vídeo pela Internet, multimídia móvel, bibliotecas multimídia, videoconferência, educação à distância e televisão interativa. Muitas dessas aplicações realizam comunicação entre duas ou mais partes e têm o potencial (e em alguns casos a necessidade) de compartilhar e trocar dados, o que torna a interoperabilidade um requisito fundamental. Contudo, sem um padrão para realizar algumas das operações envolvidas no processo de comunicação e para estruturar a troca de dados, a interoperabilidade entre aplicações se torna extremamente complicada.

O padrão MPEG-4 (ISO/IEC 14496), cujo nome oficial é Codificação de Objetos Audiovisuais, tem como meta definir um padrão internacional de codificação audiovisual que atenda às necessidades emergentes dos serviços de interação, comunicação e difusão, assim como às necessidades de serviços mistos resultantes da convergência dos mesmos. MPEG-4 combina algumas características típicas dos outros padrões MPEG, como a representação e codificação eficientes de vídeo e áudio, mas vai além, permitindo a representação e a manipulação individual dos objetos de mídia que compõem uma cena. Tais objetos podem ser imagens estáticas ou moventes (vídeo), áudio, textos, gráficos, etc. A informação multimídia é estruturada de maneira a permitir interação do usuário com o material em exibição. O padrão também especifica meios de permitir a reutilização de objetos de mídia e a associação de informações de direitos autorais (Pereira, 2002; Battista et al., 1999).

Este capítulo fornece uma visão geral sobre o padrão MPEG-4. A seção 3.1 apresenta os objetivos e as funcionalidades do padrão, como tais funcionalidades são distribuídas entre as partes do padrão e como elas são tratadas dentro da arquitetura de um terminal MPEG-4. A seção 3.2 relata como os fluxos MPEG-4 são identificados e caracterizados. Tais fluxos correspondem à forma codificada dos objetos MPEG-4, que necessitam ser decodificados e passados por descompressão antes de serem apresentados. A seção 3.3 discute as funcionalidades da codificação MPEG-4. A seção 3.4 apresenta as 
ferramentas que permitem descrever uma cena MPEG-4 em formato textual, a qual pode ser transformada em formato binário. A seção 3.5 apresenta a ferramenta MPEG-J, que permite utilizar programas em Java para controlar a apresentação de cenas MPEG-4, fornecendo suporte para complexas aplicações interativas. A seção 3.6 apresenta como o padrão MPEG-4 subdivide suas ferramentas em perfis e níveis, reduzindo a complexidade para a implementação de codificadores e decodificadores. A seção 3.7 compara o padrão MPEG-4 com alguns outros padrões e ferramentas desenvolvidos para apresentação e distribuição multimídia. Por fim, a seção 3.8 traz algumas considerações finais sobre o padrão MPEG-4 e seu status atual.

\section{1}

\section{Visão Geral do Padrão MPEG-4}

\subsection{1 - Objetivos}

Os principais objetivos do padrão MPEG-4 podem ser resumidos em seis tópicos (Avaro et al., 2002), os quais são:

- Fornecer a base tecnológica para representar conteúdo multimídia para apresentação e transmissão em uma vasta gama de serviços e redes. Fornecer uma representação comum que englobe os paradigmas de interação, difusão e conversação. Permitir o uso transparente de conteúdo entre esses diferentes tipos de serviços.

- Estender a interatividade encontrada em textos e imagens para conteúdo com dimensão temporal. Fornecer para esse tipo de conteúdo interatividade tanto no lado do cliente quanto no lado do servidor.

- Estender o uso de conteúdo multimídia em redes com grande largura de banda para todos os tipos de redes, incluindo aquelas com pequena largura de banda e alta taxa de erros.

- Integrar diferentes tipos de mídia em um único padrão, dando a cada um sua própria representação codificada ótima.

- Oferecer alta interatividade a autores e usuários de conteúdo.

- Permitir o uso de conteúdo audiovisual que respeite os direitos autorais associados. 
Para acomodar toda essa complexidade o padrão MPEG-4 se baseia em um conceito simples: uma cena audiovisual é composta de objetos audiovisuais cujas propriedades são definidas usando uma linguagem de descrição de cena.

Os objetos audiovisuais podem ser naturais ou sintéticos. Objetos naturais são aqueles capturados a partir de câmeras e microfones. Objetos sintéticos são aqueles gerados por computador, como texto, gráficos (2D e 3D), animações e música computacional. Esses objetos podem ainda variar desde áudio multicanal até fala e desde tradicionais vídeos retangulares (seqüência de quadros de vídeo) até formas arbitrárias (por exemplo, somente o contorno de uma pessoa, como ilustrado na Figura 3.1) (Avaro et al., 2002).

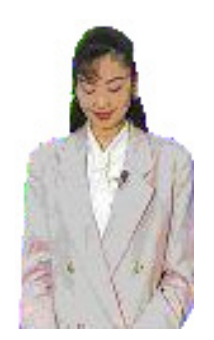

Figura 3.1 - Imagem não retangular (Ebrahimi \& Horne, 2000).

A descrição da cena fornece os relacionamentos temporais e espaciais entre os objetos de vídeo. Esses relacionamentos podem ser puramente 2D ou 3D, ou uma mistura de 2D e 3D (como um vídeo retangular 2D usado como textura em mundos virtuais 3D). As descrições da cena incluem comandos especificando o comportamento e as opções de interação associadas aos objetos audiovisuais e às cenas. MPEG-4 especifica, ainda, protocolos para modificar e animar a cena durante sua apresentação (adicionando ou removendo objetos da cena, mudando as propriedades dos objetos, etc.).

Toda informação, representando os objetos audiovisuais e as descrições da cena, é fornecida como fluxos binários comprimidos, os quais podem ser sincronizados. A Figura 3.2 apresenta um exemplo de cena audiovisual que inclui objetos naturais e sintéticos. Como pode ser observado, os vários fluxos são compostos de acordo com o fluxo de descrição da cena. A Figura 3.2 introduz o conceito de descritor de objeto (Object Descriptor - OD), o qual fornece a ligação entre a descrição da cena e os fluxos individuais com o conteúdo. A seção 3.2 traz mais detalhes sobre descritores de objetos. 


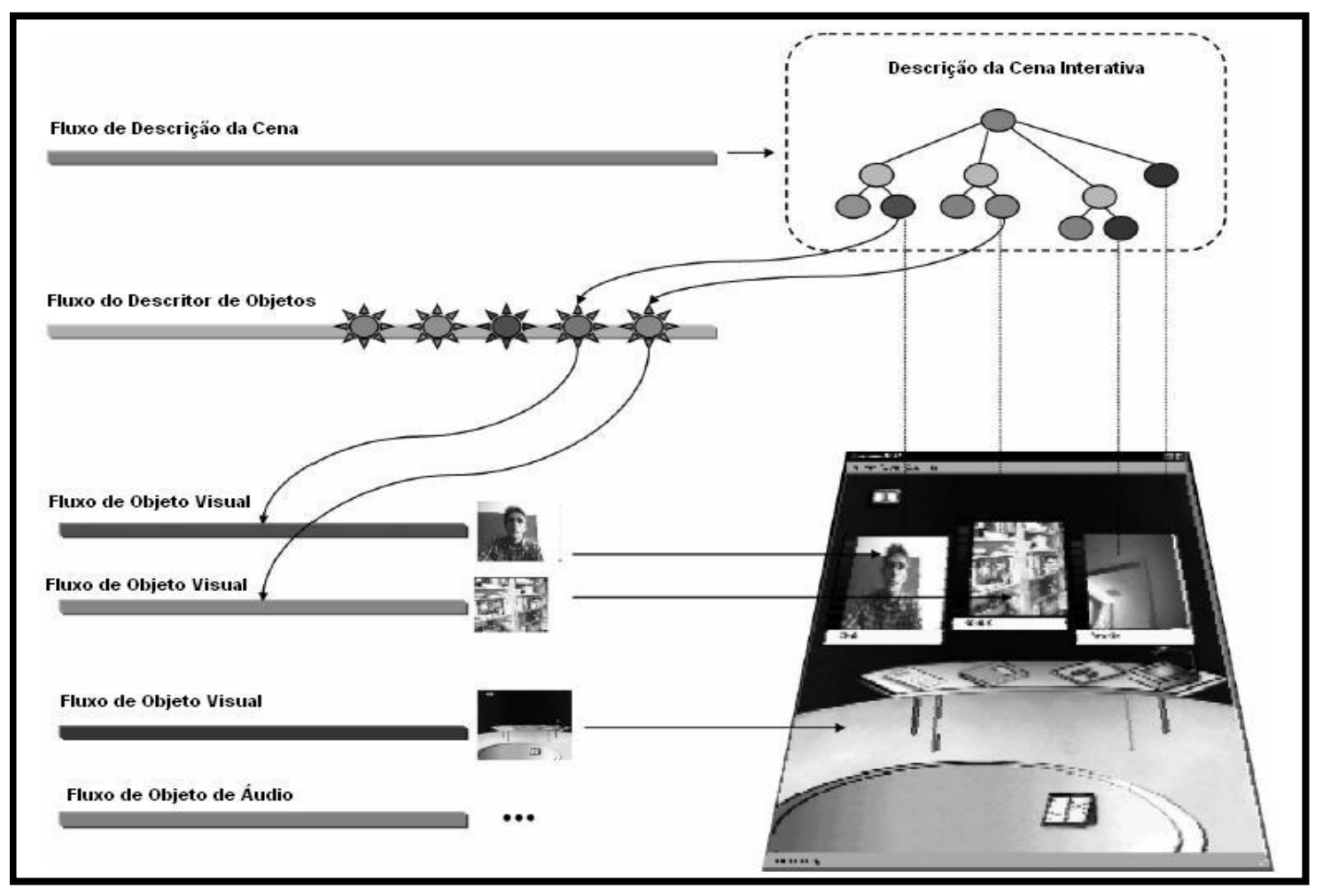

Figura 3.2 - Composição de uma cena audiovisual interativa (Avaro et al., 2000).

\subsection{2 - Funcionalidades}

Procurando facilitar o desenvolvimento de novas formas baseadas em conteúdo de comunicação, de acesso e de manipulação de dados audiovisuais digitais, o grupo MPEG identificou oito funcionalidades e as agrupou em três classes (Pereira, 2002), os quais são:

\section{Interatividade Baseada em Conteúdo.}

- Ferramentas de acesso baseado em conteúdo para dados multimídia. Acesso e organização eficientes de dados audiovisuais através de ferramentas para indexação, hiperligação, busca, navegação, carga, descarga e deleção.

- Manipulação baseada em conteúdo e edição de bitstream. Fornecimento de sintaxe e métodos de codificação que permitam manipular conteúdo sem a necessidade de transcodificação.

- Codificação de dados híbridos. Suporte a métodos eficientes que combinem dados sintéticos e naturais. 
- Acesso aleatório temporal melhorado. Métodos eficientes para acessar aleatoriamente, dentro de um intervalo de tempo e com granulação fina, partes de uma seqüência audiovisual (quadros de vídeo, por exemplo).

\section{Compressão Eficiente.}

- Codificação eficiente. Para transmissão de dados audiovisuais em redes com pouca largura de banda e para armazenamento em dispositivos com capacidade limitada (como cartões de memória).

- Codificação de múltiplos fluxos concorrentes de dados. Codificação de múltiplas visões e trilhas sonoras de uma mesma cena.

\section{Acesso Universal.}

- Robustez em ambientes propensos a erros. Acesso universal implica em fornecer às aplicações acesso a conteúdo sobre diferentes tipos de redes (com ou sem fio) e dispositivos de armazenamento. Em particular, para aplicações que trabalham com baixa taxa de bits sob condições de erro severas. Nesse cenário, sistemas MPEG-4 devem fornecer recursos de tolerância a erros.

- Escalabilidade baseada em conteúdo. Habilidade de alcançar escalabilidade com granulosidade fina em: conteúdo, resolução espacial, resolução temporal, qualidade e complexidade.

Essas funcionalidades estão especificadas no padrão MPEG-4 como ferramentas, as quais estão organizadas em quatro categorias - Sistemas, Visual, Áudio e Arcabouço de Integração para Distribuição Multimídia (Delivery Multimedia Integration Framework DMIF) - correspondendo às quatro especificações tecnológicas (partes) mais importantes do padrão (subseção 3.1.3). Uma descrição exaustiva de cada ferramenta foge aos objetivos desta tese, devido à complexidade e à extensão do assunto. Apenas as ferramentas consideradas mais importantes para o entendimento e desenvolvimento deste trabalho serão abordadas nas seções 3.2, 3.3, 3.4 e 3.5. A Tabela 3.1 apresenta as ferramentas existentes (padronizadas) até o momento em que esta tese foi escrita ${ }^{4}$ (Avaro et al., 2002).

\footnotetext{
${ }^{4}$ O grupo MPEG continua trabalhando no desenvolvimento de novas ferramentas a serem incluídas no padrão MPEG-4.
} 
Tabela 3.1 - Ferramentas MPEG-4.

\begin{tabular}{|c|l|}
\hline Categoria & \multicolumn{1}{c|}{ Ferramentas } \\
\hline \hline Sistemas & - Arcabouço Descritor de Objetos. \\
& - Modelo Decodificador do Sistema. \\
& - Formato Binário para Cenas. \\
& - MPEG-J. \\
& - Fromato Textual MPEG-4 Extensível. \\
& - Ferramentas de Transporte. \\
& - Proteção e Gerenciamento de Propriedade Intelectual. \\
\hline Visual & - Ferramentas de Compressão de Vídeo. \\
& - Robustez em Ambientes Propensos a Erros. \\
& - Escalabilidade de Granulação Fina. \\
& - Codificação de Formas e de Canal Alfa. \\
& - Animação de Faces e Corpos. \\
& - Codificação de Malhas 2D. \\
& - Codificação de Malhas 3D. \\
\hline Áudio & - Codificação de Fala. \\
& - Codificação de Áudio em Geral. \\
& - Codificação de Áudio Sintetizado. \\
& - Codificação de Fala Sintetizada. \\
\hline DMIF & - Interface de Aplicação DMIF. \\
\hline
\end{tabular}

Ainda que não sejam estritamente partes do padrão, existem duas extensões relativas a transporte de conteúdo MPEG-4 e mais os perfis MPEG-4. A extensão Transporte de MPEG-4 sobre Sistemas MPEG-2 especifica como transportar conteúdo MPEG-4 embutido em fluxos de sistema MPEG-2. A extensão Transporte de MPEG-4 sobre Redes IP, a qual complementa a parte oito do padrão MPEG-4 (ver subseção 3.1.3), é uma especificação da Internet Engineering Task Force (IETF) que descreve como transportar MPEG-4 usando o Protocolo de Transferência em Tempo Real (Real-Time Transfer Protocol - RTP). Os perfis especificam subconjuntos de ferramentas que podem ser usados por uma classe de aplicações e serviços. Isso previne que codificadores MPEG-4 tenham que implementar todas as ferramentas listadas na Tabela 3.1.

\subsection{3 - Organização do Padrão MPEG-4}

O padrão MPEG-4 está dividido em partes, cada qual de responsabilidade de um subgrupo MPEG de especialistas. O objetivo dos subgrupos é avaliar novas idéias e técnicas a serem incorporadas no padrão e transformá-las em especificações. As propostas devem atender a requisitos previamente definidos pelo grupo MPEG (ou a um subconjunto desses requisitos). Os subgrupos são formados por especialistas de vários países, pertencentes tanto à área acadêmica quanto às áreas comercial e industrial. O grupo MPEG é aberto a 
esses especialistas desde que os mesmos sejam avalizados por um comitê nacional de padronização (National Standards Body). No caso do Brasil tal comitê é a Associação Brasileira de Normas Técnicas (ABNT).

Após a análise de propostas para um determinado item do padrão, uma em especial é escolhida e colocada em processo de padronização. Este processo consiste em algumas fases de revisão técnica da proposta, seguida por uma votação para que se torne um padrão internacional, o qual será homologado pela ISO em caso de aprovação.

Mesmo após ter sido padronizada, qualquer parte do padrão pode receber novas contribuições (extensões) na forma de emendas ou de relatórios técnicos. Essas contribuições refletem evoluções tecnológicas, merecedoras de inclusão, ocorridas após a padronização, mantendo o padrão atualizado.

O padrão MPEG-4 está dividido (até o momento em que esta tese foi escrita) em dez partes, algumas sendo padrões internacionais e outras sendo relatórios técnicos (Pereira, 2002). As partes desse padrão são:

- Parte 1 (ISO/IEC 14496-1) - Sistemas. Especifica descrição de cenas, multiplexação, sincronização, gerenciamento de armazenamento local temporário (buffer) e gerenciamento e proteção de propriedade intelectual.

- Parte 2 (ISO/IEC 14496-2) - Visual. Especifica a representação codificada de objetos visuais naturais e sintéticos.

- Parte 3 (ISO/IEC 14496-3) - Áudio. Especifica a representação codificada de objetos de áudio naturais e sintéticos.

- Parte 4 (ISO/IEC 14496-4) - Teste de Compatibilidade. Define condições, no que diz respeito à bitstreams e a dispositivos, para testar implementações de ferramentas MPEG-4.

- Parte 5 (ISO/IEC 14496-5) - Software de Referência. Corresponde à implementação da maioria das partes do padrão MPEG-4. Tem valor apenas informativo e visa auxiliar o desenvolvimento de ferramentas reais compatíveis com o padrão.

- Parte 6 (ISO/IEC 14496-6) - Arcabouço para Integração de Distribuição Multimídia (Delivery Multimedia Integration Framework - DMIF). Define um 
protocolo de sessão para gerenciamento de fluxo multimídia sobre tecnologias de distribuição genéricas.

- Parte 7 (ISO/IEC 14496-7) - Software de Referência Visual Otimizado. Inclui software otimizado para ferramentas visuais como estimativa de movimento rápida e estimativa de movimento global rápida. Essa parte é um relatório técnico e não uma especificação padronizada.

- Parte 8 (ISO/IEC 14496-8) - Transporte de Conteúdo MPEG-4 sobre Redes IP. Especifica o mapeamento de conteúdo MPEG-4 para vários protocolos baseados em IP.

- Parte 9 (ISO/IEC 14496-9) - Descrição de Hardware de Referência. Incluirá descrições de ferramentas MPEG-4 em linguagem de descrição de hardware (Very High-speed Integrated Circuit Hardware Description Language VHDL). Isso facilitará o desenvolvimento de ferramentas baseadas em plataformas mistas de hardware e de software. A primeira versão da parte 9 era esperada, inicialmente, para o ano de 2003. Porém, o grupo MPEG ainda não publicou uma data exata.

- Parte 10 (ISO/IEC 14496-10) - Codificação de Vídeo Avançada. Especificará sintaxe de vídeo e ferramentas de codificação baseadas na especificação H.264 da ITU-T. A parte 10 está em fase final de padronização, onde o comitê irá votar, no terceiro quadrimestre de 2003, pela mudança de status (Final Draft International Standard para International Standard) e conseqüente homologação pela ISO.

A versão 1 do MPEG-4 tornou-se padrão internacional em Abril de 1999 e a versão 2 em Fevereiro de 2000. As principais partes (1, 2, 3 e 6) foram sincronizadas nessas duas versões. Após a segunda versão, cada parte teve seu próprio desenvolvimento, recebendo novas ferramentas através de emendas. Vale ressaltar que as novas versões são sempre compatíveis com as anteriores.

Apesar de a maioria das partes serem padrões internacionais, as partes 7 e 9 são relatórios técnicos, com valor apenas informativo. As partes 1, 2, 3, 6, 8 e 10 compõem o núcleo tecnológico do MPEG-4, enquanto as partes 4, 5, 7 e 9 são de apoio. As partes 1, 2, 
3 e 10 são independentes do método de distribuição, deixando as idiossincrasias da camada de entrega para as partes 6 e 8.

\subsection{4 - Arquitetura de um Terminal MPEG-4}

Um terminal MPEG-4, ilustrado na Figura 3.3, é o ambiente onde as apresentações MPEG4 são executadas (também chamado de player MPEG-4). O processo de exibição de apresentações envolve uma série de passos que vão desde o recebimento do arquivo contendo a apresentação codificada, até a montagem dos vários objetos que compõem a cena.

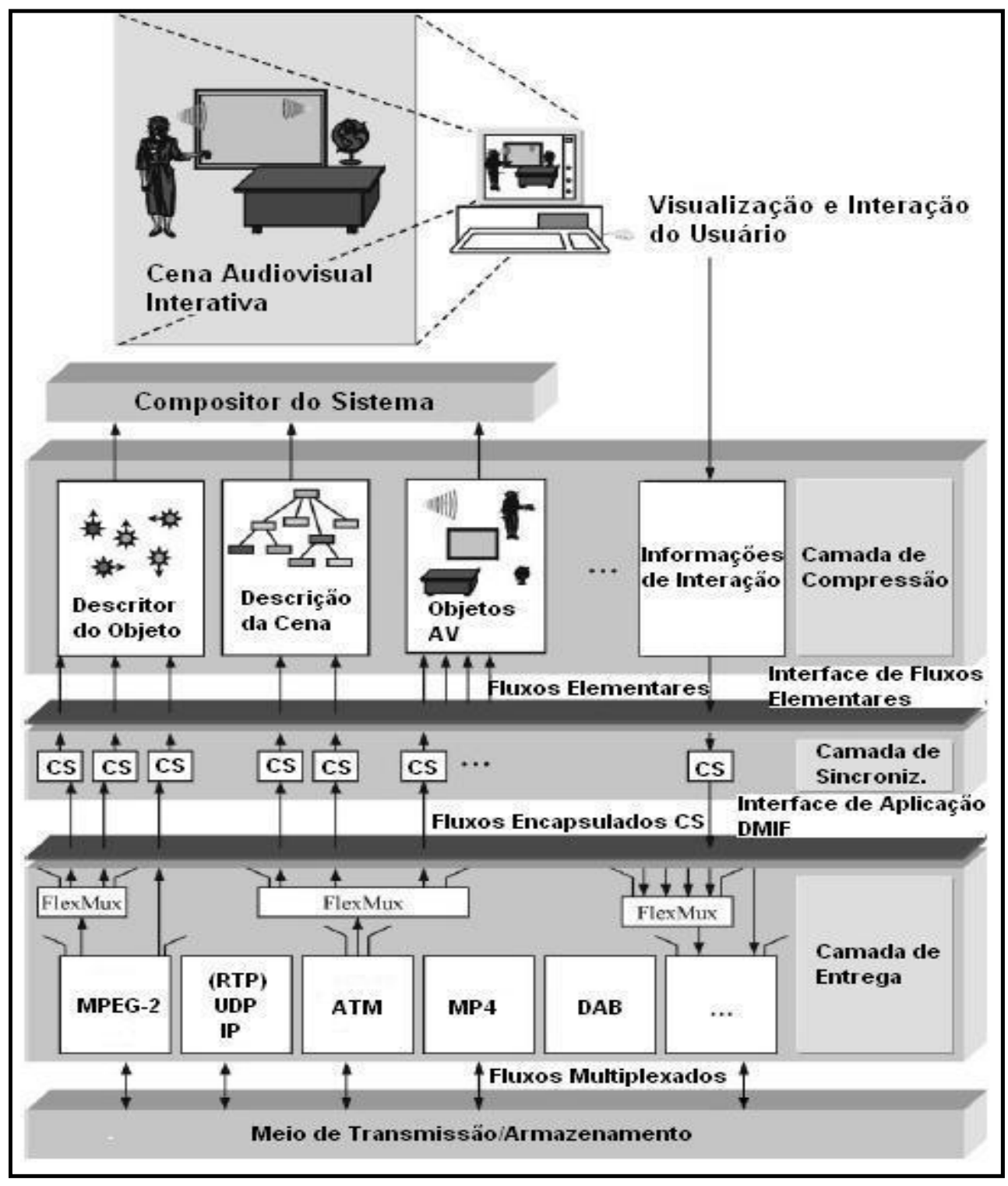

Figura 3.3 - Arquitetura de um terminal MPEG-4 (Avaro et al., 2000). 
Antes, porém, de discutir o processo de exibição de apresentações, vale a pena observar como as mesmas são geradas. O conteúdo necessário para construir as cenas MPEG-4 pode ser capturado ao vivo através de câmeras e microfones, ou pode ser gerado por computador. $\mathrm{O}$ autor da cena descreve a mesma indicando qual conteúdo (objeto) deseja adicionar e as respectivas propriedades. A descrição da cena é feita através de um formato textual específico (seção 3.4), o qual será convertido para o Formato Binário para Cenas (Binary Format for Scenes - BIFS).

A descrição da cena é utilizada por um codificador MPEG-4 para gerar fluxos elementares para cada objeto que a compõe, incluindo um fluxo representado a própria cena, conforme exemplificado na subseção 3.1.1 (Figura 3.2). Todos esses fluxos elementares podem ser multiplexados em um único fluxo MPEG-4, o qual pode ser armazenado no formato de arquivo MPEG-4 $4^{5}$ ou pode ser transmitido (por streaming, por exemplo). Esse fluxo único é que será decodificado em um terminal MPEG-4.

O padrão MPEG-4 não especifica como implementar codificadores, mas sim como deve ser o bitstream final. Por isso a arquitetura ilustrada na Figura 3.3 se refere ao lado do cliente, exemplificando como um fluxo final MPEG-4 é decodificado. A seguir será explicado o processo de decodificação realizado por um terminal MPEG-4.

Um fluxo MPEG-4 multiplexado, proveniente do meio de transmissão e armazenamento, é passado à camada de entrega e é demultiplexado conforme o protocolo de transporte utilizado. Dados MPEG-4 podem ser transportados em uma variedade de sistemas de entrega, incluindo fluxos de transporte MPEG-2, RTP/UDP sobre IP e arquivos MPEG-4. Dados MPEG-4 podem, também, ser enviados sobre outros mecanismos de transporte, tais como ATM ou Difusão de Áudio Digital (Digital Audio Broadcast - DAB), usando combinações das pilhas de protocolos anteriores. Isso confere flexibilidade aos sistemas MPEG-4.

Os dados contidos no fluxo MPEG-4, na forma de fluxos elementares, podem receber uma multiplexação adicional (que é opcional) e, conseqüentemente, necessitar de demultiplexação. Essa demultiplexação adicional ocorre no topo da camada de entrega através da ferramenta de Multiplexação Flexível (Flexible Multiplexer - FlexMux),

\footnotetext{
${ }^{5}$ O grupo MPEG-4 adotou o formato de arquivo QuickTime como base para o formato de arquivo MPEG-4. Mais informações podem ser encontradas em (Herpel et al., 2002; Apple, 2001).
} 
responsável por demultiplexar o fluxo vindo da parte baixa da camada de entrega em vários fluxos elementares MPEG-4. Tais fluxos podem ser dados referentes a objetos audiovisuais, dados de descrição da cena, dados de controle na forma de objetos descritores, ou metadados descrevendo o conteúdo ou associando direitos de propriedade intelectual ao mesmo.

A Camada de Sincronização (CS) ilustrada na Figura 3.3 fornece um mecanismo comum para sincronização e enquadramento (framing) de informações, aplicável a todos os tipos de fluxos elementares vindos da camada superior. A CS é uma ferramenta configurável e flexível de empacotamento de dados que permite inclusão de informações de sincronização, de fragmentação e de continuidade aos pacotes de dados. Essas informações são associadas a unidades de dados chamadas unidades de acesso, que são unidades de apresentação completas (por exemplo, um quadro de vídeo inteiro, que, nesse estágio, ainda está compactado). Durante a decodificação as unidades de acesso são recuperadas dos fluxos elementares, vindos da camada de sincronização, e são passadas à camada de compressão. Os fluxos elementares são então enviados aos seus respectivos decodificadores na camada de compressão. Os decodificadores processam tais fluxos, decodificando e descompactando os mesmos, e produzem unidades de composição (por exemplo, um quadro de vídeo decodificado). Para saber que tipo de informação cada fluxo contém, os decodificadores usam os Descritores de Objetos, responsáveis por descrever as propriedades dos fluxos elementares.

Em uma cena audiovisual MPEG-4 pelo menos um fluxo deve conter as informações de descrição da cena, as quais definem atributos espaciais e temporais dos objetos, o comportamento dinâmico dos mesmos e qualquer característica de interatividade embutida no conteúdo. A descrição da cena também contém ponteiros para os ODs dos objetos audiovisuais. Uma característica chave da descrição da cena é que, desde que ela é transportada em seu próprio fluxo elementar, ela pode conter informações de sincronização completas. Isso implica na possibilidade da cena poder ser alterada dinamicamente, aumentando a flexibilidade e o poder oferecidos aos criadores de conteúdo.

Após os fluxos elementares terem sido decodificados, o compositor do sistema usa a descrição da cena para agregar os vários objetos audiovisuais (naturais e sintéticos) e construir a cena final para apresentação ao usuário. $\mathrm{O}$ mecanismo de descrição da cena 
fornece mecanismos para capturar eventos do usuário ou do sistema. Em particular, esses mecanismos permitem a associação de eventos a operações do usuário sobre objetos, mudando eventualmente o comportamento dos mesmos.

Deve-se observar que nem todo dado flui no sentido servidor-cliente (downstream); canais no sentido inverso (upstream) também podem existir para tratar fluxos vindos do terminal para o transmissor ou para o servidor. As especificações MPEG-4 padronizam os mecanismos que acionam a transmissão de dados no sentido cliente-servidor, bem como o formato no qual dados são enviados de volta ao emissor.

O padrão MPEG-4 também define um conjunto de APIs em linguagem Java chamado MPEG-J. Applets Java, chamados MPEGlets, usam as APIs MPEG-J para obter acesso às funções básicas de um terminal MPEG-4. Os MPEGlets formam a base para aplicações sofisticadas, abrindo novas possibilidades para a criação de conteúdo interativo.

O objetivo deste trabalho é personalizar, dinamicamente, conteúdo interativo MPEG-4 para TV Interativa, o que envolve composição de cenas, inserção de elementos de interatividade e codificação. O objetivo não é criar novos meios de codificação (um codificador comercial está sendo usado), entretanto, é necessário entender o processo de codificação e suas funcionalidades. Em particular porque o processo de codificação produz a estrutura lógica hierárquica de um bitstream sobre a qual os elementos de interatividade irão agir. O comportamento interativo dos objetos pode ser inserido na cena através da própria descrição da cena ou através da API MPEG-J (conseguindo maior complexidade nas interações). Tanto a descrição da cena (para fins de codificação) quanto a API MPEG-J (para fins de interação) necessitam de informações sobre os objetos, as quais estão contidas nos descritores de objetos. Baseado nesse cenário, as próximas seções apresentam detalhes sobre os descritores de objetos, codificação MPEG-4, descrição de cenas e sobre a API MPEG-J.

\section{2}

Descritores MPEG-4

De modo geral, toda informação em MPEG-4 é tratada como fluxo. O termo fluxo elementar se refere aos dados que, total ou parcialmente, contêm a representação codificada 
de um único objeto, seja ele de áudio, visual, informação de controle, informação de descrição da cena ou informação de descrição de objetos.

Fluxos elementares, ou grupos deles, são identificados e caracterizados através de Descritores de Objetos. A informação contida nos descritores inclui o formato dos dados, a identificação do objeto e a indicação dos recursos necessários para a decodificação. Representações alternativas ou codificação escalável utilizando múltiplos fluxos para um único objeto audiovisual podem também ser representadas por descritores de objetos. $\mathrm{O}$ conjunto de descritores de objeto de uma cena é codificado como um fluxo elementar (Herpel, 2002).

Descrição de cena (seção 3.4) e descrição de fluxos são estritamente separadas no padrão MPEG-4, constituindo dois fluxos elementares distintos e diferentes dos fluxos elementares que representam objetos de mídia, como ilustrado na Figura 3.3. A descrição da cena não contém informação sobre quais fluxos são necessários para reconstruir um objeto audiovisual, assim como a descrição dos fluxos não contém informações sobre como um determinado objeto deve ser usado dentro da cena (Herpel \& Eleftheriadis, 2000). A separação facilita a edição e a manipulação em geral de conteúdo MPEG-4. A descrição da cena é usualmente manipulada de maneira consciente pelo autor da apresentação, enquanto a descrição dos fluxos segue preferências e configurações das ferramentas de edição.

O empacotamento de fluxos elementares definido pelo grupo MPEG é independente da tecnologia de entrega. A Camada de Sincronização empacota fluxos elementares em termos de unidades de acesso adicionando cabeçalhos com informações de sincronização. Isto é feito de uma maneira uniforme para todos os diferentes tipos de fluxos, facilitando a identificação e o processamento desse tipo de informação dentro de cada fluxo (Herpel \& Eleftheriadis, 2000; Herpel, 2002). Todo mapeamento posterior dos fluxos para formatos específicos dos protocolos de entrega é feito pela camada de entrega e é definido fora do padrão MPEG-4.

\subsection{1 - Descritor de Objeto}

A descrição das características de um objeto MPEG-4 é feita através de um conjunto hierarquicamente estruturado de descritores. O descritor de mais alto nível é o Descritor de Objeto (Object Descriptor - OD), ilustrado na Figura 3.4. Esse descritor serve como um 
invólucro para agregar outros descritores, sendo o mais importante o Descritor de Fluxo Elementar (Elementary Stream Descriptor - ES Descriptor), o qual descreve um fluxo individual. Existem ainda descritores auxiliares como o descritor de Informação de Conteúdo do Objeto (Object Content Information - OCI) e o descritor de Proteção e Gerenciamento de Propriedade Intelectual (Intellectual Property Management and Protection - IPMP) (Herpel, 2002).

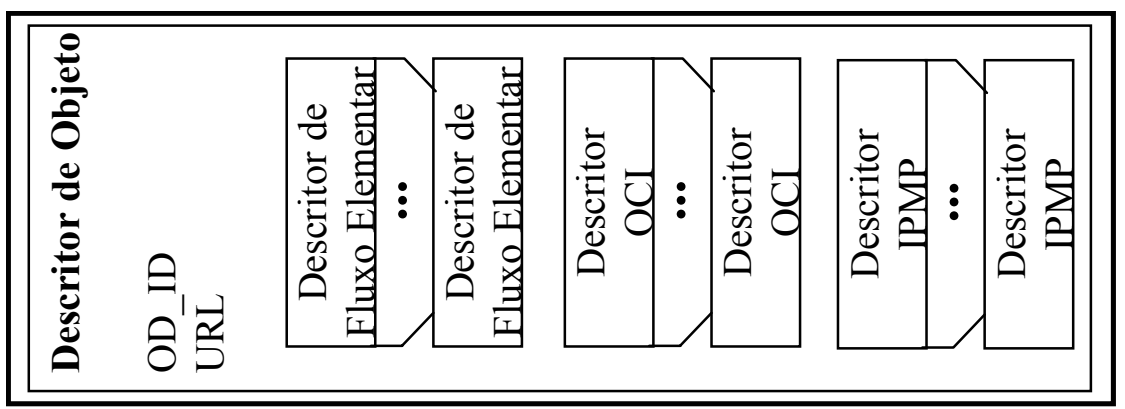

Figura 3.4 - Principais componentes do descritor de objeto (Herpel, 2002).

A ligação dos descritores de objeto com a cena é alcançada em um processo de dois estágios. Primeiro, existe um identificador numérico, chamado identificador do descritor do objeto (Object Descriptor ID - OD_ID). Esse identificador é referenciado pelo fluxo de descrição da cena, estabelecendo a ligação entre ambos. O segundo estágio envolve o endereçamento de um fluxo elementar específico, o qual é identificado e descrito pelos descritores de fluxo elementar incluídos no descritor de objeto. Para esse endereçamento é usado outro identificador, chamado identificador de fluxo elementar (Elementary Stream ID - ES_ID), o qual é parte do descritor de fluxo elementar (Herpel, 2002).

No caso mais simples um OD contém apenas um descritor ES. Tal descritor identifica, por exemplo, o fluxo de áudio que pertence a um nó AudioSource de uma cena, através do qual esse OD é referenciado, conforme ilustrado na Figura 3.5. Dentro de um único OD é possível ter dois ou mais descritores ES, por exemplo, um identificando um fluxo de áudio com baixa taxa de bits e outro identificando um fluxo com alta taxa de bits (Figura 3.6). Nesse caso, o terminal ou o usuário tem que escolher entre dois níveis de qualidade para o áudio.

Também é possível descrever (dentro de um OD) um conjunto de fluxos que correspondem à codificação escalar ou hierárquica dos dados que representam o objeto 
audiovisual. Isso vale tanto para domínio temporal (escalabilidade temporal) quanto para o domínio espacial (escalabilidade espacial).

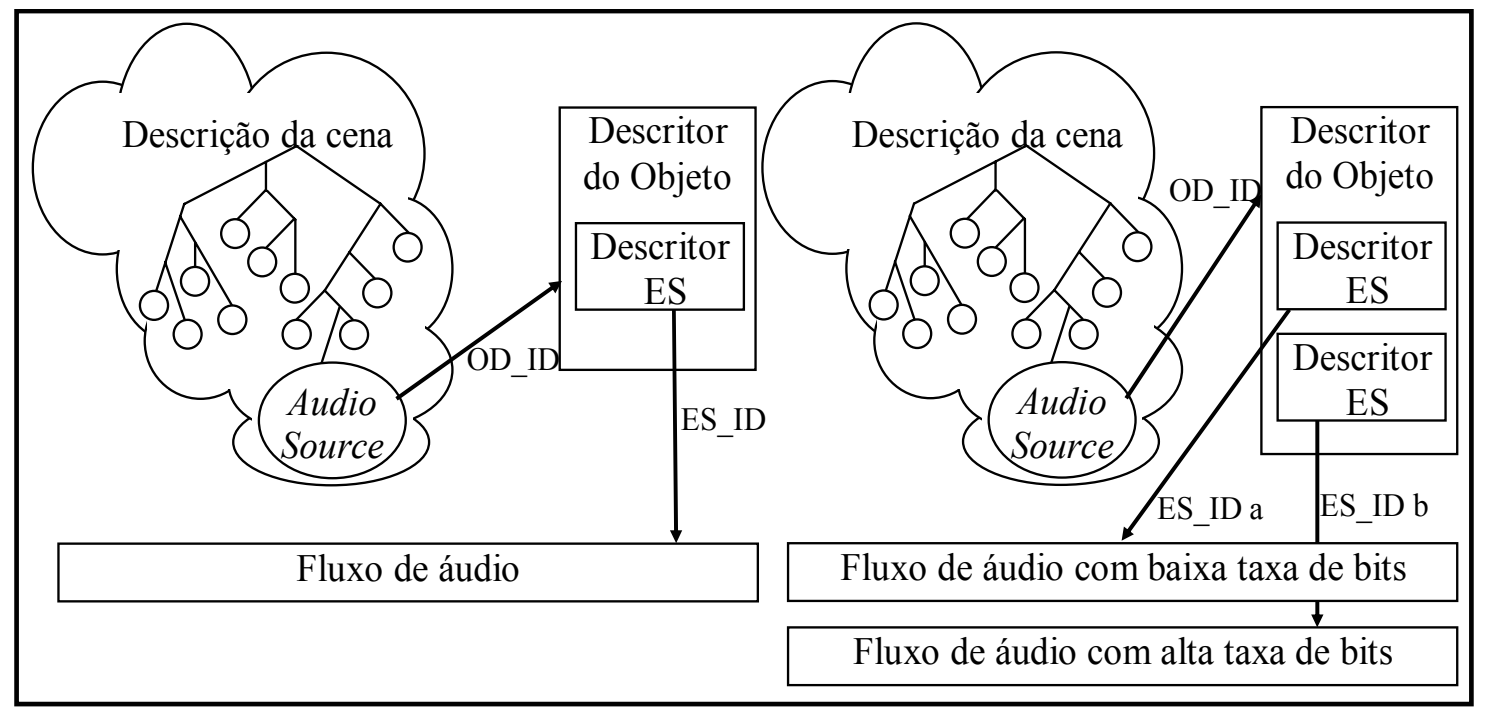

Figura 3.5 - Identificação de um fluxo através de um Descritor ES referenciado por um nó da cena (Herpel, 2002).
Figura 3.6 - Referência a múltiplos descritores ES através de um OD (Herpel, 2002).

Para iniciar uma apresentação MPEG-4 é necessário identificar o fluxo elementar que contém a descrição da cena e o fluxo que contém os descritores de objetos associados. Um OD especial, chamado Descritor Inicial de Objeto (Initial Object Descriptor - IOD), é definido para exprimir essa informação. A Figura 3.7 ilustra um IOD apontando para um fluxo de descrição da cena, através do identificador ES_ID1, e para o fluxo com os descritores de objetos, através do identificador ES_ID2. O IOD é usualmente transmitido antes da apresentação, durante a fase em que a sessão está sendo iniciada, antes de qualquer canal para fluxo elementar ser configurado (Herpel \& Eleftheriadis, 2000).

IODs podem ocorrer no lugar de ODs regulares. Por exemplo, um nó Inline permite inserir uma cena dentro de outra cena. Nesse caso, o OD apontado pelo nó Inline, o qual contém as informações sobre os fluxos de descrição da cena Inline e de descrição de objetos, é um IOD, conforme ilustrado na Figura 3.8. 


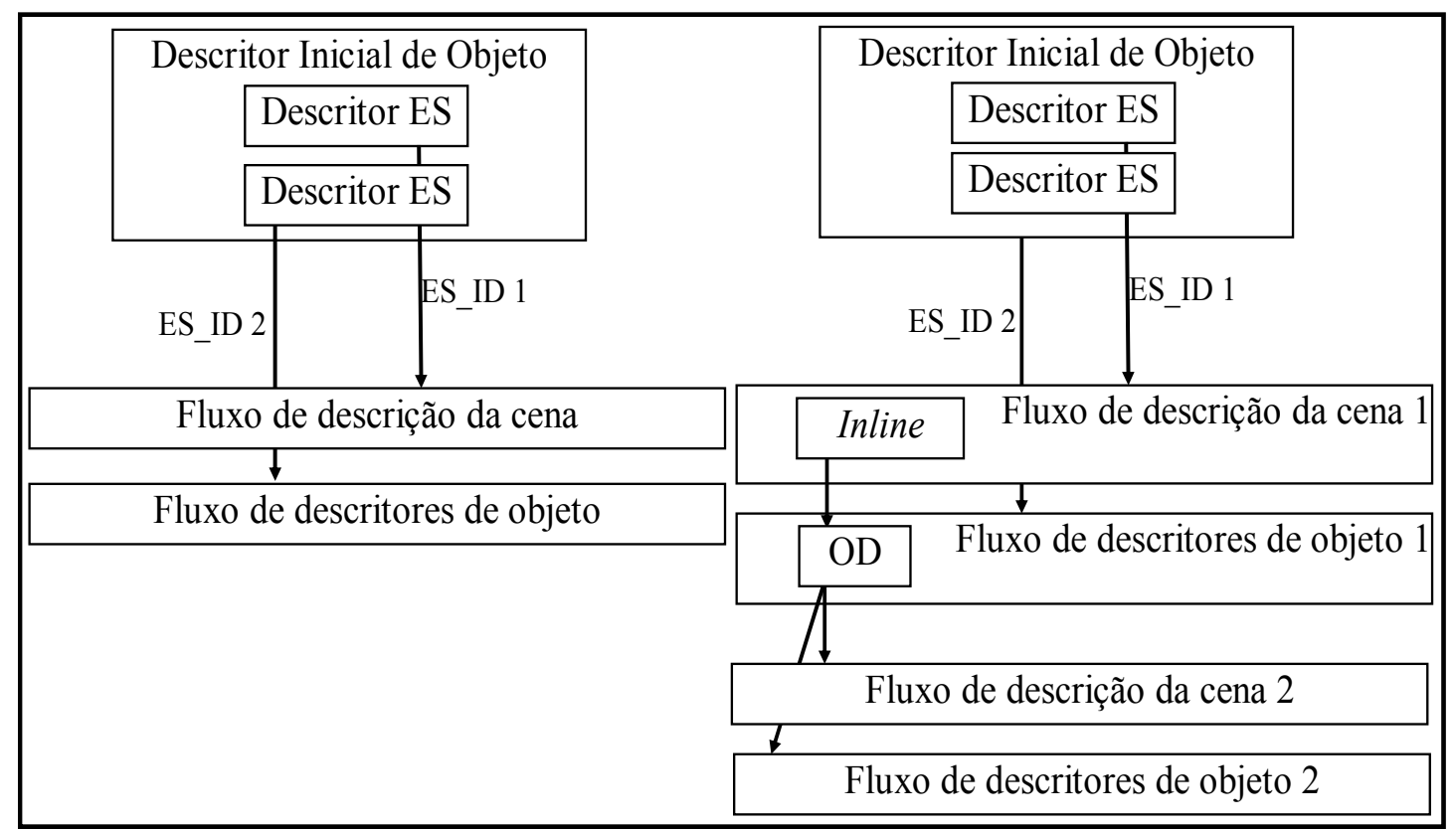

Figura 3.7 - Descritor de Objeto Inicial como

Figura 3.8 - Fluxos descrição da cena e OD referência para os fluxos descrição da cena e para uma cena hierárquica (Herpel \& descritores de objetos (Herpel \& Eleftheriadis, 2000).

\subsection{2 - Descritor de Fluxo Elementar}

Um descritor de fluxo elementar possui toda a informação disponível para um único fluxo elementar. Como ilustrado na Figura 3.9, ele representa um fluxo através de um identificador numérico - o ES_ID - e de um URI opcional. ES_IDs são únicos dentro de um escopo limitado e bem definido, relativo a uma apresentação e seus objetos associados. URIs são mais flexíveis, identificando fluxos de modo único e global, facilitando a descrição de conteúdo distribuído. As dependências de um fluxo são sinalizadas nesse descritor (dependsOn_ES_ID), assim como a prioridade do fluxo na camada de entrega (streamPriority) (Herpel \& Eleftheriadis, 2000; Herpel, 2002).

O descritor DecoderConfig é um subdescritor obrigatório de cada descritor ES. Tal subdescritor contém toda a informação necessária para iniciar a decodificação de um fluxo elementar. Essas informações incluem indicações do tipo do objeto e do tipo do fluxo, assim como informações sobre as taxas de bits média e máxima e o espaço de armazenamento local temporário necessário para decodificação no terminal receptor (Herpel \& Eleftheriadis, 2000; Herpel, 2002). 


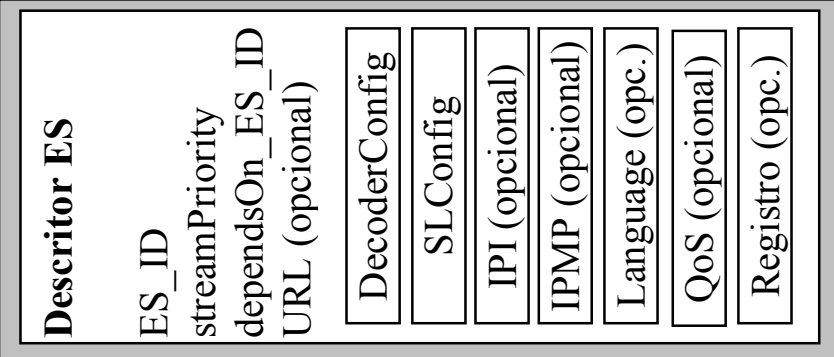

Figura 3.9 - Principais componentes de um descritor de fluxo elementar (Herpel, 2002).

A indicação do tipo de fluxo no descritor DecoderConfig apenas identifica os aspectos mais básicos do fluxo, isto é, se o fluxo é visual, de áudio, descrição de cena, descritor de objeto, referência de relógio ou informações de conteúdo do objeto. Informações mais detalhadas sobre o fluxo são fornecidas pela indicação do tipo do objeto, a qual define o subconjunto sintático de esquemas de compressão para certo objeto. O padrão MPEG-4 define uma variedade de tipos para objetos visuais e de áudio.

O descritor SLConfig é obrigatório e contém informações sobre fluxos elementares utilizadas na camada de sincronização. Os outros subdescritores são opcionais e permitem apontar para fluxos auxiliares associados a um conjunto de fluxos de mídia específico. Informações mais detalhadas sobre tais subdescritores podem ser encontradas em (Herpel, 2002). Os subdescritores auxiliares, ilustrados na Figura 3.9, são:

- IPI (Intelectual Property Identification). É um veículo para disponibilizar identificadores padrão internacionais de conteúdo, como ISBN (International Standard Book Number) e ISMN (International Standard Music Number).

- IPMP. Aponta para o fluxo contendo informações completas de direitos autorais, conforme definido no Arcabouço IPMP.

- Linguagem. Aponta para fluxos auxiliares contendo áudio ou texto em línguas diferentes da língua padrão da apresentação. Por exemplo, legendas em Português e Espanhol em um filme Inglês.

- QoS (Quality of Service). É um mecanismo para associar informações descritivas sobre a qualidade de um objeto audiovisual (taxa de bits, tamanho do quadro e freqüência, por exemplo).

- Registro. Possibilita a identificação não ambígua de fluxos não MPEG-4. 
Codificação MPEG-4

A codificação de objetos MPEG-4, realizada na camada de compressão (Figura 3.3), está dividida entre as partes Sistemas, Visual e Áudio do padrão MPEG-4. A parte Sistemas especifica a codificação da cena como um todo, a qual é composta por objetos codificados seguindo as especificações das partes Visual e Áudio. Tanto a parte Visual quanto a parte Áudio especificam ferramentas para a codificação de conteúdo natural e sintético, assim como conteúdo híbrido (mistura de conteúdo natural e sintético em um mesmo objeto), através de ferramentas de Codificação Híbrida Sintética e Natural (Synthetic and Natual Hybrid Coding - SNHC) (Wollborn et al., 2002; Jang et al., 2002).

Devido à extensão do assunto, esta seção trata apenas da codificação de objetos de vídeo naturais, por serem os mais utilizados no desenvolvimento deste trabalho. Contudo, os conceitos apresentados são aplicáveis aos outros tipos de objetos.

\subsection{1 - Funcionalidades das Ferramentas de Codificação}

Os padrões MPEG-1 e MPEG-2 tinham como objetivo tornar mais eficientes o armazenamento e a transmissão de material audiovisual através de técnicas de compressão. Ambos foram estruturados para trabalhar com vídeo baseado em quadros, o que limitava a interação àquele nível.

Diferente de seus antecessores, o padrão MPEG-4, através da parte Visual, fornece várias funcionalidades para vídeo, divididas em três categorias (ISO, 2002):

- Interatividade baseada em conteúdo. Essa classe de funcionalidade permite acesso temporal aleatório, edição de bitstream e manipulação de objetos na cena.

- Compressão. Melhora a eficiência da codificação e codifica múltiplos fluxos concorrentes de dados.

- Acesso universal. Implica que os dados MPEG-4 devem ser acessíveis através de vários tipos de redes (sem fio e cabeadas), com diferentes taxas de transmissão, e de diferentes tipos de meios de armazenamento. Também implica que os dados devem ser decodificáveis por uma grande variedade de decodificadores (com diferentes complexidades). 


\subsection{2 - Estrutura Lógica do bitstream MPEG-4}

Para alcançar novos níveis de interação, as aplicações baseadas em conteúdo necessitam de codificação e representação de objetos de vídeo (entidades que o usuário pode acessar e manipular), em vez de quadros de vídeo. Para esse fim, MPEG-4 fornece as seguintes ferramentas: representação eficiente dos objetos, escalabilidade baseada em conteúdo, manipulação de objetos e edição de bitstream (Ebrahimi \& Horne, 2000; Wollborn et al., 2002).

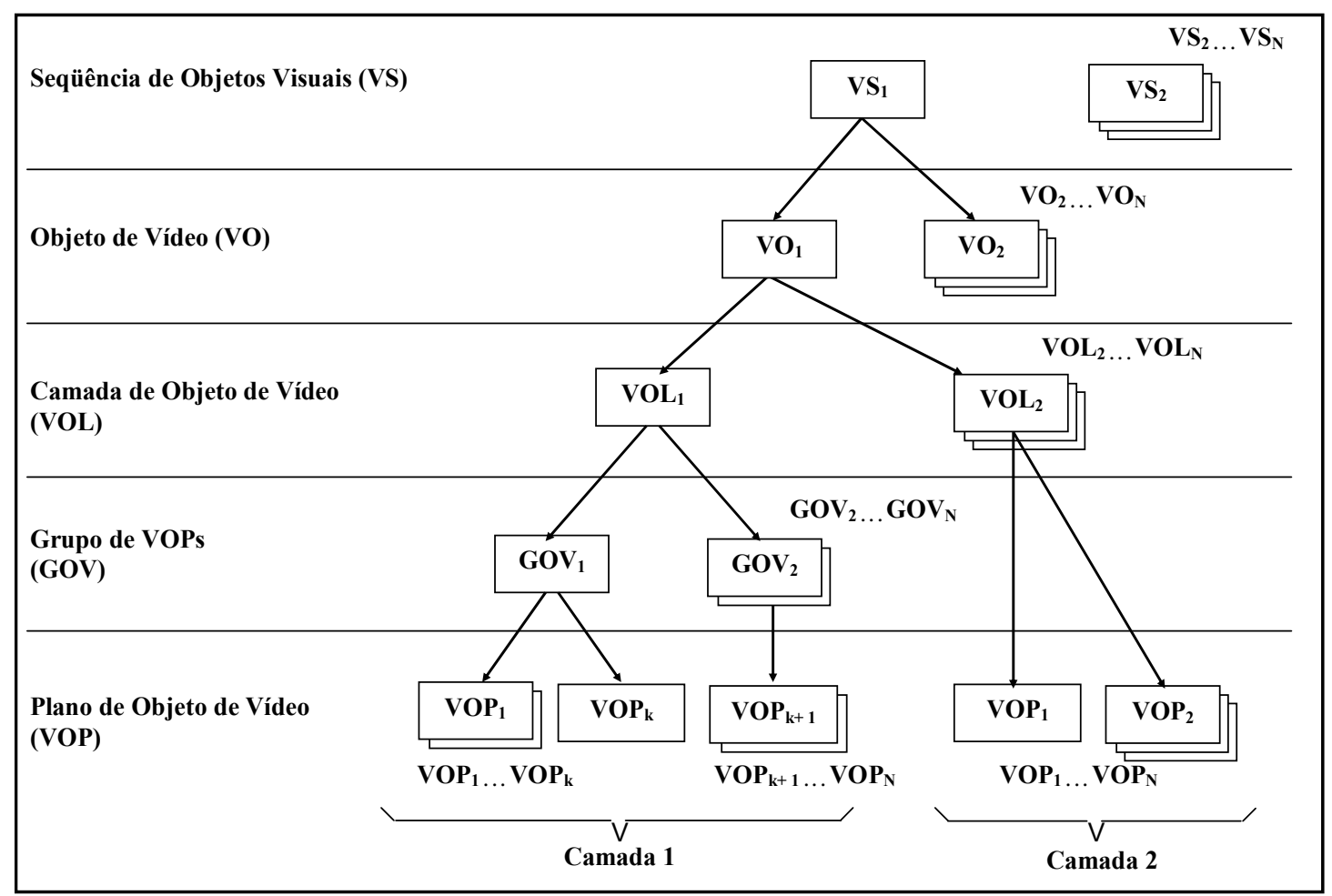

Figura 3.10 - Exemplo da estrutura lógica de um bitstream de vídeo MPEG-4 (Wollborn et al., 2002).

As ferramentas permitem acesso aleatório a qualquer objeto da cena, adicionar camadas de aprimoramento a uma camada base de vídeo (melhorando a qualidade temporal ou espacial), codificar objetos de vídeo em forma arbitrária, entre outras características. Todas essas funções são realizadas manipulando-se as entidades que compõe a estrutura lógica de um bitstream MPEG-4, ilustrado na Figura 3.10. Segundo Wollborn et al. (2002), os níveis hierárquicos que compõem a estrutura lógica são:

- Seqüência de Objetos Visuais (Visual Object Sequence - VS). É uma cena completa MPEG-4, que pode conter qualquer objeto natural ou sintético 2D ou $3 \mathrm{D}$ e suas camadas. 
- Objeto de Vídeo (Video Object - VO). Um objeto de vídeo corresponde a um objeto 2D particular na cena. No caso mais simples ele pode ser um quadro retangular, ou pode ser um objeto de forma arbitrária correspondendo ao contorno de um objeto intraquadro ou do fundo (background) da cena.

- Plano de Objeto de Vídeo (Video Object Plane - VOP). Um VOP é uma amostra no tempo de um objeto de vídeo. VOPs podem ser codificados independentemente uns dos outros, ou de maneira dependente uns dos outros, usando compensação de movimento. Um quadro de vídeo convencional pode ser representado por um VOP com forma retangular, assim como o contorno da imagem de uma pessoa pode ser codificado com um VOP com forma arbitrária.

- Grupo de Planos de Objetos de Vídeo (Group of Video Object Planes GOV). São grupos de VOPs. GOVs fornecem pontos no bitstream onde VOPs são codificados independentemente uns dos outros e podem, então, fornecer pontos de acesso aleatório no bitstream. GOVs são opcionais.

- Camada de Objeto de Vídeo (Video Object Layer - VOL). Cada objeto de vídeo pode ser codificado de modo escalável (múltiplas camadas) ou não escalável (uma única camada), dependendo da aplicação. Cada camada é representada por uma VOL. No modo escalável, um objeto de vídeo pode ser codificado usando escalabilidade espacial ou temporal, indo desde uma resolução grosseira até uma resolução fina (adicionando-se mais camadas). Cada VOL é composta por uma seqüência de VOPs. Dependendo de parâmetros como disponibilidade de banda, poder computacional e preferências do usuário, a resolução desejada pode tornar-se disponível para o decodificador.

\subsection{3 - Compressão}

A compressão de vídeo MPEG utiliza as redundâncias espaciais e temporais, existentes nos quadros de vídeo, para produzir resultados mais eficientes. A técnica conhecida como codificação intraquadro explora as redundâncias espaciais para codificar cada quadro separadamente. Como quadros de vídeo consecutivos são, quase sempre, idênticos, a técnica conhecida como codificação interquadros explora as redundâncias temporais codificando apenas as diferenças entre dois quadros sucessivos. A compressão interquadros 
tem potencial para uma maior redução em comparação à compressão intraquadros, mas o efeito é diminuído quando os vídeos contêm freqüentes mudanças de cena ou cenas com muito movimento. A codificação MPEG fornece técnicas de compensação de movimento para resolver esse problema (Ebrahimi \& Horne, 2000; ISO, 2002; Wollborn et al., 2002).

O processo de compressão MPEG-4 está diretamente ligado à codificação de fluxos. Um fluxo MPEG-4 contém três tipos principais de VOPs. Um I-VOP (I de intracodificado) é uma imagem intracodificada autocontida similar às usadas na compressão JPEG. Um PVOP (Previous VOP - VOP anterior) é uma imagem onde apenas a diferença entre o VOP atual e um conjunto de VOPs anteriores é codificada, enquanto B-VOPs (Bidirectional VOP - VOP bidirecional) são codificados bidirecionalmente usando as diferenças entre VOPs anteriores e posteriores. I-VOPs devem aparecer regularmente no fluxo uma vez que eles são necessários para decodificar P-VOPs e B-VOPs subseqüentes (Wollborn et al., 2002).

\subsection{4 - Acesso Universal}

O acesso universal (Ebrahimi \& Horne, 2000; Wollborn et al., 2002) é alcançado por meio de funcionalidades de recuperação de erros e de escalabilidade baseada em conteúdo. A recuperação de erros é importante, pois se pretende que dados MPEG-4 sejam também acessíveis em ambientes propensos a erros, como em comunicação móvel.

O padrão fornece vários mecanismos para permitir recuperação de erros com diferentes graus de poder e de complexidade. Esses mecanismos oferecem meios para ressincronização, deteç̧ão de erros, recuperação de dados e encobrimento de erros. Existem quatro ferramentas de recuperação de erros na parte visual de MPEG-4 (Wollborn et al., 2002), as quais são:

- Ressincronização. Este é o meio mais comum de tornar um bitstream recuperável. Consiste em inserir marcadores únicos no bitstream para que, no caso de um erro, o decodificador possa saltar os bits restantes até o próximo marcador e reiniciar a decodificação. MPEG-4 permite a inserção de marcadores de ressincronização após um número aproximadamente constante de bits codificados, ao contrário de outros padrões de codificação de vídeo, como 
MPEG-2 e H.263, que permitem ressincronização após um número constante de macroblocos codificados (tipicamente uma linha de macroblocos).

- Particionamento de dados. Esse método separa os bits para codificação de informação de movimento dos bits para codificação de informação de textura. No caso de um eventual erro, um encobrimento de erro mais eficiente pode ser aplicado quando a instância do erro ocorre somente nos bits de textura, possibilitando utilizar a informação de movimento decodificada.

- Código de extensão de cabeçalho. Esses códigos binários permitem a inclusão opcional de cabeçalhos de informação redundantes. Desse modo, reduzem-se as chances de danificação do cabeçalho de informação e de ignorar (saltar) completamente uma grande porção do bitstream.

- Códigos reversíveis de tamanho variável (Reversible Variable Length Codes RVLC). São palavras-código que podem ser decodificadas para frente ou para trás. No caso de um erro e no conseqüente salto de partes do bitstream até o próximo marcador de ressincronização, ainda é possível decodificar partes do bitstream corrompido em ordem reversa para limitar a influência do erro.

A escalabilidade, espacial ou temporal, baseada em objetos, permite ao usuário decidir quando usar recursos escassos, que podem ser a banda disponível ou o poder computacional. Ambas escalabilidades são implementadas utilizando-se múltiplas camadas de VOLs. Considerando o caso de dois VOLs: a camada base e a camada de aprimoramento. Para escalabilidade espacial, a camada de aprimoramento melhora a resolução de um VOP fornecido pela camada base. Similarmente, no caso da escalabilidade temporal, a camada de aprimoramento pode ser decodificada se a taxa de quadros desejada for maior que a oferecida pela camada base. Então, a escalabilidade temporal melhora a suavidade do movimento na seqüência de vídeo (Wollborn et al., 2002).

\section{$\underline{3.4}$}

Descrição de Cenas

A parte Sistemas do padrão MPEG-4 especifica a descrição de cenas audiovisuais. Uma cena audiovisual é composta por objetos primitivos (ou por objetos compostos por objetos 
primitivos), que podem ser classificados, segundo o grupo MPEG (ISO, 2002), de acordo com:

- Forma de representação. A forma de representação pode ser sintética (objetos gerados por computador, como primitivas gráficas $2 \mathrm{D}$ e $3 \mathrm{D}$, fonemas, padrões de representação musical, modelos faciais, etc.), ou natural (vídeo, áudio, imagens estáticas, texturas).

- Tipo de informação. Pode ser visual (vídeo, imagens estáticas, texturas, gráficos, ambientes virtuais, apresentação de texto), aural (voz, efeitos sonoros, música sintetizada e música natural), metainformação (dados que acompanham as informações visuais e auditivas, adicionando conteúdo semântico às mesmas).

- Tipo de mídia. Pode ser contínua ou não contínua.

Uma cena contém um número de objetos com diferentes formas (possivelmente), para serem combinados antes da apresentação para o usuário. A composição engloba a tarefa de combinar todos os objetos (separados) que fazem parte da cena.

O modelo adotado pelo MPEG-4 para descrever a composição de cenas multimídia complexas é baseado nos conceitos da VRML (Virtual Reality Modeling Language) (Web3D, 1997). Basicamente, a parte Sistemas reutiliza o máximo possível da VRML, estendendo e modificando somente quando estritamente necessário (ISO, 2002). A extensão foi necessária porque a VRML não possui algumas das características importantes para as aplicações multimídia às quais o padrão MPEG-4 se destina. Por exemplo, a VRML não fornece suporte para streaming de áudio e vídeo e o modelo de sincronização não é rigidamente especificado. Esses fatos implicam que a sincronização de múltiplos objetos em uma cena não pode ser garantida. Outro ponto é que a VRML não fornece compressão, gerando arquivos (para apresentação) muito grandes (Dufourd, 2002).

$\mathrm{O}$ autor pode gerar a descrição de uma cena em formato textual, possivelmente por meio de uma ferramenta de autoria. A descrição deve estar de acordo com a sintaxe VRML estendida. Por questões de eficiência, o padrão define uma maneira de codificar a descrição da cena em uma representação binária - Formato Binário para Cenas (Binary Format for Scene - BIFS) (Dufourd, 2002). A descrição textual, em VRML estendida, passa por um codificador, que converte a descrição textual em código binário (BIFS). Esse código pode, 
então, ser multiplexado e transmitido, ou armazenado. Logo, diferentemente da VRML que gera objetos 3D interpretando o formato textual (código VRML), a representação textual do BIFS é usada para gerar um código binário comprimido.

O padrão MPEG-4, por meio de sua parte Sistemas, especificou o formato textual MPEG-4, chamado Formato Textual MPEG-4 Extensível (Extensible MPEG-4 Textual Format - XMT) (Kim \& Wood, 2002). O XMT possui dois modos, existindo um mapeamento direto entre os dois: o XMT-A (alfa) e o XMT- $\Omega$ (ômega), ambos baseados em $\mathrm{XML}^{6}$. O primeiro é a representação textual do BIFS, enquanto o segundo é um formato de mais alto nível baseado em SMIL 2.0 (Synchronized Multimedia Integration Language) (W3C, 2001). No desenvolvimento deste trabalho apenas o XMT-A é considerado.

Cenas multimídia são entendidas como estruturas hierárquicas representadas como um grafo. Cada folha do grafo representa um objeto de mídia (áudio, vídeo, etc.). A estrutura do grafo não é, necessariamente, estática, pois quanto mais relacionamentos se desenvolverem com o passar do tempo, mais nós ou subgrafos são adicionados ou removidos. Todos os parâmetros descrevendo esses relacionamentos fazem parte da descrição da cena enviada ao decodificador (ISO, 2002).

Uma atualização da estrutura da cena pode ser realizada a qualquer momento. Essas atualizações podem acessar qualquer campo ou qualquer nó atualizável na cena. Um nó atualizável é um nó que recebeu um identificador único na estrutura da cena. $\mathrm{O}$ usuário pode também interagir logicamente com as cenas, mudando a estrutura da cena ou o valor de qualquer campo de qualquer nó atualizável (Battista et al., 1999; Dufourd, 2002).

Para que uma cena possa ser apresentada no terminal do receptor, a estrutura da cena deve estar disponível preferencialmente antes dos objetos. Dessa maneira, as informações de composição (informações sobre a composição da cena inicial e das atualizações da cena durante a evolução da seqüência) são entregues em um fluxo elementar. Porém, conforme discutido na seção 3.2, o fluxo de composição é tratado de modo diferente dos outros, por fornecer as informações requisitadas pelo terminal para configurar a estrutura da cena e mapear todos os outros fluxos elementares nos seus respectivos objetos de mídia (Battista et al., 1999; Herpel, 2002).

\footnotetext{
${ }^{6}$ Linguagem de Marcação Extensível (Extensible Markup Language - XML): é uma especificação W3C que visa tornar os dados em páginas Web independentes do modo de apresentação (W3C, 2000).
} 
O padrão MPEG-4 especifica ferramentas de codificação para objetos audiovisuais. A parte Sistemas especifica como esses objetos, que são codificados em fluxos elementares, são posicionados e sincronizados com outros objetos. Esse sistema é chamado de mecanismo de apresentação. Esse mecanismo decodifica e monta uma apresentação a partir da descrição da cena e dos descritores de objeto. De um modo simplista o mecanismo de apresentação pode ser visto como um interpretador de uma descrição paramétrica (Swaminathan et al., 2002).

O objetivo do MPEG-J, especificado na parte Sistemas do padrão MPEG-4, versão 2, é definir um mecanismo para aplicações Java. Tal mecanismo visa complementar o mecanismo de apresentação permitindo associar um comportamento programático complexo às aplicações. A plataforma ${ }^{7}$ Java foi escolhida devido às suas capacidades, entre outras, de: carregar e executar programas remotamente, executar o mesmo código em diferentes plataformas de hardware e software e ter a disponibilidade de várias interfaces e APIs para tratamento dinâmico de informações do ambiente (ISO, 2002; Swaminathan et al., 2002).

MPEG-J permite a interoperação entre terminais MPEG-4 e programas Java. Utilizando MPEG-J, autores de apresentações multimídia podem embutir em suas mídias complexos mecanismos de controle e de processamento, gerenciando a operação da sessão audiovisual de maneira inteligente. A aplicação Java é entregue ao usuário como um fluxo elementar, que é direcionado para o ambiente de execução MPEG-J. Dentro de tal ambiente o programa MPEG-J terá acesso aos vários componentes e dados do terminal MPEG-4, além de acesso aos pacotes básicos da linguagem Java.

Segundo Swaminathan et al. (2002), para alcançar esses objetivos, MPEG-J especifica:

- Um conjunto de APIs para permitir a interoperação entre aplicações Java e um terminal MPEG-4.

- O modo de entrega de uma aplicação para um terminal MPEG-4.

\footnotetext{
${ }^{7}$ Plataforma , aqui, é usada para indicar, ao mesmo tempo, Linguagem e Máquina Virtual Java.
} 
- O ciclo de vida de uma aplicação MPEG-4.

- Restrições de segurança.

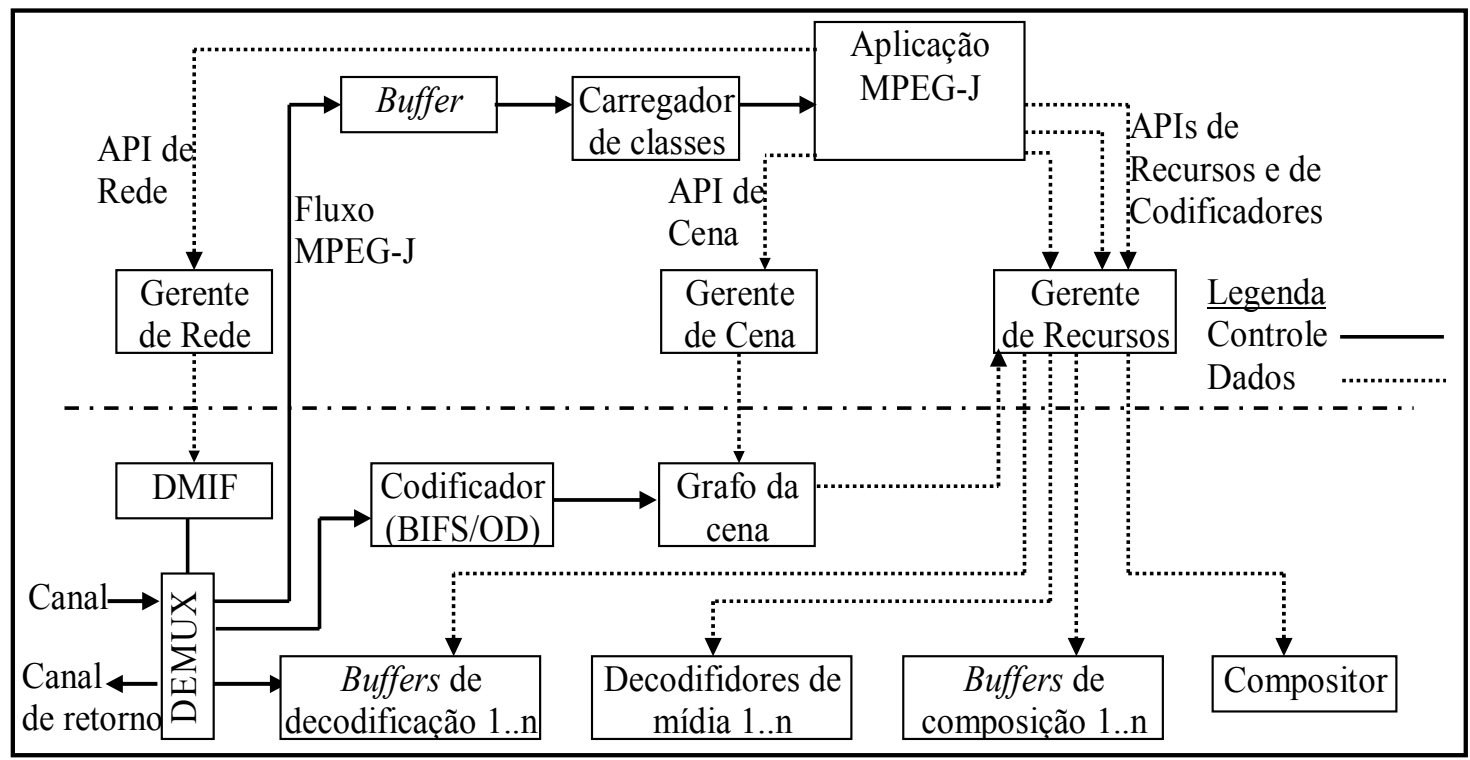

Figura 3.11 - Arquitetura de um terminal MPEG-4 equipado com o mecanismo MPEG-J (Swaminathan et al., 2002).

A Figura 3.11 ilustra a interação entre a arquitetura MPEG-J e a arquitetura de um terminal MPEG-4. O mecanismo de apresentação MPEG-4 compõe a metade mais baixa da Figura 3.11, enquanto o mecanismo de aplicação MPEG-J compõe a outra metade. Este último é usado para controlar o mecanismo de apresentação através de mecanismos de execução e de entrega definidos pelas APIs MPEG-J.

Aplicações podem ser locais (estão na mesma máquina que o terminal) ou podem ser transmitidas em fluxos MPEG-J para serem carregadas e executadas em um terminal remoto. No primeiro caso, os programas MPEG-J são genericamente chamados de Aplicações MPEG-J e, no segundo caso, de MPEGlets (em uma alusão aos applets Java). Neste trabalho apenas MPEGlets foram utilizados, sendo que os termos aplicação MPEG-J e MPEGlet são usados indistintamente.

MPEGlets necessitam implementar a interface MPEGlet definida na especificação MPEG-J. Os MPEGlets e todas as suas classes e objetos relacionados são transportados no fluxo elementar MPEG-J. No receptor, o MPEGlet é carregado pelo carregador de classes 
(Figura 3.11) e iniciado no tempo descrito nos carimbos de tempo do fluxo MPEG-J. A aplicação usa então os gerentes de rede, de cena e de recursos para controlar a rede, a cena, os decodificadores e o terminal. O acesso a esses gerentes é feito via as APIs MPEG-J.

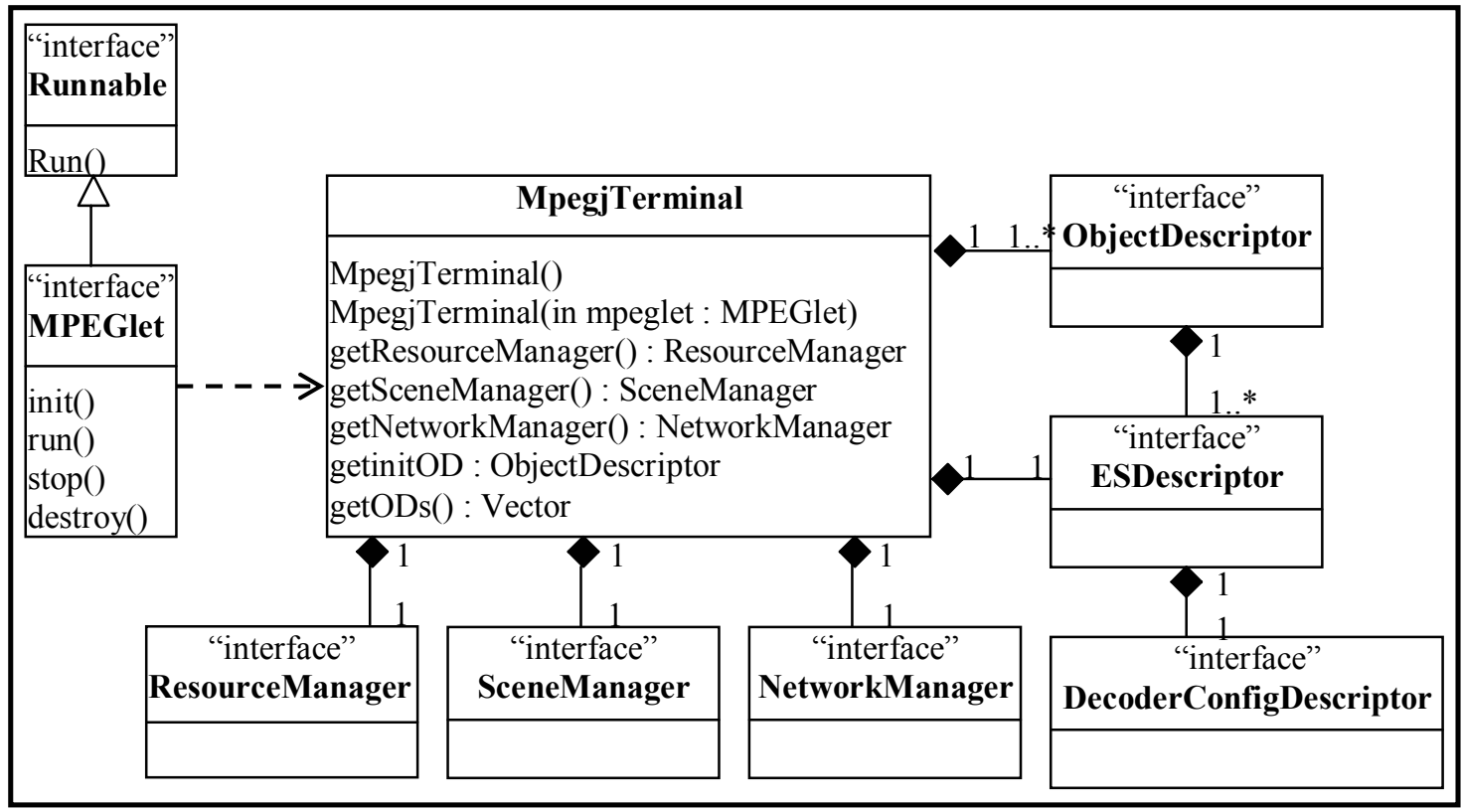

Figura 3.12 -Representação UML das APIs do terminal (Swaminathan et al., 2002).

A Figura 3.12 ilustra as APIs MPEG-J e seus relacionamentos utilizando notação UML. Toda aplicação que deseja ter acesso aos recursos de um terminal MPEG-4 deve implementar a interface MPEGlet, a qual serve de invólucro para as APIs MPEG-J. A interface MPEGlet é herdada da interface Java Runnable, permitindo que a aplicação MPEG-J seja executada na forma de linhas de execução, em vez de na forma de um processo. Aplicações MPEGlet devem, então, instanciar a classe MpegjTerminal para obter acesso às APIs MPEG-J que controlam os gerentes.

Conforme ilustrado na Figura 3.12, as APIs foram especificadas na forma de interfaces. Isso implica que apenas os nomes das classes, métodos e parâmetros estão especificados. A implementação real dos métodos fica a cargo do desenvolvedor, que deve importar a interface desejada para uma classe própria e sobrescrever os métodos da interface.

As interfaces ResourceManager, SceneManager, NetworkManager, ObjectDescriptor, ESDescriptor e DecoderConfigDescriptor não estão completamente representadas na Figura 3.12. Cada uma delas possui seu próprio conjunto de interfaces e não serão detalhadas por serem 
extensas e fugirem aos objetivos desta tese. Mais detalhes sobre as APIs podem ser encontrados em (Swaminathan et al., 2002).

\section{6}

Perfis MPEG-4

Uma das principais críticas recebidas pelo padrão MPEG-4 é relativa ao seu tamanho e complexidade. A argumentação é de que seria impraticável implementar decodificadores que contemplassem todas as ferramentas MPEG-4. Por esse motivo, subconjuntos das partes Sistemas, Visual e Áudio foram identificados para que possam ser usados por aplicações específicas. Tais subconjuntos, chamados de Perfis, limitam o conjunto de ferramentas que um decodificador tem que implementar. Para cada perfil existe um ou mais Níveis, restringindo a complexidade computacional.

São dois os objetivos que levaram de definir a combinação perfil/nível, referida dentro do padrão como perfil@nível. O primeiro objetivo é assegurar interoperabilidade: implementações de um perfil em um determinado nível resultam em um decodificador que se comporta de modo predizível. Conteúdo codificado para certa combinação perfil@nível funcionará em qualquer implementação de decodificador que seja compatível com a combinação. O segundo objetivo é permitir a verificação de compatibilidade de dispositivos MPEG-4 (testes de compatibilidade) (ISO, 2002).

Foram definidos perfis para as partes Visual e Áudio do padrão (perfis Visual e Áudio, respectivamente), assim como para a parte Sistemas (perfis Gráfico, Grafo da Cena, Descritor de Objeto e MPEG-J). Devido à complexidade e extensão do assunto, esta seção apresenta apenas um breve resumo dos perfis Visual (vídeo natural) e MPEG-J, os quais estão mais diretamente ligados a esta tese.

O MPEG-J possui dois perfis, Personal e Main, que não possuem níveis. O primeiro corresponde às APIs MPEG-J apresentadas na seção 3.5 para acesso ao terminal MPEG-4, à rede, às cenas e aos recursos e decodificadores. O segundo é um superconjunto do perfil Personal, incluindo uma API extra: informação de serviço e filtro de sessão (Koenen \& Pereira, 2002). 
Foram definidos cinco perfis para vídeo natural na Versão 1 do MPEG-4 ${ }^{8}$ : Simple, Simple Scalable, Core, Main e N-bit. Na Versão 2 foram adicionados mais quatro perfis: Core Scalable, Advanced Core, Advanced Coding Efficiency (ACE) e Advanced Real-Time Simple (ARTS). Com a primeira emenda à Versão 2 da parte Visual do MPEG-4 mais dois perfis foram adicionados: Simple Studio e Core Studio. E, por último, com a segunda emenda, dois outros perfis foram adicionados: Advanced Simple e Fine Granularity Scalability (Koenen \& Pereira, 2002).

Os perfis foram definidos de acordo com os Tipos de Objeto MPEG-4, recebendo, muitas vezes, os mesmos nomes. Um tipo de objeto define a sintaxe do bitstream para um único objeto, o qual representa uma entidade significativa na cena. Um tipo de objeto corresponde a um conjunto de ferramentas. Por exemplo, um objeto visual do tipo simple possui, entre outras, as seguintes ferramentas MPEG-4 associadas: I-VOP, P-VOP, tolerância a erros (error resilience) e escalabilidade temporal. Segundo Koenen e Pereira (2002), os tipos de objeto MPEG-4 para vídeo natural são:

- Simple. Define um objeto de vídeo natural e retangular, tolerante a erros, com razão largura-altura arbitrária. Baseado em VOPs MPEG-4 dos tipos I e P.

- Advanced real-time simple (ARTS). É um superconjunto do tipo de objeto Simple usado em situações de codificação em tempo real. Utiliza um canal de retorno para monitorar vazão de rede, adaptar resolução e diminuir propagação de erros.

- Advanced simple. Adiciona ao tipo de objeto Simple ferramentas que melhoram a eficiência da compressão, como estimativa global de movimento e quadros de vídeo do tipo B (B-VOPs).

- Fine granularity scalability (FGS). Inclui ao tipo anterior escalabilidade de granulosidade fina.

- Simple Scalable. É uma extensão do tipo de objeto Simple, possuindo escalabilidade espacial e temporal.

- Core. É um superconjunto do tipo Simple, fornecendo melhor qualidade através de interpolação bidirecional de quadros (B-VOPs) e de codificação binária de formas. Tem suporte à escalabilidade temporal por meio do envio de P-VOPs extras.

\footnotetext{
${ }^{8}$ Optou-se por manter os nomes dos perfis em Inglês.
} 
- Core scalable. Adiciona ao tipo Core tanto a escalabilidade retangular temporal quanto a espacial, além da escalabilidade espacial baseada em objeto.

- Main. Adiciona ao tipo Core codificação de formas em tons de cinza e codificação entrelaçada, em complemento à codificação progressiva.

- Advanced coding efficiency (ACE). Similar ao tipo Main, acrescentando compensação global de movimento.

- $\mathbf{N}$-bit. Igual ao tipo Core, variando apenas a profundidade do pixel de 4 para 12, tanto na luminância quanto na crominância.

- Simple studio. Define um objeto baseado apenas em quadros (VOPs) do tipo I, visando alta qualidade e alta taxa de bits.

- Core studio. Adiciona P-VOPs ao tipo Simple Studio.

Tabela 3.2 - Perfis para vídeo natural e tipos de objeto MPEG-4 (Koenen \& Pereira, 2002).

\begin{tabular}{|c|c|c|c|c|c|c|c|c|c|c|c|c|c|c|c|}
\hline $\begin{array}{l}\text { Tipos de } \\
\text { Objetos Visuais } \\
\rightarrow\end{array}$ & $\begin{array}{l}\frac{0}{0} \\
\frac{0}{\xi} \\
0\end{array}$ & 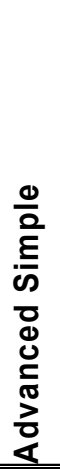 & 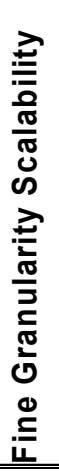 & $\begin{array}{l}\frac{0}{0} \\
\frac{\pi}{\pi} \\
\frac{\pi}{\pi} \\
\infty \\
\frac{0}{0} \\
\frac{0}{\vdots}\end{array}$ & 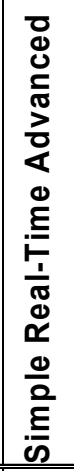 & $\begin{array}{l}0 \\
0 \\
0\end{array}$ & $\begin{array}{l}\frac{0}{0} \\
\frac{\pi}{\pi} \\
\text { ¿ } \\
\infty \\
0 \\
0 \\
0\end{array}$ & $\begin{array}{l}\stackrel{\Xi}{\bar{N}} \\
\Sigma\end{array}$ & 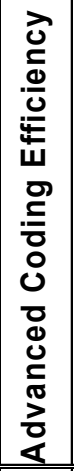 & 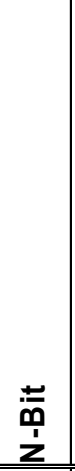 & 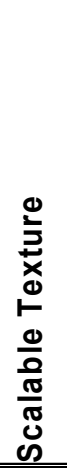 & 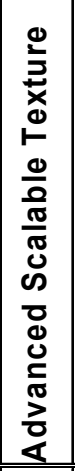 & 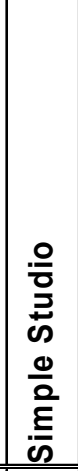 & 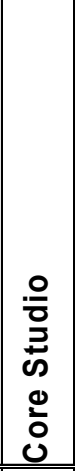 & 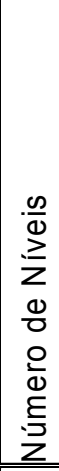 \\
\hline Simple & $\mathrm{X}$ & & & & & & & & & & & & & & 4 \\
\hline Simple Scalable & $X$ & & & $X$ & & & & & & & & & & & 2 \\
\hline Advanced Simple & $\mathrm{X}$ & $\mathrm{X}$ & & & & & & & & & & & & & 6 \\
\hline FGS & $\mathrm{X}$ & $\mathrm{X}$ & $\mathrm{X}$ & & & & & & & & & & & & 6 \\
\hline ARTS & $\mathrm{X}$ & & & & $\mathrm{X}$ & & & & & & & & & & 4 \\
\hline Core & $\mathrm{X}$ & & & & & $\mathrm{X}$ & & & & & & & & & 2 \\
\hline Core Scalable & $\mathrm{X}$ & & & $\mathrm{X}$ & & $X$ & $\mathrm{X}$ & & & & & & & & 3 \\
\hline Advanced Core & $\mathrm{X}$ & & & & & $\mathrm{X}$ & & & & & & $\mathrm{X}$ & & & 2 \\
\hline Main & $\mathrm{X}$ & & & & & $\mathrm{X}$ & & $\mathrm{X}$ & & & $\mathrm{X}$ & & & & 3 \\
\hline ACE & $X$ & & & & & $\mathrm{X}$ & & & $\mathrm{X}$ & & & & & & 4 \\
\hline N-Bit & $\mathrm{X}$ & & & & & $\mathrm{X}$ & & & & $\mathrm{X}$ & & & & & 1 \\
\hline Simple Studio & & & & & & & & & & & & & $\mathrm{X}$ & & 4 \\
\hline Core Studio & & & & & & & & & & & & & $\mathrm{X}$ & $\mathrm{X}$ & 4 \\
\hline
\end{tabular}

Os próximos dois tipos de objeto estão incluídos nessa lista porque, apesar de serem tipos para imagens estáticas, são utilizados por alguns perfis para vídeo natural. 
- Scalable texture. Define um tipo de objeto com forma arbitrária (para imagens estáticas) que usa codificação wavelet para fornecer escalabilidade.

- Advanced scalable texture. Adiciona ao tipo Scalable Texture: tolerância a erros, codificação escalar de formas melhorada e decodificação parcial de bitstream.

A Tabela 3.2 mostra quais tipos de objeto cada perfil para vídeo natural engloba. Por exemplo, o perfil Simple possui as ferramentas definidas para o tipo de objeto Simple, assim como o perfil Advanced Core engloba as ferramentas definidas para os tipos de objeto Simple, Core e Advanced Scalable Texture.

Tabela 3.3 - Níveis para os perfis Simple e Core (Koenen \& Pereira, 2002).

\begin{tabular}{|c|c|c|c|c|c|c|c|c|c|c|c|c|c|}
\hline $\begin{array}{l}\overline{\bar{z}} \\
\bar{\Phi} \\
\underline{Q}\end{array}$ & $\stackrel{\bar{D}}{z}$ & 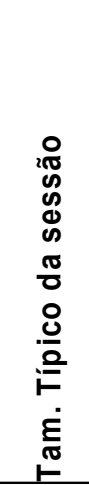 & 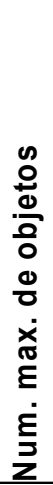 & 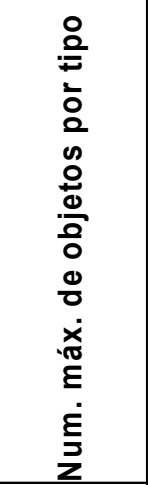 & 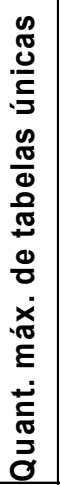 & 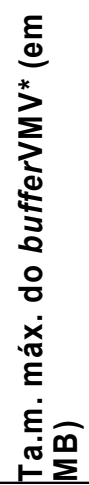 & 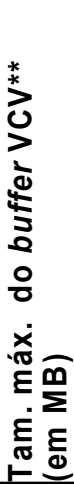 & 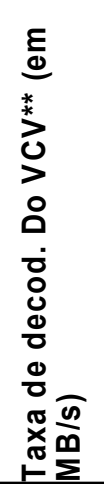 & 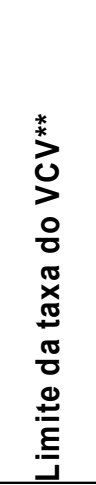 & 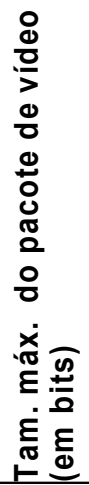 & 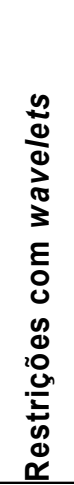 & 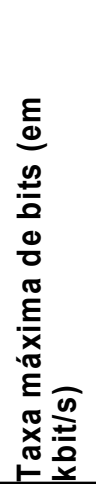 & 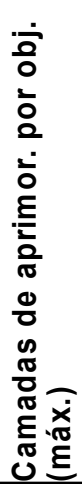 \\
\hline Simple & LO & QCIF & 1 & 1xSimple & 1 & 198 & 99 & 1.485 & N.A. & 2.048 & N.A. & 64 & N.A. \\
\hline Simple & L1 & QCIF & 4 & 4xSimple & 1 & 198 & 99 & 1.485 & N.A. & 2.048 & N.A. & 64 & N.A. \\
\hline Simple & L2 & CIF & 4 & 4xSimple & 1 & 792 & 396 & 5.940 & N.A. & 4.096 & N.A. & 128 & N.A. \\
\hline Simple & L3 & CIF & 4 & 4xSimple & 1 & 792 & 396 & 11.880 & N.A. & 8.192 & N.A. & 384 & N.A. \\
\hline Core & L1 & QCIF & 4 & $\begin{array}{c}4 \times \text { Core } \\
\text { ou } \\
\text { Simple }\end{array}$ & 4 & 594 & 198 & 5.940 & 2.970 & 4.096 & N.A. & 384 & 1 \\
\hline Core & L2 & CIF & 16 & $\begin{array}{c}16 x \text { Core } \\
\text { ou } \\
\text { Simple }\end{array}$ & 4 & 2.376 & 792 & 23.760 & 11.880 & 8.192 & N.A. & 2.000 & 1 \\
\hline
\end{tabular}

\footnotetext{
Legenda:

* VMV: Verificador de Memória de Vídeo. Indica a capacidade máxima de armazenamento do buffer de decodificação.

** VCV: Verificador de Complexidade de Vídeo. É a taxa máxima, em MB/s, em que o buffer de decodificação pode operar.

N.A.: Não Aplicável.
}

Os vários níveis de um perfil representam um aumento gradual na qualidade e na complexidade. Assim, a complexidade de Simple@L0 é menor que Simple@L3. Os parâmetros de qualidade e de complexidade associados aos níveis em cada perfil são basicamente os mesmos, existindo algumas variações onde um determinado parâmetro não 
se aplica a um nível ou perfil específico. A título de ilustração a Tabela 3.3 lista os níveis para os perfis Simple e Core.

\section{7}

\section{Alternativas Tecnológicas ao Padrão MPEG-4}

Em paralelo ao desenvolvimento do padrão MPEG-4 outros fóruns e consórcios têm desenvolvido ferramentas, aplicações e padrões para apresentação e distribuição multimídia. Esta seção descreve brevemente algumas dessas alternativas tecnológicas, comparando-as ao padrão MPEG-4.

\subsection{1 - X3D}

É a atual especificação da Web3D Consortium para a linguagem VRML (Web3D, 2001). O padrão MPEG-4 usou a VRML como base para especificar a descrição de cenas. A diferença básica é que os navegadores VRML assumem que áudio, vídeo e material audiovisual em geral devem ser primeiro carregados no terminal do cliente para depois serem exibidos. O padrão MPEG-4 integra streaming das cenas e das mídias contínuas contidas nas cenas (ISO, 2002). Além disso, o padrão MPEG-4 integra avançados modelos de sincronização entre cena e mídias, compressão eficiente e protocolos de atualização de cenas.

Várias atividades dentro do grupo VRML estão direcionadas a esse tipo de integração, devendo afetar as novas versões da linguagem. Porém, o caminho seguido pelo grupo VRML é mais adequado a aplicações cliente-servidor típicas (diferentes, por exemplo, de aplicações para ambientes propensos a erros).

\subsection{2 - Vetores Gráficos Escaláveis (Scalable Vector Graphics - SVG)}

É uma linguagem para descrever gráficos $2 \mathrm{D}$ em XML. SVG fornece três tipos de objetos gráficos: formas gráficas vetoriais (por exemplo, trilhas consistindo de linhas e curvas), imagens e texto. Os objetos gráficos podem ser agrupados, estilizados, transformados e separados em componentes. O conjunto de características inclui transformações aninhadas, recorte, máscaras alfa, filtros e objetos template (W3C, 2001a). 
As funcionalidades do SVG são fornecidas pelo padrão MPEG-4 de modo distribuído entre algumas ferramentas (notadamente composição de cena e codificação visual). Existe ainda uma sobreposição entre SVG e o formato textual MPEG-4 XMT, conforme ilustrado na Figura 3.13. O objetivo dessa sobreposição é permitir que autores compilem em MPEG-4 conteúdo anteriormente produzido em SVG (Avaro et al., 2002).

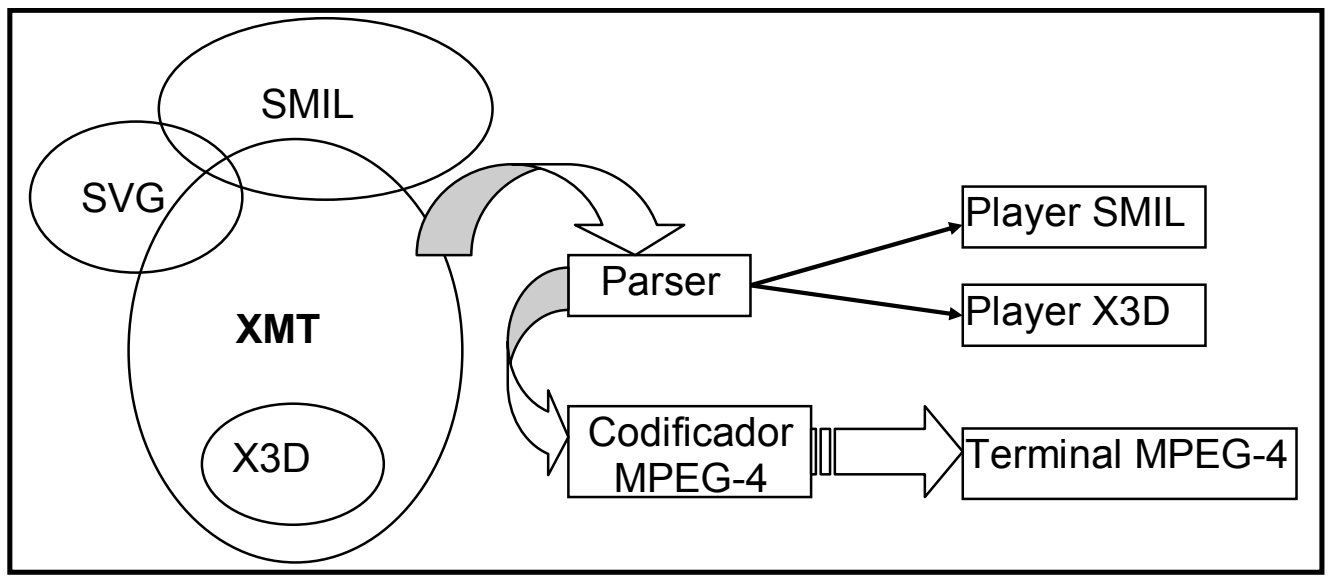

Figura 3.13 - Relacionamentos entre XMT, SMIL, SVG e X3D (Avaro et al., 2002).

\section{7 .3 - Linguagem de Integração Multimídia Sincronizada (Synchronized Multimedia Integration Language - SMIL)}

A recomendação W3C SMIL (W3C, 2001) possui as seguintes técnicas: Composição Temporal (sincronização), Composição Espacial, Associação de hyperlinks. Com essas técnicas, a recomendação SMIL endereça a questão da apresentação de conteúdo compreendendo vários objetos independentes de mídia, fornecendo extensões de HTML e XML que dizem ao navegador como posicionar os elementos no tempo e no espaço e como ligá-los a outro conteúdo (W3C, 2001). Segundo Battista et al. (1999), as maiores diferenças em relação ao MPEG-4 são que o SMIL:

- Assume que os objetos de mídia estão em URIs separadas.

- Especifica sincronização em nível de fluxo (no início e no fim do fluxo, deixando a sincronização de granulação fina para o navegador).

- Não fornece suporte explícito para objetos 3D.

- Não fornece primitivas gráficas 2D.

Assim como acontece com SVG, existe uma sobreposição entre SMIL e XMT, ilustrada na Figura 3.13. Os motivos são os mesmos apresentados na subseção 3.7.2. 


\subsection{4 - Flash}

Flash é uma ferramenta de autoria multimídia que, assim como SMIL, oferece composição temporal, composição espacial e associação de hyperlinks a objetos. Flash também fornece primitivas gráficas $2 \mathrm{D}$ e 3D, permitindo inserir vídeos, imagens, textos, áudio e animações em uma cena de maneira sincronizada. Flash também oferece recursos de interatividade com o conteúdo (em especial com primitivas gráficas 2D e 3D) (Macromedia, 2003).

Diferentemente de MPEG-4, Flash não oferece granulosidade fina de sincronização entre os objetos de uma cena (em especial com vídeos), não fornece formas variadas de codificação da cena e oferece um nível limitado de interatividade com o vídeo.

\subsection{5 - Distribuição de Vídeo Digital - Plataforma para Multimídia Caseira (Digital Video Broadcasting - Multimedia Home Platform - DVB-MHP)}

O MHP é uma especificação do consórcio de indústrias DVB que define uma interface genérica entre as aplicações digitais interativas e os terminais nos quais as aplicações são executadas. Essa interface separa diferentes provedores de aplicações dos detalhes de hardware e software específicos em diferentes implementações de terminais MHP (DVBMHP, 2001).

MPEG-4 e MHP atacam problemas diferentes. MHP pretende estabelecer uma plataforma (de hardware e software) para a distribuição e a apresentação de vídeo digital interativo. Um dos principais componentes dessa plataforma é o gravador digital pessoal (Personal Digital Recorder - PDR), o qual recebe, decodifica e armazena vídeo digital. MPEG-4 se preocupa com a produção e apresentação de conteúdo digital interativo. No contexto do MHP, MPEG-4 poderia ser usado para melhorar a funcionalidade e a interatividade do conteúdo, além de poder ser o terminal de apresentação executado dentro de um PDR (Avaro et al., 2002).

\section{$\underline{3.8}$}

Considerações Finais

O conjunto de características oferecido pelo padrão MPEG-4 o torna único na área de produção e distribuição de multimídia interativa. A grande variedade de aplicações, funcionalidades e taxas de bits que o padrão abrange o tornam bastante complexo. Contudo, 
não é necessário implementar todas as características em um único dispositivo ou aplicação. Os perfis e níveis definidos no padrão permitem a implementação consistente de subconjuntos das especificações MPEG-4, desde aplicações simples (como a transmissão e apresentação de gráficos) até as mais complexas (como vídeo sob demanda com características de realidade virtual).

Existem no mercado tecnologias e produtos que implementam algumas das características do padrão MPEG-4, como as apresentadas na seção 3.7. Algumas das alternativas apresentadas são soluções proprietárias. O padrão MPEG-4 é aberto, permitindo que diferentes organizações desenvolvam, separadamente, ferramentas de autoria, servidores, players e navegadores, abrindo o mercado e estimulando a proliferação de ferramentas e de conteúdo que podem interoperar. Outro ponto é que nenhuma das alternativas oferece uma solução com o nível de sofisticação e de abrangência que MPEG-4 fornece: composição, interatividade, variedade de codificadores, soluções em tempo-real, sincronização fina dos elementos da cena e interoperabilidade.

Atualmente, as empresas $^{9}$ pesquisando e construindo produtos com o padrão MPEG-4 têm produzido codificadores (e seus respectivos decodificadores) de vídeo somente para os perfis Simple e Advanced Simple. Isso implica que características avançadas, como escalabilidade temporal e espacial, codificação de formas arbitrárias e codificação NBit, não estão disponíveis (por enquanto).

O sucesso do padrão MPEG-4 irá eventualmente depender de vários fatores, como: as necessidades do mercado, padrões rivais, compromisso entre complexidade e funcionalidade, tempo, paradigmas de software versus de hardware, etc. Tecnicamente MPEG-4 tem potencial significativo para integrar os mundos de computação, telecomunicação e TV/filme/entretenimento e os serviços que eles oferecem. Contudo, aparentemente, apenas algumas funcionalidades básicas do MPEG-4 irão ser utilizadas em aplicações do mundo real. Conforme a demanda por aplicações multimídia sofisticadas cresça, as funcionalidades avançadas virão a ser implementadas.

\footnotetext{
${ }^{9}$ O M4IF Industry Fórum traz uma lista das empresas líderes no mercado que produzem tecnologia MPEG-4 (http://www.m4if.com/products/).
} 
Capítulo

$$
4 \text { O padrão MPEG-7 }
$$




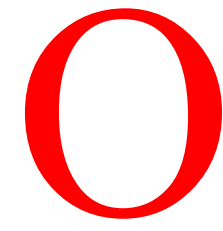

PADRÃO MPEG-7 (oficialmente conhecido como Interface para Descrição de Conteúdo Multimídia) (ISO, 2002a) visa padronizar a descrição de conteúdo multimídia. Isto é feito através da especificação de um conjunto padrão de descritores (Descriptors - Ds) que podem ser usados para representar vários tipos de informação multimídia. O MPEG-7 também especifica estruturas pré-definidas de descritores e seus relacionamentos, bem como formas de o usuário definir suas próprias estruturas. Essas estruturas são chamadas de esquemas de descrição (Description Schemes DSs). A definição de um novo descritor ou esquema de descrição é feita usando uma linguagem específica, chamada de linguagem de definição de descrição (Description Definition Language - DDL). A descrição, um conjunto de esquemas de descrição instanciados, estará associada com o conteúdo em si para permitir buscas rápidas e eficientes por material de interesse do usuário (ISO, 2002a). Uma descrição MPEG-7 pode ter duas formas: uma forma textual em XML, adequada para busca, edição e filtragem de dados; e uma forma binária, adequada para armazenamento e transmissão (Chang et al., 2001).

Deve-se ressaltar que descritores MPEG-7 são diferentes de descritores MPEG-4. Esses últimos são usados para identificar um objeto específico dentro de um fluxo MPEG4, além de carregar informações necessárias para sincronização e decodificação do objeto. Os descritores MPEG-7 são usados para compor uma descrição das características do objeto. Tais características incluem informações de índice (título, autor, data de criação, etc.), de arquivo (formato do arquivo, tipo de compressão, tamanho do quadro, localização no sistema de arquivos, etc.) e informações sobre o significado semântico do objeto (quem está aparecendo na cena, onde a cena acontece, qual atividade está se desenrolando, etc.).

Os descritores MPEG-7 não dependem da maneira com que o conteúdo descrito foi codificado ou armazenado. É possível criar uma descrição MPEG-7 para um filme assim como para uma figura que está impressa em papel. MPEG-7 permite diferentes granulosidades, oferecendo suporte a diferentes níveis de descrição.

A ênfase do padrão MPEG-7 é fornecer soluções para a descrição de conteúdo audiovisual. Dessa forma, soluções para documentos do tipo somente texto estão fora dos 
objetivos de MPEG-7. Também está fora dos objetivos do padrão MPEG-7 desenvolver algoritmos e ferramentas para a extração automática ou semi-automática de características e desenvolver ferramentas de busca (ISO, 2002a).

Existem várias aplicações e domínios de aplicações que podem se beneficiar de MPEG-7, entre eles: biblioteca digital, editoração multimídia, educação, jornalismo, informação turística, serviços culturais, entretenimento, sistemas de informação geográfica, compras, etc. (Chang et al., 2001; ISO, 2002a). A forma como os dados MPEG-7 serão usados para responder às perguntas (buscas) do usuário não faz parte dos objetivos do padrão. Em princípio, qualquer tipo de material audiovisual pode ser recuperado por meio de qualquer tipo de material de busca. Por exemplo, um vídeo pode ser pesquisado usando vídeo, música, conversação, etc. É responsabilidade dos mecanismos de busca associar os dados da pesquisa à descrição MPEG-7 do material audiovisual (Chang et al., 2001; ISO, 2002a).

Este capítulo apresenta uma visão geral do padrão MPEG-7 e está estruturado da seguinte forma: a seção 4.1 apresenta a terminologia adotada pelo padrão e que será utilizada neste capítulo. A seção 4.2 apresenta um breve resumo de cada uma das partes que compõem o padrão MPEG-7. A seção 4.3 discute com mais detalhes uma parte em especial do padrão: os Esquemas de Descrição Multimídia (Multimedia Description Schemes MDS), devido a essa parte ser a mais importante para o projeto. A seção 4.4 apresenta algumas outras abordagens para descrever conteúdo. Por último, a seção 4.5 apresenta algumas considerações finais.

\section{1}

Terminologia MPEG-7

O padrão MPEG-7 utiliza uma terminologia própria (Nack \& Lindsay, 1999), a qual será descrita a seguir:

- Dado. É a informação audiovisual que irá ser descrita usando MPEG-7, independente de armazenamento, codificação, exibição, transmissão, mídia ou tecnologia. Esta definição é bastante genérica e engloba gráficos, imagens moventes e estáticas, sons, música, texto e qualquer outro meio audiovisual. Exemplos de 
dados MPEG-7 podem ser: fluxos MPEG-4, uma imagem impressa em papel, um CD contendo música, etc.

- Característica. É uma qualidade própria, de um dado, que significa algo para alguém. Uma característica é algo abstrato. Não se pode trabalhar com uma característica sem uma representação para ela (descritor) e sem sua instanciação (valor do descritor) para algum conjunto de dados. Exemplos de características incluem: o volume de um som, a cor de um objeto, movimentos de câmera, etc.

- Descritor e valor do descritor. Um descritor é a representação de uma característica. Um descritor define a sintaxe e a semântica da representação da característica (ISO, 2002a). Para que um descritor seja funcional ele deve definir de forma precisa a semântica da característica, os tipos de dados associados, os valores permitidos e uma interpretação dos valores do descritor. Por exemplo, a representação da característica "nome" pode ser feita através da definição de um descritor Nome. A expressão XML <complexType name="Nome" type="string/> representa a definição do descritor Nome. O atributo name é o identificador do descritor e type é o tipo de dado do valor do descritor. A expressão XML < Nome>João</Nome> representa uma instância do descritor atribuída à característica e onde João é o valor do descritor.

- Esquema de descrição. Especifica a estrutura e a semântica dos relacionamentos entre seus componentes, os quais podem ser descritores e/ou esquemas de descrição. A Figura 4.1 ilustra uma representação das possíveis relações entre descritores e esquemas de descrição. A Linguagem de Definição de Descrição fornece o mecanismo para a construção de esquemas de descrição, os quais, por sua vez, formam a base para a geração de uma descrição (Nack \& Lindsay, 1999; ISO, 2002a). A diferença entre um esquema de descrição e um descritor é que um descritor diz respeito à representação de uma característica enquanto um esquema de descrição diz respeito à estrutura da descrição.

- Descrição. É uma instância de um esquema de descrição.

- Linguagem de definição de descrição. É uma linguagem que permite a criação de novos esquemas de descrição e de novos descritores. Também permite a extensão dos esquemas de descrição padrões (ver subseções 4.2.2 e 4.4.4). 


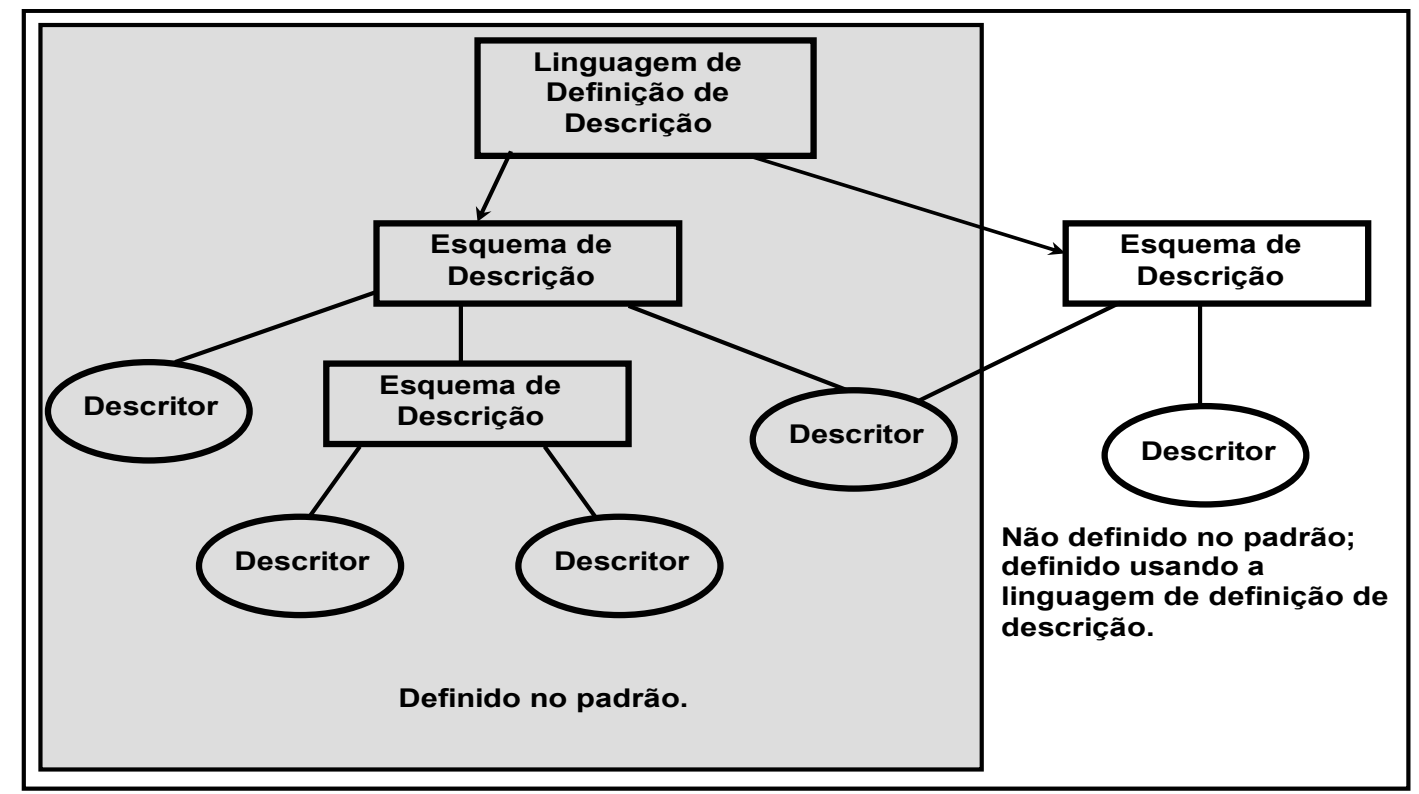

Figura 4.1 - Representação das relações entre descritores e esquemas de descrição (Nack \& Lindsay, 1999).

$\underline{4.2}$

As Partes do Padrão MPEG-7

Formalmente o padrão MPEG-7 é chamado de ISO 15938 e está dividido nas seguintes partes (ISO, 2002a):

- Parte 1 - ISO/IEC 15938-1: Sistemas.

- Parte 2 - ISO/IEC 15938-2: Linguagem de Definição de Descrição.

- Parte 3 - ISO/IEC 15938-3: Visual.

- Parte 4 - ISO/IEC 15938-4: Áudio.

- Parte 5 - ISO/IEC 15938-5: Esquemas de Descrição Multimídia.

- Parte 6 - ISO/IEC 15938-6: Software de Referência.

- Parte 7 - ISO/IEC 15938-7: Testes de Compatibilidade.

- Parte 8 - ISO/IEC 15938-8: Extração e Uso de Descrições.

Todas as partes são padrões internacionais ISO, com exceção da parte 8 , que ainda está em desenvolvimento e será publicada na forma de um relatório técnico. 


\subsection{1 - Parte 1 - Sistemas}

A parte Sistemas ter por objetivo especificar como as descrições MPEG-7 serão entregues a um terminal MPEG-7 para então serem decodificadas e descomprimidas. A parte Sistemas também especifica funcionalidades como a preparação de descrições para armazenamento ou transporte eficientes e sincronização entre conteúdo e descrições.

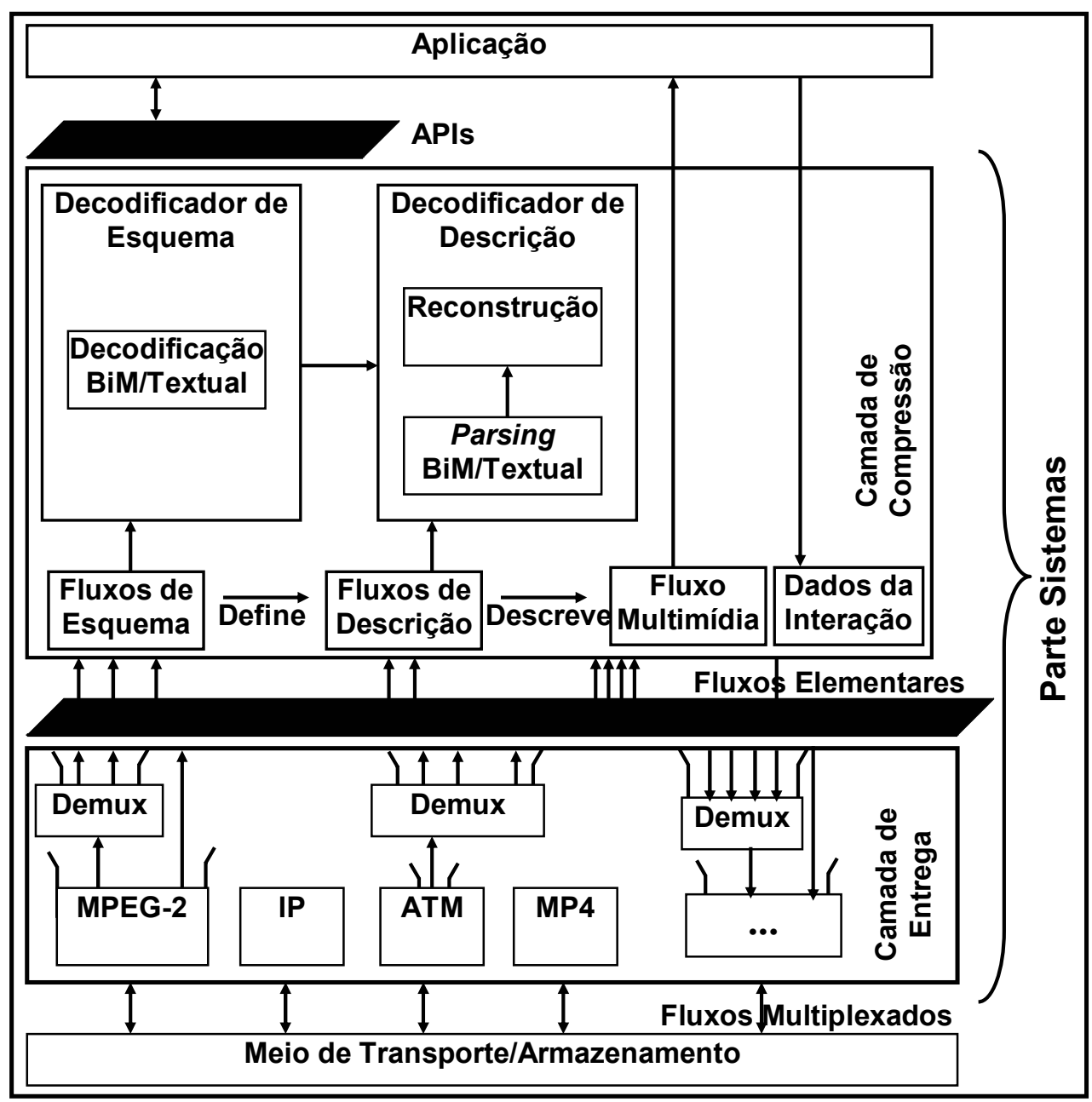

Figura 4.2 - Arquitetura de um Terminal MPEG-7 (Avaro \& Salembier, 2001).

A Figura 4.2 ilustra, em alto nível, a arquitetura de um terminal MPEG-7. Os dados MPEG-7 são obtidos do meio de transporte (pacotes IP ou fluxos MPEG-2, por exemplo) ou do meio de armazenamento (na forma de arquivos MP4, por exemplo) e processados na camada de entrega. A parte Sistemas especifica o formato do fluxo de bits final, permitindo 
que se implementem, nessa camada, métodos para realizar a extração dos fluxos elementares, desfazendo o enquadramento e a multiplexação específicos dos quadros de transporte/armazenamento. Além disso, a especificação do formato do fluxo de bits final permite desenvolver métodos para retirar a informação temporal necessária para a sincronização (Avaro \& Salembier, 2001).

Os fluxos elementares consistindo de unidades individuais de dados chamadas de unidades de acesso são passados à camada de compressão onde o fluxo descrevendo a estrutura dos dados MPEG-7, assim como o fluxo descrevendo o conteúdo, são decodificados. As descrições podem estar representadas na forma textual ou na forma binária. A forma binária, chamada de Formato Binário para MPEG-7 (Binary Format for MPEG-7 - BiM) e especificada na parte Sistemas, permite comprimir documentos MPEG7 e permite preparar os mesmos para streaming (Avaro \& Salembier, 2001).

\subsection{2 - Parte 2 - Linguagem de Definição de Descrições}

A utilização da DDL, dos esquemas de descrição e dos descritores viabilizam a criação de descrições MPEG-7. Os descritores associam uma característica a um conjunto de valores. Esquemas de descrição são modelos dos objetos multimídia e do universo que eles representam, isto é, o modelo de dados da descrição. Eles especificam os tipos de descritores que podem ser usados em uma dada descrição, além dos relacionamentos entre essas descrições ou entre outros esquemas de descrição. Nesse contexto, a DDL define as regras sintáticas para expressar esquemas de descrição e suas interpretações (Hunter, 2001; ISO, 2002a).

A DDL fornece uma base descritiva sólida que permite aos usuários criarem seus próprios esquemas de descrição e descritores em complemento aos esquemas e descritores padronizados. A DDL não é uma linguagem de modelagem (como a UML), em vez disso, é usada para representar o resultado da modelagem de dados audiovisuais (descritores e esquemas de descrição), como um conjunto de restrições sintáticas, estruturais e de valores para as quais as descrições MPEG-7 devem estar em conformidade (Hunter, 2001).

O grupo MPEG decidiu adotar a linguagem Esquema XML do W3C (World Wild Web Consostuim) como a DDL MPEG-7 (ISO, 2002a) (ver subseção 4.4.4). Contudo, devido ao fato de Esquema XML não ter sido projetada especificamente para conteúdo 
audiovisual, certas extensões foram necessárias de forma a satisfazer os requisitos MPEG7. Como resultado, a DDL é composta pelos seguintes componentes (Chang et al., 2001; Hunter, 2001):

- Componentes estruturais de Esquema XML (W3C, 2001b).

- Tipos de dados de Esquema XML (W3C, 2001c).

- Extensões específicas MPEG-7.

As extensões MPEG-7 são:

- Tipos de dados para representar arrays e matrizes, com tamanho fixo e tamanho parametrizado.

- Tipos de dados primitivos relacionados a tempo: basicTimePoint e basicDuration, os quais, respectivamente, descrevem um ponto específico no tempo e um intervalo de tempo.

\subsection{3 - Parte 3 - Visual}

A parte visual especifica um conjunto padronizado de descritores e esquemas de descrição para dados visuais. Tal conjunto trata especificamente das características de cor, textura, forma e movimento. Descritores visuais frequentemente necessitam de outros descritores de baixo nível ou elementos de suporte como estruturas (malha de leiaute, coordenadas espaciais), pontos de visualização, localização e estruturas temporais (series temporais, interpolação temporal) (Sikora, 2001).

Uma variedade de descritores para cada característica foi padronizada, tais como:

- Descritores para cor: espaço de cor; quantização de cor; cor dominante; cor escalável; leiaute de cor; estrutura de cor; entre outros.

- Descritores para textura: textura homogênea e histograma de arestas, entre outros.

- Descritores de forma: forma da região; forma do contorno e forma 3D.

- Descritores para movimento: movimento de câmera; movimento de trajetória; movimento paramétrico; entre outros.

- Outros descritores como reconhecimento de faces. 
Além desses descritores existem alguns esquemas de descrição definidos, por exemplo, o esquema para localização chamado SpatioTemporal, o qual é composto por outros esquemas, por exemplo, esquemas para definir trajetórias (FigureTrajectory e ParameterTrajectory). Os descritores e esquemas de descrição, tanto da parte Visual quanto da parte Áudio, são utilizados pela parte MDS para compor esquemas de descrição complexos. Tais esquemas permitem descrições parciais de um objeto (somente da cor do objeto, por exemplo) assim como descrições semanticamente completas (seção 4.3).

\subsection{4 - Parte 4 - Áudio}

A parte Áudio foi padronizada para tratar quatro classes de sinais de áudio: somente música, somente fala, somente efeitos sonoros e trilhas sonoras arbitrárias. Descritores de áudio podem estar associados a descritores de categorias de mais baixo nível, como séries escalares (ScalableSeries, SeriesofScalarType, etc.) e arcabouço de descrição de áudio (AudioSampledType, AudioWaveformEnvelopeType, etc.). Quackenbush e Lindsay (2001) trazem os seguintes exemplos de descritores padronizados para várias características:

- Descritor para silêncio: SilenceType.

- Descritores de conteúdo falado (representação da saída de reconhecimento automático de fala): SpokenContentSpeakerType, SpokenContentExtractionInfoType, SpokenContentConfusionInfoType, SpokenContentLinkType.

- Descritores de timbre: InstrumentalTimbreType, PercussivelnstrumentTimbreType, HarmonicInstrumentTimbreType, entre outros.

- Descritores para efeitos sonoros: AudioSpectrumBasisType, SoundEffectFeaturesType.

- Descritores para melodia: MeterType, BeatType, etc.

\subsection{5 - Parte 5 - Esquemas de Descrição Multimídia}

Os Esquemas de Descrição Multimídia (Multimedia Description Schemes - MDS) (Salembier \& Smith, 2001) são estruturas de metadados para descrever e anotar conteúdo audiovisual. Esses esquemas fornecem uma forma padronizada de descrever, em XML, os conceitos importantes relacionados com descrição e gerenciamento de conteúdo 
audiovisual facilitando buscas, indexação, filtragem e acesso. Os esquemas de descrição são definidos usando a DDL e são instanciadas como documentos ou fluxos. O resultado da descrição pode ser expresso na forma textual (em XML, adequada para edição, busca e filtragem) ou na forma binária comprimida (adequada para armazenamento e transmissão).

Em MPEG-7 os esquemas de descrição são categorizados como pertencentes ao domínio multimídia, visual ou áudio. Tipicamente os MDSs descrevem conteúdo consistindo da combinação de dados visuais e de áudio, e possivelmente dados textuais, enquanto os esquemas de descrição Visual e Áudio se referem às características únicas para os domínios visual e de áudio, respectivamente (Salembier \& Smith, 2001; ISO, 2002a). A seção 4.3 apresenta mais detalhes sobre os MDSs.

\subsection{6 - Parte 6 - Software de Referência}

Essa parte do padrão, também conhecida como Modelo de Experimentação (Experimentation Model - XM), é um arcabouço para todo código de referência do padrão MPEG-7. O XM implementa ferramentas para a verificação da funcionalidade dos descritores, esquemas de descrição e da DDL. As aplicações do XM mostram como extrair metadados (se possível) de conteúdo de mídia, ou como os metadados podem ser usados em uma aplicação simples (Chang et al., 2001).

O XM implementa apenas aplicações básicas e não aplicações que possam ser usadas em situações reais. Além disso, a interface do XM é via linha de comando, não permitindo qualquer tipo de interação durante a execução. As aplicações XM estão divididas em duas categorias: as aplicações servidoras que extraem os dados descritores dos dados de mídia e as aplicações clientes que realizam buscas em bases de dados MPEG-7 (ISO, 2002a).

\subsection{7 - Parte 7 - Testes de Compatibilidade}

Essa parte do padrão MPEG-7 envolve a especificação de testes para verificar a compatibilidade sintática das descrições em relação às partes de um a cinco. Os testes não envolvem a verificação da semântica das descrições, por exemplo, não verificam se o campo "nome" em uma descrição contém realmente o nome de uma pessoa. Contudo, o teste verifica se a descrição está sintaticamente bem estruturada (no sentido de 
processamento XML) e sintaticamente válida (no sentido de estar compatível com um esquema). Essa parte, cuja versão um já está padronizada, atualmente está recebendo emendas (ISO, 2002a).

Os Testes de Compatibilidade consistem de dois estágios: teste de sistema e teste de DDL. O teste de sistema envolve decodificar a descrição, a qual pode estar em forma de unidades de acesso binárias ou textuais, assim como verificar se a decodificação produziu um documento XML válido. No caso de a entrada (descrição) para o processador do sistema já estar em formato textual, o processador repassa a entrada, diretamente, para o processador DDL. O teste de compatibilidade DDL envolve processar a descrição textual em XML (instância de um esquema MPEG-7) verificando a estrutura dos descritores e validando os mesmos de acordo com as propriedades e restrições definidas a partir das partes Visual, Áudio, MDS e DDL do padrão (ISO, 2002a).

\subsection{8 - Parte 8 - Extração e Uso de Descrições}

Essa parte do padrão MPEG-7, que é na verdade um relatório técnico, ainda está em desenvolvimento. Ela trará exemplos de extração e uso de descrições usando os descritores, esquemas de descrição e tipos de dados definidos na versão 2 das partes Visual, Áudio e MDS (ISO, 2002a).

\section{$\underline{4.3}$}

Os Esquemas de Descrição Multimídia

Os esquemas de descrição MPEG-7 podem ser vistos como uma biblioteca de ferramentas de descrição, onde, na prática, as aplicações selecionam um subconjunto apropriado de esquemas de descrição (Salembier \& Smith, 2001). Tal biblioteca está organizada nas seguintes áreas funcionais, conforme ilustra a Figura 4.3: Elementos Básicos, Gerenciamento de Conteúdo, Descrição de Conteúdo, Navegação e Acesso, Organização de Conteúdo e Interação do Usuário. Cada uma das áreas contém um conjunto de ferramentas (por exemplo, Modelos é uma ferramenta) e cada ferramenta é composta por um conjunto de esquemas de descrição (não mostrados na Figura 4.3). 


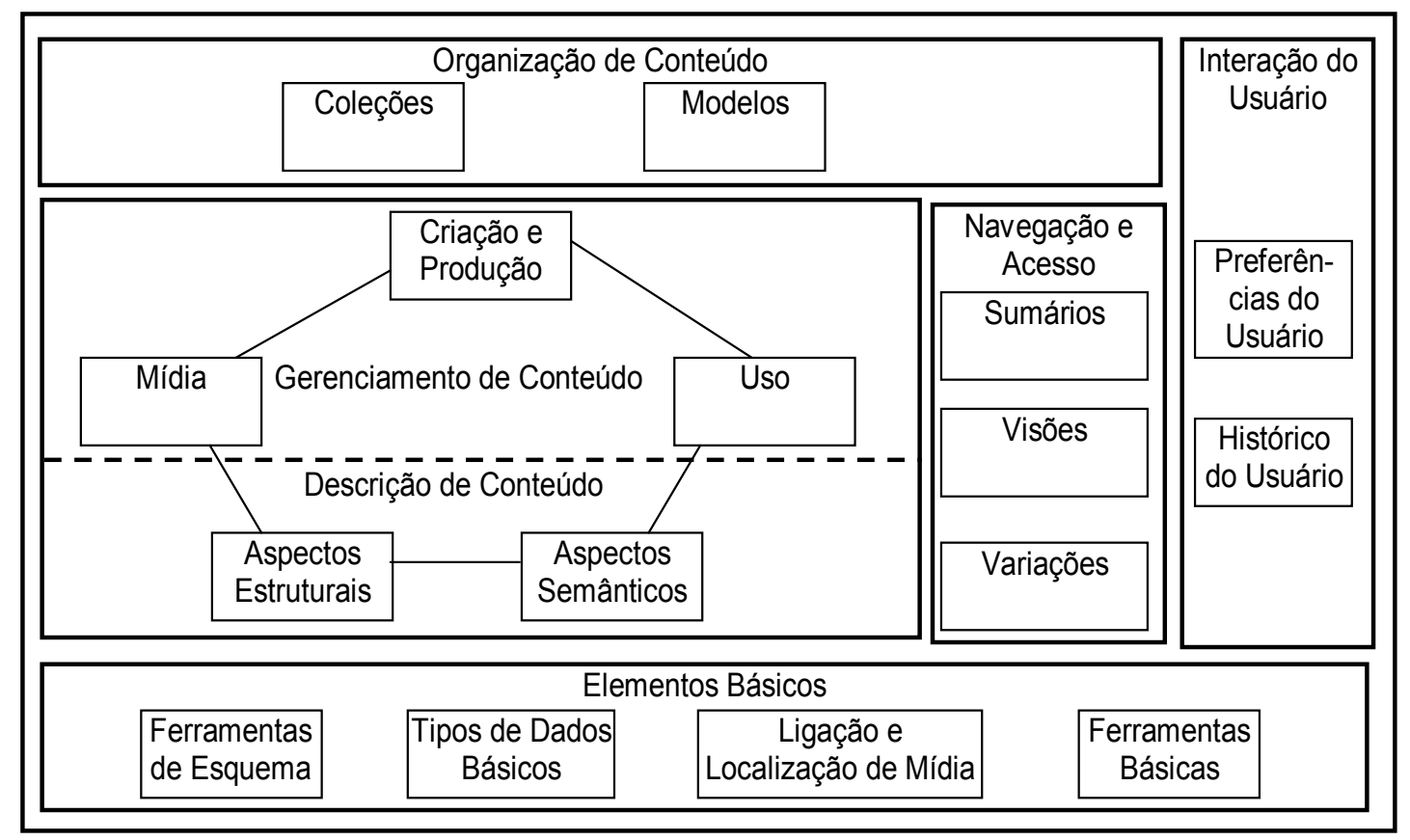

Figura 4.3 - Organização do MDS MPEG-7 (Salembier \& Smith, 2001).

$\mathrm{Na}$ camada mais baixa da Figura 4.3 está a área funcional Elementos Básicos. Essa camada contém quatro ferramentas: Ferramentas de Esquema, Tipos de Dados Básicos, Ligação e Ferramentas de Localização de Mídia e Ferramentas Básicas. Tais ferramentas são componentes básicos para esquemas de descrição mais complexos (Salembier \& Smith, 2001).

As ferramentas das áreas funcionais de Descrição de Conteúdo e de Gerenciamento de Conteúdo são definidas Baseadas na área Elementos Básicos. Essas ferramentas descrevem o conteúdo de um único documento multimídia a partir de cinco diferentes perspectivas: Criação e Produção, Mídia, Uso, Aspectos Estruturais e Aspectos Semânticos. As três primeiras ferramentas cobrem, primariamente, informação relacionada ao gerenciamento de conteúdo e as duas últimas são destinadas à descrição de informação perceptível (descrição de conteúdo) (Salembier \& Smith, 2001). A Tabela 4.1 resume a funcionalidade de cada conjunto de ferramentas de descrição. 
Tabela 4.1 - Lista de ferramentas para descrição e gerenciamento de conteúdo (ISO, 2002a).

\begin{tabular}{|c|c|}
\hline $\begin{array}{c}\text { Conjunto de Ferramentas } \\
\text { de Descrição }\end{array}$ & Funcionalidade \\
\hline Mídia & $\begin{array}{l}\text { Descrição do armazenamento da mídia: características típicas } \\
\text { incluem o formato de armazenamento, a codificação, e a } \\
\text { identificação da mídia. }\end{array}$ \\
\hline Criação e Produção & $\begin{array}{l}\text { Metainformação descrevendo a criação e a produção de } \\
\text { conteúdo: características típicas incluem título, criador, } \\
\text { classificação, propósito da criação, etc. Essa informação é, na } \\
\text { maioria dos casos, gerada pelo autor uma vez que é difícil de } \\
\text { ser extraída a partir do conteúdo. }\end{array}$ \\
\hline Uso & $\begin{array}{l}\text { Metainformação relacionada ao uso do conteúdo: } \\
\text { características típicas incluem direitos autorais, direitos de } \\
\text { acesso, publicação e informação financeira. }\end{array}$ \\
\hline Aspectos Estruturais & $\begin{array}{l}\text { Descrição do conteúdo multimídia do ponto de vista de sua } \\
\text { estrutura: a descrição é estruturada sobre segmentos que } \\
\text { representam componentes físicos, espaciais, temporais ou } \\
\text { espaço-temporais do conteúdo multimídia. Cada segmento } \\
\text { pode ser descrito por características baseadas em sinais (cor, } \\
\text { textura, forma, movimento, e áudio) e por alguma informação } \\
\text { semântica elementar. }\end{array}$ \\
\hline Aspectos Semânticos & $\begin{array}{l}\text { Descrição do conteúdo multimídia do ponto de vista de suas } \\
\text { noções conceituais e semânticas. São baseados em noções } \\
\text { de objetos, eventos, noções abstratas e seus } \\
\text { relacionamentos. }\end{array}$ \\
\hline
\end{tabular}

Apesar de essas cinco ferramentas estarem apresentadas como entidades separadas, elas são inter-relacionadas e podem ser parcialmente incluídas umas nas outras. Por exemplo, os três elementos Mídia, Uso e Criação e Produção podem ser associados a elementos individuais envolvidos na descrição estrutural do conteúdo. Dependendo da aplicação, algumas áreas da descrição do conteúdo irão ser enfatizadas e outras serão minimizadas ou descartadas (Salembier \& Smith, 2001).

Além da descrição direta de conteúdo fornecida pelas cinco ferramentas descritas na Tabela 4.1, também existem ferramentas para navegação e acesso as quais pertencem à área funcional Navegação e Acesso: é fornecido suporte à navegação através da ferramenta de descrição Sumários. O acesso a partes específicas do conteúdo é descrito através da ferramenta Visões. Variações do conteúdo multimídia que substituem o original para, se necessário, adaptar a apresentação às condições da rede, ao terminal do cliente, ou às preferências de usuário, são descritas através da ferramenta Variações (Salembier \& Smith, 2001; ISO, 2002a).

Dois outros conjuntos de ferramentas, pertencentes à área funcional Organização de Conteúdo, cobrem a organização do conteúdo através de classificação e definição de 
coleções de documentos multimídia (Coleções) e através de modelagens (Modelos). A última área funcional (Interações do Usuário) possui dois conjuntos de ferramentas que descrevem as preferências do usuário relativas ao consumo de material multimídia (Salembier \& Smith, 2001).

Mais importante que uma descrição exaustiva dos descritores e esquemas de descrição que compõem cada ferramenta da parte MDS, é entender como eles podem ser utilizados para compor uma descrição. O ponto de partida para qualquer descrição MPEG-7 são as Ferramentas de Esquema. Elas encerram os Elementos de Nível mais Alto na hierarquia MPEG-7, a partir dos quais todos os outros elementos da parte MDS, direta ou indiretamente, estão relacionados. Além disso, esse conjunto de ferramentas possui elementos abstratos que podem ser usados para estabelecer relacionamentos entre novos elementos (definidos pelo usuário) e os já existentes. As próximas subseções apresentam mais detalhes sobre o núcleo das Ferramentas de Esquema MPEG-7, permitindo entender a hierarquia utilizada para estruturar as descrições.

\subsection{1 - Ferramentas de Esquema}

As Ferramentas de Esquema especificam um conjunto de esquemas de descrição que definem: a hierarquia dos Tipos Base e dos descritores e esquemas de descrição; Elemento Raiz MPEG-7 e os Elementos MPEG-7 de Nível mais Alto. Tais esquemas compõem o núcleo das Ferramentas de Esquema. Existem ainda esquemas auxiliares, os quais não serão tratados aqui. A Tabela 4.2 sumariza as funcionalidades de cada um dos esquemas, chamados também de ferramentas.

Tabela 4.2 - Ferramentas de esquema MPEG-7 (ISO, 2001).

\begin{tabular}{|l|l|}
\hline \multicolumn{1}{|c|}{ Ferramenta } & \multicolumn{1}{c|}{ Funcionalidade } \\
\hline \hline Tipos Base & $\begin{array}{l}\text { Forma a base da hierarquia para as ferramentas de descrição } \\
\text { - Descritores, Esquemas de Descrição e Cabeçalhos. }\end{array}$ \\
\hline Elemento Raiz & $\begin{array}{l}\text { Descreve o invólucro inicial (ou elemento raiz) de documentos } \\
\text { e unidades de descrição que são instâncias válidas. }\end{array}$ \\
\hline $\begin{array}{l}\text { Elementos de Nível mais } \\
\text { Alto }\end{array}$ & $\begin{array}{l}\text { Formam os modelos de conteúdo dos elementos } \\
\text { imediatamente e hierarquicamente abaixo do elemento raiz. }\end{array}$ \\
\hline $\begin{array}{l}\text { Entidades de Conteúdo } \\
\text { Multimídia }\end{array}$ & $\begin{array}{l}\text { Descrevem diferentes tipos de conteúdo multimídia tais como } \\
\text { imagens, vídeo, áudio, etc. }\end{array}$ \\
\hline Pacotes organ ou empacotamento dos \\
\hline Metadados de descrição & $\begin{array}{l}\text { Descrevem uma organizaço ou } \\
\text { descritores e esquemas de descrição para uma aplicaço. }\end{array}$ \\
\hline
\end{tabular}




\subsection{2 - Tipos Base}

Um Tipo Base é um tipo de dado que foi definido utilizando-se a DDL, ou, usando a terminologia XML, é um complexType ou um simpleType. A hierarquia dos Tipos Base está ilustrada na Figura 4.4 seguindo uma notação UML.

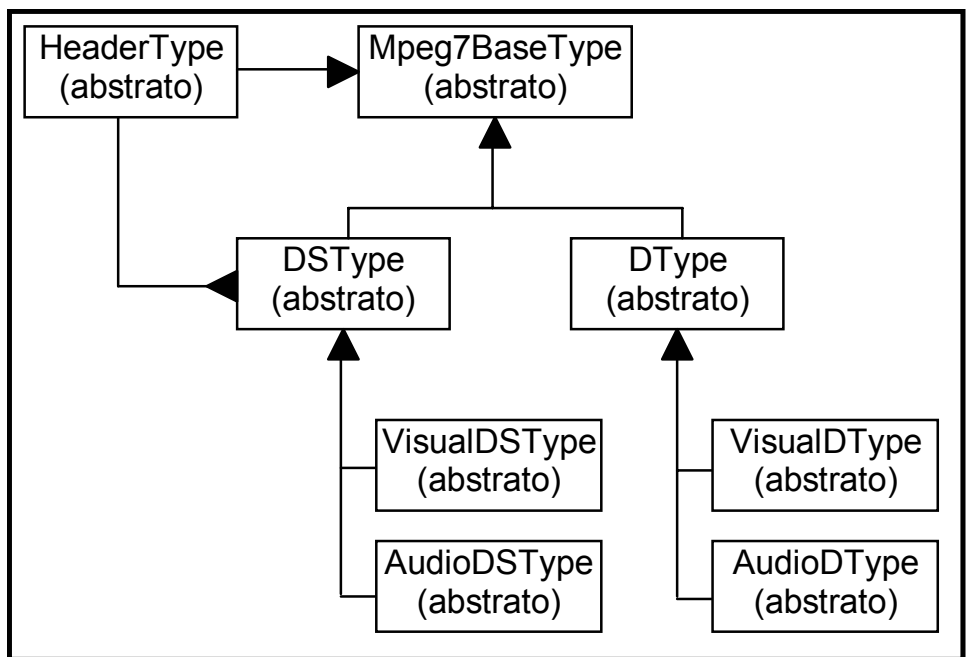

Figura 4.4 - Organização hierárquica dos tipos base MPEG-7 (ISO, 2001).

O tipo base Mpeg7BaseType é o tipo abstrato (no sentido da linguagem XML) a partir do qual todos os descritores, esquemas de descrição e cabeçalhos são derivados. $\mathrm{O}$ tipo Mpeg7BaseType é composto pelos seguintes subtipos (ISO, 2001):

- DType: estende Mpeg7BaseType para fornecer um tipo base abstrato para descritores visuais e de áudio. Todos os descritores MPEG-7 devem ser baseados no tipo DType.

- VisualDType: estende DType para fornecer um tipo base abstrato para descritores visuais. Todos os descritores visuais que são usados para descrever segmentos visuais devem ser derivados de VisualDType.

- AudioDType: estende DType para fornecer um tipo base abstrato para descritores de áudio. Todos os descritores que são usados para descrever segmentos de áudio devem ser derivados de AudioDType.

- DSType: estende Mpeg7BaseType para fornecer um tipo base abstrato para esquemas de descrição visuais e de áudio. Todos os esquemas de descrição devem ser derivados de DSType. 
- VisualDSType: estende DSType para fornecer um tipo base abstrato para esquemas de descrição visuais. Todos os esquemas de descrição que são usados para descrever segmentos visuais devem ser derivados de VisualDSType.

- AudioDSType: estende DSType para fornecer um tipo base abstrato para esquemas de descrição de áudio. Todos os esquemas de descrição que são usados para descrever segmentos de áudio devem ser derivados de AudioDSType.

- HeaderType: estende Mpeg7BaseType para fornecer um tipo base abstrato para descrever cabeçalhos em descrições. O objetivo do cabeçalho é agrupar informações que sejam comuns para os componentes da descrição e que possam ser instanciados dentro de qualquer elemento do tipo DSType.

\subsection{3 - Elemento Raiz MPEG-7}

O elemento raiz é o principal elemento englobando, como um invólucro, os dois tipos possíveis de descrição: descrição completa e unidade de descrição. Uma descrição completa descreve conteúdo audiovisual de forma semanticamente completa. Uma unidade de descrição encerra somente informação parcial e/ou incremental a ser, possivelmente, adicionada a uma descrição existente (ISO, 2001).

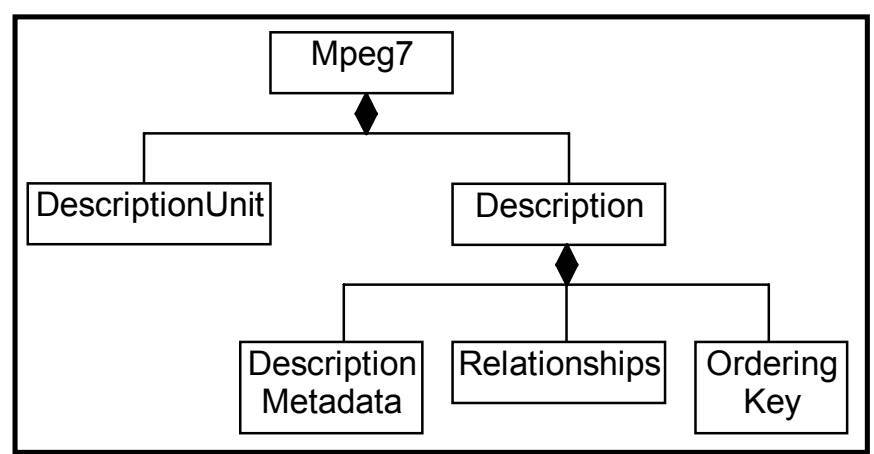

Figura 4.5 - Composição do elemento raiz MPEG-7 (ISO, 2001).

A Figura 4.5 ilustra, em notação UML, a composição do elemento raiz (<Mpeg7>). Os dois tipos de descrição, unidade de descrição e completa, estão respectivamente representados pelos elementos <DescriptionUnit> e <Description>. O primeiro é do tipo 
Mpeg7BaseType (Figura 4.4), estabelecendo uma relação direta com os tipos base MPEG-7. O segundo é do tipo CompleteDescriptionType (ver subseção 4.3.4, Figura 4.6) e seus elementos componentes, <DescriptionMetadata> e <OrderingKey>, são de tipos derivados do tipo base HeaderType, enquanto o elemento <Relationships> é de um tipo derivado do tipo base DSType (Figura 4.4).

Vale ressaltar que o tipo CompleteDescriptionType é abstrato. Isso significa que um elemento <Description> não pode ser instanciado diretamente. É necessário criar um tipo (usando a DDL), derivado de CompleteDescriptionType, para implementar um elemento <Description>. Essa abordagem permite a existência de diversas implementações diferentes para um elemento com tipo abstrato. De fato, a parte MDS possui diversos esquemas derivados de CompleteDescriptionType que permitem instanciar um elemento <Description> para representar descrições semanticamente completas a respeito de conteúdo audiovisual diverso. Tais esquemas estão difundidos entre as áreas funcionais e ferramentas da parte MDS. A mesma situação ocorre com o elemento <DescriptionUnit>, que é do tipo abstrato Mpeg7BaseType.

\subsection{4 - Os Elementos de Nível mais Alto}

Os chamados Elementos de Nível mais Alto da parte MDS do padrão MPEG-7 são na verdade tipos. Ou, usando a terminologia XML, são tipos complexos (complexType). Esses elementos estão hierarquicamente logo abaixo do elemento raiz e servem de invólucro para, seletivamente, incluir ferramentas MPEG-7 para realizar uma descrição em particular (ISO, 2001). A hierarquia desses elementos está ilustrada na Figura 4.6.

Comparando a Figura $4.6 \mathrm{com}$ a Figura 4.5, percebe-se que o tipo CompleteDescriptionType está diretamente ligado ao elemento raiz, uma vez que o elemento <Description> é do tipo CompleteDescriptionType. A partir desse tipo são possíveis dois caminhos de derivação: um para ContentManagementType e outro para ContentDescriptionType. A partir do primeiro caminho já é possível derivar ferramentas para descrever gerenciamento de conteúdo (por exemplo, CreationDescriptionType). A partir do segundo, são possíveis mais dois caminhos de derivação: 1) ContentEntityType, que não é abstrato, e contém um elemento do tipo MultimediaContentType a partir do qual as ferramentas para descrição de características de mídias são derivadas. MultimediaContentType não é considerado um elemento de nível mais 
alto. Esse tipo é, na verdade, a ferramenta de esquema Entidades de Conteúdo Multimídia (apresentada na Tabela 4.2). 2) ContentAbstractionType, a partir do qual as ferramentas para descrever modelos, visões, variações e aspectos semânticos são derivadas.

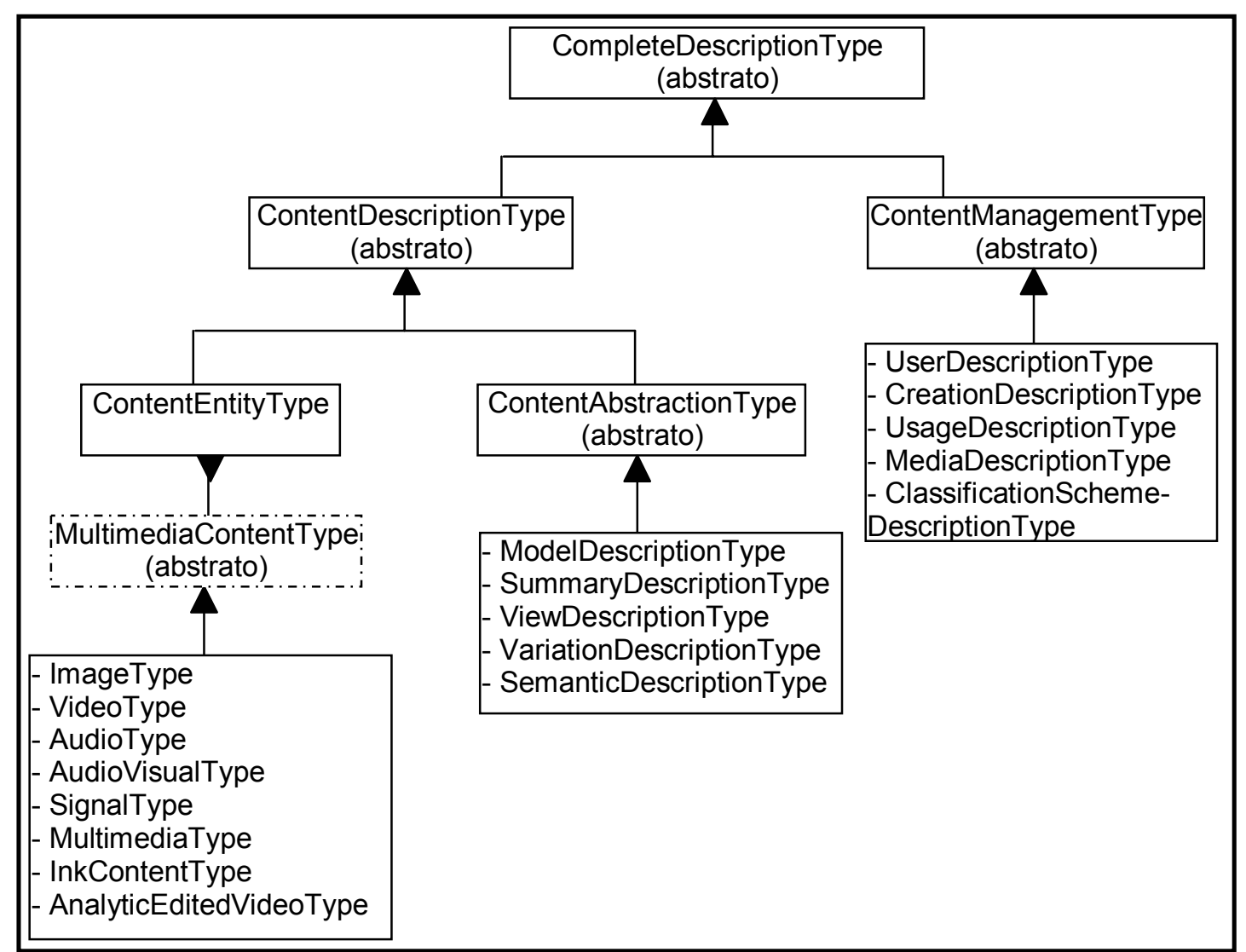

Figura 4.6 - Organização hierárquica dos tipos de mais alto nível (ISO, 2001).

Hierarquicamente abaixo dos Elementos de Nível mais Alto estão as diversas ferramentas de descrição padronizadas pelo MPEG-7 (algumas delas ilustradas na Figura 4.6, por exemplo, VideoType e ViewDescriptionType). Para se instanciar uma descrição completa MPEG-7 deve-se seguir a hierarquia Elemento Raiz - elemento <Description> - Elementos de Nível mais Alto (o mais adequado) e então selecionar um conjunto de ferramentas de descrição. A Figura 4.7 ilustra a instanciação de um elemento <Description>. Qualquer descrição MPEG-7 deve começar com o elemento raiz (<Mpeg7>), o qual tem xmlns como atributo obrigatório indicando o espaço de nomes MPEG-7 (linha 1). O elemento $<$ Description> (linha 2) é instanciado indicando-se, através do atributo xsi:type, qual tipo 
implementa o elemento. No caso do exemplo, o referido tipo é ContentEntityType, o qual é derivado do tipo ContentDescriptionType, que é derivado de CompleteDescriptionType.

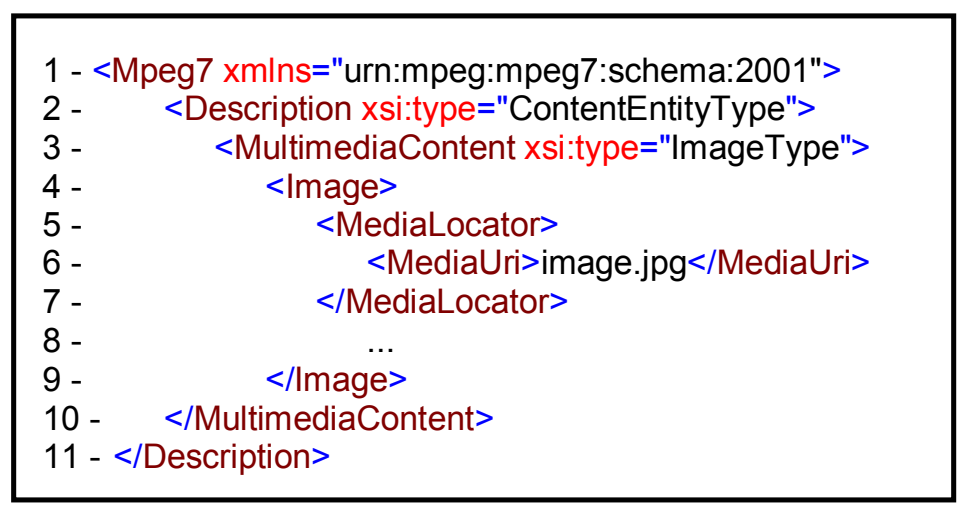

Figura 4.7 - Exemplo de instância do elemento raiz MPEG-7.

Indicar qual tipo implementa o tipo abstrato CompletDescriptionType é a forma de instanciar a maioria das ferramentas MPEG-7, sejam elas Visuais, de Áudio, MDS, ou definidas pelo usuário. A mesma técnica é usada para instanciar descrições parciais, através de tipos que implementem algum dos tipos abstratos derivados de Mpeg7BaseType.

\section{$\underline{4.4}$}

\section{Outras Abordagens para Descrição de Conteúdo}

Esta seção descreve, brevemente, algumas outras soluções para a descrição de conteúdo, dando especial atenção à abordagem Esquema XML, a qual foi adotada para compor a DDL MPEG-7.

\subsection{1 - Linguagem Generalizada Padrão para Marcação (Standard Generalized Markup Language - SGML)}

A SGML (van Herwijenen, 1994) foi adotada como um padrão ISO (número ISO IS-8879) em outubro de 1986. O padrão é uma linguagem aberta não proprietária para descrever a estrutura de documentos.

Descrevendo a estrutura de documentos, SGML fornece meios para armazenar, indexar e buscar por informações arquivadas. Além disso, SGML trata do problema de como transferir documentos através de técnicas que permitem que computadores com 
diferentes conjuntos de caracteres e esquemas de codificação se comuniquem de uma forma conhecida internacionalmente.

Documentos SGML consistem de um número de componentes de documentos relacionados entre si, chamados de elementos (como título, autor, resumo, etc.). A cada elemento encontrado no documento é dado um identificador único - uma marca - como $<$ autor>, que representa o início e </autor>, que representa o fim do elemento "autor". A definição do tipo de documento (Document Type Definition - DTD), com o qual cada documento SGML inicia, define a estrutura da classe de documento em termos dos elementos que ele contém, de forma hierárquica.

A força da SGML está em identificar e representar elementos lógicos para um documento, mas não é flexível em permitir extensões e manutenção da descrição. Desde que SGML foi projetada para descrever a estrutura e o conteúdo de documentos de texto, ela não fornece suporte para descrever dados multimídia (como tipos de dado audiovisuais), tipos de dados primitivos e tipos de dados compostos. Além disso, SGML não define mecanismos de acesso à descrição de metadados e ligações para dados orientados de forma temporal e espacial (Nack \& Lindsay, 1999).

\subsection{2 - Linguagem de Estruturação Hipermídia/Baseada em Tempo (Hypermidia/Time-based Structurig Language - HyTime)}

O padrão HyTime (DeRose \& Durand, 1994), é um arcabouço padrão baseado em SGML para hipermídia aberta integrada.

Por definição, documentos HyTime são documentos SGML. Em termos de funcionalidade, contudo, HyTime estende o poder de SGML de várias maneiras. HyTime oferece uma lista de definições para tipos de elementos, chamados formas arquiteturais. Essas formas, ou classes, permitem a modelagem de componentes para documentos hipermídia, como escalonamento de eventos. Esses elementos permitem herança múltipla, o que significa que podem herdar suas características sintáticas e semânticas não somente do DTD do documento, mas também de qualquer número de outros DTDs.

A maior força do HyTime é o suporte para ligações e escalonamento de documentos no tempo e espaço. HyTime fornece uma interface padronizada para o uso de diversos tipos de ligação (como ligação contextual, ligação independente, etc.). Apesar de HyTime ser um 
dos mais poderosos padrões para gerenciamento de informações de forma geral, ele é muito genérico e difícil de aplicar (Nack \& Lindsay, 1999). Além disso, HyTime não se tornou um padrão amplamente aceito no mercado, dificultando o intercâmbio entre desenvolvedores, que têm dado preferência aos padrões e recomendações W3C.

\subsection{3 - Linguagem de Marcação Extensível (Extensible Markup Lnaguage - XML)}

Apesar de SGML ser uma linguagem muito poderosa, sua complexidade e conseqüente dificuldade de uso restringiram sua utilização em larga escala (por exemplo, na Web). Por outro lado, o HTML (derivado do SGML) foi rapidamente difundido por sua simplicidade, porém, é muito limitado no que diz respeito à reutilização e à separação do conteúdo do documento da forma de apresentação do mesmo (Johnson, 1999).

Para resolver essa limitação do HTML o W3C definiu o XML (Extensible Markup Language) (W3C, 2000), dando a desenvolvedores o poder para distribuir dados estruturados, a partir de uma grande variedade de aplicações, para processamento e apresentação locais. O XML em si é uma versão simplificada do SGML, permitindo a separação entre o conteúdo e a forma de apresentação de documentos.

Enquanto SGML requer que documentos estruturados façam referência a um DTD para serem válidos, XML permite que dados bem estruturados (Johnson, 1999) possam ser entregues sem um DTD. Esse é um dos pontos fortes de XML.

Outro ponto forte é o conceito de espaço de nomes. Um espaço de nomes deixa desenvolvedores qualificarem de modo único os nomes dos elementos e suas relações. $\mathrm{O}$ espaço de nomes evita colisão de nomes em elementos que, apesar de terem o mesmo nome, foram definidos em diferentes vocabulários. Isso permite misturar identificadores de múltiplos espaços de nomes, o que é essencial se os dados vêm de múltiplas fontes. Espaço de nomes pode ajudar a fazer a distinção entre o identificador $<$ Título $>$ no contexto de uma livraria (o título de um livro) e o identificador $<$ Título $>$ no contexto de uma seção de pessoal (a posição de uma pessoa dentro da empresa).

Apesar das suas qualidades estruturais e declarativas serem desejáveis para o desenvolvimento da DDL MPEG-7, o XML foi desenvolvido tendo a Web em mente, tratando de documentos textuais. Mídias audiovisuais são mais dinâmicas e imprevisíveis 
que texto, de modo que a DDL necessita de técnicas e características adicionais como derivação e instanciação condicional de elementos, entre outros (Nack \& Lindsay, 1999; ISO, 2002a). Contudo, XML é utilizado para representar instâncias de descrições MPEG-7. As características da DDL supracitadas estão definidas em outros documentos (Esquema XML, subseção 4.4.4), os quais são usados para criar e validar as instâncias em XML.

\subsection{4 - Esquema XML (XML Schema)}

O Esquema XML (W3C, 2001d) é uma abordagem do W3C para descrição de conteúdo. O Esquema XML define uma classe de documentos XML que pode documentar seu próprio significado, uso e função através de um vocabulário de documentação comum. A definição da classe é feita especificando construções particulares que restrinjam a estrutura e o conteúdo dos documentos. Restrições possíveis incluem: elementos e seus conteúdos, atributos e seus valores, cardinalidades e tipos de dados.

O Esquema XML consiste de três categorias de componentes (Hunter, 2001; W3C, 2001d). Os componentes primários são:

- O espaço de nomes e invólucro ao redor das definições e declarações.

- Declaração de elementos.

- Declaração de atributos.

- Definições de tipo: simples, complexos, derivados e anônimos.

Os componentes secundários são:

- Definições de atributo de grupo.

- Definições de modelo de grupo.

- Definições de restrição de identidade.

- Declarações de notação.

O terceiro grupo são componentes auxiliares, os quais contribuem com outros componentes e não podem ser usados sozinhos:

- Anotações.

- Modelos de grupo.

- Partículas.

- Wildcards. 
Esta subseção descreve apenas as características de maior importância para o padrão MPEG-7: os componentes primários e as definições de grupo. Detalhes sobre os outros componentes são encontrados nas definições e recomendações do W3C (W3C, 2001b; W3C, 2001c; W3C, 2001d).

\subsubsection{1 - O Espaço de Nomes e o Invólucro schema}

O espaço de nomes XML (W3C, 2001d) fornece um método simples para referenciar descritores e esquemas de descrição, a partir de múltiplos esquemas diferentes, para que eles possam ser reusados para criar novos esquemas. Qualificadores de espaço de nomes associam elementos e atributos com um espaço de nomes particular identificado por um URI. Cada definição de esquema deve começar com um preâmbulo para que seja possível identificar o espaço de nomes corrente. Isso também habilita a geração de descrições baseadas em esquemas, os quais combinam componentes de esquemas vindos de múltiplos espaços de nomes diferentes. O preâmbulo mandatório consiste do elemento XML "schema" o qual inclui os seguintes atributos (ilustrados na Figura 4.8):

- xmlns: um URI para o espaço de nomes do Esquema XML (XML Schema Namespace).

- targetNamespace: o URI pelo qual o esquema corrente é identificado.

- xmlns: referências a esquemas externos.

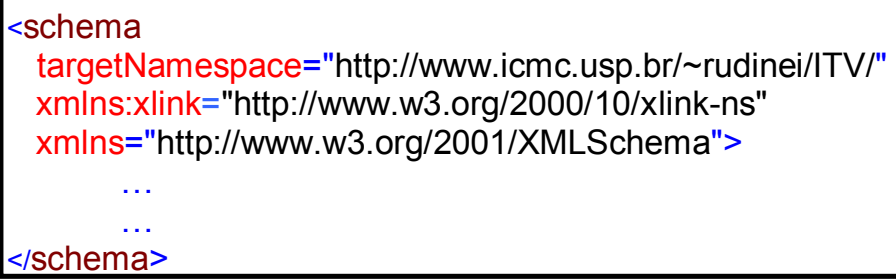

Figura 4.8 - Exemplo de atributos do invólucro do esquema XML.

\subsubsection{2 - Declaração de Elementos}

A declaração de elementos (W3C, 2001d) habilita a ocorrência, em instâncias de documentos, de elementos com nomes e tipos específicos. A declaração de um elemento especifica a definição de tipo para um elemento do esquema ou explicitamente ou por 
referência, pode especificar o número de ocorrências mínima e máxima (minOccurs e maxOccurs, respectivamente) e informação padrão (através do atributo default). Por exemplo, a declaração de elemento na Figura 4.9 associa o nome País ao tipo (previamente definido) códigoPaís, especifica que o valor padrão para o elemento <País> é "br" e que o elemento $<$ País> pode ocorrer zero ou mais vezes.

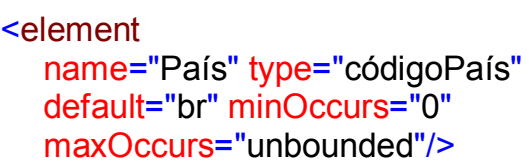

Figura 4.9 - Exemplo de definição de um elemento.

\subsubsection{3 - Declaração de Atributos}

A declaração de atributos (W3C, 2001d) permite a ocorrência, nos documentos de instância, de atributos com nomes e tipos específicos associando um nome de atributo com um tipo de dado simples. Dentro de uma declaração de atributo, o atributo use especifica a presença (required | optional | fixed | default | prohibited); e o atributo value indica um valor fixo ou padrão. $\mathrm{O}$ valor padrão do atributo use é optional. $\mathrm{O}$ exemplo de declaração de atributo ilustrado na Figura 4.10 indica que a ocorrência do atributo obj_type é opcional e que seu valor padrão é “AUDIO”.

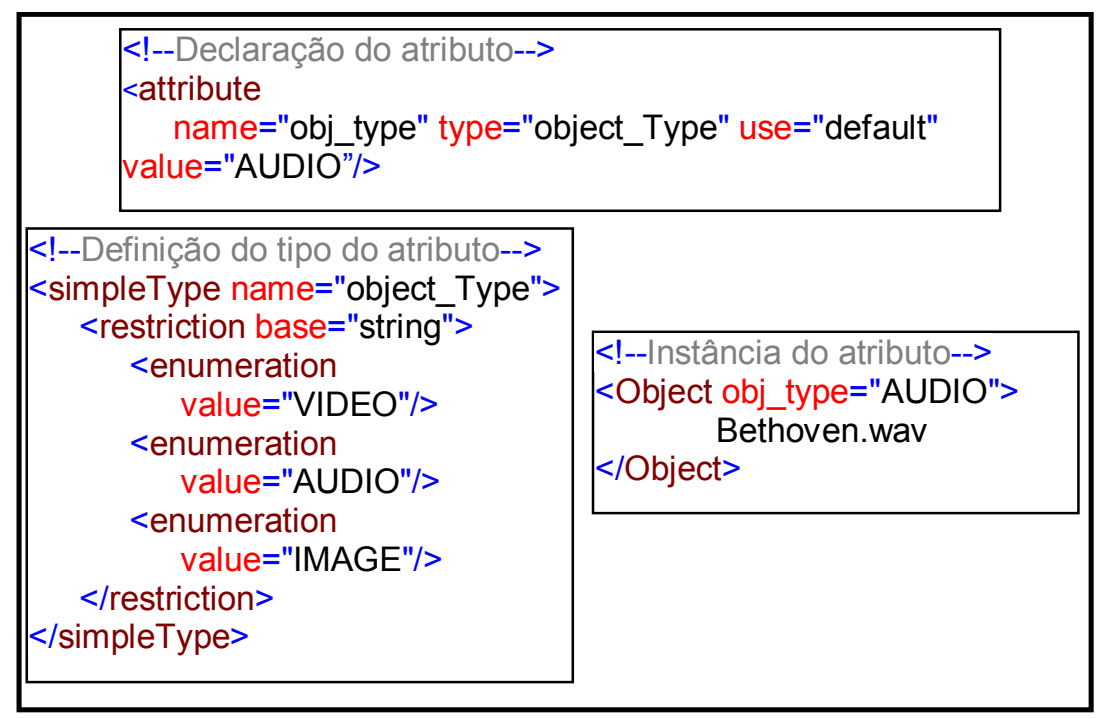

Figura 4.10 - Exemplo de declaração, definição, e de instanciação de um atributo. 


\subsubsection{4 - Definição de Tipos}

Na linguagem Esquema XML existe uma distinção fundamental entre definição de tipos (que cria novos tipos) e declarações. Estas últimas habilitam a ocorrência de elementos e atributos nas instâncias de documentos com nomes e tipos específicos. Definições de tipos definem os componentes internos de um esquema, os quais podem ser usados em outros componentes de esquema, tais como declarações de elementos e atributos ou em outra definição de tipos. O Esquema XML fornece as seguintes definições de tipo (W3C, 2001d):

Definições de tipo simples: não podem ter elementos nem atributos. Elementos e atributos podem ser declarados como sendo do tipo simples (simpleType). O Esquema XML fornece um grande número de tipos simples através de um conjunto de tipos primitivos e de um outro conjunto de tipos derivados dos tipos primitivos (W3C, 2001c; W3C, 2001d). Em adição a esses tipos primitivos novos tipos simples podem ser derivados através de restrições, como enumarattion aplicada a um tipo string (como ilustrado na Figura $4.10 \mathrm{em}$ "Definição do tipo do atributo"). Além desses tipos simples atômicos, o Esquema XML fornece dois tipos de agregação: lista (list) e união (union).

Definições de tipo complexo: permitem elementos filhos em seu conteúdo e podem ter atributos. Definições de tipo complexo fornecem (Hunter, 2001; W3C, 2001d):

- Restrições de ocorrência e de conteúdo dos atributos.

- Restrições sobre os elementos filhos e sobre o modelo de conteúdo do tipo.

- Derivação de tipos complexos a partir de outros tipos simples ou complexos através de extensão (extension) ou restrição (restriction).

Novos tipos complexos são definidos usando o elemento XML complextype e tais definições geralmente contêm um conjunto de declarações de elementos e de atributos. Por exemplo, a declaração do tipo complexo ObjectNodeType, ilustrada na Figura 4.11, contém uma declaração de elemento e duas declarações de atributos. A Figura 4.11 também ilustra a declaração de um elemento, instância do tipo ObjectNodeType. 


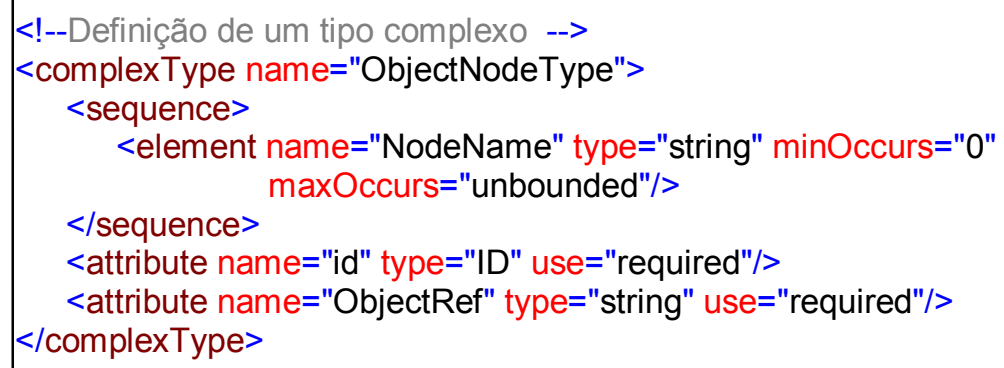

<!--Declaração de elemento do tipo ObjectNodeType-->

<element name="Node" type="ObjectNodeType"/>

Figura 4.11 - Exemplo de definição de um tipo complexo.

Definições de tipo derivado: é possível derivar novos tipos complexos, por extensão ou restrição, de definições baseadas em tipos simples ou complexos (W3C, 2001d). Um tipo complexo estende um outro adicionando declarações de atributos ou de elementos, ou ambos, no fim da definição do modelo de conteúdo. Um novo tipo complexo (complexType) pode ser derivado estendendo-se um tipo simples através da adição de atributos. Para indicar que o modelo de conteúdo do novo tipo não contém elementos, o elemento XML simpleContent é usado (Figura 4.12 (a)).

\begin{tabular}{||}
\hline$<$-- Extensão de um tipo complexo via \\
simpleContent--> \\
$<$ complexType name="Relation"> \\
$<$ simpleContent> \\
$<$ extension base="string"> \\
$<$ attribute name="role" \\
$</$ textension> $>$ "string"/> \\
$</$ simpleContent> \\
$</$ complexType>
\end{tabular}

(a)

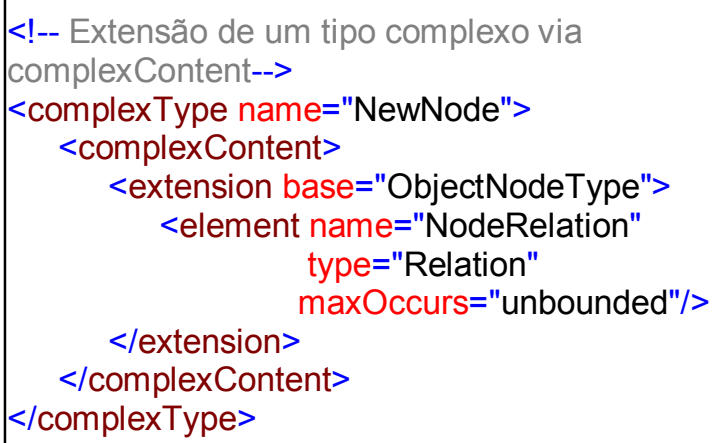

(b)

Figura 4.12 - (a) Tipo derivado com extensão via simpleContent. (b) Tipo derivado com extensão via complexContent.

Também se pode derivar um novo complexType estendendo-se um tipo complexo existente. O elemento XML complexContent é usado, nesse caso, para indicar que se deseja 
restringir ou estender o modelo de conteúdo de um tipo complexo e que o novo tipo contém apenas elementos (Figura 4.12 (b)).

Definições de tipo anônimo: esse é um estilo mais sucinto de definir um tipo, sem ter a necessidade de explicitamente nomear e referenciar o tipo (W3C, 2001c; W3C, 2001d). Esse estilo é útil quando se tem muitas definições de tipo que são referenciadas apenas uma vez e contém poucas restrições. A Figura 4.13 ilustra um exemplo de tipo anônimo.

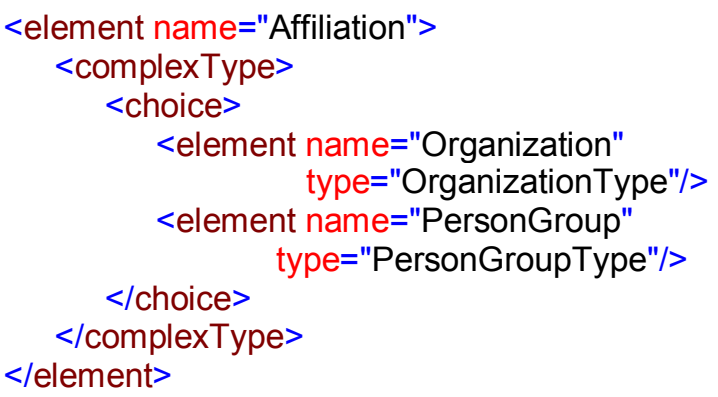

Figura 4.13 - Exemplo de tipo anônimo.

Definições de grupo: os grupos mais utilizados são os grupos não nomeados. Esses grupos aparecem com freqüência na definição de tipos complexos. Eles são formados através de três compositores (W3C, 2001c; W3C, 2001d):

- Sequence: restringe os elementos de um grupo para aparecerem na mesma ordem em que foram declarados.

- Choice: apenas um dos elementos do grupo pode aparecer em uma instância.

- All: todos os elementos em um grupo podem aparecer uma ou nenhuma vez e em qualquer ordem.

A Figura 4.13 ilustra um exemplo de um grupo anônimo onde o compositor choice define que somente um dos dois elementos (ou <Organization> ou <PersonGroup $>$ ) pode aparecer na instância. Existem ainda os elementos XML attributeGroup e group, os quais fornecem um mecanismo para criar e nomear grupos de atributos e grupos de elementos, respectivamente. Tais grupos podem então ser incorporados por referência em uma definição de tipo complexo, conforme ilustrado na Figura 4.14. 


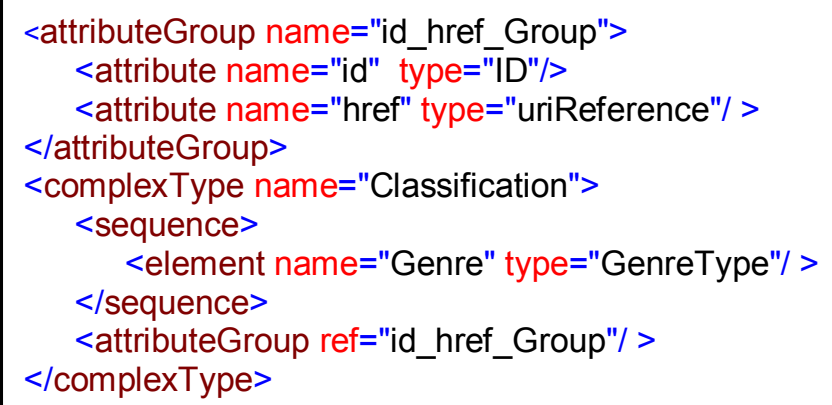

Figura 4.14 - Exemplo de grupo de atributos.

\section{$\underline{4.5}$}

\section{Considerações Finais}

Devido às suas capacidades de fornecer significado semântico a dados multimídia, o padrão MPEG-7 apresenta-se como uma abordagem adequada para a estruturação e para a descrição de aplicações de vídeo interativo. Nesse cenário, o usuário pode requisitar, a qualquer momento, informações a respeito de um componente da imagem sendo exibida (ficha técnica de um jogador de basquete prestes a executar lances livres em uma partida, por exemplo). Esse tipo de informação é disponível, nos sistemas tradicionais de transmissão de TV, por meio de difusão. A emissora coloca as informações no sinal de TV e todos os usuários a recebem (querendo ou não). Para que os usuários tenham acesso às informações de maneira personalizada (e individualizada) são necessárias novas formas de organização e de transmissão das informações (em complemento à digitalização dos dados).

Por outro lado, o fato de MPEG-7 fornecer um conjunto poderoso de ferramentas padronizadas para descrição, organização e estruturação de metadados de conteúdo audiovisual torna, muitas vezes, as descrições grandes, complexas e difíceis de reutilizar. Este projeto de protótipo de TV Interativa exige formas adequadas de representação de programas e dos objetos de mídia que tais programas contêm. Porém, MPEG-7 não fornece esquemas padrões para descrição de programas (apesar de os esquemas para descrição de objetos audiovisuais atenderem às necessidades do projeto). Além disso, este projeto pretende dar suporte à utilização de informações contextuais, uma vez que o suporte oferecido pelo padrão MPEG-7 a esse tipo de informação é limitado a anotações textuais 
livres para seis elementos (who, where, when, what object, what action e why), chamados dentro do padrão de seis Ws semânticos.

Por esses motivos existe a necessidade de se desenvolver esquemas próprios para a descrição dos programas de TV Interativa com suporte mais estruturado a informações contextuais. Tais esquemas devem ser construídos utilizando-se a DDL e selecionando-se esquemas padrões de forma a simplificar a descrição resultante, minimizar o trabalho de projeto e manter a compatibilidade com o padrão MPEG-7. A construção desses esquemas será tratada nos capítulos seis (contexto) e sete (programas de TV Interativa). 
Capítulo

Computação Ciente de Contexto 
OMPUTAÇÃO ciente de contexto é um tema de pesquisa originário da área de computação ubíqua. O termo computação ubíqua foi utilizado pela primeira vez por Mark Weiser em 1991 (Weiser, 1991), descrevendo um ambiente dotado de recursos computacionais que auxiliam atividades humanas. A idéia de Weiser é fazer com que os referidos recursos se adaptem ao comportamento humano de modo não intrusivo, em vez de forçar os usuários a se adaptarem aos dispositivos de interação. Para isso, a computação deve estar presente em todo o ambiente, de forma transparente para o usuário, oferecendo-lhe serviços e informações quando e onde desejado.

Segundo Abowd et al. (2002), para concretizar as idéias lançadas por Weiser (1991; 1993), é necessário entender e auxiliar as práticas cotidianas das pessoas, estender o ambiente através do fornecimento de dispositivos heterogêneos que ofereçam diferentes formas de interação e, finalmente, gerenciar dispositivos em rede de forma a fornecer ao usuário uma experiência holística. Durante a última década, pesquisadores têm desenvolvido tecnologias para atender tais objetivos, sendo que seus esforços podem ser atualmente agrupados em três grandes focos de pesquisa na área de computação ubíqua (Abowd \& Mynatt, 2000): interfaces naturais, computação ciente de contexto e captura e acesso automatizados de atividades humanas.

A área de interfaces naturais busca adaptar as interfaces à forma segundo a qual os seres humanos interagem com o mundo físico. Interfaces computacionais que suportam modos mais naturais de comunicação, tais como fala, escrita manual e expressão corporal, são exploradas de forma a substituir ou complementar elementos do paradigma de interfaces gráficas. Exemplos relevantes de pesquisa nessa área incluem: o trabalho realizado por Schilit et al. (1998) que trata da utilização da escrita manual (em lousas e similares) como meio de interação; o trabalho realizado por Ishii e Ullmer (1997), que utiliza objetos do mundo físico com o objetivo de manipular artefatos eletrônicos, criando o conceito de interfaces tangíveis; e o trabalho de Harisson et al. (1998), que utiliza sensores acoplados a dispositivos computacionais permitindo que a manipulação física dos mesmos seja corretamente interpretada por aplicações. 
A área de captura e acesso automatizados de atividades humanas estuda o uso de recursos computacionais para o registro, processamento e acesso de informações relacionadas às atividades dos usuários. As aplicações nessa área visam permitir o registro simultâneo de diversos fluxos de informação em diversas formas de mídia, preservando as inter-relações existentes entre cada um deles, o que possibilita uma série de facilidades de acesso ao conteúdo capturado. Como exemplos de pesquisas nessa área podem-se citar o projeto Tivoli (Minneman et al., 1995), desenvolvido nos laboratórios da Xerox PARC, e o eClass (Abowd, 1999), desenvolvido no Georgia Institute of Technology. Ambos são relacionados à captura e acesso de informações provenientes de vídeos, áudios e lousas eletrônicas, o primeiro durante reuniões e o segundo durante aulas.

A área de computação ciente de contexto explora a comunicação usuáriocomputador durante interações de forma a aproveitar as informações contextuais presentes nessa comunicação. Tais informações são convertidas em subsídios para o gerenciamento e adaptação de serviços de acordo com as necessidades (ou desejos) atuais dos usuários e de acordo com as características dos dispositivos de interação. Um dos projetos pioneiros na utilização computacional de informação contextual foi o Active Badge (Want et al., 1992) do Olivetti Research Lab's, onde a localização de pessoas usando crachás especiais pode ser rastreada através de sensores espalhados pelo ambiente. Outro exemplo é o projeto Informedia, da Carnegie Mellon University, que utiliza técnicas de reconhecimento de faces e legendas em vídeos de forma a estendê-los com metainformação contextual (Wactlar et al., 1996). Um outro exemplo é o Context Kernel (Arruda Júnior, 2003), desenvolvido no ICMC-USP, o qual é um serviço Web para armazenamento e recuperação de informações de contexto.

Não existem atualmente muitas pesquisas sobre computação ubíqua no Brasil, de forma que a tradução direta de termos da área para o Português ainda é polêmica. Os termos context-awareness e context-aware são empregados na área de computação ubíqua no sentido de se ter o conhecimento, ser sabedor, estar ciente do contexto em determinada situação. Neste trabalho tais termos serão traduzidos, respectivamente, como ciência de contexto e ciente de contexto, observando-se o sentido original dos termos em Inglês.

De modo a compreender melhor o que é contexto e sua utilização no desenvolvimento de aplicações, este capítulo revisa as definições de contexto na seção 5.1 e 
de computação ciente de contexto na seção 5.2. A seção 5.3 apresenta algumas classificações de contexto existentes na literatura. A seção 5.4 revisa modos de representar informações de contexto e, por fim, a seção 5.5 apresenta algumas considerações sobre a utilização de contexto no projeto de protótipo de TV Interativa.

\section{$\underline{5.1}$}

Definição de Contexto

A utilização da noção de contexto é antiga. Pesquisando-se a literatura pode-se encontrar uma variedade de trabalhos baseados em contexto em diferentes áreas, como Lingüística, Inteligência Artificial, Visão Computacional e Interação Usuário-Computador. Com a emergência da Computação Ubíqua os pesquisadores estão redescobrindo essa noção, usando diferentes perspectivas para servir propósitos distintos. Devido a essa diversidade de propósitos e pelo fato de a Computação Ubíqua ser recente, ainda não existe um consenso sobre a definição de contexto:

- Schilit et al. (1994) referem-se a contexto como localização, identificação de pessoas e objetos ao redor, situações sociais e condições ambientais como iluminação e barulho. Também definem três aspectos importantes de contexto: onde o usuário está, com quem o usuário está, e quais os recursos próximos ao usuário.

- Brown et al. (1997) sugerem que contexto pode ser usado para descrever o ambiente, pessoas ao redor do usuário, situação, estado, temperatura, entre outros.

- Ryan et al. (1997) referem-se a contexto como localização, ambiente, identificação e tempo.

- Salber et al. (1998) definem contexto como informações sobre pessoas ou dispositivos que podem ser usados para transformar o modo como um sistema fornece serviços. Exemplos de tais informações são: dados emocionais, dados históricos, dados de localização, dados de intenção e de foco de atenção do usuário.

- Pascoe (1998) define contexto como o subconjunto de estados físico e conceitual de interesse para uma entidade particular.

Dey e Abowd (1999) e Dey (2001) argumentam que essas definições são difíceis de serem aplicadas na prática, ou por serem restritivas demais, ou por serem baseadas em exemplos. Segundo esses autores, contexto é tudo o que envolve uma situação relevante 
para uma aplicação e seu conjunto de usuários, sendo difícil enumerar quais aspectos de todas as situações são importantes, pois eles irão mudar de situação para situação. Baseado nessas constatações, Dey (2001) elaborou uma definição mais genérica, a qual vem sendo utilizada em várias pesquisas recentes:

Contexto é qualquer informação que pode ser utilizada para caracterizar a situação de uma entidade. Uma entidade é uma pessoa, lugar, ou objeto que é considerado relevante para a interação entre um usuário e uma aplicação, incluindo o usuário e a aplicação em si.

Tal definição deixa a cargo do projetista da aplicação decidir quais informações podem ser contexto. Segundo Dey e Abowd (1999) e Dey (2001), se uma informação pode ser usada para caracterizar a situação de um participante de uma interação, então esta informação é contexto.

A tarefa de definir qual informação é importante ou relevante é facilitada utilizandose as diretrizes quem (who), onde (where), o quê (what) e quando (when), relacionadas a alguma entidade, para se determinar o porquê (why) de uma determinada situação estar ocorrendo (Dey, 1999; Abowd \& Mynatt, 2000). Tais diretrizes são também conhecidas como os cinco Ws semânticos, ou as cinco dimensões semânticas. No domínio de captura e acesso automatizados de atividades humanas existe ainda a diretriz como (how), relacionada aos métodos de captura e de acesso utilizados (Truong et al., 2001).

A literatura (Schilit et al., 1994; Brown et al., 1997; Pascoe, 1998; Dey \& Abowd, 1999; Dey, 2001) sugere que existem certos tipos de informação de contexto que, na prática, são mais importantes que outros: localização, identidade, atividade e tempo. Tais tipos de informação de contexto são chamados de contexto primário, pois além de responderem às questões quem, onde, o quê e quando, também podem ser usados como índices para outras fontes de informação contextual (Dey \& Abowd, 1999; Dey, 2001). Por exemplo, dada a identidade de uma pessoa pode-se adquirir uma série de informações relacionadas como endereço, telefone, e-mail, relações com outras pessoas no ambiente, etc. 


\section{Definição de Computação Ciente de Contexto}

O primeiro trabalho em computação ciente de contexto foi o Active Badge (Want et al., 1992), desenvolvido nos laboratórios de pesquisa da Olivetti (Olivetti Research Lab's), o qual utilizava informação de localização espacial de usuários para realizar transferências automáticas de chamadas telefônicas. Contudo, o termo Computação Ciente de Contexto (Context-Aware Computing) foi introduzido por Schilit e Theimer (1994), que o definiram como sendo "o estudo de aplicações que se adaptam de acordo com sua localização de uso, com a coleção de objetos e pessoas nas proximidades e também de acordo com as mudanças ocorridas com esses objetos ao longo do tempo".

A partir desses trabalhos vários pesquisadores têm tentado definir computação ciente de contexto. Dey e Abowd (1999) fazem uma revisão de definições anteriores e classificam tais definições em dois casos. No primeiro caso as definições requerem que o comportamento de uma aplicação seja modificado para que a mesma seja considerada ciente de contexto (Schilit \& Theimer, 1994; Ward et al., 1997; Ryan et al., 1997; Brown, 1998; Korteum et al., 1998). No segundo caso, as definições requerem que o sistema seja capaz de detectar, interpretar e responder ao contexto (Hull et al., 1997; Pascoe, 1998; Salber et al., 1998).

Dey (2001) e Dey e Abowd (1999) argumentam que as definições do primeiro caso fazem com que aplicações que apresentam informações sobre o contexto para o usuário, sem alterar seu comportamento, não sejam consideradas cientes de contexto. Por isso, esses autores propõem uma definição mais genérica, não excluindo as aplicações cientes de contexto já existentes:

Um sistema é ciente de contexto se usa contexto para fornecer informação elou serviço relevante para o usuário, onde a relevância depende da tarefa do usuário.

Essa definição difere das definições do segundo caso, de acordo com Dey (2001), por estar focada no usuário, não limitar a ciência a apenas interfaces de aplicações, não requerer que as aplicações realizem serviços automaticamente e por não requerer aquisição de contexto em tempo real. 
Encontram-se na literatura propostas de categorização das características para aplicações cientes de contexto. As mais importantes (por serem as mais citadas) são as propostas de Schilit et al. (1994), Pascoe (1998) e de Dey e Abowd (1999). Uma mesma característica aparece em diferentes propostas com diferentes nomes. Contudo, sem perdas, tais características podem ser agrupadas em:

- Percepção contextual: é a capacidade de detectar o contexto e apresentar as informações que o descrevem ao usuário.

- Associação de informação contextual: permite associar informação contextual a dados. Por exemplo, em uma reunião, as pessoas presentes e o local da reunião podem ser associados à ata da reunião.

- Descoberta de recursos: permite que aplicações descubram e explorem recursos e serviços relevantes para um determinado contexto.

- Adaptação contextual: essa característica é usada na literatura para descrever casos onde o contexto causa uma ação e casos onde o contexto é usado para modificar ou adaptar serviços. Chalmers (2002) propõe a separação desses dois casos em:

- Ações disparadas pelo contexto: é o caso mais comum na literatura, onde uma ação é disparada quando um determinado conjunto de informações contextuais atinge valores específicos.

- Mediação contextual: adapta serviços e dados de acordo com os limites e preferências impostos pelo contexto. A requisição pelos dados ou serviços sendo mediados não necessita ser originada do contexto.

\section{3}

\section{Classificação de Contexto}

A literatura reporta algumas classificações de tipos de contexto em adição ao contexto do Usuário. Segundo os trabalhos de Schilit (1995), Dix et al. (2000), Chalmers (2002) e Crowley et al. (2002), os conjuntos de características usualmente utilizados em aplicações cientes de contexto podem ser classificados nos seguintes tipos de contexto: InfraEstrutura, Sistema, Domínio e Ambiente. 
Schilit (1995) e Dix et al. (2000) argumentam que é importante representar o estado atual da infra-estrutura de comunicação (contexto da Infra-Estrutura) entre a aplicação e o dispositivo usado pelo usuário para acessar a aplicação. Tal representação fornece subsídios para que se possa reportar, eventualmente, mudanças de estado devido a falhas, saída ou entrada de um dispositivo no ambiente.

Dix et al. (2000), Crowley et al. (2002) e Chalmers (2002) argumentam que o contexto do Sistema deve conter informações que permitam saber até que ponto um dispositivo está ciente dos outros dispositivos nas suas proximidades e, relacionado a isso, até que ponto uma aplicação está ciente de outras aplicações oferecendo serviços. Essa argumentação está baseada em dois fatos. O primeiro é que dispositivos podem afetar o funcionamento uns dos outros, uma vez que eles eventualmente competem por recursos. $\mathrm{O}$ segundo é que combinações de dispositivos podem oferecer serviços mais avançados ao usuário. Segundo a visão desses autores, o contexto do Sistema é formado pelo contexto do Usuário mais o estado atual dos dispositivos e serviços utilizados. Essa visão, contudo, não apresenta uma separação clara entre os contextos do Sistema e da Infra-Estrutura, uma vez que ambos tratam com aplicações e dispositivos.

O contexto do Domínio agrega informações sobre a semântica do domínio da aplicação, considerando os relacionamentos entre os dispositivos e seus usuários e como isso pode ser usado para determinar a natureza da interface ou serviço sendo apresentado. Outro aspecto do domínio é o nível de segurança da informação e de privacidade em situações onde informações sobre um determinado usuário (localização e atividade, por exemplo) podem se tornar disponíveis para outros usuários (Dix et al., 2000; Abowd et al., 2002).

O contexto do Ambiente engloba informações sobre o ambiente onde uma determinada entidade se encontra (luminosidade, temperatura, localização, endereço, entre outros). Isso inclui ambientes reais (desde uma sala de escritório, até um rádio digital embutido em um carro) e virtuais (Dix et al., 2000).

De um modo geral, os trabalhos discutidos nesta seção utilizam classificações de contexto como um meio de situar o trabalho dos autores. Por exemplo, Dix et al. (2000) descrevem os tipos de contexto discutidos nesta seção, porém, seu trabalho está centrado no 
desenvolvimento de uma taxonomia para localização e espaço, os quais fazem parte do contexto do Ambiente. Não existe uma organização estruturada dos tipos de contexto.

\section{$\underline{5.4}$}

\section{Representação de Contexto}

Um dos desafios da área de ciência de contexto é a questão de como representar contexto. Abowd et al. (2002) argumentam que, sem boas representações, os desenvolvedores de aplicações são levados a implementar esquemas proprietários e limitados para armazenamento e manipulação, dificultando o intercâmbio desse importante tipo de informação.

A definição de contexto e as cinco dimensões contextuais (who, where, when, what e how) ajudam a decidir quais informações são relevantes para um dado sistema. Porém, os projetistas ainda necessitam analisar os requisitos da aplicação e decidir como modelar e representar as informações dentro de cada dimensão.

A maior parte dos trabalhos em representação de contexto está preocupada em fornecer suporte a abstrações de informações contextuais que possam ser pesquisas por aplicações. O Context Toolkit (Salber et al., 1999) e a arquitetura de sensores de Schmidt et al. (1999) dão suporte à aquisição de dados de contexto vindos de sensores, e ao processamento desses dados para obter informação de contexto de alto nível. O primeiro é uma ferramenta de programação para desenvolvedores de aplicações cientes de contexto. Essa ferramenta fornece componentes abstratos (widgets, interpreters e agregators) que podem ser conectados para processar a informação contextual vinda dos sensores. $\mathrm{O}$ segundo fornece um modelo em camadas de processamento de contexto no qual a saída dos sensores é transformada em dados, os quais são processados para formar uma descrição abstrata de contexto compreendendo um conjunto de valores. Em ambos os projetos as informações de contexto são representadas como variáveis.

Outros trabalhos no campo da ciência de contexto se concentram em modelar informações de contexto e entregar as informações para a aplicação. O projeto pioneiro nessa área foi desenvolvido por Schilit et al. (1994), que propôs o uso de servidores dinâmicos de ambiente para gerenciar e disseminar informação de contexto. O modelo de contexto usado nesse trabalho foi extremamente simples, com as informações de contexto 
sendo manipuladas por um conjunto de variáveis de ambiente. O projeto Cooltown (Kindberg et al., 2000) representa contexto através de páginas HTML representando as entidades contextuais. A desvantagem dessa abordagem é que as informações nessas páginas são desestruturadas e voltadas para uso humano (dificultando o uso por aplicações). O projeto Sentient Computing (Harter et al., 1999) representa contexto por meio de um modelo Entidade-Relacionamento, de modo que as informações de contexto são armazenadas em uma base de dados relacional. Gray e Salber (2001) apresentam um modelo de contexto que tem como objetivo permitir o projeto de atividades associadas à ciência de contexto. O modelo é informal, sendo direcionado ao suporte ao desenvolvimento de software, incluindo análise de requisitos e exploração das questões de projeto, do que com a captura de informações de contexto que possam ser processadas por aplicações. Crowley et al. (2002) representam contexto como um conjunto de variáveis representando o estado do sistema. Os valores das variáveis são obtidos e processados através de federações de processos.

As abordagens citadas apresentam algumas limitações. A maioria não se preocupada em classificar os tipos de contexto de forma a obter uma representação estruturada e abrangente das informações de contexto. Outro problema é que tais abordagens apresentam falta de flexibilidade para compartilhar as informações de contexto com outras aplicações.

\section{5}

\section{Considerações Finais}

Para atender às expectativas dos usuários em relação à interação e acesso, as aplicações de TV Interativa necessitam ter conhecimento do contexto. Tal conhecimento é utilizado para, automaticamente, adaptar serviços e conteúdo de acordo com preferências dos usuários e limitações dos dispositivos de acesso. Para que diferentes aplicações possam trocar informações de contexto de forma homogênea é necessária uma forma organizada e estruturada de representar tais informações. Contudo, como discutido neste capítulo, esse ainda é um problema na área de Computação Ubíqua, não existindo até o momento mecanismos eficientes para representar contexto que facilitem o compartilhamento desse tipo de informação. 
O projeto de protótipo de TV Interativa prevê a construção de uma série de serviços que utilizam e trocam informações de contexto. Sendo assim, o capítulo seis propõe um modo de representar contexto através de um conjunto de esquemas. Além disso, o capítulo seis também apresenta como contribuições deste trabalho o desenvolvimento de representações para programas de TV Interativa e de esquemas de descrição para objetos de mídia, mostrando como os mesmos utilizam as representações de contexto. 
Capítulo

\section{Representação de Contexto}


O projeto de protótipo de TV Interativa pretende-se utilizar informações de contexto para potencializar o desenvolvimento de serviços avançados, como geração e adaptação automática e personalizada de conteúdo, seleção fina de conteúdo de interesse e sugestão em tempo real de conteúdo relacionado. Para que esses diversos serviços compartilhem as informações de contexto de forma homogênea é necessário um modo padronizado de representá-las. Contudo, como discutido no capítulo cinco, esse tem sido um dos problemas da área de computação ciente de contexto.

Este capítulo tem por objetivo propor um modo flexível de representar contexto em direção à construção de uma biblioteca padronizada e extensível de elementos contextuais. A seção 6.1 apresenta uma classificação dos tipos de contexto baseada nas discussões da seção 5.3. Essa classificação é a base da representação de contexto proposta na seção 6.2. A seção 6.3 apresenta as considerações finais sobre a proposta.

\section{$\underline{6.1}$}

\section{Proposta para Classificação e Organização de Contexto} Santos Júnior (2002) sugere que informações de contexto podem ser usadas para auxiliar no gerenciamento de interações em ambientes que incluam mobilidade, como é o caso do protótipo de TV Interativa. Questões pertinentes incluem: como caracterizar um ambiente, como saber quais serviços estão disponíveis em determinado ambiente e qual a forma mais adequada de se oferecer serviços tendo em vista os dispositivos disponíveis e as preferências do usuário. Para tratar essas questões existe a necessidade de se conhecer, além do contexto do Usuário, a situação das aplicações, da rede e a situação das possíveis interações entre as aplicações e o sistema (Santos Júnior et al., 2001).

A definição de contexto de Dey (2001), apresentada na seção 5.1, é restrita a interações entre o usuário e a aplicação. É necessário estender a definição para que a mesma possa ser aplicada em ambientes interativos de uma forma mais ampla, explorando também as interações entre as aplicações e o sistema: 
Contexto é qualquer informação que possa ser usada para caracterizar a situação de uma entidade. Uma entidade é uma pessoa, lugar ou objeto físico ou software que é considerado relevante para a interação entre um usuário e uma aplicação, elou entre uma aplicação e o sistema, incluindo usuário, aplicação e sistema em si.

Tendo em mente a definição estendida de contexto e a discussão sobre classificação de contexto apresentada na seção 5.3, pode-se classificar os tipos de contexto em: InfraEstrutura, Sistema, Usuário, Aplicação, Domínio e Ambiente. Essa classificação precisa ser organizada de modo a auxiliar no desenvolvimento de uma representação de contexto.

A Figura 6.1 ilustra a organização proposta, a qual, em um primeiro momento, não inclui os contextos do Domínio e do Ambiente. Os retângulos indicam entidades com representação própria e os retângulos pontilhados indicam entidades cuja representação é o conjunto das representações de seus componentes. Algumas informações contextuais tipicamente pertencentes ao contexto do Ambiente (como espaço e localização) são utilizadas nas representações de contexto propostas (como será mostrado na seção 6.2). O objetivo, contudo, é apenas viabilizar a implementação de alguns serviços. A modelagem e a representação dos contextos do Domínio e do Ambiente serão explorados em trabalhos futuros.

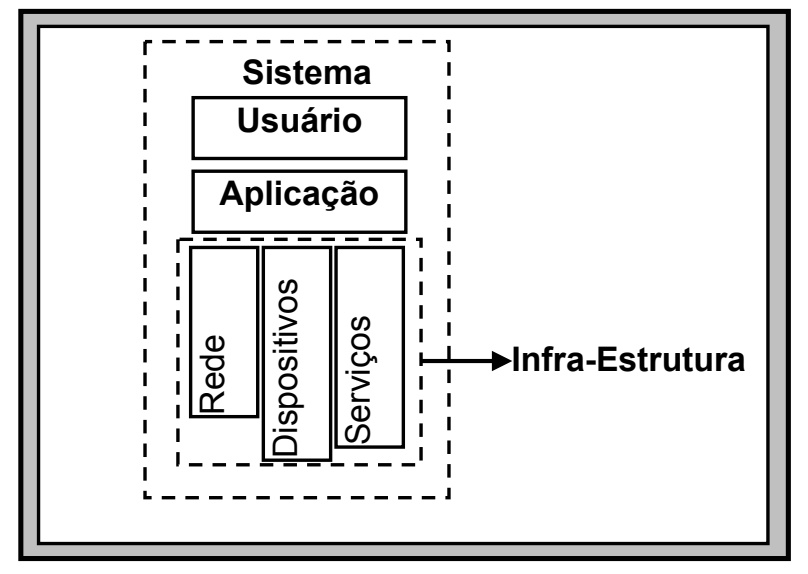

Figura 6.1 - Componentes do contexto do sistema.

$\mathrm{Na}$ organização proposta o sistema computacional é composto por usuários, aplicações e por uma infra-estrutura. Os usuários utilizam dispositivos (um computador de bolso ou um controle-remoto, por exemplo) para acessar aplicações e requisitar o 
cumprimento de uma tarefa. As aplicações utilizam os dispositivos (impressoras, projetores, etc.) e os serviços (servidores de impressão, serviços de transferência de arquivos e de busca, etc.) da infra-estrutura para realizar a tarefa requisitada. A comunicação entre usuários, dispositivos e aplicações é fornecida pela rede, a qual vai desde infravermelho até a Internet.

Conforme discutido na seção 5.3, as abordagens de Schilit (1995) e de Dix et al. (2000) consideram que o contexto da Infra-Estrutura possui apenas informações sobre o estado da rede comunicando usuários e aplicações. Esses autores não consideram que mudanças de estado nos serviços e dispositivos utilizados pela aplicação também afetam a comunicação entre o usuário e a aplicação, podendo alterar o resultado da tarefa requisitada. Sendo assim, este trabalho considera que o contexto da Infra-Estrutura é composto por representações do estado dos componentes: rede, dispositivos e serviços. Cada um desses componentes é uma classe de entidades contextuais, onde cada entidade deverá ser caracterizada por informações de contexto.

A abordagem adotada por outros autores (Dix et al., 2000; Crowley et al., 2002; Chalmers, 2002) (seção 5.3) para organizar o contexto do Sistema considera que o mesmo é formado por uma representação do contexto do Usuário, mais representações dos estados de dispositivos e serviços, sendo esses últimos considerados atributos diretos do contexto do Sistema. A organização proposta (Figura 6.1) difere por considerar o contexto do Sistema como sendo composto por representações dos contextos do Usuário, da Aplicação e da Infra-Estrutura, e por considerar dispositivos e serviços como parte do contexto da Infra-Estrutura. Contudo, essa nova organização não perde em significado semântico, uma vez que as informações sobre serviços e dispositivos ainda estão presentes no contexto do Sistema - o contexto da Infra-Estrutura é um componente do contexto do Sistema.

Ainda sobre contexto do Sistema, outro ponto que distingue a classificação feita neste trabalho é que, apesar de Dix et al. (2000), Crowley et al. (2002) e Chalmers (2002) reconhecerem a importância das informações sobre as aplicações para o contexto do Sistema, eles não conferem a essa classe de informações um tratamento diferenciado, que torne explícito o contexto da Aplicação. Essa necessidade, evidenciada por Santos Júnior et al. (2001), é tratada neste trabalho, que classifica o contexto da Aplicação como parte do contexto do Sistema. 
As vantagens da abordagem proposta são: a organização estruturada dos tipos de contexto e a separação clara entre os contextos do Sistema e da Infra-Estrutura. Tais características facilitam o entendimento dos tipos de contexto e, conseqüentemente, facilitam a criação de representações para informações de contexto (tema explorado na seção 6.2).

\section{2}

Proposta para Representação de Contexto Conforme discutido na seção 5.4, um dos desafios da área de computação ubíqua é a representação das informações de contexto. Trabalhos anteriores apresentam limitações na estruturação das informações e na flexibilidade em compartilhá-las entre aplicações distintas.

Uma solução possível é a construção de esquemas de descrição usando padrões para representação semântica como MPEG-7, XML Schema ou RDF (Resource Description Framework) (W3C, 1999). Tais esquemas devem estruturar e organizar a modelagem de informações contextuais. Uma vez que os requisitos de contexto variam muito de aplicação para aplicação, acaba sendo difícil (ou talvez impossível) cobrir todas as possibilidades de uso de contexto. Contudo, de forma semelhante ao que fez o padrão MPEG-7, é possível criar um conjunto de esquemas que representem informações contextuais comuns a uma grande parcela de aplicações e, além disso, fornecer meios para que os projetistas criem (se necessário) suas próprias representações.

Nesse sentido, este trabalho propõe representar contexto por meio de um espaço de nomes XML que componha uma biblioteca extensível de elementos contextuais estruturados. A biblioteca é constituída por conjuntos de esquemas desenvolvidos em XML Schema. A escolha de XML Schema para implementar a biblioteca tem como objetivo facilitar a integração da mesma com as representações de programas e de objetos de mídia para TV Interativa (capítulo sete), os quais, por sua vez, foram também desenvolvidos utilizando XML Schema para facilitar a integração com o padrão MPEG-7. Vale lembrar que a linguagem de definição de dados do padrão MPEG-7 é a XML Schema estendida (subseção 4.2.2). 
As funcionalidades dos conjuntos de esquemas da biblioteca estão sumarizadas na Tabela 6.1, sendo as próximas subseções (de 6.2.1 a 6.2.3) dedicadas a explicar cada conjunto.

Tabela 6.1 - Funcionalidades dos elementos da biblioteca.

\begin{tabular}{|l|l|}
\hline Conjuntos de Esquemas & \multicolumn{1}{c|}{ Funcionalidade } \\
\hline \hline Elemento Raiz & Forma o topo da hierarquia para a representação de contexto. \\
\hline Tipos de Contexto & São representações de cada tipo de contexto. \\
\hline Contexto Primário & $\begin{array}{l}\text { É a representação do contexto primário, o qual é usado para } \\
\text { caracterizar as entidades contextuais. }\end{array}$ \\
\hline
\end{tabular}

\subsection{1 - Elemento Raiz}

O Elemento Raiz (Context, como ilustrado na Figura 6.2) é o elemento de nível mais alto na hierarquia proposta para representação de contexto, servindo de invólucro para os demais conjuntos de esquemas.

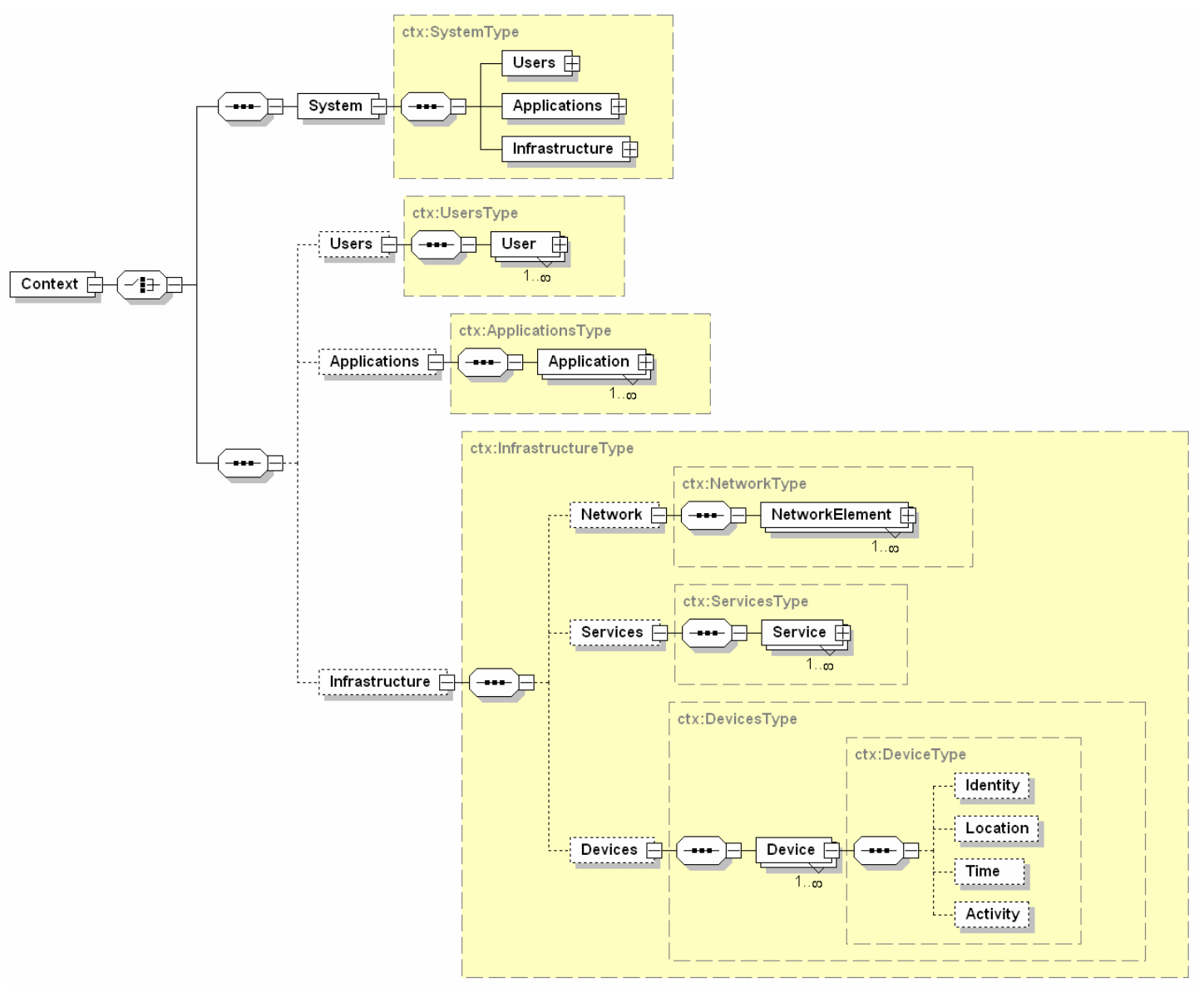

Figura 6.2 - Diagrama hierárquico do elemento raiz e sua relação com os elementos de contexto. 
Conforme ilustrado na Figura 6.2, a partir do elemento raiz são possíveis dois caminhos: o primeiro para descrever o contexto do Sistema (através do elemento <System>) e, o segundo, para descrever uma combinação qualquer dos contextos do Usuário (Users), da Aplicação (Applications) e da Infra-Estrutura (Infrastructure). Essa divisão na representação do modelo de organização, apresentado na seção 6.1 (Figura 6.1), é necessária porque uma representação direta daquele modelo fica limitada ao contexto do Sistema, excluindo aplicações (incluindo as já existentes) que utilizam apenas um tipo de contexto (o do Usuário, por exemplo).

A hierarquia de tipos do elemento raiz está ilustrada na Figura 6.3. O elemento raiz é uma extensão do tipo abstrato ContextType. Por sua vez, ContextType é uma generalização dos tipos SystemType, UsersType, ApplicationsType e InfrastructureType. Esses últimos formam o conjunto de esquemas Tipos de Contexto.

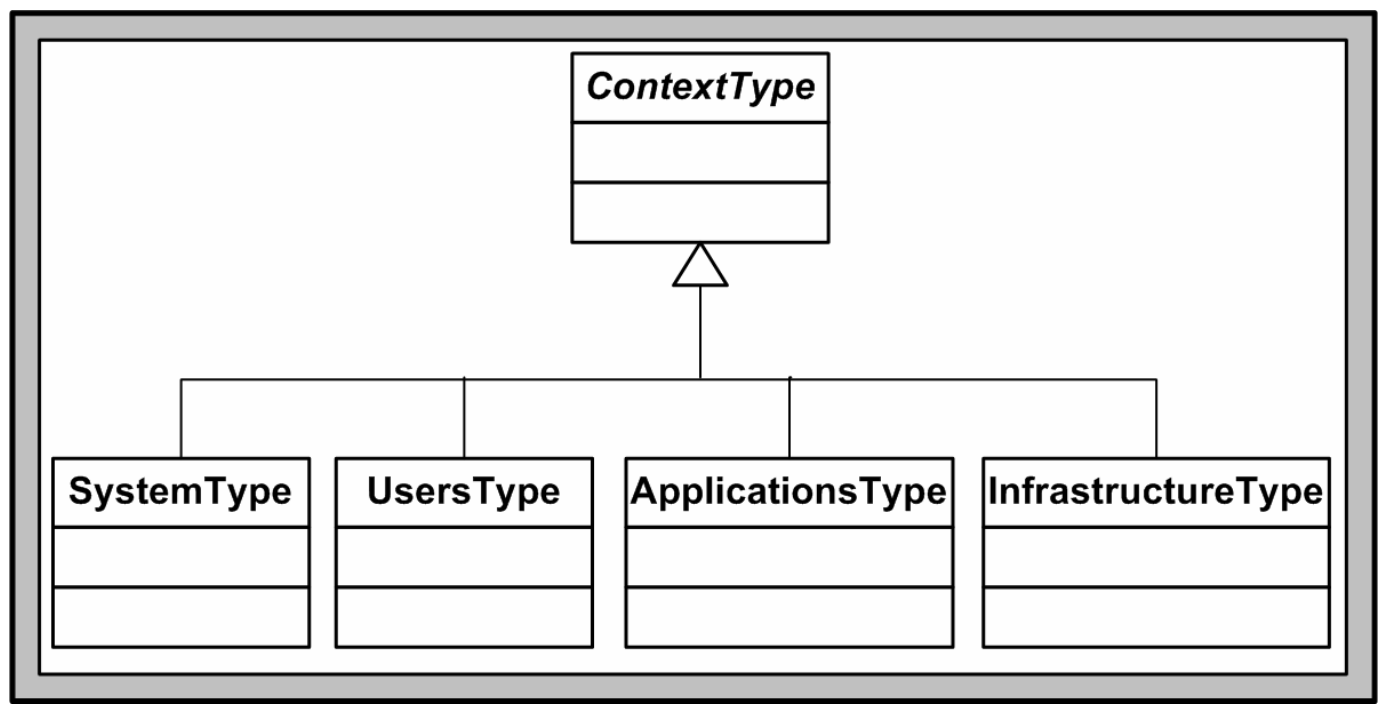

Figura 6.3 - Diagrama de classes UML para o tipo ContextType.

\subsection{2 - Conjunto de Esquemas Tipos de Contexto}

O conjunto de esquemas Tipos de Contexto representa os tipos de contexto Sistema, Usuário, Aplicação e Infra-Estrutura, segundo a organização discutida na seção 6.1. Segundo aquela organização, a representação do contexto da Infra-Estrutura se dá através da representação de seus componentes. Esses componentes representam conjuntos de entidades contextuais com características comuns. Por isso, foi criado o elemento <Infrastructure>, composto pelos 
elementos $<$ Network $>$, $<$ Service $>$ e $<$ Device $>$ (Figura 6.2). A hierarquia de tipos correspondentes está ilustrada na Figura 6.4.

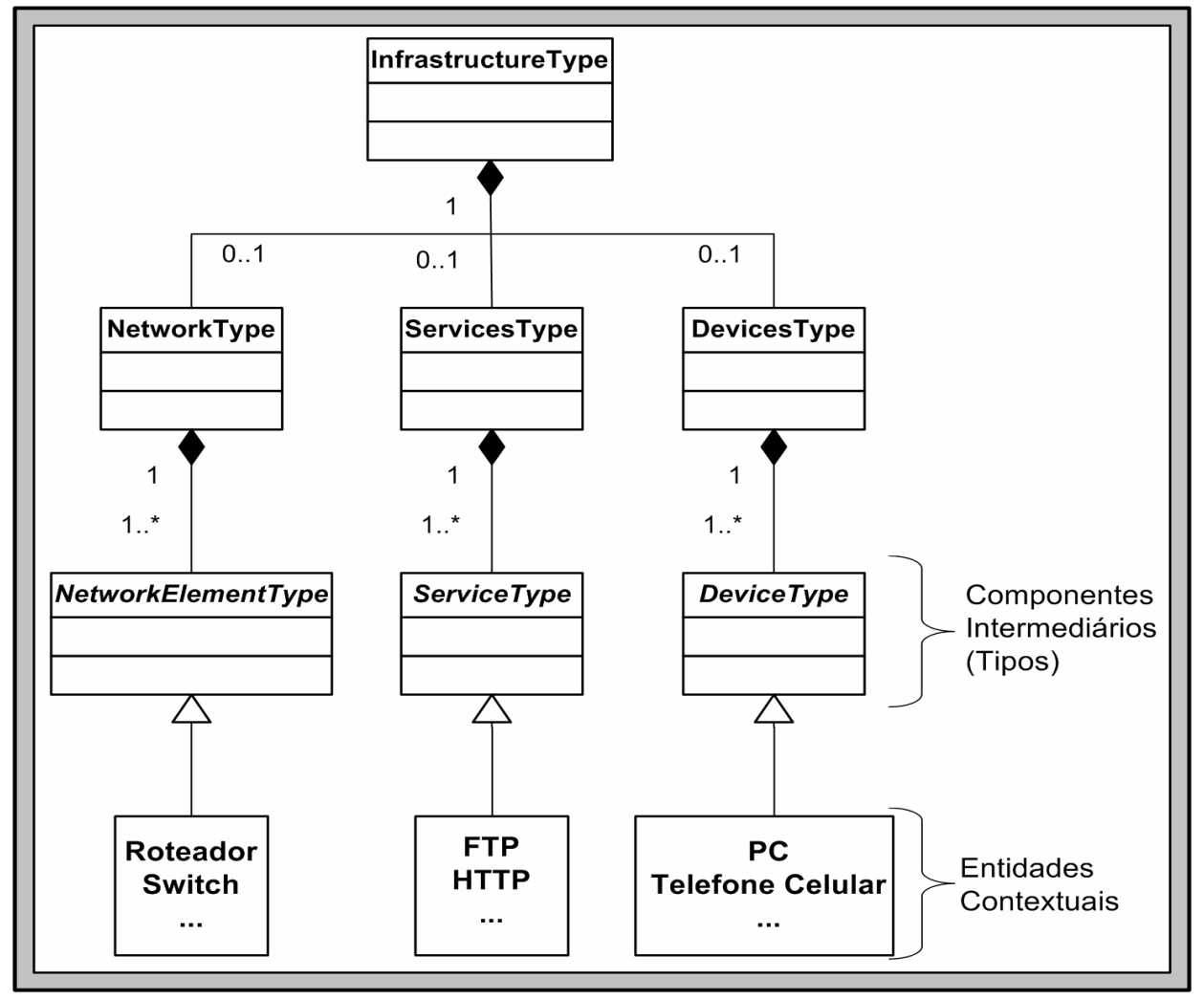

Figura 6.4 - Diagrama de Classes UML para o contexto da Infra-Estrutura (InfrastructureType).

$\mathrm{Na}$ representação dos componentes, o que se busca é um modo de representar uma entidade contextual específica classificando-a como pertencente a um dos componentes e, além disso, permitir que novas entidades sejam criadas pelos desenvolvedores. Por isso, cada componente foi implementado como sendo composto por um componente intermediário (Figura 6.4). A diferença entre um componente e seu respectivo componente intermediário é que o primeiro representa a classe, enquanto o segundo representa uma instância específica da classe. Por exemplo, na Figura 6.2 o elemento <Devices> representa todos os dispositivos que compõem a infra-estrutura, enquanto o elemento <Device> representa um dispositivo em particular. O mesmo acontece com os elementos < $<$ Network $>$ e <Services>. 
Os componentes intermediários são abstratos, servindo como generalizações para as entidades contextuais. A representação de uma entidade contextual é dada através da criação de um tipo que estenda o tipo abstrato apropriado. Por exemplo, a Figura 6.5 (a) ilustra o tipo LapTopType, o qual é derivado por extensão do tipo abstrato DeviceType (linha 4), criado para representar um novo dispositivo - um laptop. A instanciação de um dispositivo é feita através do elemento <Device>. Contudo, por ser de um tipo abstrato, <Device> não possui um tipo definido. Logo, é necessário indicar qual tipo implementa o elemento <Device> através do atributo XML xsi:type. No exemplo ilustrado na Figura 6.5 (b) (linha 3) tal tipo é LapTopType. O mesmo procedimento é usado para representar entidades contextuais pertencentes aos componentes Redes e Serviços.

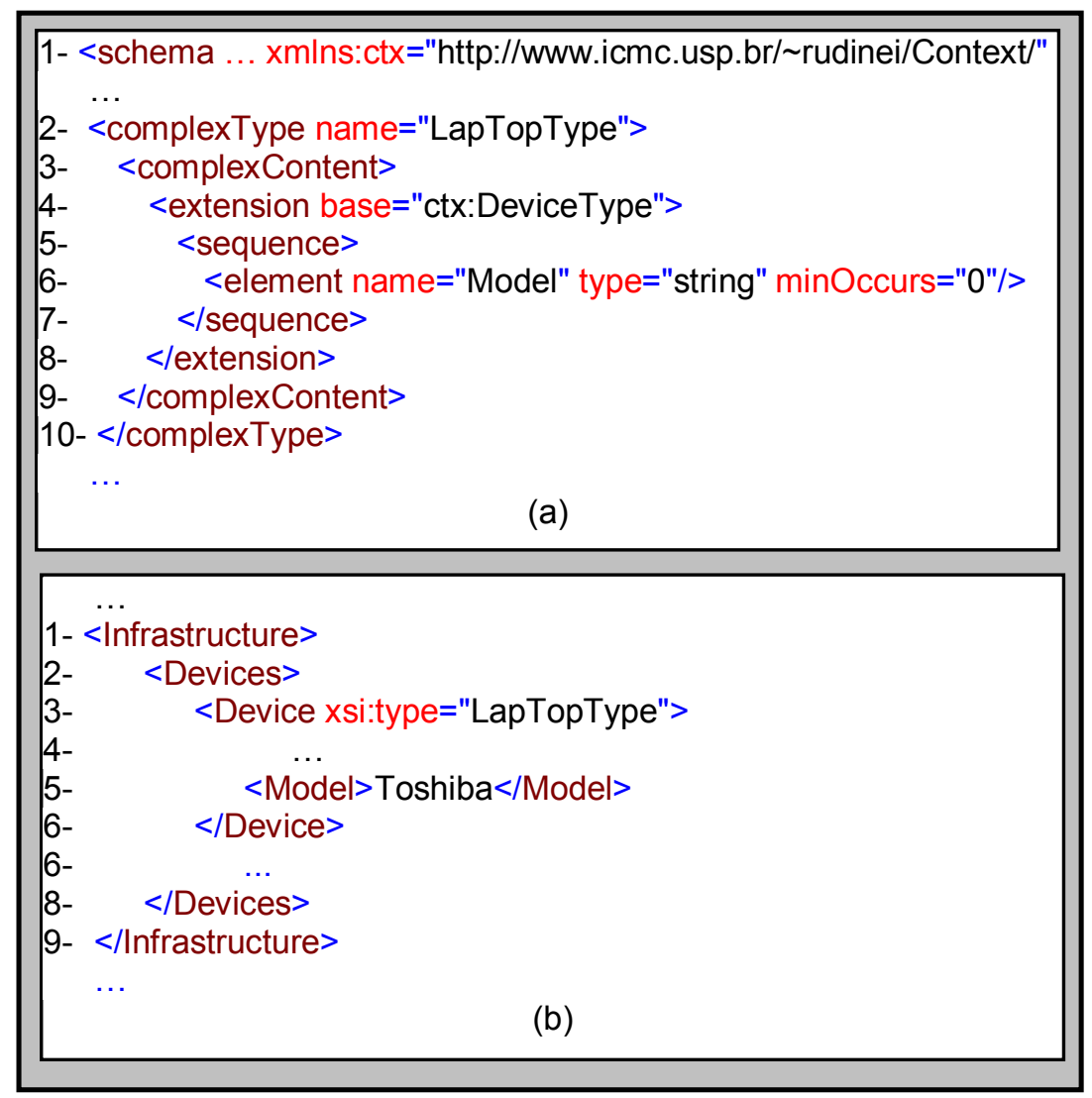

Figura 6.5 - (a) Tipo LapTopType representando um novo dispositivo. (b) Instância de um dispositivo do tipo LapTopType.

A biblioteca possui uma série de tipos representando entidades contextuais, comuns a um grande número de aplicações, para os três componentes do contexto da InfraEstrutura. Por outro lado, tipos específicos, não presentes na biblioteca, podem ser criados 
da maneira ilustrada na Figura 6.5, aproveitando-se do fato de os componentes intermediários serem abstratos. Mais ainda, o novo tipo não precisa estar no mesmo arquivo da biblioteca, bastando indicar o espaço de nomes da biblioteca de contexto, de onde o novo tipo importa os tipos e elementos de que necessita (conforme ilustrado na Figura 6.5 (a), linhas 1 e 4$)$.

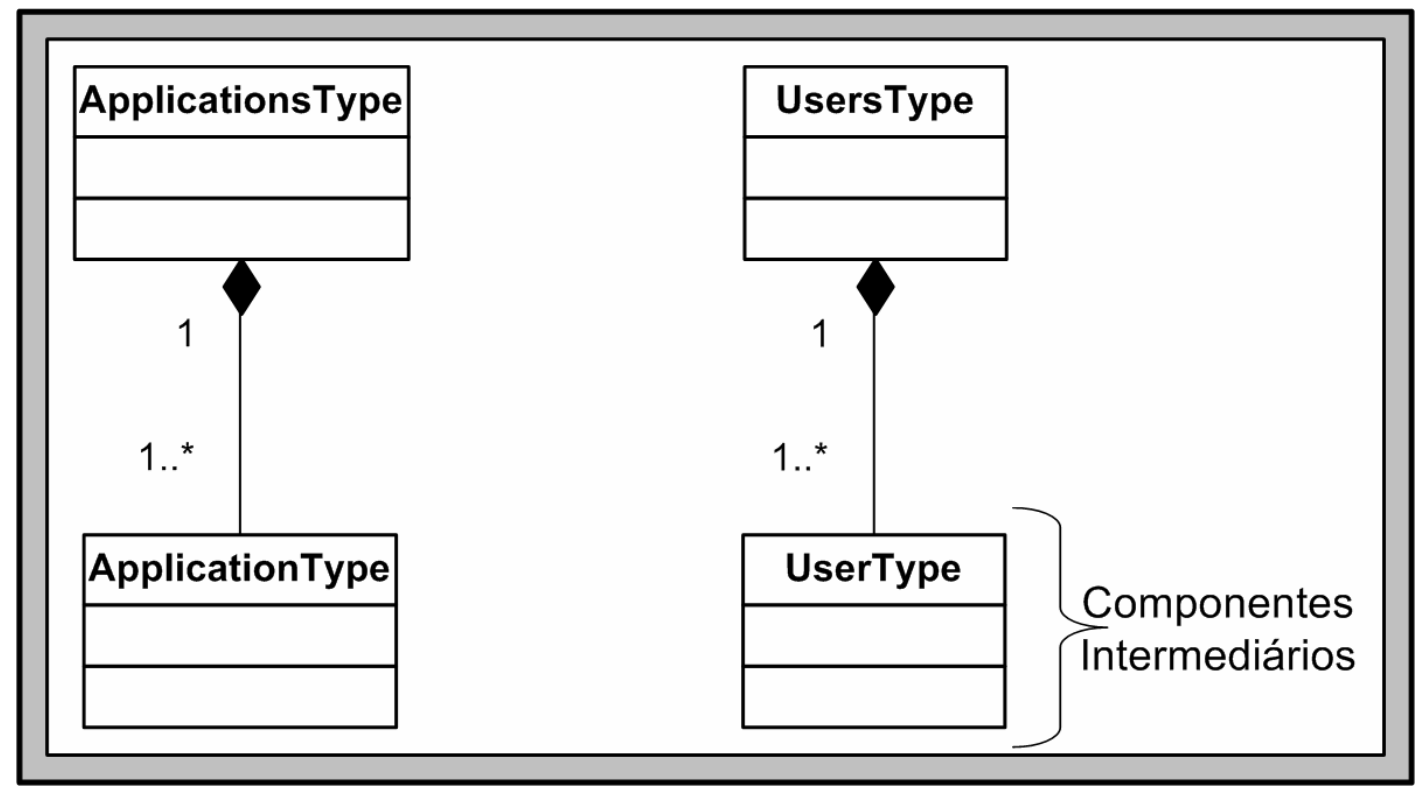

Figura 6.6 - Diagrama de Classes UML para os contextos da Aplicação (ApplicationsType) e do Usuário (UsersType).

A representação dos contextos da Aplicação e do Usuário é mais direta. Conforme ilustrado na Figura 6.6, também existem tipos representando uma classe de entidades (ApplicationsType e UsersType) e tipos representando componentes intermediários (ApplicationType e UserType). Porém, diferente dos tipos representando os componentes intermediários do contexto da Infra-Estrutura, ApplicationType e UserType não são abstratos. Esses tipos representam, diretamente, instâncias de entidades contextuais.

O contexto do Sistema é composto pelas representações dos contextos do Usuário, da Aplicação e da Infra-Estrutura. Logo, um tipo para representar o contexto do Sistema é uma composição dos tipos UsersType, ApplicationsType e InfrastructureType, conforme ilustrado na Figura 6.7. 


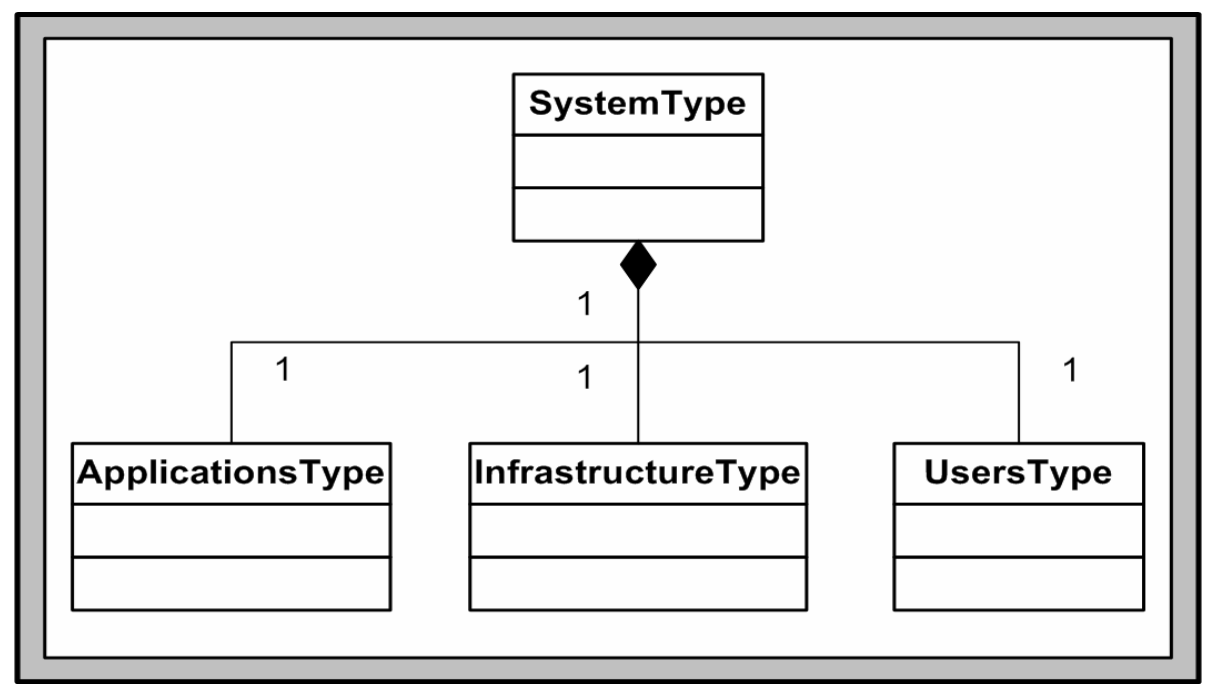

Figura 6.7 - Diagrama de classes UML para o contexto do Sistema (SystemType).

Até aqui foram discutidas as abstrações de alto nível que estruturam e organizam a descrição de contexto. A caracterização das entidades contextuais através das informações de contexto é explicada a seguir, na subseção 6.2.3.

\subsection{3 - Contexto Primário}

Segundo a definição de contexto apresentada na seção 5.1, a situação de uma entidade é caracterizada por um conjunto de informações de contexto. Tais informações podem ser indexadas através do contexto primário. A representação para o contexto primário, ilustrada na Figura 6.8, é dada através do tipo abstrato PrimaryContextType, o qual é composto pelos seguintes tipos abstratos: IdentityType, LocationType, TimeType e ActivityType. Esses últimos representam, respectivamente, os tipos primários de informação de contexto identidade, localização, tempo e atividade.

As informações de contexto são representadas por meio de tipos derivados dos componentes de PrimaryContextType. A biblioteca fornece um conjunto pré-definido de informações de contexto. Contudo, uma vez que os componentes de PrimaryContextType são abstratos, desenvolvedores podem criar informações de contexto específicas, utilizando o mesmo método explicado na subseção 6.2.2 para criar entidades contextuais específicas. 


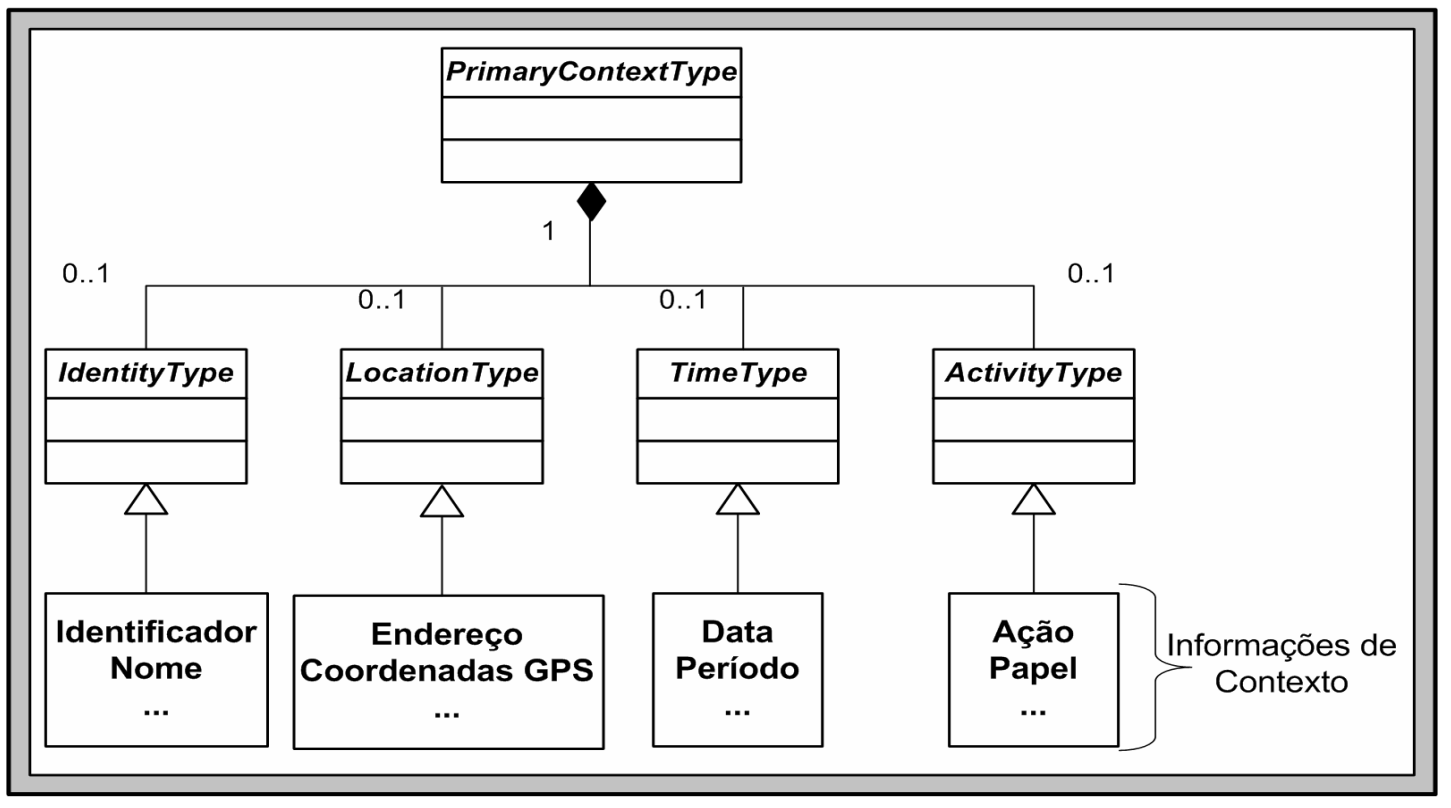

Figura 6.8 - Diagrama de classes UML representando o contexto Primário (PrimaryContextType).

Todos os componentes intermediários são tipos derivados (por extensão) de PrimaryContextType. Isso implica que qualquer entidade contextual automaticamente herda o contexto primário, o qual possibilita a utilização das informações de contexto para caracterizar a situação da entidade. Por exemplo, a Figura 6.9 ilustra uma instância válida para o tipo LapTopType (apresentado na subseção 6.2.2, Figura 6.5). Esse tipo contém apenas o elemento <Model $>$.

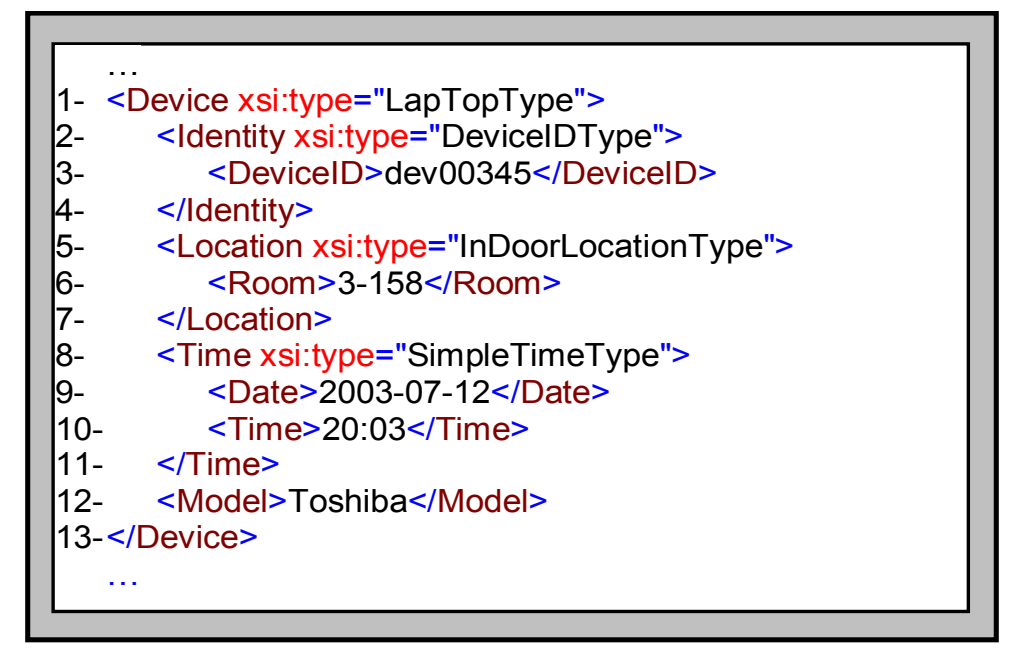

Figura 6.9 - Instância válida para o tipo LapTopType.

Contudo, como é um tipo derivado de DeviceType, que é um componente intermediário, herda os elementos <Identitys, <Location>, <Time> e <Activity $>$ do contexto 
primário $^{10}$. Esses elementos são opcionais (por isso <Activity> não aparece na Figura 6.9) e a partir deles as representações para informações de contexto podem ser utilizadas.

\subsection{4 - Tipos para Informações de Contexto}

A representação das informações de contexto é feita através da criação de tipos XML, os quais podem ser simples ou compostos. Os tipos simples são declarações de esquemas XML para representar informações contextuais atômicas.

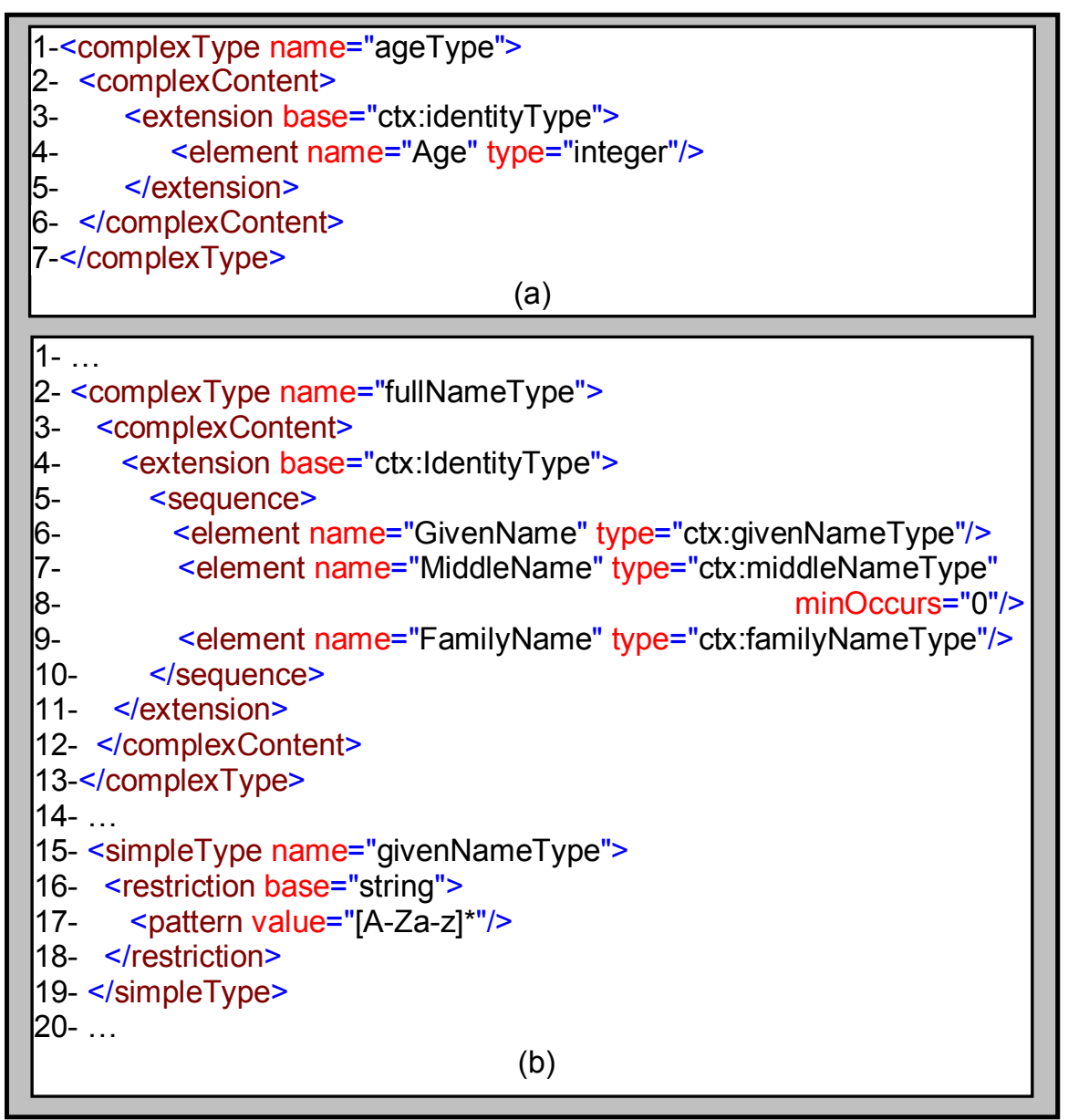

Figura 6.10 - Exemplos de tipos representando informações de contexto, (a) um tipo simples e (b) um tipo composto.

Por exemplo, a representação de "idade", ilustrada na Figura 6.10 (a) pelo tipo ageType e pelo elemento <Age> do tipo integer (linha 4). Os tipos compostos são declarações de esquemas XML para representar informações contextuais compostas por outras

${ }^{10}$ Uma entidade contextual deve ser criada através da extensão de um componente intermediário. 
informações. Por exemplo, a representação para "nome", ilustrada na Figura 6.10 (b) pelo tipo fullNameType e seus quatro elementos. Nesse caso, um "nome" é composto por um nome próprio (<GivenName>), um nome do meio opcional (<MiddleName>) e nome de família (<FamilyName $>$ ). Tais elementos podem ser de tipos XML primitivos (como integer e string), tipos simples como givenNameType (Figura 6.10 (b), linha 15), ou tipos compostos.

Os tipos representando informações de contexto devem estender um dos componentes do contexto primário (identityType, locationType, timeType e activityType), classificando o tipo dentro da hierarquia de contexto.

Para caracterizar a situação de uma entidade contextual, durante uma instanciação, o desenvolvedor deve utilizar os componentes do contexto primário. A decisão de implementar tais componentes como tipos abstratos (não possuem um tipo definido) representa uma vantagem: o desenvolvedor tem a liberdade de selecionar da biblioteca os tipos representando as informações de contexto que melhor caracterizam a situação da entidade. Para isto deve-se indicar qual tipo implementa o componente através do atributo XML xsi:type, do mesmo modo explicado na subseção 6.2.2 para instanciar entidades contextuais.

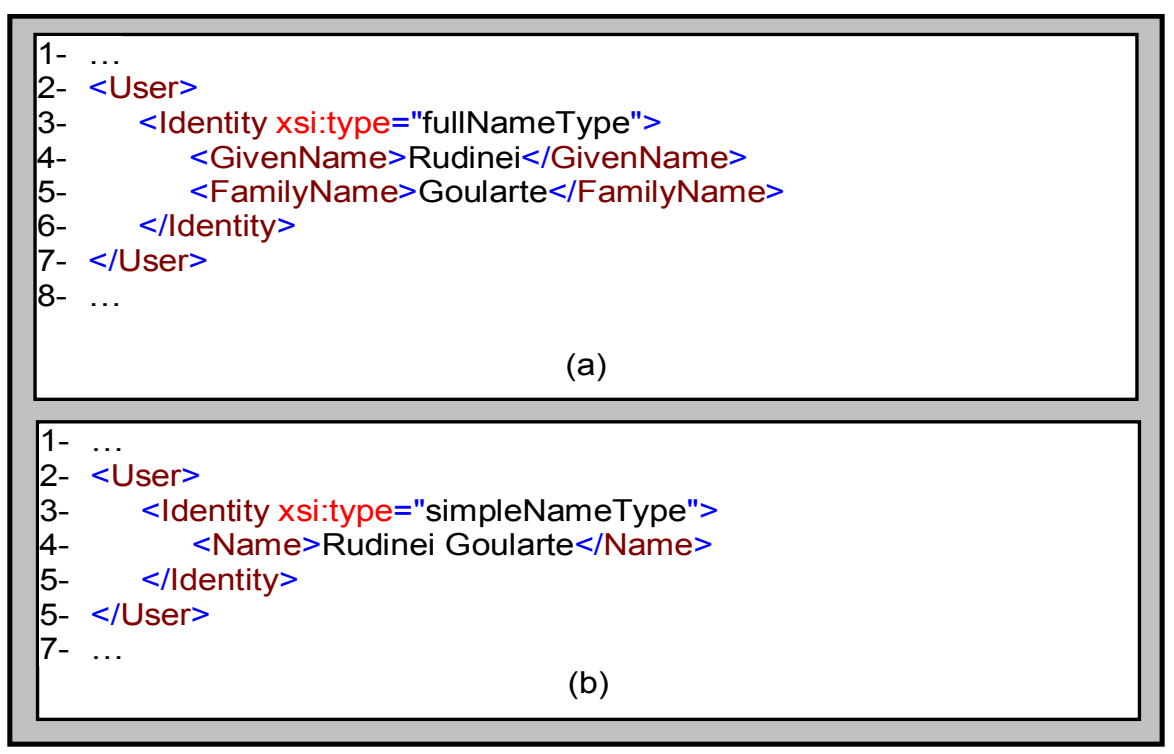

Figura 6.11 - Exemplos de instâncias de tipos diferentes para um componente de contexto Primário, (a) fullNameType e (b) simpleNameType.

A Figura 6.11 ilustra dois modos possíveis de caracterizar a identidade de um usuário. Em (a) o componente <Identity> é implementado através do tipo fullNameType (linha 3), e em (b) através do tipo simpleNameType (linha 3). 
A biblioteca possui um conjunto de elementos pré-definidos para cada componente do contexto primário, permitindo a criação de variadas hierarquias para um mesmo tipo de informação contextual. Por exemplo, um "nome" pode ser representado por um tipo simples, contendo um elemento do tipo string, ou pode ser representado por um tipo composto, como no caso do tipo fullNameType ilustrado na Figura 6.10. A tarefa do desenvolvedor fica facilitada no sentido de que ele não mais necessita projetar e implementar a representação para "nome". Ele apenas deve decidir o quanto de informação é necessário para representar "nome". Dessa forma nota-se o surgimento de uma nova dimensão - o quanto (How Much). Deve-se deixar claro que o uso dessa dimensão na biblioteca é implícito.

Tabela 6.2 - MPEG-7 e representações de informações de contexto.

\begin{tabular}{|c|c|c|c|}
\hline \multirow{2}{*}{$\begin{array}{l}\text { Contexto } \\
\text { Primário } \\
\end{array}$} & \multicolumn{3}{|c|}{ Tipos de Contexto } \\
\hline & Usuário & Infra-Estrutura & Aplicação \\
\hline Identidade & $\begin{array}{l}\text { Preferências e Histórico } \\
\text { MPEG-7 são adequa- } \\
\text { dos. Identificação do } \\
\text { usuário apenas pelo } \\
\text { nome. Representação } \\
\text { para nomes não é es- } \\
\text { truturada. }\end{array}$ & $\begin{array}{l}\text { Preferências e Histórico } \\
\text { MPEG-7 não são ade- } \\
\text { quados. São neces- } \\
\text { sárias abstrações para } \\
\text { identificar serviços, dis- } \\
\text { positivos e redes. }\end{array}$ & $\begin{array}{l}\text { Preferências e Histórico } \\
\text { MPEG-7 não são ade- } \\
\text { quados. São necessárias } \\
\text { abstrações para identificar } \\
\text { aplicações e formas de } \\
\text { relacioná-las a serviços. }\end{array}$ \\
\hline Localização & $\begin{array}{l}\text { Representações MPEG- } \\
7 \text { para localização são } \\
\text { pouco estruturadas. }\end{array}$ & $\begin{array}{l}\text { MPEG-7 não possui } \\
\text { abstrações para repre- } \\
\text { sentar a localização de } \\
\text { serviços e de elementos } \\
\text { de rede. }\end{array}$ & 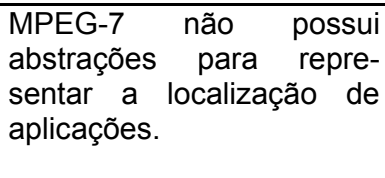 \\
\hline Tempo & $\begin{array}{l}\text { MPEG-7 não representa } \\
\text { datas. Representações } \\
\text { de intervalos de tempo } \\
\text { apenas para horas. } \\
\text { São necessárias abs- } \\
\text { trações para repre- } \\
\text { sentar períodos de tem- } \\
\text { po diários, semanais, } \\
\text { intercalados, etc. }\end{array}$ & $\begin{array}{lrr}\text { MPEG-7 } & \text { não } & \text { possui } \\
\text { representações } & \text { para } \\
\text { datas nem } & \text { para } \\
\text { intervalos de tempo. }\end{array}$ & $\begin{array}{l}\text { MPEG-7 não possui } \\
\text { representações para datas } \\
\text { nem para intervalos de } \\
\text { tempo. }\end{array}$ \\
\hline Atividade & $\begin{array}{l}\text { MPEG-7 representa } \\
\text { apenas ações relacio- } \\
\text { nadas a acessos a con- } \\
\text { teúdo multimídia. }\end{array}$ & $\begin{array}{l}\text { MPEG-7 não possui } \\
\text { abstrações para repre- } \\
\text { sentar a atividade de } \\
\text { serviços e dispositivos. }\end{array}$ & $\begin{array}{llr}\text { MPEG-7 } & \text { não } & \text { possui } \\
\text { abstrações } & \text { para } & \text { repre- } \\
\text { sentar a atividade } & \text { de } \\
\text { aplicações. } & & \\
\end{array}$ \\
\hline
\end{tabular}

O padrão MPEG-7 possui alguns tipos (descritores na terminologia MPEG-7) que podem ser aproveitados como representações contextuais. Contudo, MPEG-7 foi projetado para descrever conteúdo multimídia. A Tabela 6.2 resume os principais tipos de informações contextuais, em cada tipo de contexto, que MPEG-7 não contempla. 
Por outro lado, a utilização criteriosa de algumas representações MPEG-7 na biblioteca de contexto pode ajudar a manter a compatibilidade entre descrições compartilhadas por diferentes aplicações. Por exemplo, provedores de conteúdo utilizam diversos tipos de descrições de programas, de mídias e de preferências do usuário. Dentre essas, estão esquemas de descrição MPEG-7 para histórico de acesso. Um histórico pode ser usado para embutir comerciais direcionados na programação personalizada do usuário. O mesmo histórico pode ser usado por provedores de acesso para descobrir os horários de pico e determinar políticas de gerenciamento de tráfego.

$\mathrm{Na}$ versão da biblioteca desenvolvida neste trabalho foram incluídos alguns descritores MPEG-7, como preferências do usuário (UserPreferencesType) e histórico de uso (UsageHistoryType). A Tabela 6.3 mostra alguns tipos presentes na biblioteca. Uma lista completa pode ser consultada no Apêndice A.

Tabela 6.3 - Exemplos de tipos de informações contextuais presentes na biblioteca.

\begin{tabular}{|c|c|c|}
\hline $\begin{array}{l}\text { Contexto } \\
\text { Primário }\end{array}$ & Tipos Compostos & Tipos Simples \\
\hline \multirow{5}{*}{ Identidade } & & $\begin{array}{l}\text { userIDType, devicelDType, roleType, } \\
\text { simpleNameType. }\end{array}$ \\
\hline & fullNameType & $\begin{array}{l}\text { givenNameType, middleNameType, } \\
\text { familyNameType. }\end{array}$ \\
\hline & personallnformationType & $\begin{array}{l}\text { ageType, heightType, weightType, eyesType, } \\
\text { hairType, birthDateType. }\end{array}$ \\
\hline & $\begin{array}{l}\text { UserPreferencesType } \\
\text { (MPEG-7) }\end{array}$ & \\
\hline & $\begin{array}{l}\text { UsageHistoryType } \\
\text { (MPEG-7) }\end{array}$ & \\
\hline \multirow{3}{*}{ Localização } & inDoorLocationType & $\begin{array}{l}\text { floorType, roomType, corridorType, gateType, } \\
\text { exitType. }\end{array}$ \\
\hline & postalAddressType & $\begin{array}{l}\text { streetType, streetNumberType, stateType, } \\
\text { countryType, zipCodeType. }\end{array}$ \\
\hline & electronicLocationType & $\begin{array}{l}\text { urlType, emailType, phoneType, icqType, } \\
\text { pathType. }\end{array}$ \\
\hline Tempo & & $\begin{array}{l}\text { occasionType, dateType, simpleTimeType, } \\
\text { durationType. }\end{array}$ \\
\hline Atividade & & actionType. \\
\hline
\end{tabular}

\section{3}

\section{Considerações Finais}

Este capítulo apresentou uma proposta para organizar e estruturar informações de contexto. A abordagem proposta tem como vantagens: 
- Uma classificação dos tipos de contexto.

- A construção de estruturas de alto nível que organizam a descrição de contexto.

- Permite a criação estruturada de uma biblioteca de informações contextuais.

- Facilita a tarefa de desenvolvedores em projetar aplicações cientes de contexto. Utilizando uma biblioteca o desenvolvedor não necessita projetar representações de informações contextuais; ele apenas decide o quanto de informação é necessário para caracterizar uma entidade contextual.

- Permite aos desenvolvedores criarem suas próprias representações para entidades contextuais e para informações de contexto.

- Facilita desenvolver representações para os contextos do Ambiente e do Domínio e integrá-las às representações desenvolvidas neste trabalho.

A biblioteca ainda não está completa. Neste trabalho foram exploradas características das preferências do usuário, da descrição de dispositivos e da situação da rede. O objetivo, em um primeiro momento, é viabilizar o desenvolvimento de um serviço de personalização de conteúdo demonstrando o uso e a importância das informações de contexto. A construção de modelos completos para a representação de informações para cada dimensão do contexto primário, em cada tipo de contexto, fica como trabalho futuro.

As representações para o contexto da Aplicação e para o componente Serviços do contexto da Infra-Estrutura também ficam como trabalhos futuros. Essas representações serão importantes em uma etapa posterior do projeto de protótipo de TV Interativa, quando se pretende explorar as interações entre aplicações e o sistema.

Os esquemas para representação de contexto apresentados neste capítulo são importados pelos esquemas de representação de programas de TV Interativa e pelos esquemas de representação de objetos de mídia, ambos a serem apresentados no capítulo sete. Com isso, consegue-se um modo de fornecer suporte à ciência de contexto para os serviços do protótipo de TV Interativa, alcançando-se um dos objetivos deste projeto. 
Capítulo

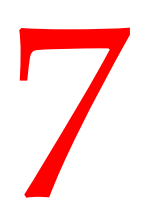

\section{Descrição de}

Objetos de Mídia 


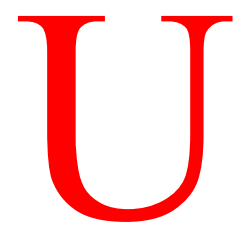

M dos objetivos deste trabalho é explorar informações de contexto para, em conjunto com as características de interatividade oferecidas pelo padrão MPEG-4 (capítulo três), potencializar o desenvolvimento de serviços avançados em TV Interativa. Exemplos desses serviços são: geração e adaptação automática de conteúdo personalizado, sugestão em tempo real de conteúdo relacionado ao que o usuário está assistindo ou interagindo, busca baseada em objetos e navegação baseada em segmentos.

Esses tipos de serviços necessitam que objetos multimídia (vídeo, por exemplo) possam ser segmentados em subobjetos e necessitam de documentos que descrevam os programas e objetos componentes dos programas (Merialdo et al., 1999; TV-Anytime, 2002). Essas descrições incluem: composição estrutural, características da mídia (como tamanho e método de codificação), informações de índice (como autor e data de criação), ligações e relacionamentos entre objetos e programas e informações de contexto (como posição de um objeto em relação à tela, local onde a cena acontece, quem está na cena e quando ocorre a atividade mostrada na cena) (Santos Júnior et al., 2001; Goularte \& Moreira, 2002; Goularte \& Moreira, 2003).

A decomposição de objetos de mídia em subobjetos é completamente suportada pelo padrão MPEG-4. Contudo, os métodos encontrados na literatura, como em Benetiz et al. (2000), Dublin Core (2003) e Lagoze \& Hunter (2001), para descrever objetos de mídia apresentam alguns problemas em suportar as características supracitadas. A maioria das abordagens anteriores sobre descrição de conteúdo multimídia foi absorvida e melhorada pelo padrão MPEG-7 (capítulo quatro). Todavia, a despeito do poder desse padrão, o uso direto dos esquemas de descrição MPEG-7 pode gerar documentos desnecessariamente complexos. Além disso, o suporte a descrições contextuais em MPEG-7 é limitado a anotações textuais livres pobremente estruturadas.

O problema de como produzir documentos específicos para a área de TV Interativa foi abordado em trabalhos anteriores (Boll et al., 1999; Chorianopoulos et al., 2003; Cosmas et al., 1999; Hu \& Ye, 1999; Merialdo et al., 1999; Hjelsvold et al., 2001; Tsinaraki et al., 2001). A maioria desses trabalhos falha em fornecer uma combinação 
adequada de representações estruturais e de metadados tanto para programas quanto para objetos de mídia. Uma exceção importante é o trabalho sendo desenvolvido pelo TVAnytime Forum (capítulo dois). Contudo, as especificações TV-Anytime não fornecem suporte estruturado a contexto e não fornecem meios de produzir documentos descrevendo objetos de mídia e programas de modo independente uns dos outros, dificultando a reutilização desses documentos. Além disso, o modo com que o TV-Anytime usa o padrão MPEG-7 para descrever objetos de mídia não permite descrever objetos intraquadro (TVAnytime, 2002).

Outro problema relacionado com documentos para TV Interativa é como fazer ligações entre descrições de programas e seus objetos componentes. A solução TVAnytime cria um URI (TV-Anytime, 2003) que aponta para um único e grande objeto representando o programa (um vídeo na maioria das vezes). A ligação é feita colocando esse URI nas descrições dos programas e nos guias de programação. Nessa abordagem a segmentação de programas em seqüências, cenas e quadros é feita apenas de modo lógico, por meio das descrições de mídia MPEG-7 dos programas. Isso dificulta a reutilização dos segmentos e de descrições relacionadas na composição de novos programas.

A utilização conjunta dos padrões MPEG-4 e MPEG-7 permite: segmentar fisicamente os programas em objetos de mídia (seqüências, cenas, quadros e objetos intraquadro), descrever a segmentação e a composição dos objetos e descrever as características de cada objeto. Essa abordagem abre diversas oportunidades de desenvolvimento de serviços multimídia interativos (Nack \& Lindsay, 1999). Contudo, até o momento em que esta tese estava sendo escrita, os comitês ainda não haviam padronizado um modo de ligar conteúdo MPEG-4 à sua descrição MPEG-7 relacionada.

Tendo em vista o cenário exposto e a utilização das descrições de programas (e de seus correspondentes objetos de mídia) no desenvolvimento de serviços para o projeto de protótipo de TV Interativa, este capítulo propõe um esquema para organizar e estruturar documentos contendo descrições de objetos de mídia componentes de programas de TV Interativa. Tal esquema representa uma contribuição original deste trabalho.

O esquema proposto, encapsulado em um invólucro MPEG-7, fornece suporte a: representação de informações contextuais, separação entre descrições de programas e descrições de objetos de mídia, descrições de objetos intraquadro e representação das 
ligações entre objetos de mídia e suas descrições. O esquema abstrai mídias em objetos, sendo as características particulares de cada objeto descritas por meio de esquemas MPEG7 cuidadosamente selecionados, reduzindo a complexidade da descrição. O invólucro, o esquema desenvolvido e os esquemas MPEG-7 selecionados são integrados utilizando-se a DDL MPEG-7, tornando essa proposta compatível com o padrão MPEG-7.

Este capítulo está estruturado do seguinte modo: a seção 7.1 resume a representação de programas utilizada no trabalho, a qual é fruto de trabalhos anteriores do grupo. A seção 7.2 apresenta em detalhes o esquema para representação de objetos de mídia proposto neste trabalho, mostrando como as descrições podem ser separadas e como as ligações entre objetos e programas podem ser representadas. A seção 7.3 apresenta algumas considerações finais a respeito dos esquemas discutidos neste capítulo.

\section{$\underline{7.1}$}

Representação de Programas

A representação dos programas de TV Interativa, utilizada nesta tese, está baseada no trabalho de Faria (2001; Faria et al., 2001). Esse trabalho propôs um modo para descrever programas e para compor perfis de programas, permitindo um maior grau de adaptabilidade do conteúdo ao usuário, assim como uma definição mais apurada do público-alvo por parte dos provedores de serviço e de conteúdo. Isso é feito criando-se perfis diferentes de um mesmo programa para atender a diferentes interesses.

A Figura 7.1 ilustra a utilização do conceito de perfis em um programa composto por diversos tipos de objetos de mídia (quatro vídeos, três áudios e duas figuras). Os objetos contêm diferentes versões do mesmo conteúdo, por exemplo, diferentes ângulos de câmera para os vídeos e diferentes linguagens para o áudio. Os perfis contêm diferentes conjuntos dos objetos componentes do programa, permitindo que diferentes usuários tenham diferentes visões do mesmo programa. Por exemplo, uma vez que os usuários 1 e 4 têm acesso ao perfil 3 eles podem assistir ao vídeo 4. Do mesmo modo, apenas os usuários com acesso ao perfil 1 podem assistir ao vídeo 3 (usuários 1 e 2). 


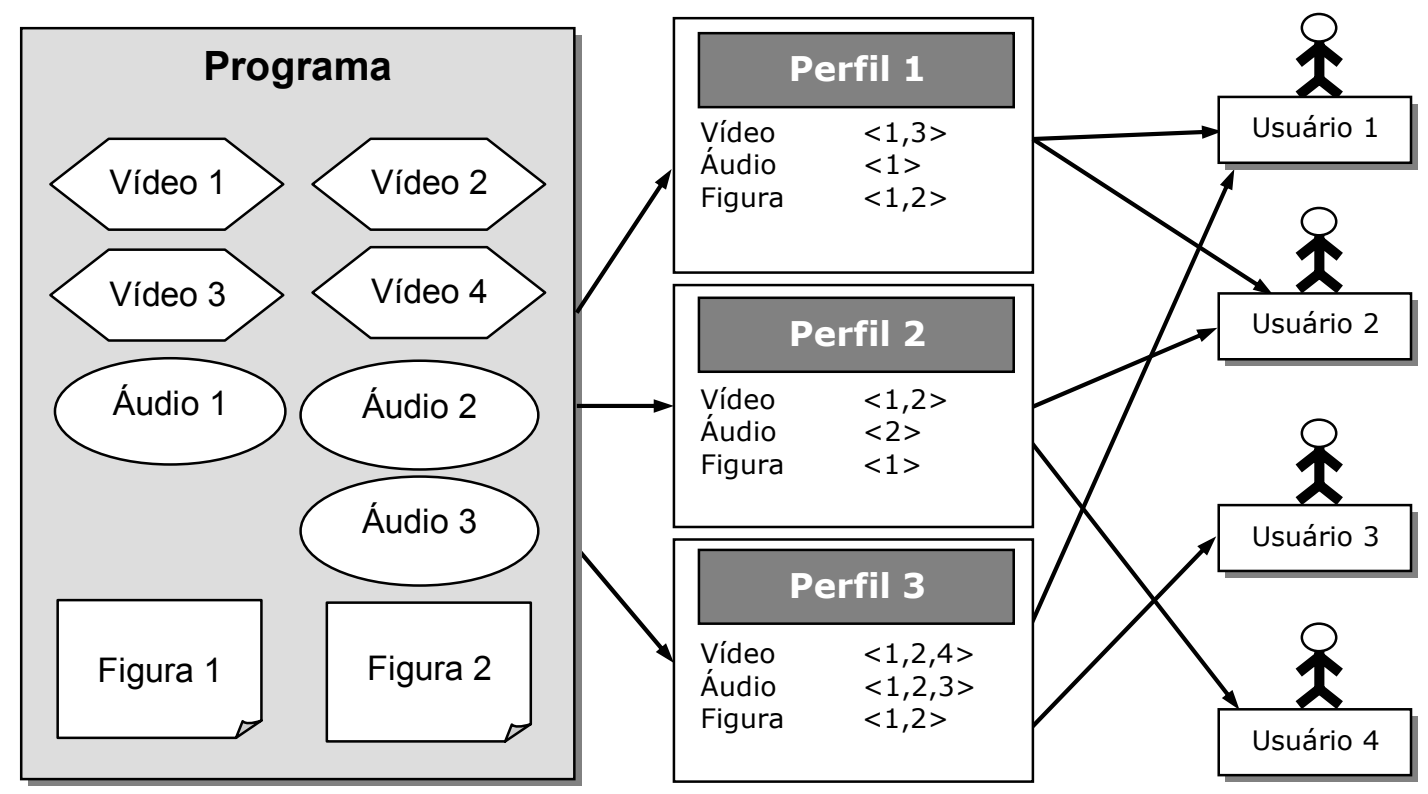

Figura 7.1 - Composição de perfis de programas.

Os esquemas desenvolvidos por Faria utilizam os esquemas do TV-Anytime para representar programas, não contemplando a separação entre descrições de programas e descrições de objetos. Assim, este trabalho reestruturou àqueles esquemas de modo a apenas indicar quais objetos compõem um programa. A Figura 7.2 ilustra uma representação UML do esquema reestruturado (ITV_Program).

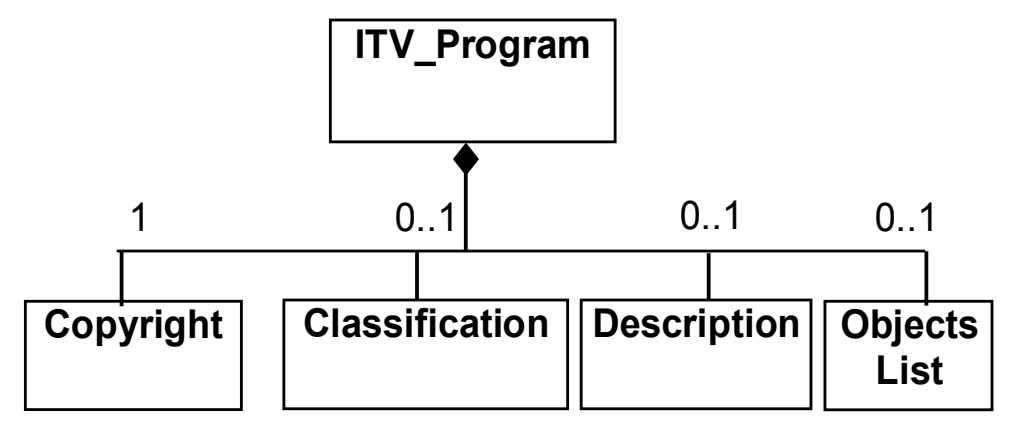

Figura 7.2 - Diagrama UML do esquema ITV-Program.

O esquema ITV_Program importa do esquema TV-Anytime os tipos CopyrightNotice, ClassificationSchemeTableType e ProgramDescriptionType, os quais são, respectivamente, os tipos dos elementos <Copyright $>$, <Classification $>$ e $<$ Description $>$ ilustrados na Figura 7.2. O elemento $<$ ObjectsLists> foi implementado para conter apenas as ligações entre o programa e todos os 
seus objetos componentes. O modo como essas ligações são feitas será explicado na subseção 7.2.3.

\section{2}

\section{Representação de Objetos de Mídia}

O esquema desenvolvido neste trabalho para representar objetos de mídia - MediaObject possui os seguintes objetivos: descrever objetos de mídia (como vídeo, áudio, imagem e objetos intraquadro), estabelecer a ligação entre descrições de objetos e a descrição de um programa, descrever as relações entre os objetos, fornecer suporte para a ligação entre um objeto e sua descrição e fornecer suporte a descrições contextuais.

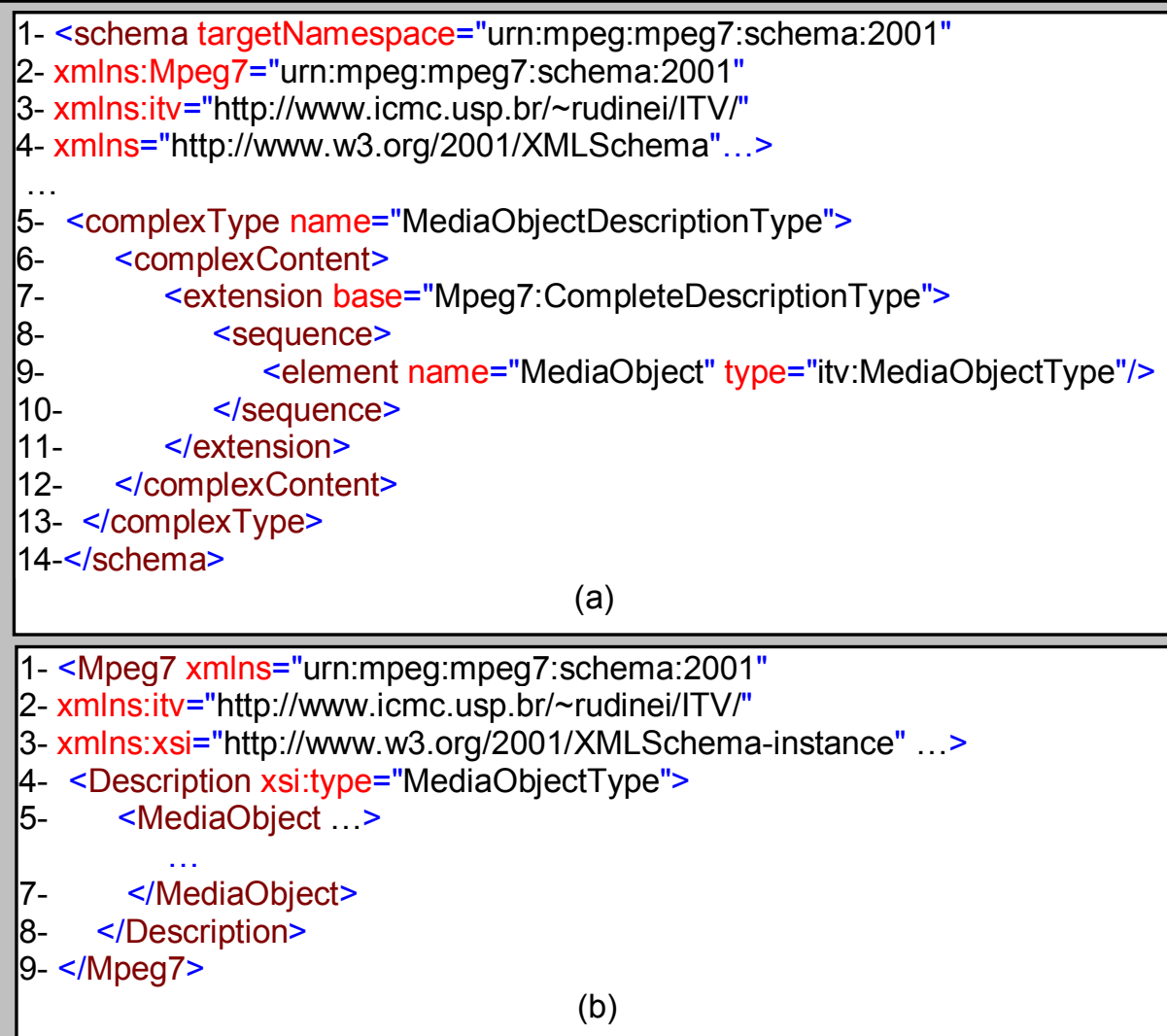

Figura 7.3 - (a) Elemento <MediaObject> como extensão do MPEG-7. (b) Uma instância do esquema MediaObject.

Para ser compatível com o padrão MPEG-7 um esquema necessita ser definido como uma extensão de uma das ferramentas de alto nível MPEG-7. Utilizando a DDL 
MPEG-7 definiu-se o tipo MediaObjectDescriptionType (Figura 7.3 (a), linha 5), o qual é derivado por extensão (linha 7) do tipo MPEG-7 CompleteDescriptionType (seção 4.3). O tipo MediaObjectDescriptionType serve de invólucro para o elemento <MediaObject>, cujo tipo (MediaObjectType) implementa o esquema MediaObject. Em tempo, os tipos CompleteDescriptionType e MediaObjectType estão definidos em outros espaços de nomes. Os atributos qualificadores Mpeg7 e itv, definidos conforme ilustrado na Figura 7.3 (a) (linhas 2 e 3), identificam a que espaço de nomes os tipos em questão pertencem (linhas 7 e 9).

Definido desse modo o esquema MediaObject passa a ser um tipo para descrição completa MPEG-7 definido pelo usuário (ver subseção 4.3.3). Para instanciá-lo é necessário, primeiro, instanciar o elemento raiz MPEG-7, como ilustrado na Figura 7.3 (b) (linha 1). Além disso, é necessário indicar qual tipo implementa a descrição completa. No exemplo da Figura 7.3 (b) (linha 4) esse tipo é MediaObjectType.

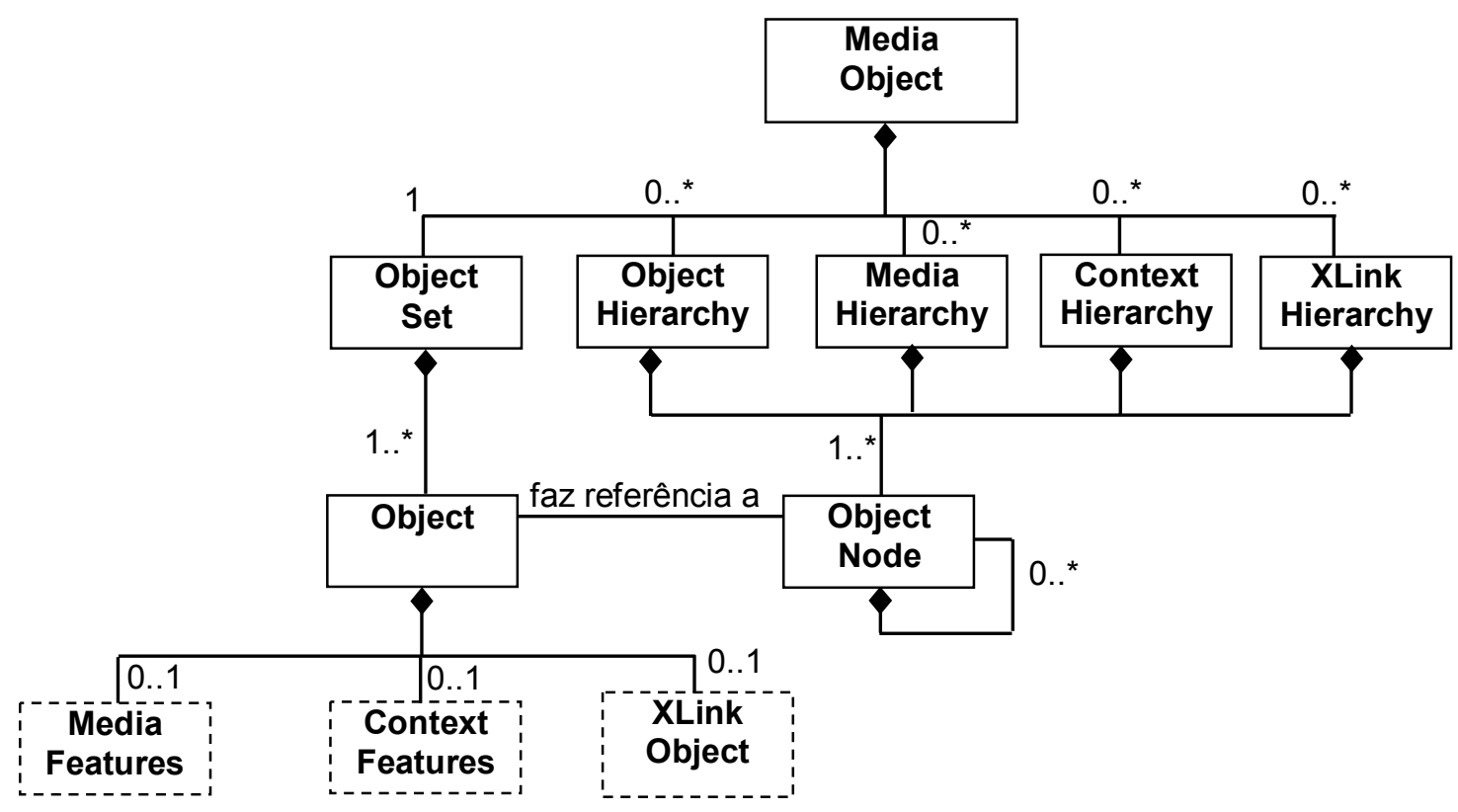

Figura 7.4 - Diagrama UML do esquema MediaObject.

A Figura 7.4 ilustra uma representação gráfica do esquema de descrição MediaObject usando notação UML. O elemento <MediaObject> representa um objeto de mídia, que pode ser um objeto único ou pode ser composto por diversos segmentos. O conjunto de todos os segmentos que compõem um objeto de mídia é representado pelo elemento <ObjectSet>. A estrutura da composição dos objetos é representada pelo elemento <ObjectHierarchy>, o qual 
utiliza elementos <ObjectNode> para criar hierarquias e fazer referências aos objetos. Essa organização estrutural é baseada na abordagem em hierarquias proposta por Benitez et al. (2000). Usar hierarquia explicitamente em um esquema de descrição tem as seguintes vantagens (Benitez et al., 2000): é uma estrutura mais eficiente para recuperação do que grafos, hierarquia é a forma mais natural de definir objetos compostos e os objetos MPEG4 são construídos de acordo com uma estrutura hierárquica. O mesmo conceito é aplicado aos elementos <MediaHierarchy $>$, <ContextHierarchy $>$ e <XLinkHierarchy $>$ para, se necessário, representar hierarquicamente a estrutura das descrições de mídia, contextuais e de ligações associadas aos objetos.

Cada objeto (elemento <Object>) pode conter descrições de suas características de mídia (elemento <MediaFeatures>) e de contexto (elemento <ContextFeatures $>$ ), assim como das ligações entre os objetos e dos objetos para seus respectivos programas (elemento $<$ XLinkObject>). Os três elementos componentes de <Object> representam esquemas distintos de MediaObject, sendo que suas instâncias podem estar em arquivos separados (separação de descrições) ou no mesmo arquivo da instância de MediaObject a que se referem.

Essa flexibilidade de separação entre MediaObject e os três esquemas é possível, pois, apesar de esses esquemas também terem sido criados usando a DDL, eles são derivados do tipo MPEG-7 DSType (subseção 4.3.2). Desse modo, tais esquemas constituem unidades de descrição MPEG-7 (DescriptionUnit - subseção 4.3.3), podendo ser instanciados isoladamente ou aninhados em uma descrição completa MPEG-7 como MediaObject.

A seguir, nas subseções de 7.2.1 a 7.2.3, o esquema MediaObject será detalhado, apresentando-se como são feitas as descrições de composição, de características de mídia e contextuais e de ligações e relações entre objetos.

\subsection{1 - Composição de objetos}

Um objeto pode ser composto por (ou segmentado em) vários outros objetos. Por exemplo, um vídeo pode ser composto por um conjunto de cenas, que, por sua vez, podem ser compostas por um conjunto de quadros de vídeo. Como ilustrado na Figura 7.5, cada componente de um objeto segmentado é representado por um elemento <Object>, incluindo o objeto principal (o objeto sendo descrito). Todos os elementos <Object> são encapsulados dentro de um elemento <ObjectSet> e cada elemento <Object> possui como atributos: 
- type. É o tipo do objeto, o qual pode ter os valores: VIDEO, ÁUDIO, IMAGE, MEDIA_FEATURES, CONTEXT_FEATURES e XLINK_FEATURES.

- scope. É um identificador do escopo do objeto. Pode ser dos seguintes tipos:

- GLoBAL. É o objeto que está sendo descrito, o qual pode ou não estar segmentado.

- SEQUENCE. Normalmente associado a objetos de mídia contínua. É uma porção do objeto de mídia, por exemplo, um conjunto de cenas em um vídeo.

- SCENE. Corresponde a uma cena em objetos de vídeo.

- FRAME. Corresponde a um quadro de vídeo, de áudio ou de animação.

- LOCAL. Corresponde a uma região em uma imagem ou em um quadro de vídeo, áudio ou animação.

- id. É o identificador único do objeto.

Vale destacar que, devido aos objetos poderem ser segmentados e os segmentos utilizados na composição de outros objetos, um objeto com escopo SEQUENCE em uma descrição poder ter escopo GLOBAL em outra.

$\cdots$

1- <ObjectSet>

2- < < Object type="VIDEO" scope="GLOBAL" id="ID001"> ..</Object $><$ !-- objeto principal -->

3- <Object type="VIDEO" scope="SEQUENCE" id="ID002"> .. <</Object $><$ !-- cena 1-->

4- <!-- quadro de vídeo -->

5- < $<$ Object type="VIDEO" scope="FRAME" id="ID003"> . . $<<$ Object $>$

6- <Object type="VIDEO" scope="LOCAL" id="ID004"> . .</Object> <!-- João-->

7- <Object type="VIDEO" scope="LOCAL" id="ID005"> ...</Object> <!-- Pedro-->

8- <Object type="VIDEO" scope="SEQUENCE" id="ID006"> .. <</Object> <!-- cena 2-->

9- </ObjectSet>

...

Figura 7.5 - Segmentação de um objeto de mídia.

A descrição da relação de composição entre os objetos contidos em <ObjectSet> é realizada de modo hierárquico por meio do elemento <ObjectHierarchy>, conforme ilustrado na Figura 7.6. Cada hierarquia de objeto é uma árvore de elementos do tipo <ObjectNode>, que fazem referências aos objetos do elemento <ObjectSet>. Uma hierarquia implica em uma relação do tipo está contido; dos nós filhos para o nó pai. Por exemplo, na Figura 7.6 o nó 
“node002" (nó pai) é composto pelos nós “node003” e "node004” (nós filhos). Tais nós fazem referências (ObjectRef), respectivamente, aos objetos “ID003", “ID004”, e “ID005”, e exprimem a relação de composição entre o quadro de vídeo (ID003) e os objetos "João" (ID004) e "Pedro" (ID005) da Figura 7.7.

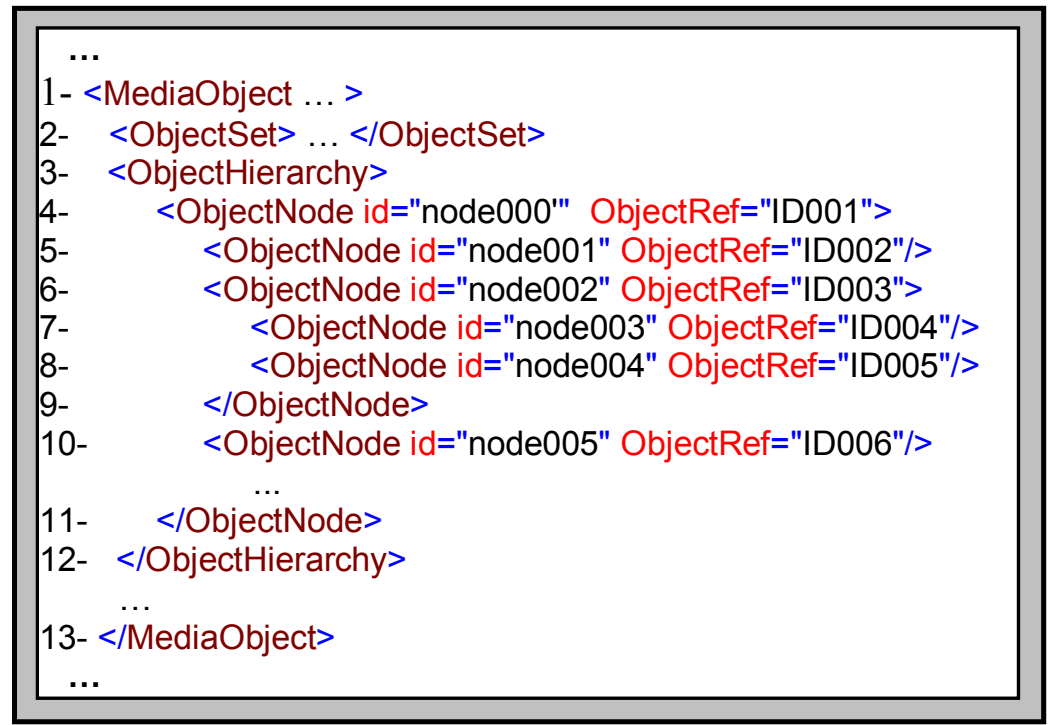

Figura 7.6 - Hierarquia de objetos.
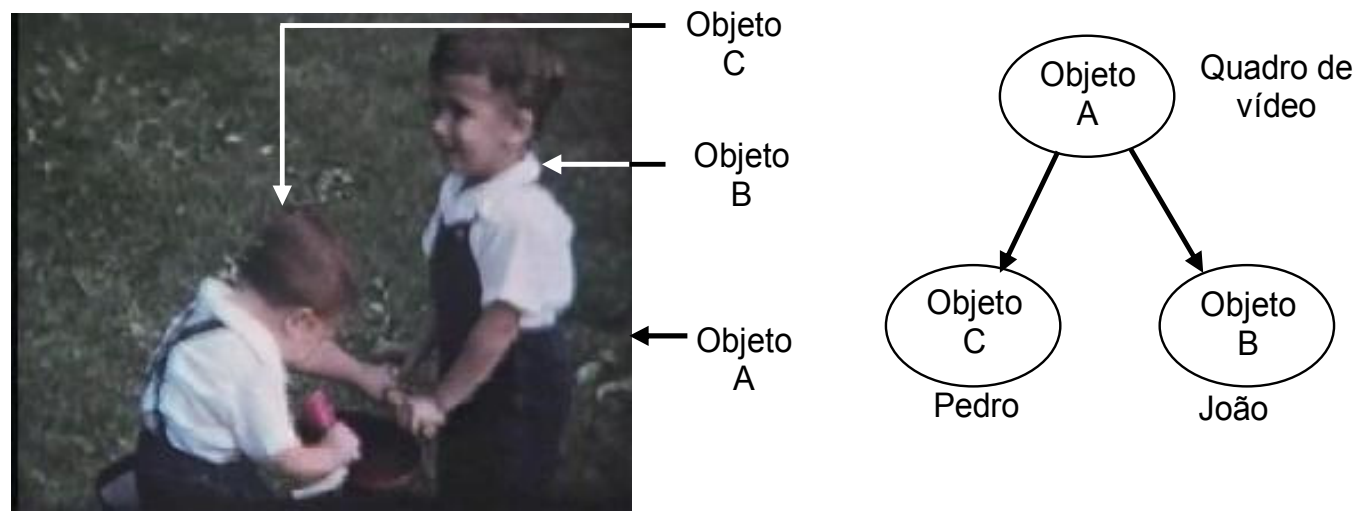

Figura 7.7 - Objetos compondo um quadro de vídeo.

A Figura 7.7 ilustra o quadro de vídeo identificado na Figura 7.5 como o elemento <Object> com atributo id="ID003". Esse quadro, que será utilizado na subseção 7.2.2 para explicar como um elemento <Object> é composto, apresenta duas crianças brincando, João e Pedro, sendo que João está à direita de Pedro (da perspectiva de quem está assistindo). Tal 
quadro (Objeto A) é composto por dois outros objetos: B, representado João; e C, representado Pedro.

\subsection{2 - Descrições de mídia e contextuais}

Cada um dos três componentes do elemento <Object> pode ser descrito de três modos: 1) aninhado dentro de <Object>; 2) encapsulados nos elementos <MediaHierarchy>, $<$ ContextHierarchy $>$ e $<$ XLinkHierarchy $>$ ou 3 ) em arquivos separados. A seguir o elemento <MediaFeatures> será detalhado utilizando-se o modo um. Na subseção 7.2.2.2 o elemento $<$ ContextFeatures> será abordado utilizando-se como exemplo o modo dois e, o modo três será exemplificado. O elemento <XLinkObject> será detalhado na subseção 7.2.3.

\subsubsection{1 - Características da Mídia}

O elemento <MediaFeatures> é formado por um conjunto de descritores e esquemas de descrição selecionados da parte MDS do padrão MPEG-7, estando esse conjunto relacionado na Tabela 7.1. A função de <MediaFeatures> é descrever as características típicas da mídia como formato e tamanho de arquivo, tipo de codificação, taxa de bits, histograma de cor, taxa de amostragem, número de canais, etc.

Tabela 7.1 - Esquemas de descrição MPEG-7 utilizados pelo elemento MediaFeatures.

\begin{tabular}{|c|c|c|}
\hline & Tipo & Descrição \\
\hline \multirow{5}{*}{ Gerais } & MediaFormatType & "Descreve o formato do objeto de mídia. \\
\hline & MediaQualityType & Descreve a qualidade do objeto de mídia. \\
\hline & MediaLocatorType & $\begin{array}{l}\text { Descreve a localização do objeto de mídia: URI, } \\
\text { número do fluxo, etc. }\end{array}$ \\
\hline & MediaTimeType & $\begin{array}{l}\text { Descreve pontos no tempo, relativo ou } \\
\text { absoluto, onde o objeto aparece. }\end{array}$ \\
\hline & CreationInformationType & $\begin{array}{l}\text { Contém informações sobre a produção da } \\
\text { mídia, como: autor, gênero, classificação, } \\
\text { linguagem, etc. }\end{array}$ \\
\hline \multirow{3}{*}{ Vídeo } & $\begin{array}{l}\text { VideoSegmentSpatialDe- } \\
\text { compositionType }\end{array}$ & $\begin{array}{l}\text { Descreve regiões moventes dentro de um } \\
\text { objeto de vídeo. }\end{array}$ \\
\hline & $\begin{array}{l}\text { VideoSegmentTemporalDe- } \\
\text { compositionType }\end{array}$ & $\begin{array}{l}\text { Descreve subobjetos definidos por intervalos de } \\
\text { tempo. }\end{array}$ \\
\hline & $\begin{array}{l}\text { VideoSegmentSpatioTem- } \\
\text { poralDecompositionType }\end{array}$ & $\begin{array}{l}\text { Descreve subobjetos definidos por regiões } \\
\text { dentro do objeto durante um intervalo de tempo. }\end{array}$ \\
\hline Áudio & $\begin{array}{l}\text { AudioSegmentTemporalDe- } \\
\text { compositionType }\end{array}$ & $\begin{array}{l}\text { Descreve um subobjeto de áudio definido por } \\
\text { intervalo de tempo. }\end{array}$ \\
\hline Imagem & RegionLocatorType & $\begin{array}{l}\text { Descreve a região (coordenadas, polinômios ou } \\
\text { retângulos) de um objeto visual. }\end{array}$ \\
\hline
\end{tabular}


A Figura 7.8 ilustra como o elemento <MediaFeatures> pode ser utilizado para descrever um dos objetos apresentados na Figura 7.7: o objeto intraquadro B (“João"). Nesse exemplo, o elemento <MediaFeatures> está aninhado dentro do elemento <Object> que se pretende descrever (linhas 3 e 4 ). A partir de <MediaFeatures $>$ pode-se utilizar descritores MPEG-7 (<MediaFormat> no caso, linhas 5 a 12) para descrever o objeto. As características contextuais e as ligações do Objeto B podem ser descritas do mesmo modo, bastando-se aninhar os elementos $<$ ContextFeatures $>$ e $<$ XLinkObject $>$ dentro do elemento <Object $>$, conforme indicado na Figura 7.8 (linhas 15 e 16).

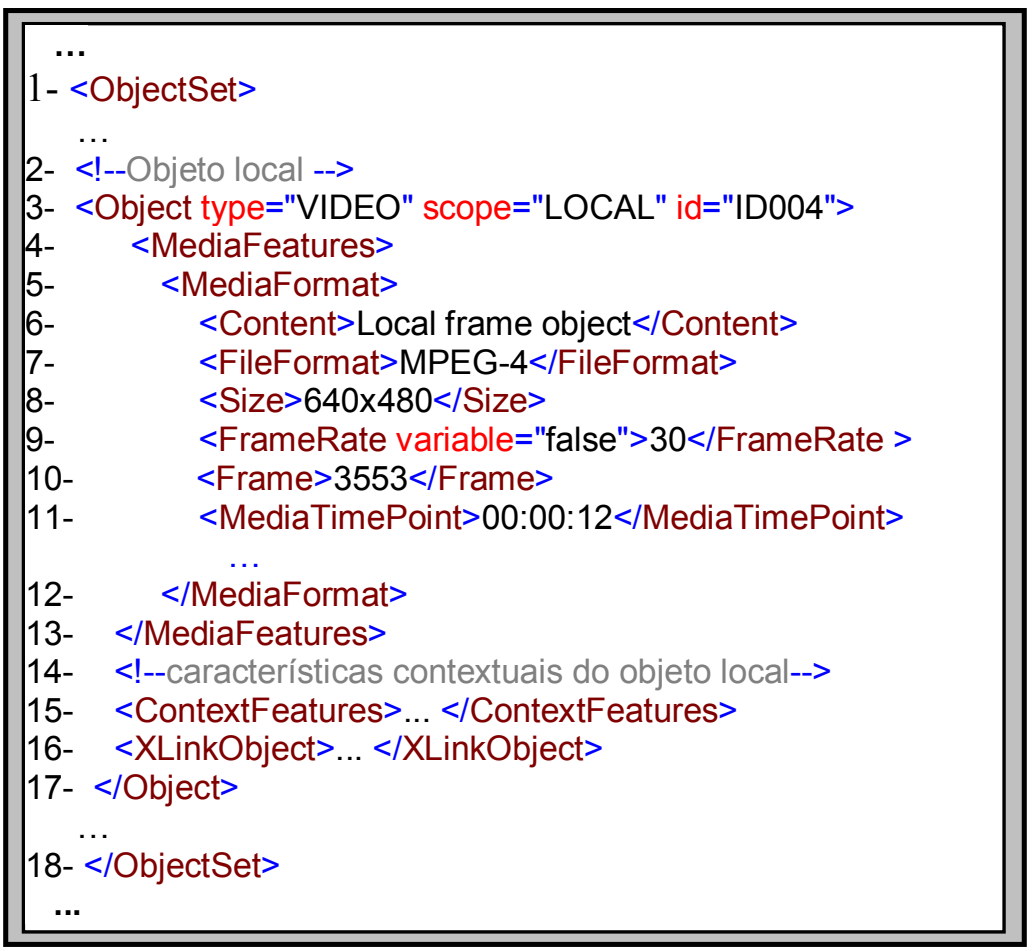

Figura 7.8 - Descrição das características de mídia de um objeto.

O tipo de abordagem aninhada para realizar descrições, ilustrado na Figura 7.8, é conveniente quando: o objeto a ser descrito possui pouca segmentação, as descrições são pequenas e a quantidade de ligações e relacionamentos entre objetos é também pequena. Nessas situações, onde são poucas as informações sobre os objetos, ter todas as informações sobre o objeto descritas dentro do elemento <Object> ajuda a manter a simplicidade da descrição. Um exemplo de aplicação dessa abordagem seria a descrição de um álbum digital de fotos, onde: os objetos são as fotos e eventualmente algum objeto intraquadro (pouca segmentação); as descrições de mídia e contextuais (quem está na foto, 
local e atividade, etc.) para as imagens são simples e as relações e ligações entre objetos (ligações para outras fotos da mesma pessoa, por exemplo) são poucas.

\subsubsection{2 - Características Contextuais}

A função do elemento <ContextFeatures> é servir de invólucro para as informações de contexto relacionadas a um dado objeto de mídia. A descrição das informações de contexto é feita, conforme ilustrado na Figura 7.9, utilizando-se a biblioteca apresentada no capítulo seis. Para utilizar a biblioteca basta incluir o espaço de nomes da biblioteca de contexto na descrição (linha 1) e utilizar o elemento <Context>, que é o elemento raiz da biblioteca, como filho do elemento <ContextFeatures>. Como os elementos de contexto são importados de outro espaço de nomes deve-se usar nesses elementos o atributo qualificador context (definido na linha 1 e referenciado nas linhas de 5 a 25 da Figura 7.9).

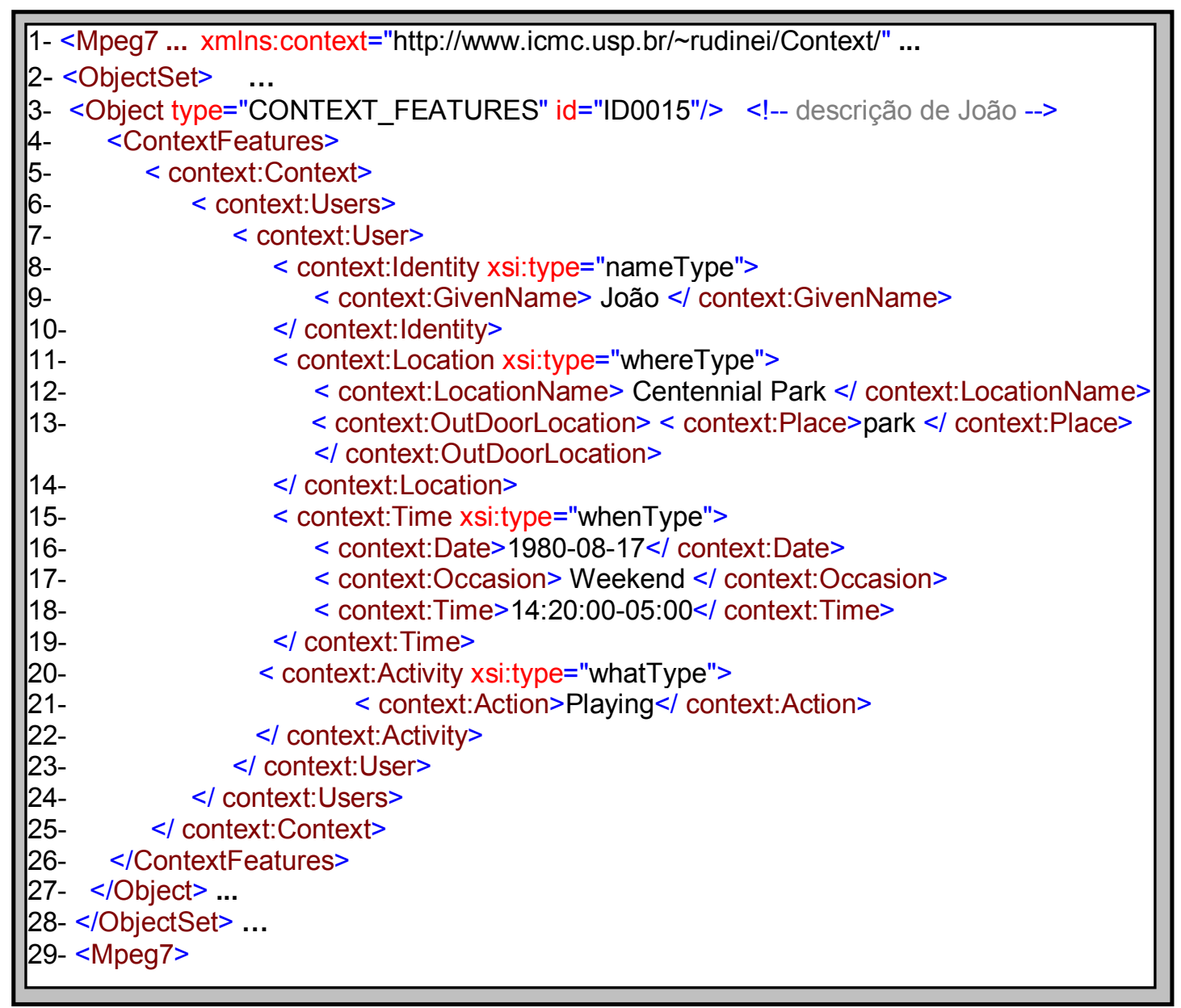

Figura 7.9 - Descrição das características contextuais de um objeto intraquadro (local). 
A rigor, um atributo qualificador do espaço de nomes de <MediaObject> deveria estar presente no exemplo (o espaço de nomes padrão do exemplo é o do MPEG-7). Contudo, por questões de simplicidade e legibilidade, o mesmo foi omitido.

A Figura 7.9 ilustra a descrição das informações contextuais (contexto do Usuário, nesse caso) do objeto intraquadro "João" (Objeto B na Figura 7.7). Nesse exemplo é utilizado o modo dois de descrição, onde um novo objeto (do tipo CONTEXT_FEATURES) é criado para representar a descrição de contexto (linha 3). Esse objeto é associado ao Objeto B por meio de um elemento <ContextHierarchy>, conforme ilustrado na Figura 7.10.

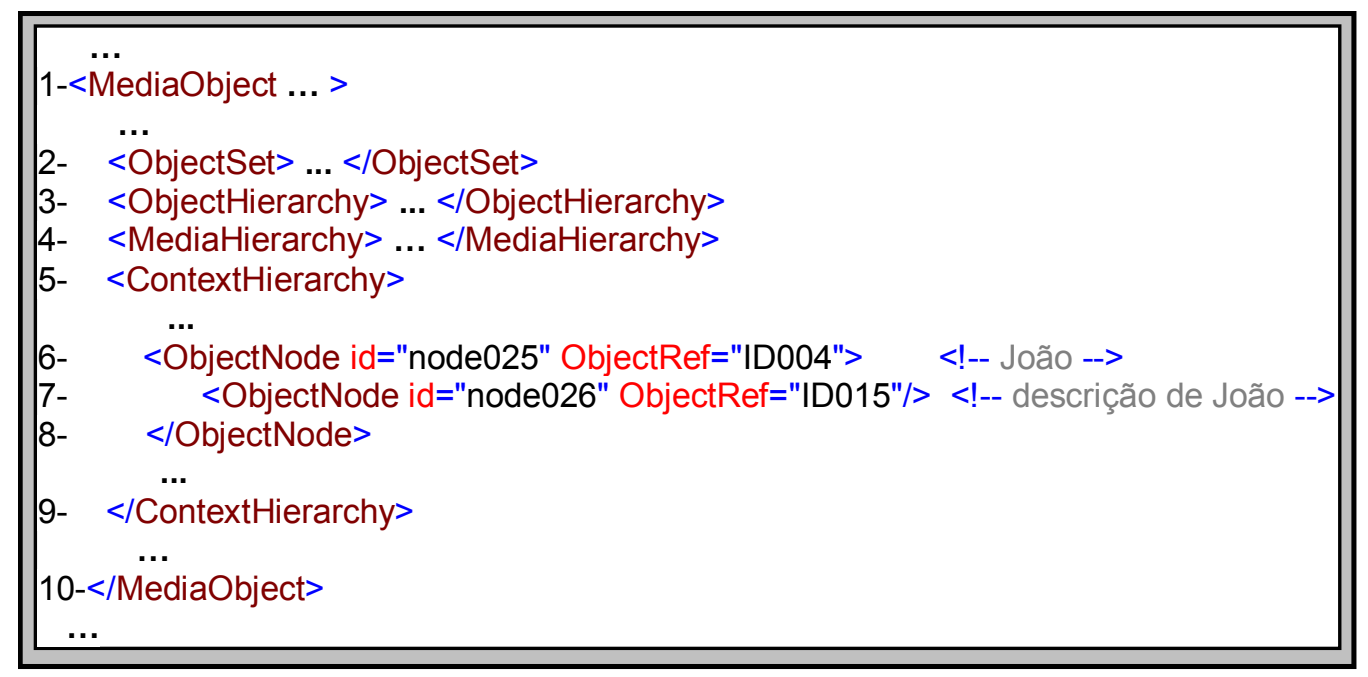

Figura 7.10 - Associação ente um objeto e sua descrição.

A Figura 7.10 mostra o nó "node26" fazendo referência à descrição de "João" através do atributo ObjectRef, cujo valor (ID015) é o identificador do elemento <Object> contendo a descrição de "João"(linha 7). O nó "node26" é filho do nó "node25”, o qual faz referência ao objeto “João", estabelecendo assim uma relação de hierarquia onde "descrição de João" está contida em "João".

Essa abordagem intermediária é conveniente para realizar descrições de médio porte, onde o objeto a ser descrito possui vários segmentos e cada subobjeto necessita de uma complexidade maior nas descrições. Nessas situações a adoção do modo um resultaria em uma descrição "carregada", difícil de ser manipulada por desenvolvedores. As construções hierárquicas do modo dois também são úteis para a criação de estruturas de 
indexação, que por sua vez tem larga aplicação no desenvolvimento de parsers para esse tipo de documento.

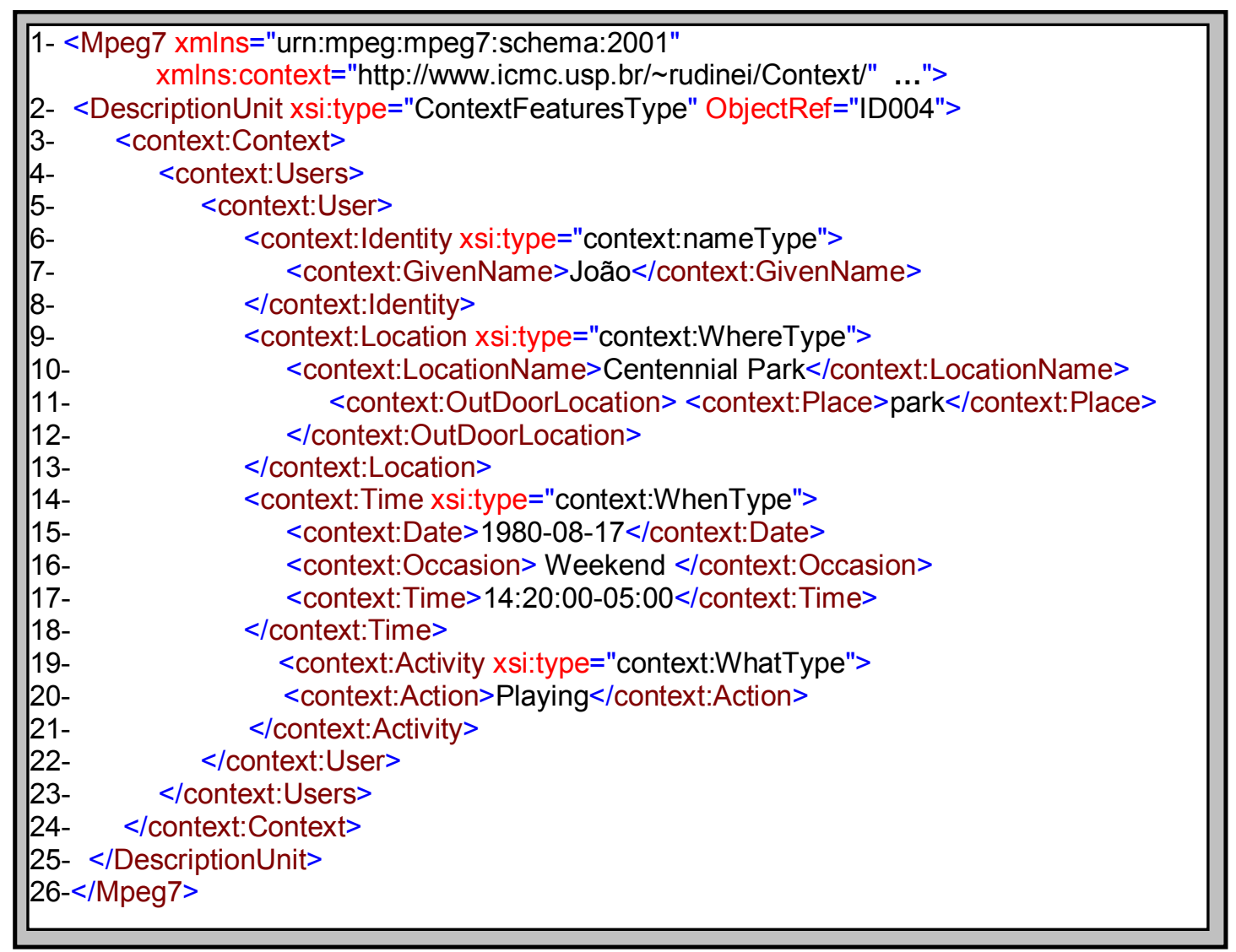

Figura 7.11 - Exemplo de descrição em arquivo separado.

Nos exemplos dados até aqui, as descrições estão contidas no mesmo arquivo que define o objeto. A Figura 7.11 ilustra um exemplo da terceira abordagem para descrição, utilizando o exemplo anterior. As características contextuais do objeto intraquadro "João", são descritas, porém, em um arquivo separado do arquivo contendo a definição do objeto "João". A ligação entre a descrição contextual e seu respectivo objeto é feita por meio do atributo ObjectRef (linha 2), o qual identifica o objeto "João" (ID="004"). O arquivo de definição do objeto "João" deve indicar qual arquivo contém a descrição contextual por meio do atributo URI, como ilustrado na Figura 7.12, linha 5. Essa abordagem é útil quando as descrições são extensas e o volume de descrições é alto. 


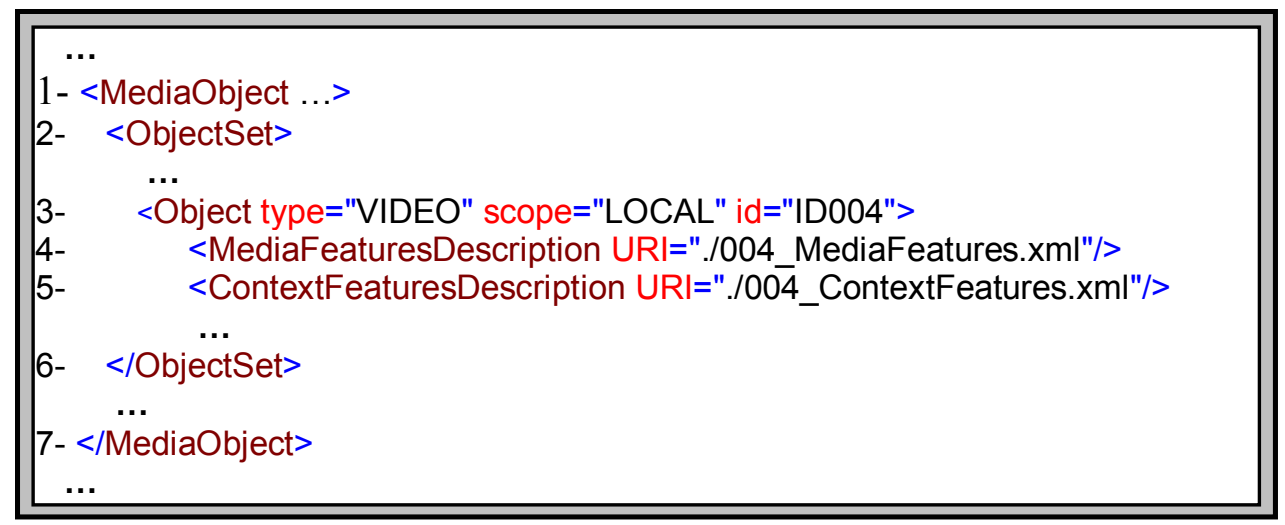

Figura 7.12 - Referência ao arquivo contendo as descrições contextuais do objeto ID004 (“João").

\subsection{3 - Ligações e Relações entre Objetos}

Conforme citado no início deste capítulo, um dos objetivos deste trabalho é fornecer uma solução para representar as ligações entre objetos de mídia MPEG-4 e suas respectivas descrições MPEG-7.

A solução proposta é a utilização da recomendação XLink da W3C (W3C, 2001e), a qual define ligações em documentos XML. Essa recomendação está baseada na definição de dois conceitos importantes: recurso e xlink. Um recurso é uma abstração para qualquer elemento que possa ser endereçado: uma página Web, um trecho dentro de uma página Web ou uma imagem, só para ficar no domínio Web. Um xlink representa a ligação entre recursos e pode ser de dois tipos: simples (simple xlink) e estendido (extended xlink). Um xlink simples é uma ligação entre dois recursos com a mesma funcionalidade que as ligações convencionais HTML. Um xlink estendido pode representar tanto ligações do tipo "um para um" quanto ligações "um para muitos". Além disso, um xlink estendido pode representar ligações bidirecionais e a semântica da ligação. A recomendação XLink, diferente de XML, não é uma linguagem e sim um conjunto de atributos e regras de utilização desses atributos em elementos XML.

Atualmente o suporte a xlink em navegadores Web é limitado. Apenas poucos navegadores (como o Amaya ${ }^{11}$ e o Mozilla ${ }^{12}$ ) implementam xlink simples. A despeito desse fato, a recomendação XLink é uma ferramenta poderosa para a representação de ligações,

\footnotetext{
${ }^{11} \mathrm{http}: / /$ www.w3.org/Amaya/. Acesso em 27 ago. 2003.

$12 \mathrm{http}: / /$ www.mozilla.org/. Acesso em 27 ago. 2003.
} 
preenchendo os requisitos do projeto de protótipo de TV Interativa: representar ligações entre descrições de programas e descrições de objetos de mídia, representar ligações entre descrições de objetos de mídia e estabelecer relações entre recursos participantes de uma ligação. Além disso, a utilização de xlink permitirá a navegação entre descrições e objetos associados, em aplicações Web, conforme os navegadores forem oferecendo suporte a xlink estendido.

A utilização de xlink neste projeto requer a implementação de um parser que processe as informações xlink contidas nas descrições, fornecendo suporte para que aplicações possam realizar uma ligação. Esta subseção apresenta como tais ligações são representadas dentro do esquema proposto. O método que efetivamente utiliza as representações para implementar a ligação será explicado no capítulo oito.

A representação das ligações é feita utilizando-se o elemento <XLinkObject>, que é um componente do esquema MediaObject. Tal elemento deve indicar o espaço de nomes XLink e o tipo de $x$ link utilizado, respectivamente, através dos atributos xmlns:xlink e xlink:type (Figura 7.13, linha 2). Uma vez que se pretende representar ligações complexas e relações entre objetos o xlink utilizado deve ser do tipo estendido.

Representado desse modo o elemento <XLinkObject> está habilitado a conter os elementos que efetivamente irão representar a ligação. Usando a terminologia XLink, esses elementos são as pontas (inicial e final) da ligação e um arco que une as pontas. Para representar as pontas foi criado o elemento <Locator>, o qual deve conter os seguintes atributos xlink:

- type: identifica o tipo do elemento dentro do xlink. O tipo locator permite fazer referências a qualquer parte de um documento XML e a documentos externos.

- href: contém a localização do recurso. Esse atributo é formado por um URI e uma expressão XPointer (W3C, 2002) opcional. O URI identifica o documento e a expressão XPointer identifica um trecho dentro do documento.

- role: indica o papel do elemento na ligação.

- label: é o identificador do participante da ligação.

Para representar o arco que une as duas pontas de uma ligação foi criado o elemento $<$ Arc>, o qual deve conter os seguintes atributos xlink: 
- type: identifica o tipo do elemento dentro do xlink. O tipo arc define um arco xlink.

- from: identifica a ponta inicial do arco. $\mathrm{O}$ valor desse atributo deve ser igual ao valor do atributo label de um xlink do tipo locator.

- to: identifica a ponta final do arco. O valor desse atributo deve ser igual ao valor do atributo label de um $x$ link do tipo locator.

- arcrole: define a relação entre os participantes da ligação.

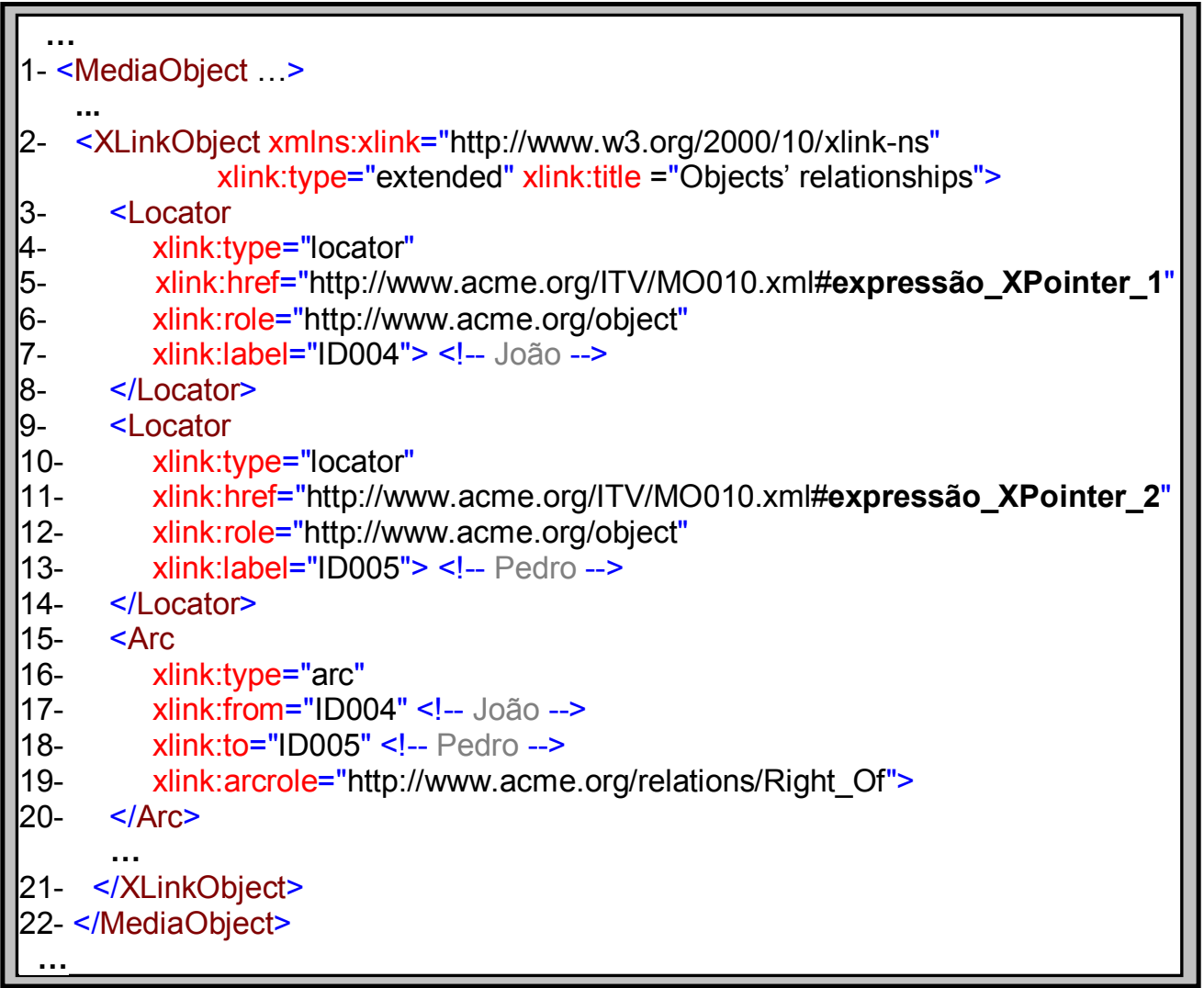

Figura 7.13 - Exemplo de relação entre dois objetos.

A Figura 7.13 ilustra, como exemplo, a representação de uma ligação entre os dois objetos intraquadro da Figura 7.7 - "João" e "Pedro". O primeiro elemento <Locator> (linha 3) aponta para o objeto "João" (linha 5), enquanto o segundo elemento <Locator> (linha 9) aponta para o objeto "Pedro" (linha 11). Como os dois objetos estão definidos no mesmo documento (MO010.xml), ambos os apontadores possuem o mesmo URI (fictício): http://www.acme.org/ITV/MO010.xml. O caractere “\#” separa o URI da expressão xpointer que identifica o trecho do documento onde cada objeto está definido. 
Os identificadores dos elementos <Locator> na Figura 7.13 (linhas 7 e 13) são também os identificadores dos objetos: ID004 e ID005. Isso tem implicações na implementação da ligação entre objetos e suas descrições, como será explicado no capítulo oito. O elemento <Arc> utiliza os atributos label dos elementos < Locator> para definir a direção do arco. Esse tipo de ligação, utilizando dois xlinks do tipo locator, é chamado dentro da especificação XLink de arco third-party (W3C, 2001e). No exemplo da Figura 7.13 (linhas 15 a 20) o arco vai de ID004 para ID005. A relação entre esses dois recursos (ou objetos) é descrita pelo atributo $x$ link arcrole, indicando que o recurso ID004 Right_Of ID005, ou seja, “João" está à direita de "Pedro". Desse modo, os mais diversos tipos de relações (temporais, espaciais, ordinárias, etc.) podem ser estabelecidas entre objetos.

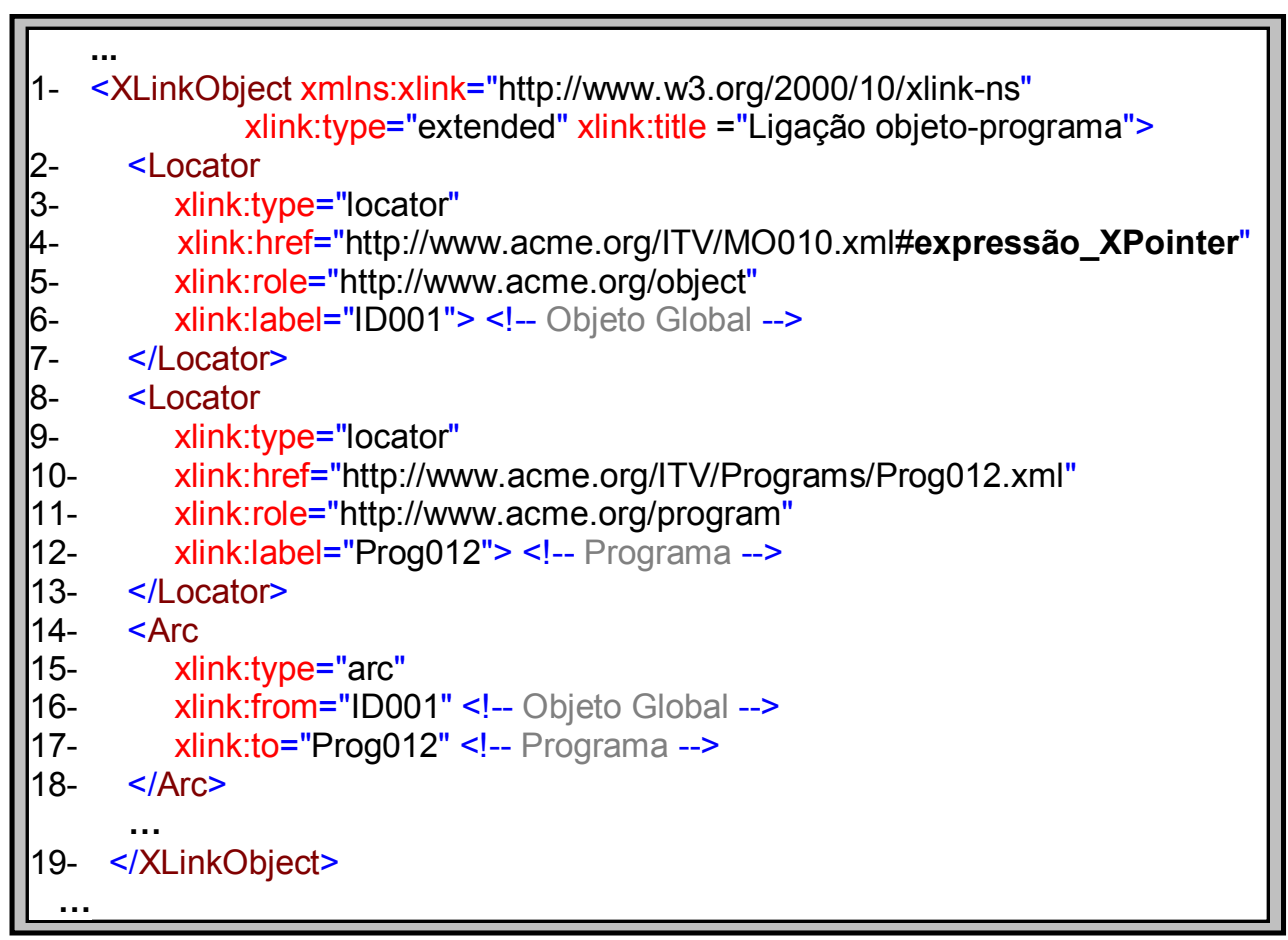

Figura 7.14 - Exemplo de ligação entre a descrição de um objeto e a de um programa.

O exemplo da Figura 7.13 ilustra bem o estabelecimento de relações entre objetos. A ligação propriamente dita não faz sentido, em termos práticos, pois une dois objetos pertencentes ao mesmo quadro de vídeo. Contudo, o mecanismo para ligar um objeto às suas descrições ou mesmo a outros objetos é exatamente o mesmo. O que muda, obviamente, é o conteúdo do atributo href dos elementos <Locator>, que devem apontar para os recursos desejados. 
A ligação entre um objeto e a descrição do programa que o contém é também realizada como no exemplo anterior, conforme ilustrado na Figura 7.14. Na linha 4, a expressão xpointer indica o objeto global, e na linha 10 o atributo href aponta para a descrição do programa. A partir da descrição do programa pode-se obter informações sobre o mesmo que permitam, por exemplo, navegar pelos segmentos.

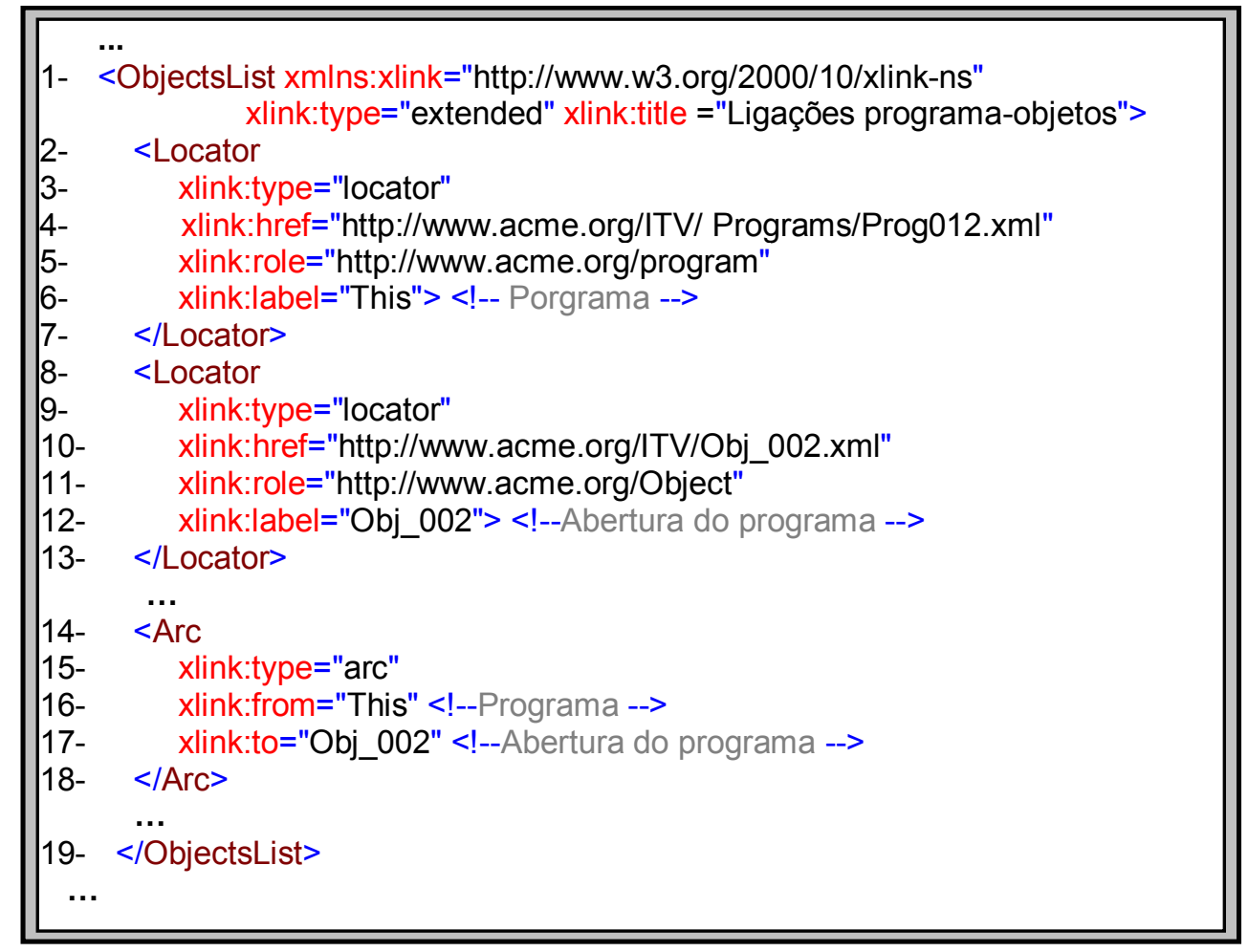

Figura 7.15 - Exemplo de ligação entre um programa e seus objetos.

A representação da ligação entre um programa e seus objetos componentes está ilustrada na Figura 7.15. Como dito anteriormente na seção 7.1, o elemento <ObjectsList> contém uma relação de todos os objetos que compõem um programa. Essa relação é na verdade um xlink do tipo "um para muitos", onde o primeiro elemento < Locator> representa o programa em si (linhas 2 a 7). Os elementos <Locator> subseqüentes representam, cada um, os objetos de mídia. Como ilustrado na Figura 7.15 (linha 10), o elemento <Locator> aponta para o documento contendo a descrição do objeto, instância de MediaObject. A partir do elemento <XLinkObject> contido na descrição do objeto, pode-se obter ligações para as descrições de composição, características de mídia e características contextuais do objeto. Além, é claro, das ligações para os segmentos (ou subsegmentos) do objeto. 
Vale observar que nem todos os segmentos necessitam estar presentes no elemento <ObjectsList>. O esquema é flexível para permitir indicar apenas os segmentos principais, cujas descrições poderão conter segmentação adicional. Por exemplo, no caso de um telejornal os segmentos principais poderiam ser compostos seguindo a divisão: vinheta de abertura, abertura, manchetes, âncora, reportagem 1, âncora, reportagem 2, ..., reportagem $n$, propaganda1, ..., propaganda $n$, vinheta, âncora, reportagem $n+1, \ldots$, fechamento. Cada um desses segmentos poderia ainda ser subdividido em cenas, quadros-chaves e objetos intraquadro, onde essas subdivisões estariam representadas nas descrições de cada segmento, conforme discutido neste capítulo.

\section{3}

Considerações Finais

Este capítulo apresentou uma proposta para descrever objetos de mídia no domínio de TV Interativa, fornecendo suporte à ciência de contexto. Descrições estruturadas dos objetos de mídia são feitas por meio do esquema de descrição MediaObject, o qual usa descritores e esquemas de descrição MPEG-7 de modo seletivo. Isto é feito criando-se abstrações, através da DDL MPEG-7, que encapsulam os esquemas desenvolvidos e os selecionados. Além disso, o esquema proposto fornece suporte a informações estruturadas de contexto, permite a separação entre descrições de programas e de objetos de mídia, permite descrever segmentação intraquadro e permite descrever relacionamentos genéricos entre objetos.

O suporte à descrição de contexto é dado utilizando a biblioteca de contexto apresentada no capítulo seis. Os elementos da biblioteca de contexto são importados pelo esquema MediaObject, permitindo descrições das informações semânticas dos objetos de mídia. Isso é útil, por exemplo, em buscas por conteúdo relacionado ou em adaptação automática de serviços.

O esquema proposto permite descrever relacionamentos entre objetos além dos relacionamentos hierárquicos inerentes à composição dos objetos. Isso é feito utilizando-se a recomendação XLink da W3C. Tal recomendação permite enriquecer ligações com informações semânticas sobre o conteúdo que as mesmas unem e sobre o relacionamento entre os objetos indicados. 
Capítulo

Personalização e

Adaptação de

Conteúdo 


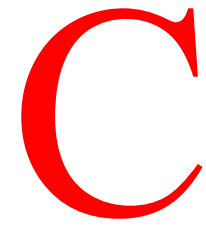

ONFORME discutido na introdução desta tese, o objetivo do trabalho é o desenvolvimento de técnicas para a construção de programas personalizados de TV Interativa com suporte à utilização de informações de contexto. As pesquisas apontaram para algumas lacunas existentes no modo de representar os programas e seus componentes, assim como no modo de representar informação de contexto, dificultando o desenvolvimento de serviços interativos.

Os capítulos seis e sete apresentaram propostas para a representação de informações de contexto e para a representação de objetos de mídia. Tais propostas foram utilizadas no desenvolvimento de um serviço de adaptação e personalização de conteúdo, o qual opera em uma infra-estrutura para produção, distribuição e consumo de programas de TV Interativa. A definição dessa infra-estrutura o primeiro esforço do grupo em direção à construção de um protótipo de TV Interativa.

Este capítulo apresenta, na seção 8.1, o modelo seguido para a definição da infraestrutura, o qual está baseado nos modelos de referência do TV-Anytime apresentados no capítulo 2. A seção 8.2 apresenta a infra-estrutura e o seus serviços. A seção 8.3 apresenta o serviço de adaptação e personalização de conteúdo desenvolvido, exemplos de programas interativos personalizados e a técnica desenvolvida para associar conteúdo MPEG-4 às suas respectivas descrições MPEG-7. A seção 8.4 apresenta as considerações finais.

\section{1}

\section{O Modelo Adotado}

Conforme apresentado no capítulo dois, o TV-Anytime Forum especificou um modelo funcional de referência (Figura 2.4) para sistemas de TV Interativa. Esse modelo define o fluxo de conteúdo dentro do sistema e identifica um conjunto de unidades funcionais, as quais podem ser implementadas de diferentes maneiras por diferentes entidades participantes do processo de produção, distribuição e consumo de programas. Esse modelo, juntamente com o modelo de metadados (Figura 2.5), traz algumas funcionalidades gerais do sistema (como criação de conteúdo) embutidas na definição de cada unidade funcional. 
Também como apresentado no capítulo dois, as funcionalidades específicas possíveis em um sistema (como indexação) foram definidas pelo TV-Anytime em três modelos de negócios (TV-Anytime, 2003a), sendo que este trabalho segue o modelo bidirecional em banda larga, descrito no Anexo A.

A abrangência e variedade das funcionalidades definidas nos modelos TV-Anytime são grandes. Desse modo, foi selecionado um subconjunto dessas funcionalidades, gerais e específicas, para compor um núcleo básico da infra-estrutura que permita produzir, distribuir e consumir programas de TV Interativa. O subconjunto de funcionalidades selecionado, agrupado por unidade funcional, é:

- Criação de Conteúdo.

○ Produção de conteúdo audiovisual.

- Produção de conteúdo gerado por computador.

- Autoria de conteúdo.

- Associação de metadados ao conteúdo.

- Fornecimento de Conteúdo. Apesar do nome, essa unidade funcional também trata do fornecimento de serviços. Isso fica claro ao se analisar o modelo de metadados, onde figura o provedor de serviços, e as funcionalidades do modelo bidirecional em banda larga. O modelo é flexível no sentido de permitir que provedores de conteúdo e de serviços possam constituir uma única entidade ou então entidades separadas. As funcionalidades selecionadas são:

○ Publicação de conteúdo e de programação.

- Gerenciamento de perfis.

○ Personalização.

- Autoria de conteúdo.

- Associação de metadados ao conteúdo.

- Gerenciamento de Armazenamento Local. Em um primeiro momento pretende-se utilizar um computador pessoal para desempenhar algumas funções de um PDR. As funções relativas ao gerenciamento de armazenamento local serão desempenhadas remotamente por um servidor desempenhando o papel de um NDR (Network Digital Recorder, Anexo A). As funcionalidades selecionadas são: 
- Captura e armazenamento de conteúdo.

○ Transferência de conteúdo.

- Acesso a conteúdo via múltiplos dispositivos.

○ Compartilhamento de conteúdo.

- Apresentação de Conteúdo. As funções dessa unidade funcional, previstas nos modelos TV-Anytime como pertencentes ao PDR, serão desempenhadas por um computador pessoal mais softwares específicos. As funcionalidades selecionadas são:

○ Decodificação de conteúdo.

○ Apresentação de conteúdo.

- Interação com o Usuário. Assim como na unidade funcional anterior, um computador pessoal mais softwares específicos irão substituir o PDR durante as interações com o usuário. As funcionalidades selecionadas são:

○ Interação com o conteúdo.

○ Utilização de EPGs.

- Resolução de Localização. O TV-Anytime especifica a utilização de CRIDs para a resolução de localização. Durante as pesquisas não foram encontradas ferramentas que implementem resolução baseada em CRIDs e o desenvolvimento de tais ferramentas está fora dos objetivos deste trabalho tese. Assim, em um primeiro momento, a resolução de localização será feita utilizando-se protocolos Web (como HTTP) e, quando necessário, realizando buscas em uma base de dados que contenha descrições indicando a localização de determinado conteúdo no sistema de arquivos.

- Busca e Navegação. As funcionalidades selecionadas são:

- Permitir buscas remotas (Web e outros servidores), locais (no próprio PDR) e intraprograma. As buscas devem poder ser baseadas em diversos critérios como: nome, título, formato de arquivo, palavra-chave, objetos, etc.

○ Utilização de EPGs para navegar pelos guias de programação e pelos segmentos dos programas.

- Acesso. As funcionalidades selecionadas são:

- Acesso a conteúdo via redes cabeadas e redes sem fio. 
○ Acesso a conteúdo via múltiplos dispositivos.

- Gerenciamento de Direitos e Segurança. Não serão tratados nesta tese, ficando como trabalhos futuros. As questões pertinentes envolvem direitos autorais e intelectuais sobre conteúdo e segurança no acesso e uso tanto de conteúdo quanto de informações do usuário. Alguns serviços que podem oferecer riscos de segurança ou de privacidade foram indicados na Tabela A1 do Anexo A.

Vale a pena esclarecer que a funcionalidade de personalização aparece diluída entre outras funcionalidades dos modelos TV-Anytime, como suporte às preferências do usuário e indexação personalizada de conteúdo. Contudo, como o serviço de personalização é um dos focos desta tese, o mesmo foi destacado como uma funcionalidade no subconjunto apresentado.

Também se deve destacar o fato de que o modelo funcional de referência não exige que as unidades funcionais existam como módulos de software. Elas apenas organizam e agrupam as funcionalidades que podem ser implementadas.

\section{$\underline{8.2}$}

A Infra-Estrutura

O objetivo principal da infra-estrutura é permitir a produção, a distribuição e o consumo de programas de TV Interativa, representando os primeiros esforços na implementação do protótipo de TV Interativa. Tal infra-estrutura servirá de base para a implementação de novos serviços e para a exploração dos ambientes interativos modelados por Santos Júnior (2002).

A Figura 8.1 ilustra a organização da infra-estrutura e os seus elementos, que serão detalhados mais adiante, nas subseções de 8.2.1 a 8.2.3. Os elementos em azul representam softwares comercias da empresa Envivio ${ }^{13}$, adotados para produção, streaming e apresentação de conteúdo MPEG-4. Os elementos em amarelo representam as aplicações desenvolvidas, as quais estão inseridas no projeto do protótipo de TV Interativa e poderão ser estendidas. As setas indicam o fluxo dos dados, incluindo dados audiovisuais, programas, descrições e dados de controle. As setas pontilhadas indicam que a interface

\footnotetext{
${ }^{13} \mathrm{http}: / /$ www.envivio.com. Acesso em 07 set. 2003.
} 
para comunicação entre dois elementos existe, porém o serviço que utiliza essa interface ainda não está implementado.

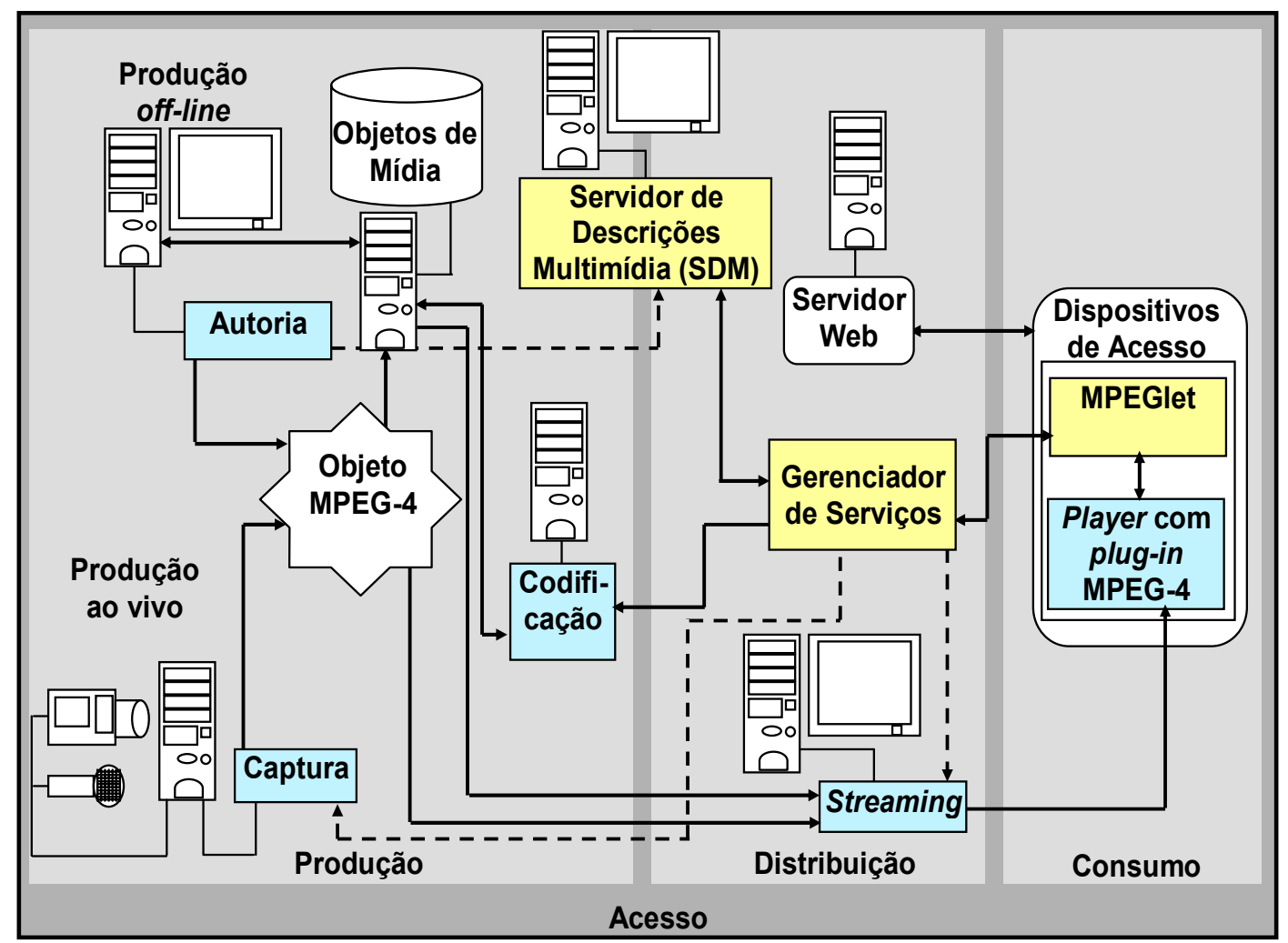

Figura 8.1 - Infra-estrutura para produção, distribuição e consumo de programas de TV Interativa.

A construção da infra-estrutura seguiu o modelo funcional de referência do TVAnytime segundo os critérios apresentados na seção 8.1. O mapeamento das funcionalidades selecionadas para os elementos da infra-estrutura está sumarizado na Tabela 8.1 .

Tabela 8.1 - Mapeamento das características do modelo para os elementos da infra-estrutura.

\begin{tabular}{|c|l|l|}
\hline $\begin{array}{c}\text { Unidade funcional TV- } \\
\text { Anytime }\end{array}$ & \multicolumn{1}{|c|}{$\begin{array}{c}\text { Subconjunto de } \\
\text { características }\end{array}$} & \multicolumn{1}{|c|}{$\begin{array}{c}\text { Elemento da infra- } \\
\text { estrutura }\end{array}$} \\
\hline \hline \multirow{5}{*}{ Criação de conteúdo } & $\begin{array}{l}\text { Produção de conteúdo } \\
\text { audiovisual. }\end{array}$ & \multirow{2}{*}{$\begin{array}{l}\text { Codificação, autoria e } \\
\text { captura. }\end{array}$} \\
\cline { 2 - 2 } & $\begin{array}{l}\text { Produção de conteúdo gerado } \\
\text { por computador. }\end{array}$ & Autoria, captura e SDM. \\
\cline { 2 - 3 } & $\begin{array}{l}\text { Autoria de conteúdo } \\
\text { Associação de metadados ao } \\
\text { conteúdo. }\end{array}$ & \\
\hline
\end{tabular}


Tabela 8.1 - (Continuação).

\begin{tabular}{|c|c|c|}
\hline $\begin{array}{c}\text { Unidade funcional TV- } \\
\text { Anytime }\end{array}$ & $\begin{array}{l}\text { Subconjunto de } \\
\text { características }\end{array}$ & $\begin{array}{c}\text { Elemento da infra- } \\
\text { estrutura }\end{array}$ \\
\hline \multirow{4}{*}{$\begin{array}{c}\text { Fornecimento } \\
\text { de } \\
\text { conteúdo }\end{array}$} & $\begin{array}{l}\text { Publicação de conteúdo e de } \\
\text { Programação. }\end{array}$ & SDM. \\
\hline & Gerenciamento de perfis. & $\begin{array}{l}\text { Gerenciador } \\
\text { de serviços. }\end{array}$ \\
\hline & Autoria de conteúdo. & Autoria e \\
\hline & $\begin{array}{l}\text { Associação de metadados ao } \\
\text { conteúdo. }\end{array}$ & SDM. \\
\hline \multirow{4}{*}{$\begin{array}{c}\text { Gerenciamento } \\
\text { de armazenamento local }\end{array}$} & $\begin{array}{l}\text { Captura e armazenamento de } \\
\text { conteúdo. }\end{array}$ & $\begin{array}{l}\text { Captura e Gerenciador de } \\
\text { Serviços. }\end{array}$ \\
\hline & Transferência de conteúdo. & \multirow{3}{*}{ Gerenciador de Serviços. } \\
\hline & $\begin{array}{l}\text { Acesso a conteúdo } \\
\text { múltiplos dispositivos. }\end{array}$ & \\
\hline & $\begin{array}{l}\text { Compartilhamento } \\
\text { conteúdo. }\end{array}$ & \\
\hline \multirow{2}{*}{$\begin{array}{l}\text { Apresentação } \\
\text { de conteúdo }\end{array}$} & Decodificação de conteúdo. & \multirow{2}{*}{$\begin{array}{l}\text { Player com plug-in } \\
\text { MPEG-4. }\end{array}$} \\
\hline & Apresentação de conteúdo. & \\
\hline \multirow{2}{*}{$\begin{array}{l}\text { Interação com } \\
\text { o usuário }\end{array}$} & Interação com o conteúdo. & $\begin{array}{l}\text { Player com plug-in MPEG- } \\
4 \text { e MPEGlet. }\end{array}$ \\
\hline & Utilização de EPGs. & MPEGlet. \\
\hline $\begin{array}{l}\text { Resolução de } \\
\text { localização }\end{array}$ & & $\begin{array}{l}\text { Servidor Web, Gerenciador } \\
\text { de Serviços e SDM. }\end{array}$ \\
\hline \multirow{2}{*}{$\begin{array}{c}\text { Busca e } \\
\text { navegação }\end{array}$} & $\begin{array}{l}\text { Buscas remotas, locais e } \\
\text { intraprogramas. }\end{array}$ & Gerenciador de Serviços. \\
\hline & $\begin{array}{lrll}\text { Uso de } & \text { EPGs } & \text { para } \\
\text { navegação. }\end{array}$ & MPEGlet. \\
\hline \multirow[t]{2}{*}{ Acesso } & $\begin{array}{l}\text { Acesso a conteúdo via redes } \\
\text { cabeadas e sem fio. }\end{array}$ & Acesso e streaming. \\
\hline & $\begin{array}{l}\text { Acesso a conteúdo } \\
\text { múltiplos dispositivos. }\end{array}$ & Acesso e streaming. \\
\hline
\end{tabular}

\subsection{1 - Produção de Conteúdo}

A produção de conteúdo, consistindo matéria prima para os programas de TV Interativa, pode ocorrer de dois modos: off-line ou ao vivo. Como ilustrado na Figura 8.1, nos dois casos o conteúdo produzido consiste de objetos MPEG-4, os quais são armazenados em um repositório (Objetos de Mídia).

No modo off-line, as ferramentas utilizadas no processo de autoria (Autoria na Figura 8.1) de programas são:

- Envivio Encoding Station (EES): é um software para a conversão de vídeo (AVI, MPEG-1, MPEG-2, MOV) e áudio (MP3, WAV, MPEG-1) para o formato MPEG-4 (MP4). Implementa o perfil visual MPEG-4 Advanced Simple@0-5 (Envivio, 2003). 
- Envivio Broadcast Studio (EBS): é um software para a composição de cenas MPEG-4. Permite inserir áudio, vídeo e imagem especificando o ponto no tempo onde cada objeto deve aparecer. Permite associar algumas ações aos objetos, acionadas pelo mouse, como: aparecer e desaparecer da cena e modificar o tamanho ou a posição do objeto. A cena composta pode ser convertida para um arquivo MPEG-4. Implementa o perfil visual MPEG-4 Advanced Simple@0-5 (Envivio, 2003a).

A produção ao vivo utiliza o software Envivio Live Broadcaster (ELB) (Envivio, 2003b) para captura e codificação de áudio e vídeo quase em tempo real (Captura, na Figura 8.1). O processo de captura e codificação ao vivo requer um computador com características especiais. Neste projeto foi utilizado um computador com a seguinte configuração: processador Intel Dual Xeon de 2.4 gigahertz, 1 gigabyte de memória RAM e uma placa de captura de vídeo modelo Osprey 500 DV Pro.

Cada objeto MPEG-4 produzido possui descrições de suas características contextuais, de mídia e de suas ligações e relacionamentos. Essas descrições são instâncias dos esquemas desenvolvidos neste trabalho, conforme discutido nos capítulos seis e sete. As descrições ainda são feitas manualmente e, depois de terminadas, são enviadas ao Servidor de Descrições Multimídia (SDM). O SDM está ilustrado na Figura 8.1 entre os processos de produção e distribuição de conteúdo por desempenhar papéis em ambos os processos.

O SDM é uma interface, entre aplicações e uma base de dados, desenvolvida em Java utilizando a API JDBC (Patel \& Moss, 1996). Além das descrições dos objetos de mídia, o SDM também é responsável por gerenciar o armazenamento de descrições de programas de perfis de programas.

Outra função do SDM é gerenciar consultas à base de dados contendo as informações dos programas e dos objetos de mídia. O SGBD escolhido para implementar a base de dados foi o Oracle 9i (versão 9.2) (Oracle, 2003). Esse SGBD possui uma funcionalidade chamada Oracle XDB (Oracle, 2003a), a qual manipula nativamente documentos XML. Basicamente, o Oracle XDB registra esquemas XML transformando-os em bases de dados Oracle. A entrada de dados na base é feita simplesmente inserindo documentos XML, instâncias dos esquemas registrados. Antes de gravar os dados na base, o XDB valida o documento XML de acordo com os esquemas apropriados (registrados no 
$\mathrm{XDB}$ ). Os dados só são gravados se o documento XML for válido. A consulta aos dados pode ser feita via SQL ou via XPath (W3C, 1999a). As respostas às consultas podem ser na forma dos valores contidos nos documentos XML inseridos na base ou documentos XML inteiros.

A vantagem da utilização do Oracle XDB está em aproveitar a modelagem feita na construção dos esquemas XML para criar as bases de dados, além de contar com os serviços do SGBD para garantir a validação e a consistência dos dados.

O elemento Codificação da Figura 8.1 conta com dois softwares para codificar conteúdo: o já citado EES e o Envivio Coding Tools (ECT) (Envivio, 2003c). O ECT recebe como entrada uma especificação textual de uma apresentação MPEG-4 (em XMT) e, opcionalmente, arquivos fonte de MPEGlets. Como saída o ECT gera um arquivo binário no formato MP4, o qual é armazenado no repositório ou no NDR do usuário.

\subsection{2 - Distribuição de Conteúdo}

A parte de distribuição de conteúdo é formada pelos elementos SDM, Gerenciador de Serviços, Streaming e por um Servidor Web. Um dos serviços fornecidos pela parte de distribuição é a publicação do conteúdo produzido para o usuário. Atualmente, a publicação é feita de dois modos: utilizando o SDM ou utilizando um servidor Web. No primeiro caso, o SDM é responsável por responder às aplicações sobre a existência de objetos de mídia e de programas armazenados no repositório. Nesse processo, as aplicações devem realizar consultas ao SDM apresentando o resultado ao usuário. No caso específico das aplicações sendo executadas na parte de consumo de conteúdo (MPEGlet na Figura 8.1), a comunicação com o SDM é realizada através do Gerenciador de Serviços. Isso é necessário para facilitar a autenticação das requisições feitas pelos usuários.

No segundo caso, o usuário acessa uma página Web contendo uma lista dos programas disponíveis (uma espécie de lista de programação). Os elementos da lista apontam para a localização dos programas no sistema de arquivos. Essa lista ainda está sendo produzida manualmente nesse estágio do projeto.

Uma outra abordagem é fazer com que os elementos da lista apontem para as descrições dos programas e, a partir das descrições, obter a localização dos programas no sistema de arquivos. Essa abordagem tem a vantagem de permitir a navegação pelos 
segmentos do programa - deve-se lembrar que as descrições dos programas contêm ligações para as descrições de seus respectivos objetos componentes. A construção automática da lista utilizando essa abordagem fica como trabalho futuro.

O Gerenciador de Serviços é uma interface entre aplicações e os serviços da infraestrutura. Sua função é receber requisições e acionar os serviços apropriados para atendêlas. Para isso o Gerenciador foi implementado como um servidor Java com suporte a múltiplas conexões simultâneas, aproveitando-se do trabalho realizado em Goularte \& Moreira (2001).

Ter o Gerenciador como um centralizador dos serviços tem as desvantagens de uma arquitetura centralizada: se o Gerenciador falhar todos os serviços ficam indisponíveis e pode ocorrer sobrecarga do servidor. Contudo, por ser mais simples de ser implementada que a abordagem distribuída, a abordagem centralizada é adequada ao estágio atual de desenvolvimento do projeto.

O Gerenciador possui interfaces para as ferramentas de codificação, captura e streaming da infra-estrutura, permitindo que aplicações utilizem as mesmas. Um exemplo desse tipo de aplicação é o serviço de personalização desenvolvido, o qual utiliza as ferramentas de codificação (detalhes na seção 8.3) utilizando as interfaces do Gerenciador. Serviços específicos que utilizem as ferramentas de captura e streaming ainda não foram implementados. Um cenário para tais serviços seria a captura de um evento ao vivo enviado sob demanda a um usuário que já está assistindo a um programa. Ao usuário seria oferecida a opção de assistir aos dois programas ou só ao evento ao vivo. Nesse cenário a ferramenta de streaming deve ser acionada e configurada para gerar um fluxo compatível com as capacidades da rede e do dispositivo do usuário.

Deve-se esclarecer que a ferramenta de streaming está funcionando permitindo que conteúdo seja acessado via um terminal MPEG-4 compatível. Apenas não foi implementado nenhum serviço específico que se comunique com a ferramenta via a interface do Gerenciador.

O último componente da parte de distribuição de conteúdo é Acesso. Como ilustrado na Figura 8.1, esse componente na verdade envolve todos os aspectos da infra-estrutura e representa as redes disponíveis: uma LAN ethernet de $100 \mathrm{Mb}$ e uma rede sem fio IEEE 
$802.11 \mathrm{~b}$ de $11 \mathrm{Mb}$. A segunda é utilizada apenas na comunicação de alguns dispositivos de acesso com o servidor Web, o Gerenciador de Serviços ou com a ferramenta de streaming.

\subsection{3 - Consumo de Conteúdo}

O consumo de conteúdo é realizado por dispositivos de acesso executando alguns softwares específicos. Um dispositivo de acesso pode ser um computador pessoal (workstation), um computador de colo (um laptop ou um tablet), um computador de bolso ou um telefone celular. Para acessar programas os dispositivos de acesso necessitam executar um software que realize as funções de um terminal MPEG-4. Neste projeto está-se utilizando o software EnvivioTV (Envivio, 2003d), que é um plug-in MPEG-4 para os players RealOne ${ }^{\mathrm{TM}}$, QuickTime $^{\mathrm{TM}}$ e WindowsMedia ${ }^{\mathrm{TM}}$.

Para poder ter acesso ao Gerenciador de Serviços e a algumas funções de interação, os dispositivos precisam ter instalada uma versão da plataforma Java igual ou superior à JDK 1.3.1. Isso porque a comunicação com o Gerenciador de Serviços e a manipulação do grafo da cena MPEG-4 são realizados via um MPEGlet (detalhes sobre MPEGlets na seção 3.5), que é implementado em Java e, portanto, necessita de uma máquina virtual Java sendo executada no cliente.

\section{$\underline{8.3}$}

Serviço de Personalização

O serviço de personalização desenvolvido utiliza a infra-estrutura apresentada na seção 8.2 para produzir, armazenar e transmitir programas de TV Interativa. Em um primeiro momento, optou-se por trabalhar apenas com telejornais, devido ao fato de que esse tipo de programa possui uma estrutura bem definida, facilitando a segmentação e a composição de programas personalizados.

O conteúdo transmitido pela TV aberta é gravado em formatos como AVI ou MPEG-1, segmentado e codificado em diversos objetos MPEG-4 com tamanho de quadro $352 \times 288$ a 30 quadros por segundo. A segmentação, que ainda não está sendo feita de modo automático, respeita basicamente a estrutura do telejornal: vinheta de abertura, âncora, manchetes, âncora, reportagem 1, âncora, etc., como ilustrado na Figura 8.2, a qual representa de modo esquemático o serviço descrito nesta seção. Cada um desses segmentos 
pode ainda ser dividido em seqüências de cenas, cenas, quadros e objetos intraquadro, de acordo com o interesse do autor do programa interativo. Cada segmento é então codificado, utilizando-se o software EES (subseção 8.2.1) em um objeto MPEG-4 e armazenado no repositório.

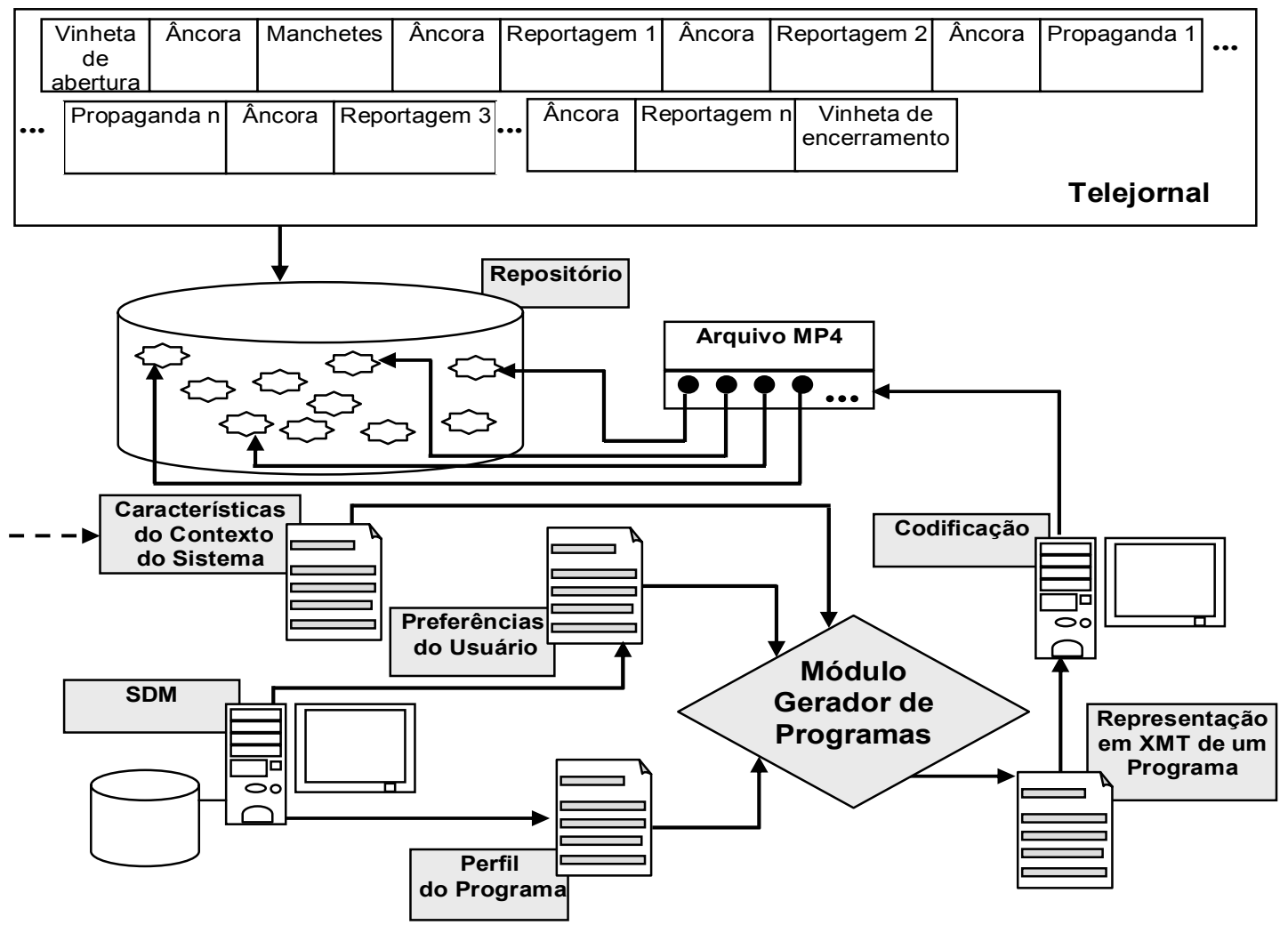

Figura 8.2 - Representação esquemática do serviço de personalização.

Após a segmentação ocorre a fase de descrição do programa. Como citado anteriormente, o programa e cada objeto componente possuem descrições que são instâncias dos esquemas desenvolvidos neste trabalho. Essas descrições, feitas pelo autor do programa interativo, são armazenadas no SDM.

A partir dos objetos armazenados no repositório e de suas descrições é possível compor programas personalizados. O responsável por realizar essa tarefa é o Módulo Gerador de Programas (Figura 8.2). Esse módulo é uma aplicação Java e é um dos serviços coordenados pelo Gerenciador de Serviços. Após receber como entrada um arquivo contendo as preferências de um usuário em particular, o módulo realiza um consulta ao 
SDM para comparar as descrições dos objetos com as preferências do usuário e obter uma lista de quais segmentos contêm assuntos de interesse do usuário, essa lista é armazenada no NDR do usuário para uso futuro.

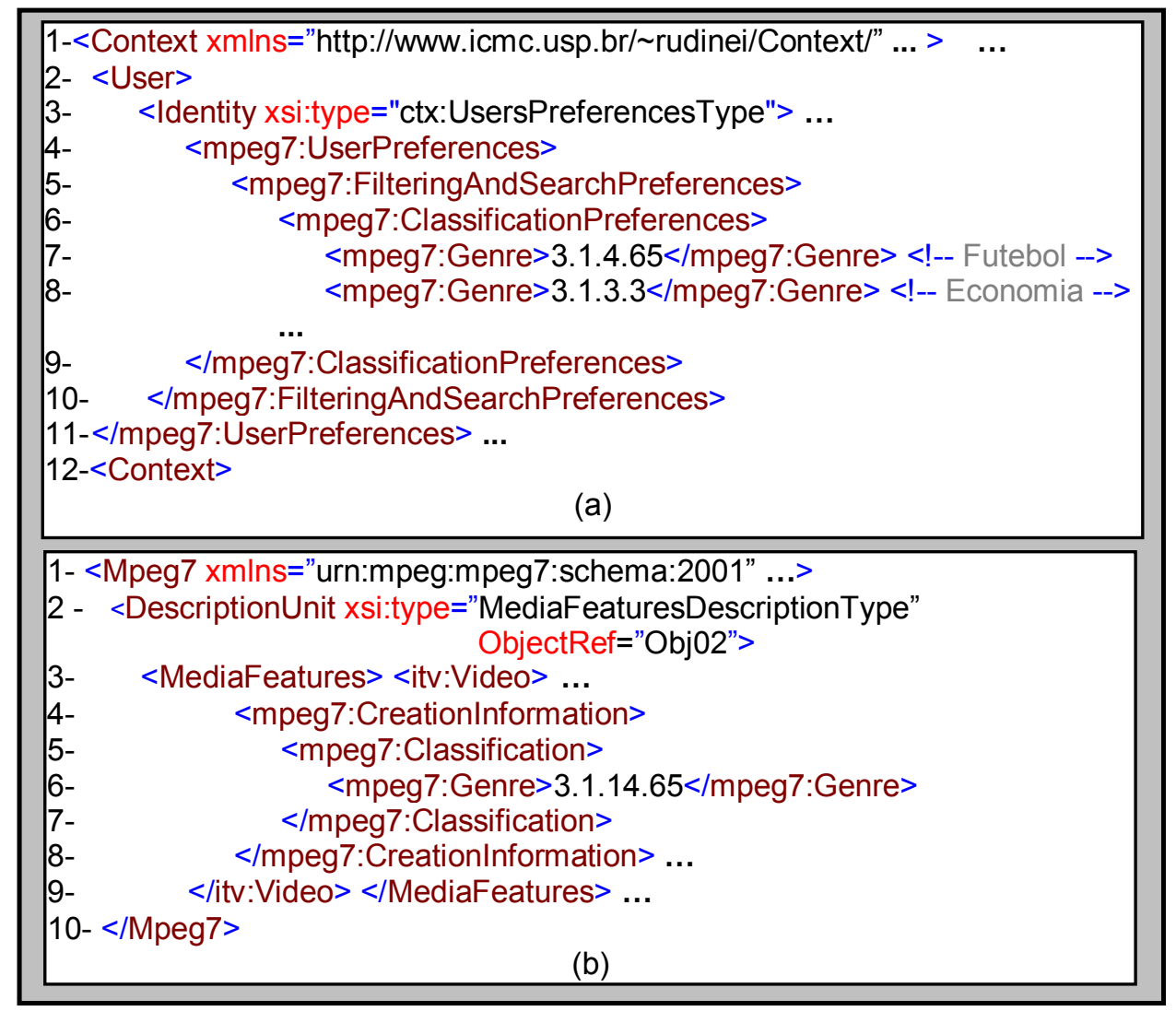

Figura 8.3 - Exemplos de descrições: (a) preferências de gênero de programas do usuário e (b) descrição do gênero de um objeto de mídia.

As preferências do usuário estão descritas em um documento XML instância do contexto do usuário. $\mathrm{O}$ descritor que contém a informação sobre gênero de programas é o tipo MPEG-7 UserPreferencesType, importado pela biblioteca de contexto conforme discutido no capítulo 6. UserPreferencesType inclui o tipo ClassificationPreferencesType, específico para encapsular classificações. Conforme ilustrado na Figura 8.3, a classificação de assunto segue o padrão estabelecido pelo TV-Anytime Forum para gênero de programação (TVAnytime, 2002) (ver Anexo B), que é também utilizado pelo elemento <Classification> do esquema de descrição de programas ITV_Program (capítulo sete, seção 7.1), assim como pelo elemento <MediaFeatures> (por meio do seu elemento componente <CreationInformation>) do esquema MediaObject (capítulo sete, subseção 7.2.2.1). Nesse exemplo, a Figura 8.3 (a) (linha 7) ilustra a preferência do usuário pelo assunto 3.1.4.65 - 3: conteúdo, 1: informação, 
4: esportes, 65: futebol (ver Anexo B) - que é o assunto do objeto Obj02 ilustrado na Figura 8.3 (b) (linha 6).

Após a obtenção da lista de segmentos que combinam com as preferências do usuário, o Módulo Gerador de Programas requisita ao SDM um perfil de programa apropriado. Um perfil pode ser entendido como um arquivo XMT incompleto, construído pelo provedor de serviços. Um perfil define que objetos integram a interface do programa, mas não o conteúdo, que é definido pela lista. A interface é projetada, previamente, utilizando as ferramentas de autoria MPEG-4 da infra-estrutura para criar uma cena MPEG4 contendo alguns objetos: uma imagem de fundo, botões, menus e textos. Esses objetos são usados para interagir com o conteúdo. A cena é então codificada de modo a gerar um fluxo elementar MPEG-4 para cada objeto, os quais são armazenados no repositório. A criação do arquivo representando um perfil é realizada especificando-se os fluxos elementares que compõem a interface, o número de segmentos a serem inseridos, a indicação do MPEGlet associado, a posição no tempo e no espaço e as ações de cada objeto.

Tendo recebido o perfil, o Módulo Gerador de Programas realiza então um parsing no mesmo, inserindo informações provenientes da lista sobre a localização dos segmentos selecionados. Como saída, o Módulo gera um novo arquivo XMT representando o programa personalizado a ser produzido apenas com os segmentos selecionados, conforme ilustrado na Figura 8.2.

O arquivo XMT é enviado ao codificador MPEG-4 ECT (representado pelo elemento Codificação na Figura 8.2), o qual gera um arquivo binário .mp4. O arquivo gerado é armazenado no NDR do usuário, conforme o modelo adotado (seção 8.1). Esse arquivo contém apenas ponteiros para os objetos de vídeo, armazenados no repositório, que compõem o programa personalizado. Essa abordagem não duplica conteúdo e diminui substancialmente o tamanho do arquivo gerado (algumas centenas de Kbytes), economizando tempo de processamento.

O serviço de personalização também leva em consideração algumas características contextuais do sistema (Características do Contexto do Sistema, na Figura 8.2), que incluem informações sobre o dispositivo utilizado para realizar o acesso (um computador ou um PDA) e informações sobre a rede. Essas informações deverão ser entregues ao Módulo 
Gerador de Programas pelo Gerente de Contexto. O desenvolvimento do Gerente de Contexto é um trabalho de mestrado em andamento dentro do grupo. Esse projeto utiliza os esquemas desenvolvidos neste trabalho para permitir mediação contextual de serviços. A caracterização dos dispositivos utiliza o modelo CC/PP (W3C, 2003) e a caracterização da rede ainda está em estudo.

Por enquanto, o serviço de personalização obtém as características do dispositivo e da rede por meio de um arquivo descritor simulando a resposta do Gerente de Contexto. Esse arquivo contém informações sobre as capacidades de processamento e de memória do dispositivo e capacidade de banda da rede. Baseado nessas informações, o módulo decide se o dispositivo tem capacidade para executar um MPEGlet e se a taxa de quadros original deve ser mantida.

Caso o Módulo Gerador de Programas descubra que o dispositivo tem capacidades de processamento e de memória limitadas, um perfil de programa diferente é selecionado, o qual não inclui a interface e nem o MPEGlet. Se o acesso estiver sendo realizado via rede sem fio, a taxa de quadros dos segmentos deve ser ajustada. Nesse caso, antes de gerar o arquivo XMT, o Módulo requisita a recodificação dos segmentos da lista. Para isso o módulo passa ao codificador ESS o nome original, a localização, o novo nome e a nova localização para cada objeto, instruindo o codificador a realizar a codificação com taxa de quadros de 10 quadros por segundo. O arquivo XMT é então gerado apontando para os novos objetos e é enviado ao codificador ECT. Esse processo resulta em um programa mais "leve" para ser transmitido e apresentado.

\subsection{1 - Exemplos de Programas Personalizados}

A Figura 8.4 (a) apresenta um exemplo de programa personalizado. Nesse exemplo foi utilizado um perfil de programa que aborda um telejornal completo, com ligações para os segmentos que satisfazem às três primeiras preferências de assunto do usuário: Economia, Comentário e Cultura. A interface apresenta opções para assistir: ao jornal na íntegra (botão Jornal), às manchetes (botão Manchetes) e aos segmentos correspondentes às preferências (botões Economia, Comentário e Cultura).

Como opções de interatividade baseada em conteúdo, o usuário pode clicar sobre a imagem fazendo a mesma aumentar de tamanho (modo "tela cheia", conforme ilustrado na 
Figura 8.4(b)). Além disso, é possível clicar em alguns objetos intraquadro específicos e obter a descrição contextual do objeto, como ilustrado na Figura 8.5. A técnica aplicada para associar o objeto à sua descrição está detalhada na subseção 8.3.2.

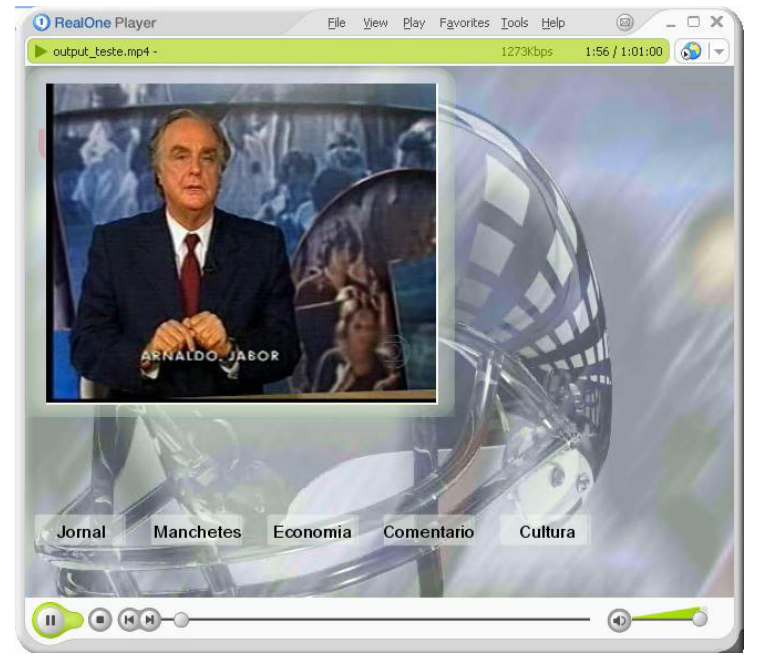

(a)

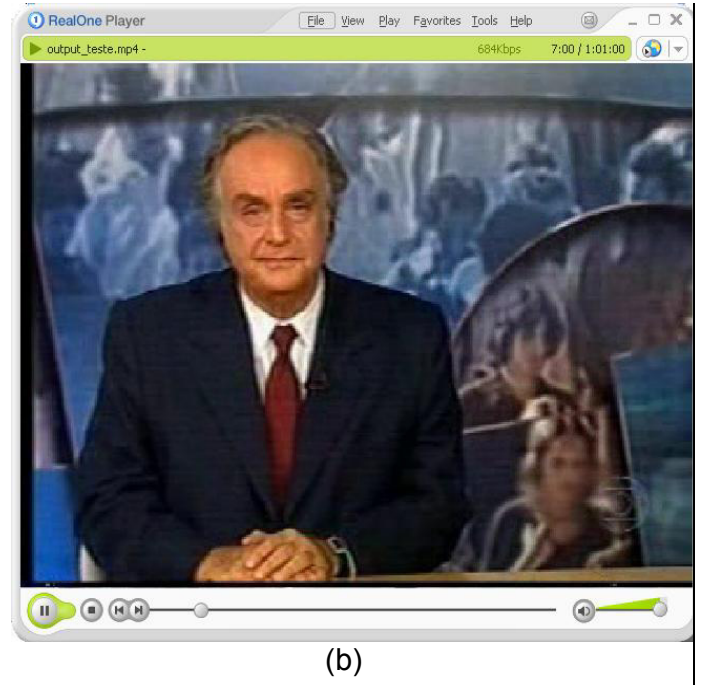

(b)

Figura 8.4 - Exemplo de acesso a um segmento de um programa interativo (Comentário). (a) Modo normal. (b) Em "tela cheia".

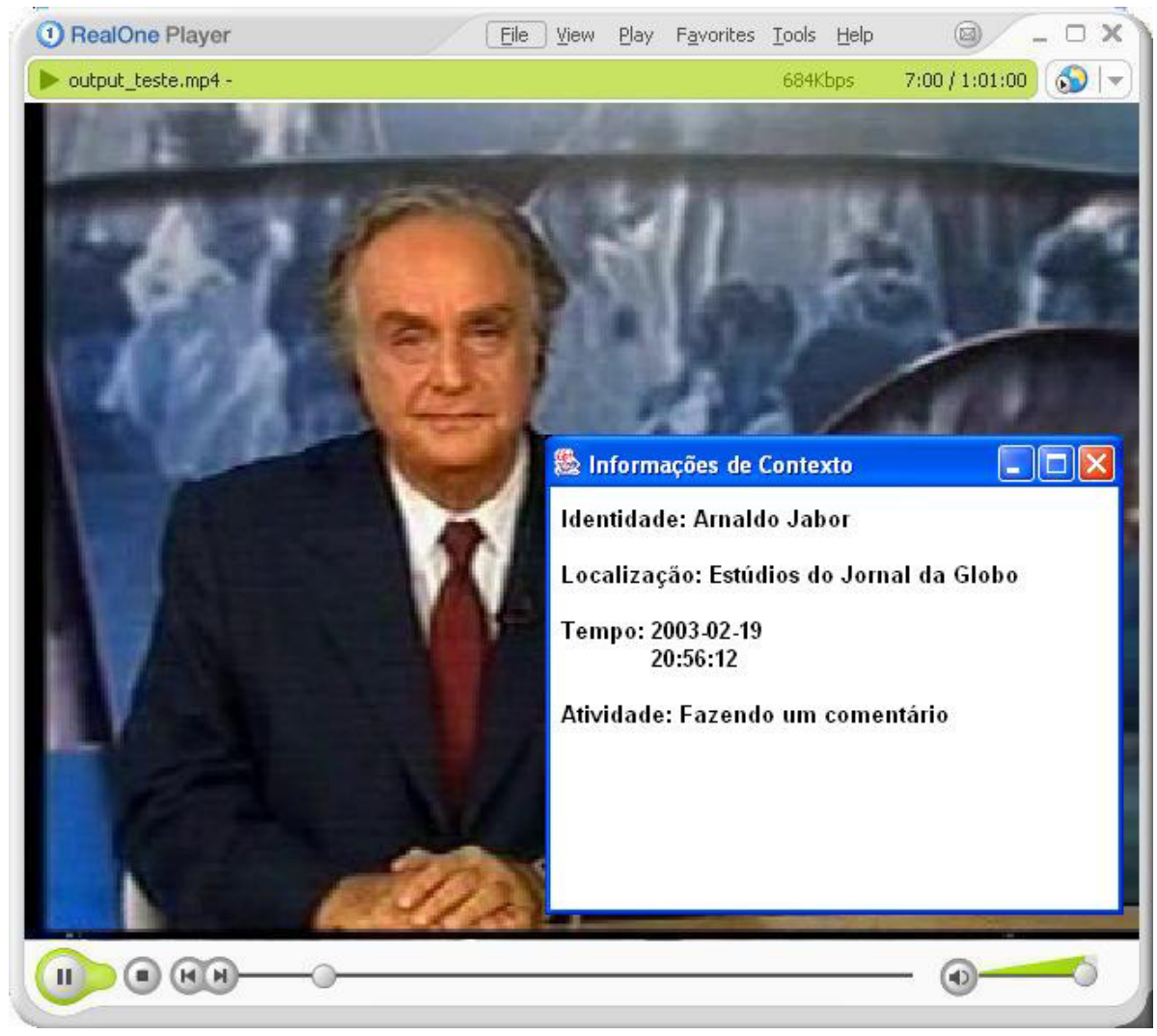

Figura 8.5 - Exemplo de recuperação de informação de contexto associada a um objeto intraquadro. 
A Figura 8.6 ilustra um exemplo de programa personalizado onde a preferência do usuário é pelo assunto futebol e o perfil de programa utilizado seleciona apenas os segmentos sobre futebol do telejornal. Além disso, o conteúdo foi adaptado para ser acessado via um PDA.

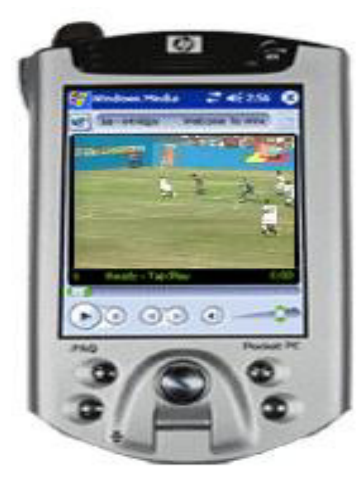

Figura 8. 6 - Exemplo de um programa personalizado e adaptado para acesso via PDA.

Interações e serviços mais complexos são possíveis. Por exemplo, pode-se utilizar o MPEGlet sendo executado no cliente para realizar buscas no SDM por conteúdo relacionado ao conteúdo que o usuário está assistindo. $\mathrm{O}$ resultado da busca pode ser uma lista contendo ponteiros (URIs) para os segmentos relacionados, ou um programa personalizado contendo a junção desses segmentos.

\subsection{2 - Associação de Descrições a Objetos de Mídia}

A associação das descrições a objetos de mídia, como a exemplificada na Figura 8.5, é feita durante o processo de parsing do perfil do programa, inserindo trechos de código em XMT que identificam um objeto, apontam para sua descrição e estabelecem a ligação entre ambos. O processo desenvolvido foi aplicado apenas a objetos intraquadro e descrições contextuais, porém, pode ser generalizado para qualquer tipo de segmento e descrição.

Para realizar a associação, o Módulo Gerador de Programas analisa as descrições dos segmentos selecionados verificando se existem objetos intraquadros - um elemento <Object> com o atributo scope igual a LOCAL, conforme apresentado no capítulo sete. O identificador do elemento <Object> é assinalado no arquivo XMT como o identificador do 
descritor de fluxo elementar do objeto MPEG-4. Desse modo, a descrição e o fluxo binário do objeto conterão o mesmo identificador.

Como os codificadores MPEG-4 sendo utilizados não dão suporte ao perfil MPEG4 Core, não é possível gerar objetos binários com formas arbitrárias constituindo objetos intraquadro. Desse modo, utilizou-se um artifício para representar objetos intraquadro: foi gerado um objeto retangular transparente como parte da interface. O arquivo XMT contém instruções posicionando esse objeto no tempo e no espaço, inserindo-o e removendo-o da cena, de acordo com as descrições do objeto intraquadro. Após inserir os segmentos, associar o MPEGlet e associar as descrições, o Módulo Gerador de Programas envia o arquivo XMT para o codificador ECT.

A interação com o objeto intraquadro (com o objeto transparente, na verdade) é possível graças a API MPEG-J. Essa API permite manipular o grafo da cena MPEG-4 por meio da interface SceneManger, que por sua vez possui a interface Node, a qual permite manipular os nós do grafo. Um dos métodos de Node - getID - permite recuperar o identificador de um nó e, um nó, nada mais é que um fluxo elementar MPEG-4. Desse modo, programou-se o MPEGlet para responder a um clique do mouse sobre o objeto transparente com uma chamada ao método Node.getID(). O resultado dessa chamada é passado como parâmetro na chamada de uma função, a qual tem como tarefa pesquisar as descrições recuperando as informações contextuais do objeto indicado no parâmetro, possibilitando interações como a ilustrada na Figura 8.5.

Essa pesquisa é feita localmente, em memória, no cliente. Quando o usuário acessa o programa, o MPEGlet é carregado e executado. Sua primeira tarefa é requisitar as descrições dos segmentos para o Gerenciador de Serviços. Esse, por sua vez, acessa a lista de segmentos do programa armazenada no NDR do usuário e realiza consultas ao SDM para recuperar as descrições.

As descrições, na forma de documentos XML, são enviadas ao MPEGlet que utiliza um parser para realizar pesquisas nas descrições. Esse parser foi desenvolvido utilizando a ferramenta Xerces (Apache, 2003), a qual permite criar árvores DOM de documentos XML, em memória, e possui métodos para navegar pela árvore e recuperar informações dos nós. Esse parser foi programado para reconhecer as instruções xlink nas descrições localizando o elemento <Locator> cujo atributo label seja igual ao identificador do objeto 
seguido do símbolo “_contexto", por exemplo: OBJ005_contexto. Tendo localizado o elemento, o parser recupera o valor do atributo href, e obtém o nome do arquivo que contém a descrição contextual do objeto. Assim, o MPEGlet pode recuperar as informações e exibi-las em uma janela, conforme ilustrado na Figura 8.5.

A vantagem dessa abordagem é permitir que buscas por conteúdo relacionado ao programa em exibição sejam feitas localmente, evitando consultas ao SDM. A desvantagem é ter que carregar, junto com o MPEGlet, as classes Java relativas ao parser e ao Xerces para tratamento das informações XLink contidas nas descrições. Isso torna inadequada a utilização do MPEGlet em dispositivos com restrições de memória e de processamento.

\section{$\underline{8.4}$}

\section{Considerações Finais}

Este capítulo apresentou uma infra-estrutura para produção, distribuição e consumo de programas de TV Interativa, desenvolvida tendo como base o modelo de referência TVAnytime para sistemas de TV Interativa. Espera-se, ao longo do desenvolvimento do projeto de protótipo de TV Interativa, que a infra-estrutura seja expandida com os outros serviços e funcionalidades dos modelos TV-Anytime. Também se espera, em uma segunda etapa do protótipo, desenvolver técnicas de interação e serviços segundo a modelagem de ambientes interativos feita por Santos Júnior (2002).

Essa infra-estrutura é o primeiro esforço do grupo em direção ao desenvolvimento de um protótipo de TV Interativa que dê suporte a serviços avançados como interatividade baseada em objetos, buscas baseadas em objetos, EPGs, indexação e navegação por segmentos, suporte a computação ciente de contexto, entre outros.

Os esquemas desenvolvidos nesta tese, apresentados nos capítulos 6 e 7, fornecem suporte ao desenvolvimento desses serviços. Como um modo de aplicar os esquemas, foi desenvolvida uma aplicação que utiliza os serviços da infra-estrutura, juntamente com instâncias dos esquemas, para personalizar e adaptar conteúdo de programas de TV Interativa. O método de seleção de programas e segmentos para compor um programa personalizado é baseado na comparação das descrições dos mesmos com as preferências do usuário. As descrições e o conteúdo selecionado estão em servidores do sistema local. Podem-se utilizar outros métodos de seleção de conteúdo que associem não só conteúdo 
local, mas também conteúdo de servidores remotos (outros provedores de conteúdo) e outros tipos de conteúdo além de vídeo, como reportagens em jornais e revistas eletrônicas na Web. Uma solução possível é a utilização do LinkDigger (Macedo et al., 2002), que justamente faz o trabalho de busca por assuntos relacionados em diversas fontes, incluindo Web.

Como resultados do desenvolvimento da aplicação e da infra-estrutura obtiveram-se a implementação de uma técnica para associar conteúdo MPEG-4 à sua respectiva descrição MPEG-7 e a definição de dois projetos de mestrado em andamento: um Gerente de Contexto e um Gerente de Segurança. O Gerente de Contexto, como explicado na seção 8.3, tem como função monitorar o sistema coletando informações de contexto de modo a permitir a mediação contextual de serviços.

A necessidade do Gerente de Segurança vem do fato de o sistema ter diversos usuários acessando informações e conteúdo em diferentes tipos de rede (cabeadas e sem fio), gerando questões relacionadas à privacidade e à segurança da informação. Aspectos como controle de conexão, autenticação e criptografia de dados confidenciais devem ser tratados. O Gerente de Segurança pretende utilizar informações contextuais como um meio de facilitar o tratamento dessas questões. Tal gerente deve se comunicar com o Gerente de Contexto e com Gerenciador de Serviços, garantindo ou proibindo acesso a determinado conteúdo, serviço ou informação. 
Capítulo

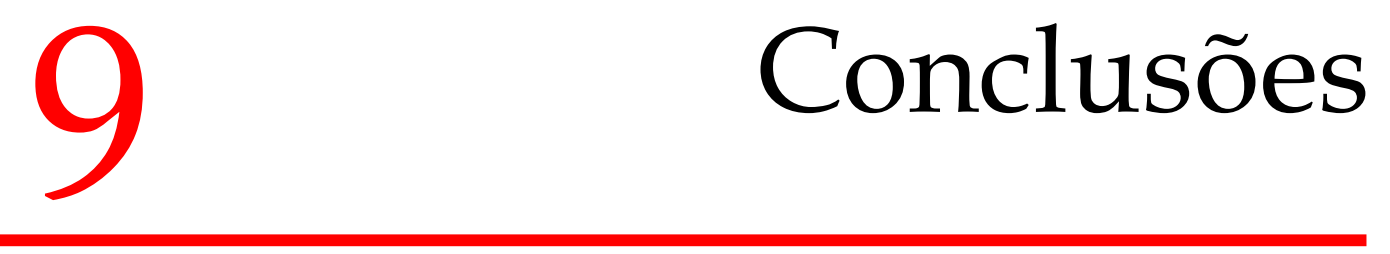




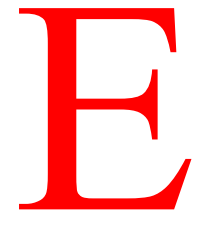

STE trabalho desenvolveu técnicas com suporte à ciência de contexto para personalizar e adaptar conteúdo em TV Interativa, permitindo que usuários possam acessar, sob demanda, programas contendo apenas assuntos de seu interesse e que o acesso possa ser realizado utilizando-se diferentes dispositivos.

As técnicas desenvolvidas estão baseadas em esquemas de descrição, compatíveis com o padrão MPEG-7, para representar e estruturar informações de contexto, descrições de programas e descrições dos objetos de mídia que compõem um programa. Também foi definida e implantada uma infra-estrutura para a produção, distribuição e consumo de programas. Essa infra-estrutura segue o modelo de referência TV-Anytime para sistemas de TV Interativa e suas ferramentas permitem a codificação de conteúdo de acordo com o padrão MPEG-4.

A utilização conjunta da infra-estrutura e dos esquemas de descrição permite o desenvolvimento de aplicações avançadas de TV Interativa. Como um exemplo dessas aplicações, foi desenvolvido um serviço automático de personalização e adaptação de conteúdo. O serviço utiliza as descrições dos objetos de mídia para compará-las às preferências do usuário e selecionar segmentos de programas que satisfaçam os interesses do usuário. Os segmentos selecionados são codificados como um novo programa MPEG-4 personalizado.

As próximas seções deste capítulo descrevem as contribuições deste trabalho (seção 9.1), discutem as limitações do mesmo (seção 9.2), apresentam os trabalhos decorrentes desta pesquisa (seção 9.3) e apresentam sugestões de trabalhos futuros (seção 9.4).

\section{1}

\section{Contribuições}

A principal contribuição deste trabalho, na área de TV Interativa, é o desenvolvimento de esquemas de descrição para programas e para objetos de mídia que possuem as seguintes características, não encontradas em trabalhos relacionados:

- Permitem a separação entre descrições de programas e descrições de objetos de mídia que compõem um programa. Essa característica facilita a reutilização de 
descrições durante, por exemplo, a composição de um novo programa a partir de segmentos vindos de diferentes fontes. As descrições podem ser facilmente localizadas e utilizadas por aplicações sem a necessidade de edição.

- Permitem representar e descrever a segmentação de objetos de mídia indo até o nível intraquadro.

- Permitem descrever a ligação entre um objeto de mídia e seus respectivos programa e subobjetos.

- Fornecem suporte à descrição de informações de contexto.

Outra contribuição deste trabalho é o desenvolvimento de uma técnica para associar conteúdo MPEG-4 à suas respectivas descrições MPEG-7. A técnica é baseada em associar o identificador de um objeto, em uma descrição, ao identificador de fluxo elementar MPEG-4 no arquivo XMT correspondente ao programa (ou apresentação MPEG-4) a ser codificado. Desse modo, com o auxílio da API MPEG-J, é possível implementar MPEGlets que recuperem o identificador de um objeto MPEG-4 durante a interação do usuário com um programa em exibição.

A partir do identificador do objeto é possível recuperar as informações presentes nas descrições (contextuais, de mídia e de ligações) do mesmo, potencializando o desenvolvimento de aplicações com interatividade baseada em objetos. A técnica foi aplicada a objetos intraquadros, porém, a mesma técnica pode ser aplicada a qualquer tipo de objeto MPEG-4: áudio, animação, vídeo, segmentos, cenas, quadros, etc. Apesar de o grupo MPEG estar trabalhando na associação de descrições MPEG-7 a conteúdo MPEG-4, até o momento em que esta tese estava sendo escrita não havia trabalho publicado a respeito de uma técnica para esse fim.

Uma contribuição adicional deste trabalho, valiosa na área de ciência de contexto, é a proposta de um modo flexível de organizar e representar informações de contexto, o qual permite o compartilhamento homogêneo desse tipo de informação. A proposta é baseada na construção de esquemas XML compondo um espaço de nomes extensível de elementos contextuais. Esses esquemas foram importados pelos esquemas de descrição de programas e de objetos de mídia fornecendo suporte à descrição de informações contextuais em aplicações de TV Interativa. A proposta de representação de contexto tem como características: 
- Uma classificação dos tipos de contexto.

- A construção de estruturas de alto nível que organizam a descrição de contexto.

- Permite a criação estruturada de uma biblioteca de informações contextuais.

- Facilita a tarefa de desenvolvedores em projetar aplicações cientes de contexto. Utilizando uma biblioteca o desenvolvedor não necessita projetar representações de informações contextuais; ele apenas decide o quanto de informação é necessário para caracterizar uma entidade contextual.

- Permite aos desenvolvedores criarem suas próprias representações para entidades contextuais e para informações de contexto.

\section{2}

Limitações

Uma limitação do trabalho realizado é que as ferramentas de codificação utilizadas na infra-estrutura são softwares comerciais, não se tendo acesso ao código fonte para desenvolver melhorias. Uma dessas melhorias seria a codificação de objetos de vídeo com formas arbitrárias (objetos intraquadros), característica definida no perfil core do padrão MPEG-4 - as ferramentas adotadas implementam apenas o perfil Advanced Simple@0-5.

Outra limitação proveniente das ferramentas MPEG-4 adotadas é que não é possível codificar e distribuir arquivos de texto junto com apresentações MPEG-4. Isso facilitaria o envio das descrições MPEG-7 para o MPEGlet no cliente. A solução implementada realiza consultas ao SDM para obter as descrições e envia as mesmas através da conexão entre o Gerenciador de Serviços e o MPEGlet. Vale notar que essa conexão é diferente da conexão por onde o programa está sendo enviado. Apesar de as descrições constituírem arquivos pequenos e mais fáceis de transmitir quando comparados aos vídeos dos programas de TV Interativa, o processo de obtenção e envio dessas descrições impõem processamento e atraso extras para o início da apresentação do programa. $\mathrm{O}$ impacto desses atrasos ainda não foi avaliado.

Algumas informações sobre os objetos de mídia podem ser extraídas automaticamente, notadamente as informações de mídia como tamanho do arquivo e tipo de codificação. Contudo, neste trabalho, todas as descrições dos objetos (de mídia ou 
semânticas) são criadas e armazenadas no SDM pelo autor do programa. Logo, a infraestrutura não fornece ferramentas automáticas e semi-automáticas de autoria de metadados integradas à ferramenta de produção de conteúdo.

O processo de gravação e posterior segmentação dos programas de telejornais também é feito de modo não automático. Existem meios para segmentar vídeo que utilizam técnicas de detecção automática de cenas, como o trabalho descrito em Merialdo et al. (1999). A implementação desse serviço fica como trabalho futuro.

\section{3}

Trabalhos Decorrentes desta Pesquisa

Como citado em outros capítulos, dois trabalhos de mestrado, em andamento, foram decorrentes das investigações realizadas nesta pesquisa. Um tem como meta o desenvolvimento de um Gerente de Contexto, que irá monitorar as informações contextuais do sistema, utilizando a biblioteca contextual desenvolvida neste trabalho, para promover intercâmbio homogêneo de informações e realizar mediação contextual entre serviços.

O outro trabalho tem como objetivo desenvolver um Gerente de Segurança, que irá investigar meios de se beneficiar das informações contextuais fornecidas pelo Gerente de Contexto para autenticar ações de usuários e de aplicações no acesso a serviços do Protótipo de TV Interativa, além de garantir integridade e autenticidade na transmissão de informações entre diferentes redes e dispositivos de acesso.

\section{4}

\section{Sugestões para Trabalhos Futuros}

Ao longo desta tese alguns trabalhos foram sugeridos como trabalhos futuros. Esta seção recapitula essas sugestões e apresenta outras. Trabalhos com pequeno grau de dificuldade são: implementar aplicações que configurem e acionem as ferramentas de captura e streaming da infra-estrutura utilizando as interfaces fornecidas pelo Gerenciados de Serviços; construção de um guia de programação em uma página Web onde os elementos do guia apontam para a localização das descrições dos programas no sistema de arquivos, permitindo a navegação entre os segmentos do programa; implementação de algumas funcionalidades previstas no modelo adotado para compor o núcleo básico da infra- 
estrutura e não contempladas neste trabalho como transferência e compartilhamento de conteúdo.

Trabalhos mais elaborados, com potencial para mestrado e doutorado, são:

- Modelagem e representação dos contextos do Domínio e do Ambiente.

- Modelos formais para a representação de informações para cada dimensão do contexto primário.

- Representações para o contexto da Aplicação e para o componente Serviços do contexto da Infra-Estrutura.

- Implementação de uma ferramenta de autoria para metadados integrada à ferramenta de produção de conteúdo, que permita extração automática e semiautomática das características dos objetos de mídia, salvando as descrições no SDM.

- Avaliação de desempenho do sistema.

- Utilização de outros métodos para a seleção de segmentos e programas relacionados, além das preferências dos usuários, incluindo buscas em outros servidores e outras fontes (como páginas na Web). Uma sugestão é a integração do LinkDigger (Macedo et al., 2002) na infra-estrutura proposta.

- Criação de EPGs que façam carga automática de guias de programação de diversos provedores de conteúdo e que também ofereçam conteúdo relacionado às preferências do usuário, além de fornecerem meios de interação com o usuário (funcionalidades de busca, navegação, seleção e controle de apresentação). 


\section{Anexo A}

A Tabela A1 apresenta as características do modelo de negócios (modelo bidirecional em banda larga) especificado pelo TV-Anytime, apresentado na subseção 2.4.3. Cada característica desse modelo pode ser implementada por uma ou mais unidades do modelo funcional de referência (apresentado na subseção 2.3.1), as quais são: 1) criação de conteúdo, 2) fornecimento de conteúdo, 3) gerenciamento de armazenamento local, 4) apresentação de conteúdo, 5) interação com o usuário, 6) resolução de localização, 7) busca e navegação, 8) acesso e 9) gerenciamento de direitos e segurança.

Tabela A1 - Características do modelo bidirecional em banda larga especificado pelo TV-Anytime Forum.

\begin{tabular}{|c|c|c|}
\hline Características do Modelo & Descrição & $\begin{array}{l}\text { Unidades } \\
\text { Funcionais } \\
\text { Responsáveis }\end{array}$ \\
\hline $\begin{array}{l}\text { Uso de EPG para procurar e } \\
\text { selecionar conteúdo. }\end{array}$ & $\begin{array}{l}\text { Além de ser um guia de programação, o } \\
\text { EPG pode ser a interface para busca e } \\
\text { gravação de conteúdo e para o } \\
\text { agendamento de gravações. Os critérios } \\
\text { de busca podem ser: título, ator, série, } \\
\text { formato da mídia, etc. }\end{array}$ & 5 e 7. \\
\hline $\begin{array}{l}\text { Suporte às preferências do } \\
\text { usuário. }\end{array}$ & $\begin{array}{l}\text { Agentes de busca podem ser configurados } \\
\text { em termos de programação, gênero, } \\
\text { preferências de visualização, ou podem se } \\
\text { adaptar ao usuário criando preferências } \\
\text { baseadas nos hábitos de uso. }\end{array}$ & $2,3,4,5$ e 7 \\
\hline $\begin{array}{l}\text { Suporte a preferências multi- } \\
\text { usuário. }\end{array}$ & $\begin{array}{l}\text { Múltiplos usuários de uma mesma casa } \\
\text { devem possuir preferências individuais. As } \\
\text { preferências podem ser exportadas entre } \\
\text { PDRs. }\end{array}$ & $\begin{array}{l}2,3,4,5,7 \mathrm{e} \\
8 .\end{array}$ \\
\hline $\begin{array}{l}\text { Captura e reprodução de } \\
\text { conteúdo. }\end{array}$ & $\begin{array}{l}\text { O PDR captura e armazena conteúdo para } \\
\text { posterior reprodução. Como em } \\
\text { videocassetes. }\end{array}$ & 3. \\
\hline Gravação por impulso. & $\begin{array}{l}\text { Essa característica habilita o usuário o } \\
\text { gravar um programa, a qualquer momento, } \\
\text { desde o início. }\end{array}$ & $2,3,4,5$ e 8 \\
\hline
\end{tabular}


Tabela A1 - (Continuação).

\begin{tabular}{|c|c|c|}
\hline Características do Modelo & Descrição & $\begin{array}{c}\text { Unidades } \\
\text { Funcionais } \\
\text { Responsáveis } \\
\end{array}$ \\
\hline $\begin{array}{l}\text { Gravação e exibição simultâ- } \\
\text { neas. }\end{array}$ & $\begin{array}{l}\text { Permite ao usuário gravar um ou mais } \\
\text { programas enquanto assiste outro(s), } \\
\text { pré-gravado(s) ou ao vivo. }\end{array}$ & $2,3,4$ e 5 \\
\hline $\begin{array}{l}\text { Reprodução em modo } \\
\text { highlight. }\end{array}$ & $\begin{array}{l}\text { O usuário pode reproduzir apenas as } \\
\text { manchetes ou segmentos selecionados. }\end{array}$ & 4. \\
\hline $\begin{array}{l}\text { Referência cruzada entre } \\
\text { conteúdo audiovisual e } \\
\text { material relacionado. }\end{array}$ & $\begin{array}{l}\text { Os programas podem ter referência } \\
\text { cruzada para conteúdo relacionado. Se o } \\
\text { conteúdo não foi previamente gravado, o } \\
\text { usuário recebe opções para capturar, } \\
\text { reproduzir ou receber uma notificação } \\
\text { sobre onde o conteúdo (audiovisual ou } \\
\text { não) está disponível. }\end{array}$ & $2,3,5,7$ e 8 \\
\hline Conteúdo sob demanda. & $\begin{array}{l}\text { O consumidor pode iniciar a gravação de } \\
\text { certo conteúdo no PDR a partir de várias } \\
\text { fontes. A transmissão começa de modo } \\
\text { instantâneo e o conteúdo pode ser usado } \\
\text { imediatamente. }\end{array}$ & 3 e 7 \\
\hline $\begin{array}{l}\text { Conteúdo pode ser gravado } \\
\text { no NDR. }\end{array}$ & $\begin{array}{l}\text { O gravador digital de rede (Network } \\
\text { Digital Recorder - NDR) é um espaço de } \\
\text { armazenamento na rede privada do } \\
\text { provedor de serviço. Deve ser protegido. }\end{array}$ & 7 e 8 \\
\hline $\begin{array}{l}\text { Gravação e reprodução de } \\
\text { conteúdo de forma local e } \\
\text { remota. }\end{array}$ & $\begin{array}{l}\text { Interoperação transparente entre PDR e } \\
\text { NDR. PDR pode automaticamente } \\
\text { solicitar espaço adicional ao NDR. } \\
\text { Envolve questões de segurança. }\end{array}$ & $3,5,7$ e 8 \\
\hline $\begin{array}{l}\text { Suporte a compartilhamento } \\
\text { de conteúdo. }\end{array}$ & $\begin{array}{l}\text { O provedor de serviço pode gerenciar o } \\
\text { compartilhamento de conteúdo entre } \\
\text { PDRs e/ou NDRs de usuários. Esse } \\
\text { serviço possui aplicações em vídeos } \\
\text { caseiros. }\end{array}$ & 2,3 e 8 \\
\hline $\begin{array}{l}\text { Transferência de conteúdo } \\
\text { para outros dispositivos que } \\
\text { não um PDR. }\end{array}$ & $\begin{array}{l}\text { Dispositivos como PDAs, computadores } \\
\text { pessoais e dispositivos de } \\
\text { armazenamento portáteis podem acessar } \\
\text { e copiar o conteúdo de um PDR. }\end{array}$ & 3 e 8. \\
\hline $\begin{array}{l}\text { Controle e gerenciamento } \\
\text { remoto do PDR. }\end{array}$ & $\begin{array}{l}\text { PDAs e celulares, por exemplo, podem } \\
\text { acessar, controlar e configurar } \\
\text { remotamente o PDR. Isso implica em } \\
\text { questões de segurança. }\end{array}$ & 3 e 8. \\
\hline $\begin{array}{l}\text { Gerenciamento de armaze- } \\
\text { namento local. }\end{array}$ & $\begin{array}{l}\text { O usuário pode especificar o quanto de } \\
\text { espaço de armazenamento do PDR deve } \\
\text { ser alocado para cada serviço. }\end{array}$ & 3. \\
\hline
\end{tabular}


Tabela A1 - (Continuação).

\begin{tabular}{|c|c|c|}
\hline \\
\hline Características do Modelo & Descrição & $\begin{array}{c}\text { Unidades } \\
\text { Funcionais } \\
\text { Responsáveis } \\
\end{array}$ \\
\hline $\begin{array}{l}\text { Captura e indexação de } \\
\text { segmentos de programas. }\end{array}$ & $\begin{array}{l}\text { A indexação por segmentos fornece } \\
\text { novas capacidades: 1) Indexação básica } \\
\text { (criada pelos provedores de conteúdo, } \\
\text { pode-se navegar por capítulos, } \\
\text { momentos-chave, cenas, etc.). 2) } \\
\text { Captura seletiva de segmentos. 3) İndice } \\
\text { pessoal (como um bookmark). 4) } \\
\text { Compartilhamento de índices entre } \\
\text { usuários. 5) Referência cruzada entre } \\
\text { segmentos de diferentes fontes. 6) } \\
\text { Ligações (hiperlinks) entre segmentos e } \\
\text { conteúdo Web, conteúdo audiovisual e } \\
\text { aplicações. }\end{array}$ & $2,3,4,5$ e 7 \\
\hline $\begin{array}{l}\text { Indexação personalizada do } \\
\text { conteúdo capturado. }\end{array}$ & $\begin{array}{l}\text { O usuário pode dispor de um sumário do } \\
\text { que foi capturado. }\end{array}$ & 2 e 4 \\
\hline $\begin{array}{llr}\text { Inserção/troca } & \text { dinâmica } & \text { de } \\
\text { segmentos } & \text { durante } & \text { a } \\
\text { reprodução. } & & \\
\end{array}$ & $\begin{array}{l}\text { Por exemplo, comerciais locais, } \\
\text { previamente armazenados no PDR, } \\
\text { podem substituir comerciais nacionais. }\end{array}$ & 2,3 e 4 \\
\hline $\begin{array}{l}\text { Acesso a conteúdo via } \\
\text { múltiplos dispositivos. }\end{array}$ & $\begin{array}{l}\text { Um usuário assistindo conteúdo } \\
\text { audiovisual na TV pode acessar dados } \\
\text { adicionais, ligados ao programa, em um } \\
\text { PDA. }\end{array}$ & 8. \\
\hline $\begin{array}{l}\text { Sincronização de material } \\
\text { audiovisual com material não } \\
\text { audiovisual. }\end{array}$ & $\begin{array}{l}\text { Em uma partida de futebol, por exemplo, } \\
\text { podem ser disponibilizadas estatísticas } \\
\text { sobre o time ou sobre um jogador } \\
\text { específico, sob demanda. }\end{array}$ & 3,4 e 5 \\
\hline $\begin{array}{lcc}\text { Sincronização } & \text { entre } & \text { mídia } \\
\text { armazenada } & \text { e } & \text { mídia } \\
\text { entregue sob demanda. }\end{array}$ & $\begin{array}{l}\text { Permite ao consumidor obter dados } \\
\text { relacionados ao conteúdo que se está } \\
\text { assistindo. Por exemplo, se o consumidor } \\
\text { está assistindo a um documentário sobre } \\
\text { o deserto do Saara e existe conteúdo } \\
\text { sobre camelos no servidor, o consumidor } \\
\text { pode ser questionado se lhe interessa ver } \\
\text { informações adicionais sobre camelos. O } \\
\text { PDR poderá então acessar o conteúdo e } \\
\text { disponibilizá-lo ao consumidor. }\end{array}$ & $2,3,5$ e 8 \\
\hline $\begin{array}{l}\text { Sincronização de conteúdo } \\
\text { gravado com material ao } \\
\text { vivo. }\end{array}$ & $\begin{array}{l}\text { Para atualizar ou melhorar o conteúdo } \\
\text { gravado. Por exemplo, durante a exibição } \\
\text { de um noticiário (ao vivo) sobre uma } \\
\text { enchente causada pela chuva em uma } \\
\text { determinada região, pode ser exibido um } \\
\text { noticiário (gravado) sobre a previsão do } \\
\text { tempo para o dia seguinte. }\end{array}$ & 3,4 e 5 \\
\hline
\end{tabular}


Tabela A1 - (Continuação).

\begin{tabular}{|c|c|c|}
\hline Características do Modelo & Descrição & $\begin{array}{l}\text { Unidades } \\
\text { Funcionais } \\
\text { Responsáveis } \\
\end{array}$ \\
\hline $\begin{array}{l}\text { Verificação de entrega de } \\
\text { conteúdo. }\end{array}$ & $\begin{array}{l}\text { Provedores podem se beneficiar ao saber } \\
\text { exatamente o que foi entregue ao } \\
\text { usuário. Aplicações em sistemas pay-per- } \\
\text { view. Envolve questões de segurança e } \\
\text { de privacidade. }\end{array}$ & 2 e 8 \\
\hline $\begin{array}{l}\text { Verificação de uso de } \\
\text { conteúdo. }\end{array}$ & $\begin{array}{l}\text { Provedores de serviços podem rastrear o } \\
\text { uso efetivo de conteúdo nos PDRs dos } \\
\text { usuários. Envolve questões de segurança } \\
\text { e de privacidade. }\end{array}$ & 2,3 e 8 \\
\hline $\begin{array}{l}\text { Preferências portáveis de } \\
\text { usuários. }\end{array}$ & $\begin{array}{l}\text { As preferências podem ser transferidas } \\
\text { entre diferentes dispositivos (PDAs, } \\
\text { celulares, computadores, PDRs, etc.). } \\
\text { Envolve questões de segurança. }\end{array}$ & 3 e 8. \\
\hline $\begin{array}{l}\text { Habilidade para coletar } \\
\text { dados de uso. }\end{array}$ & $\begin{array}{l}\text { Provedores de serviço e de conteúdo } \\
\text { podem utilizar dados de uso do } \\
\text { consumidor em cenários } \\
\text { personalização onde os serviços são } \\
\text { baseados em certas características da } \\
\begin{array}{ll}\text { audiência. Envolve questões de } \\
\text { segurança e privacidade. }\end{array}\end{array}$ & 2,3 e 8 \\
\hline Agregação de perfis. & $\begin{array}{l}\text { Habilita provedores de serviço e } \\
\text { anunciantes a atingir grupos de } \\
\text { consumidores com serviços específicos } \\
\text { baseados em interesses similares. }\end{array}$ & 2 e 8 \\
\hline
\end{tabular}




\section{Anexo B}

A seguir encontra-se a lista desenvolvida pelo TV-Anytime Forum (TV-Anytime, 2002) para classificar programação em TV Interativa. Essa classificação é utilizada para definir o gênero do programa, nas instâncias do esquema ITV_Program, para definir as preferências de programas do usuário, nas instâncias do esquema Context e para definir o gênero do assunto de um segmento ou objeto de vídeo nas instâncias do esquema MediaObject.

3.1 INFORMATION

3.1.1 General non-fiction topics

3.1.1.1 Daily news

3.1.1.2 Current affairs

3.1.1.3 Weather forecasts

3.1.1.4 Service information

3.1.1.5 Special news programs

3.1.1.6 Local / regional

3.1.1.7 Traffic

3.1.1.8 Magazines

3.1.1.9 News magazine

3.1.1.10 News/Report

3.1.1.11 Periodical/General

3.1.1.12 Special Edition/Documentary

3.1.1.13 Politics/National Assembly

3.1.1.14 Economy/Market

3.1.1.15 Foreign/International

3.1.1.16 Commentary

3.1.1.17 Debate/Talk

3.1.1.18 Special Report

3.1.1.19 Sports News

3.1.1.20 Others

3.1.2 Philosophies of life

3.1.2.1 Religious philosophies

3.1.2.1.1 Buddhism

3.1.2.1.2 Hinduism

3.1.2.1.3 Christinanity

3.1.2.1.4 Islam

$\begin{array}{lll} & 3.1 .2 .1 .5 & \text { Judaism } \\ \text { 3.1.2.2 } & \text { Non-religious philosophies }\end{array}$

3.1.2.2.1 Communism

3.1.3 Social/Political

3.1.3.1 Political

3.1.3.2 Social

3.1.3.3 Economical

3.1.3.4 Legal

3.1.4 Sports

3.1.4.1 Aeronautics 


\begin{tabular}{|c|c|}
\hline 3.1 .4 .2 & Aikido \\
\hline 3.1.4.3 & American Football \\
\hline 3.1.4.4 & Archery \\
\hline 3.1.4.5 & Athletics \\
\hline 3.1.4.6 & Badminton \\
\hline 3.1.4.7 & Bandy \\
\hline 3.1.4.8 & Baseball \\
\hline 3.1.4.9 & basketball \\
\hline 3.1.4.10 & Biathlon \\
\hline 3.1.4.11 & Bicycle \\
\hline 3.1.4.12 & Billiards \\
\hline 3.1 .4 .13 & Bobsleigh/tobogganing \\
\hline 3.1.4.14 & Body-building \\
\hline 3.1.4.15 & Boules sport \\
\hline 3.1.4.16 & Bowling \\
\hline 3.1.4.17 & Boxing \\
\hline 3.1.4.18 & Canoeing \\
\hline 3.1.4.19 & Casting \\
\hline 3.1 .4 .20 & Cricket \\
\hline 3.1.4.21 & Croquet \\
\hline 3.1.4.22 & Curling \\
\hline 3.1 .4 .23 & Cycling \\
\hline 3.1.4.24 & Dance sport \\
\hline 3.1 .4 .25 & Diving \\
\hline 3.1 .4 .26 & Equestrian \\
\hline 3.1.4.27 & Faustball \\
\hline 3.1.4.28 & Fencing \\
\hline 3.1.4.29 & Fishing \\
\hline 3.1.4.30 & Flying disc \\
\hline 3.1 .4 .31 & football \\
\hline 3.1.4.32 & golf \\
\hline 3.1.4.33 & gymnastics \\
\hline 3.1.4.34 & handball \\
\hline 3.1.4.35 & hockey \\
\hline 3.1.4.36 & ice-hockey \\
\hline 3.1.4.37 & jai-alai \\
\hline 3.1.4.38 & judo \\
\hline 3.1.4.39 & ju-jitsu \\
\hline 3.1 .4 .40 & karate \\
\hline 3.1.4.41 & korfball \\
\hline 3.1.4.42 & lacrosse \\
\hline 3.1.4.43 & luge \\
\hline 3.1.4.44 & maccabi \\
\hline 3.1.4.45 & Marathon \\
\hline 3.1.4.46 & modern pentathlon \\
\hline 3.1.4.47 & motor boating \\
\hline 3.1.4.48 & motor racing \\
\hline 3.1.4.49 & motor cycling \\
\hline 3.1 .4 .50 & mounteneering \\
\hline 3.1.4.51 & netball \\
\hline 3.1.4.52 & orienteering \\
\hline 3.1 .4 .53 & polo \\
\hline 3.1.4.54 & powerlifting \\
\hline 3.1.4.55 & racquetball \\
\hline 3.1 .4 .56 & roller skating \\
\hline 3.1.4.57 & rowing \\
\hline 3.1.4.58 & rugby \\
\hline 3.1 .4 .59 & Running \\
\hline
\end{tabular}




\begin{tabular}{|c|c|c|}
\hline & 3.1 .4 .60 & shooting \\
\hline & 3.1.4.61 & skating \\
\hline & 3.1 .4 .62 & skiing \\
\hline & 3.1 .4 .63 & skibob \\
\hline & 3.1 .4 .64 & sleddog \\
\hline & 3.1 .4 .65 & soccer \\
\hline & 3.1 .4 .66 & softball \\
\hline & 3.1.4.67 & soft tennis \\
\hline & 3.1 .4 .68 & sombo \\
\hline & 3.1.4.69 & sport acrobatics \\
\hline & 3.1 .4 .70 & squash \\
\hline & 3.1 .4 .71 & subaquatics \\
\hline & 3.1.4.72 & surfing \\
\hline & 3.1.4.73 & swimming/diving \\
\hline & 3.1.4.74 & table tennis \\
\hline & 3.1 .4 .75 & taekwondo \\
\hline & 3.1.4.76 & tennis \\
\hline & 3.1 .4 .77 & trampoline \\
\hline & 3.1 .4 .78 & Track/Field \\
\hline & 3.1.4.79 & triathlon \\
\hline & 3.1 .4 .80 & tug-of-war \\
\hline & 3.1.4.81 & volleyball \\
\hline & 3.1 .4 .82 & water polo \\
\hline & 3.1 .4 .83 & water-skiing \\
\hline & 3.1 .4 .84 & weightlifting \\
\hline & 3.1.4.85 & wrestling \\
\hline & 3.1 .4 .86 & yachting \\
\hline & 3.1.4.87 & Other ball games \\
\hline & 3.1 .4 .88 & combative sports \\
\hline & 3.1 .4 .89 & Snowboarding \\
\hline & 3.1.4.90 & Team sport (excluding football / soccer) \\
\hline & 3.1.4.91 & Martial sports \\
\hline & 3.1 .4 .92 & SUMO/Fighting Games \\
\hline & 3.1.4.93 & Snooker \\
\hline & 3.1.4.94 & Pool \\
\hline & 3.1.4.95 & Darts \\
\hline & 3.1.4.93 & Others \\
\hline 3.1 .5 & Human interest & \\
\hline & 3.1.5.1 & Reality \\
\hline & 3.1.5.2 & Show business \\
\hline & 3.1 .5 .3 & Notable personalities \\
\hline & 3.1.5.4 & Personal problems \\
\hline 3.1 .6 & Leisure & \\
\hline & 3.1.6.1 & Do-it-yourself \\
\hline & 3.1.6.2 & Cookery \\
\hline & 3.1 .6 .3 & Gardening \\
\hline & 3.1.6.4 & Tourism \\
\hline & 3.1 .6 .5 & Travel \\
\hline & 3.1.6.6 & fishing \\
\hline & 3.1.6.7 & Outdoors \\
\hline & 3.1 .6 .8 & Motoring \\
\hline & 3.1.6.9 & Keep-fit \\
\hline & 3.1.6.10 & Fashion \\
\hline & 3.1.6.11 & Computing \\
\hline & 3.1.6.12 & handicrafts \\
\hline & 3.1.6.13 & pets \\
\hline & 3.1.6.14 & Music \\
\hline & 3.1.6.15 & Igo / shogi (Japanese chess) \\
\hline
\end{tabular}




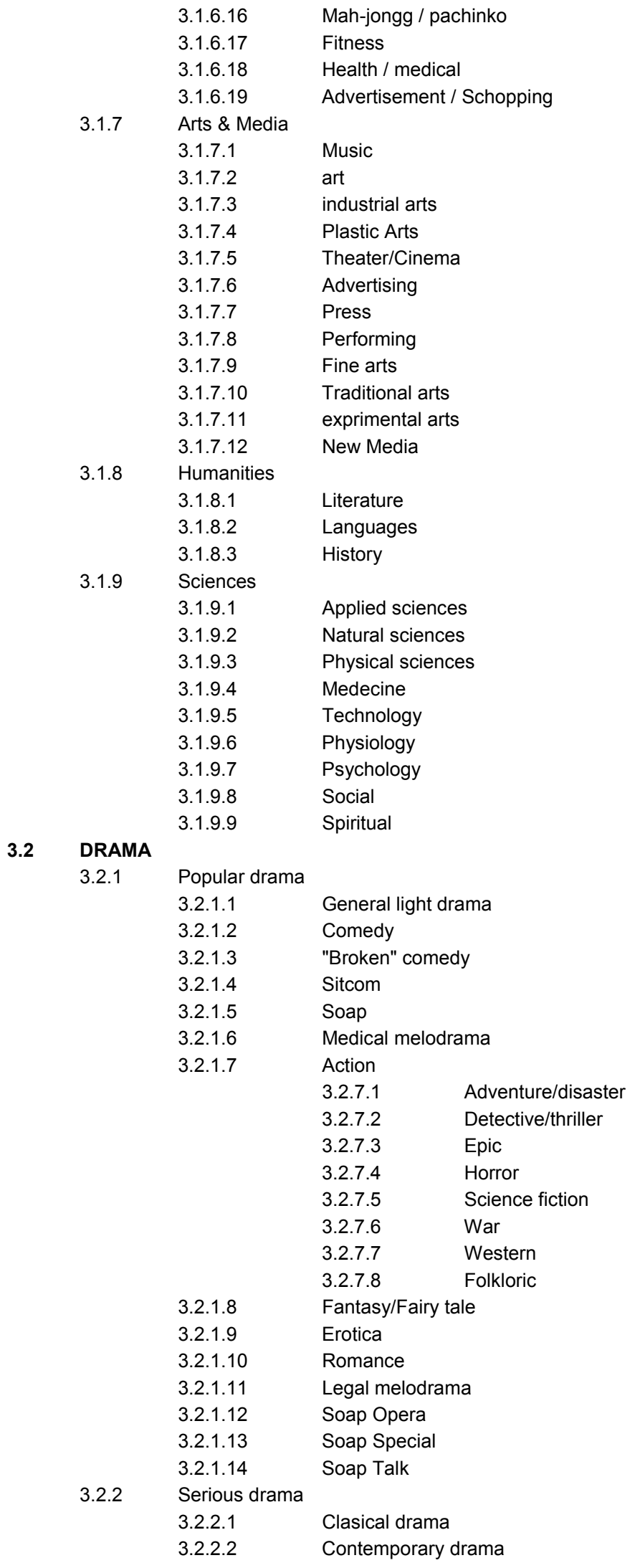


3.2.2.3 Religious

3.2.3 Docudrama

3.2.4 Poems / Stories

3.2.5 Performed drama

3.2.6 Drama with puppets

3.2.7 Animated drama

3.2.8 Action

3.2.9 Japanese drama

3.2.10 Foreign drama

3.2.11 Samurai drama

3.2.12 Kabuki / classical theater

3.2.13 Adult

3.2.14 Domestic Drama

3.2.15 Costume Play

3.2.16 Theater Drama

3.2.17 Modern Drama

3.2.18 Western Drama

3.2.19 Musical Drama

3.2.20 RAKUGO

3.2.21 Traditional drama

3.2.22 Others

3.3 ENTERTAINMENT

$\begin{array}{ll}\text { 3.3.1 } & \text { Simple game show } \\ \text { 3.3.2 } & \text { Big game show } \\ \text { 3.3.3 } & \text { Quiz/Contest } \\ \text { 3.3.4 } & \text { Variety Show } \\ \text { 3.3.5 } & \text { Surprise show } \\ \text { 3.3.6 } & \text { Humour } \\ \text { 3.3.7 } & \text { Candid camera etc. } \\ \text { 3.3.8 } & \text { Pure entertainment } \\ \text { 3.3.9 } & \text { Informative entertainment } \\ \text { 3.3.10 } & \text { Hosted show } \\ \text { 3.3.11 } & \text { Panel-show } \\ \text { 3.3.12 } & \text { Non-hosted show } \\ \text { 3.3.13 } & \text { Game show } \\ \text { 3.3.14 } & \text { Game shows } \\ \text { 3.3.15 } & \text { Talk shows } \\ \text { 3.3.16 } & \text { Comedy } \\ \text { 3.3.17 } & \text { Standup commedian(s) } \\ \text { 3.3.18 } & \text { "Rakugo" / stand-up performance } \\ \text { 3.3.19 } & \text { Surprise show } \\ \text { 3.3.20 } & \text { Travel variety } \\ \text { 3.3.21 } & \text { Music variety } \\ \text { 3.3.22 } & \text { Musicals } \\ \text { 3.3.23 } & \text { Musical comedy } \\ \text { 3.3.24 } & \text { Musical romance } \\ \text { 3.3.25 } & \text { Cooking variety } \\ \text { 3.3.26 } & \text { Show Business } \\ \text { 3.3.27 } & \text { Game } \\ \text { 3.3.28 } & \text { Variety Show } \\ \text { 3.3.29 } & \text { Gossip } \\ \text { 3.3.30 } & \text { Fashion } \\ \text { 3.3.31 } & \text { Life } \\ \text { 3.3.32 } & \text { Sports quiz } \\ & \text { Action } \\ & \text { Detective } \\ & \text { Drama } \\ & \text { Game Show } \\ & \\ & \\ & \\ & \end{array}$


Science Fiction

Soap

Factual

3.4 MUSIC

3.4.1 Serious music

3.4.1.1 Early

3.4.1.2 Classical and Romantic

3.4.1.3 Contemporary

3.4.1.4 Light classical

3.4.1.5 Opera

3.4.1.6 Classical

3.4.2 Jazz

3.4.2.1 Jazz / fusion

3.4.2.2 Traditional

3.4.2.3 modern

3.4.2.4 Pop Jazz

3.4.3 Middle-of-the-road

3.4.3.1 European popular traditional

3.4.3.2 Wolrd Music

3.4.4 Pop/rock/pop-rock

3.4.4.1 Wolrd Music

3.4.4.2 Folk

3.4.4.2.1 Traditional

3.4.4.2.2 Contemporary

3.4.5 Country

3.4.6 Traditional

3.4.5.1 Ethnic

3.4.6 Popular music

3.4.6.1 Foreign rock / pop

3.4.6.2 Japanese rock / pop

3.4.6.3 Japanese ballads / "Enka"

3.4.6.4 Live performances / concerts

3.4.6.5 Rankings / requests

3.4.6.6 Karaoke / singing contests

3.4.6.7 Folk music / (Japanese) folk music

3.4.6.8 Nursery songs / children's music

3.4.6.9 Culture-specific music / world music

3.4.6.10 Domestic Rock/Pop

3.4.7 Ballet

3.4.7.1 Ballet

3.4.8 Dance

3.4.8.1 Dance

3.4.9 Live Concert

3.4.10 Hit-Chart/Song Requests

3.4.11 Traditional Folksong/TraditionalMusic

3.4.12 Children"s Song

3.4.13 Ethnic Music/World Music

3.4.14 National Music

3.4.15 Alternative

3.4.16 Events

3.4.17 Hip Hop

3.4.18 Soul Ritme and Bleus

3.4.19 Club and Dance

3.4.20 Others

$3.5 \quad$ ENRICHMENT

3.5.1 General enrichment 


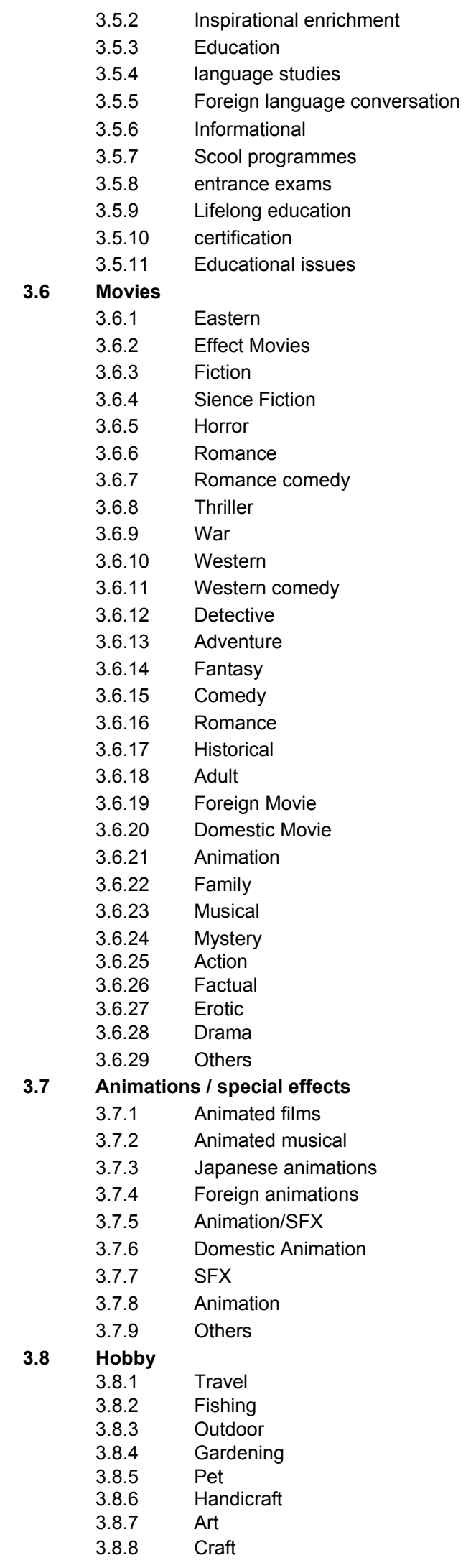




$\begin{array}{ll}3.8 .9 & \text { Music } \\ 3.8 .10 & \text { SHOGI } \\ 3.8 .11 & \text { GO } \\ 3.8 .12 & \text { PACHINCO } \\ 3.8 .13 & \text { MAJAN } \\ 3.8 .14 & \text { Car } \\ 3.8 .15 & \text { Motorcycle } \\ 3.8 .16 & \text { Computer } \\ 3.8 .17 & \text { Video Game } \\ 3.8 .18 & \text { Life/ House Keeping } \\ 3.8 .19 & \text { Technology } \\ 3.8 .20 & \text { Shopping } \\ 3.8 .21 & \text { Others }\end{array}$

3.9 Sport Events

3.9.1 international competitions

3.9.2 Horseracing / Government-sponsored sporting events (cycling, boat races,

etc.)

3.9.3 Marine

3.9.4 Sports Event

3.9.5 winter sports

3.9.6 Sports Non-Event

3.9.7 Sports Talk

3.9.8 track and field

3.9.9 Special Events

3.9.10 Olympic games

3.9.11 Woldcup

3.9.12 Sports magazine

3.9.13 Water sport

3.9.14 Live sports events

3.9.15 Motorsport

3.9.16 Others

3.10 Pure information

3.10.1 Infotainment

3.10.2 Advice

3.10.3 Politics / the Diet

3.10.4 Economy / Market conditions

3.10.5 Overseas / international

3.10.6 Commentary

3.10.7 Debates / conferences

3.10.8 Social issues

3.10.9 Economics advisory

3.10.10 Discussion

3.10.11 Social advisory

3.10.12 Interviews

3.10.13 Others

3.11 Information/ tabloid

3.11.1 Entertainment / tabloid

3.11.2 Fashion

3.11.3 Lifestyle / living space

3.11.4 Health

3.11.5 Shopping / mail order \& telephone shopping

3.11.6 Gourmet eating / cooking

3.11.7 Special Events

3.11.8 Program introductions / notices

3.11.9 Remarkable people

3.11.10 medical care

3.11.11 Others

3.12 Documentary
3.12.1
Society
3.12 .2
current events 


\begin{tabular}{|c|c|c|}
\hline \multicolumn{2}{|c|}{3.12 .3} & \multirow{2}{*}{$\begin{array}{l}\text { History } \\
\text { travelogues }\end{array}$} \\
\hline & 3.12 .4 & \\
\hline & 3.12 .5 & Nature \\
\hline & 3.12 .6 & animals \\
\hline & 3.12 .7 & the environment \\
\hline & 3.12 .8 & Space \\
\hline & 3.12 .9 & science \\
\hline & 3.12 .10 & medicine \\
\hline & 3.12 .11 & Culture \\
\hline & 3.12 .12 & tradition \\
\hline & 3.12 .13 & Literature and the arts \\
\hline & 3.12 .14 & Sports \\
\hline & 3.12 .15 & General documentaries \\
\hline & 3.12 .16 & Interviews \\
\hline & 3.12 .17 & debates \\
\hline & 3.12 .18 & Discussion \\
\hline & 3.12 .19 & Lecture \\
\hline & 3.12 .20 & Speech \\
\hline & 3.12 .21 & Presentation \\
\hline & 3.12 .22 & Textual (incl. relayed teletext) \\
\hline & 3.12 .23 & Special features \\
\hline & 3.12 .24 & Foreign countries \\
\hline & 3.12 .25 & Expeditions \\
\hline & 3.12 .26 & Current Topics \\
\hline & 3.12 .27 & Universe \\
\hline & 3.12 .28 & Traditional Culture \\
\hline & 3.12 .29 & War \\
\hline & 3.12 .30 & Transport \\
\hline & 3.12 .31 & Business \\
\hline & 3.12 .32 & World Culture \\
\hline & 3.12 .33 & Biography \\
\hline & 3.12 .34 & Adventure \\
\hline & 3.12 .35 & Features \\
\hline & 3.12 .36 & Politics \\
\hline & 3.12 .37 & Educational \\
\hline & 3.12 .38 & Features \\
\hline & 3.12 .39 & Religious \\
\hline & 3.12 .40 & Showbiz \\
\hline & 3.12 .41 & Others \\
\hline 3.13 & Educatio & \\
\hline & 3.13 .1 & Education \\
\hline & 3.13 .2 & Further education \\
\hline & 3.13 .3 & Languages \\
\hline & 3.13 .4 & Infants \\
\hline & 3.13 .5 & School Children \\
\hline & 3.13 .6 & Junior High-school \\
\hline & 3.13 .7 & High-school \\
\hline & 3.13 .8 & Students \\
\hline & 3.13 .9 & Entrance Examination \\
\hline & 3.13 .10 & Lifelong Education \\
\hline & 3.13 .11 & Qualification \\
\hline & 3.13 .12 & Educational Problems \\
\hline 3.14 & Children & \\
\hline & 3.14 .1 & Cartoons \\
\hline & 3.14 .2 & Comedy \\
\hline & 3.14 .3 & Drama \\
\hline & 3.14 .4 & Educational \\
\hline
\end{tabular}


3.14 .5

3.14 .6

3.14 .7

3.14 .8
Factual

Magazine

Game Shows

Other 


\section{Anexo C}

Este anexo apresenta os resumos dos artigos publicados durante o desenvolvimento deste trabalho:

Artigo 1: "Modeling of User Interaction in Context-Aware Interactive Television Application on Distributed Environments".

Abstract. The possibility of using multimedia objects in modern applications has proven to be a bonus. We want to provide ways in which the user can interact with multimedia objects while it is been presented with features that go beyond the regular controls of a VCR. Furthermore, the presentation of the video can be modified by events happening in the surrounding environment. This paper presents a proposal to model the user actions from contextual information, in a way to ease its interaction with context-aware interactive applications like Interactive TV (ITV). The paper also discusses how and which kind of contextual information could be used in one ITV environments that have an active network as the underlying infrastructure.

Referência: SANTOS JR., J.B. DOS; GOULARTE, R.; FARIA, G.; MOREIRA, E. D. S. Modeling of User Interaction in Context-Aware Interactive Television Application on Distributed Environments. Proceedings. First Workshop on Future Television at Eigth International Conference on User Modelling (UM'2001). Sonthofen, Alemanha, v. 1, n. 1, p. 49-61, julho de 2001.

Artigo 2: "Uso de perfis em aplicações de televisão interativa conscientes de contexto" Resumo: A TV Interativa é uma aplicação multimídia que insere novas funcionalidades em um ambiente anteriormente não interativo. Um grande número de tecnologias pode ser usado em sua implementação e, devido ao crescente interesse da indústria na área, diversos esforços têm sido feitos para sua padronização. Este artigo apresenta um novo conceito para 
programas interativos que provê um avanço na adaptação dos programas às necessidades ou expectativas dos usuários, utilizando os padrões e tecnologias para a TV Interativa e estendendo-os para o uso em ambientes conscientes de contexto.

Referência: FARIA, G. B.; SANTOS JÚNIOR, J. B.; GOULARTE, R.; MOREIRA, E. D. S. Uso de perfis em aplicações de televisão interativa conscientes de contexto. In: SIMPÓSIO BRASILEIRO DE SISTEMAS MULTIMÍDIA E HIPERMÍDIA - SBMÍDIA. 7., 2001, Florianópolis. Anais. Florianópolis:SBC, 2001.p. 139-154

Artigo 3: "The Modeling of Structured Context-Aware Interactive Environments".

Abstract: The possibility of using multimedia objects in modern applications has proven to be a bonus. We want to provide ways in which the user can interact with multimedia objects while it is been presented with features that go beyond the regular controls of a VCR. Furthermore, the presentation of the video can be modified by events happening in the surrounding environment. This paper presents a proposal for modeling Structured Context-Aware Interactive Applications as an approach for covering the user-networkapplication interactions that occur in an interactive environment, like is the case of Interactive Television (ITV). In this scenario, the work discusses mainly how and which kind of contextual information could be used in one interactive environments that have an active network as the underlying infrastructure, for example. The concept of profile is also presented and methods for using profiles in interactive programs are discussed.

Referência: SANTOS JÚNIOR, J. B.; GOULARTE, R.; MOREIRA, E. D. S.; FARIA, G. B. The Modeling of Structured Context-Aware Interactive Environments. Transactions of the SDPS - Journal of Integrated Design and Process Science, v. 5, n. 4, p. 77-93, 2001.

Artigo 4: "Representação de Objetos de Mídia para Aplicações Conscientes de Contexto em TV Interativa".

Resumo: Este artigo apresenta uma forma de representar objetos de mídia (como vídeo e imagens) que compõem um programa de TV Interativa. Tal representação é baseada em um esquema de descrição desenvolvido utilizando o padrão MPEG-7, que contempla composição, segmentação, e relacionamentos entre objetos, além de dar suporte à representação de informações de contexto. O artigo discute: os detalhes do esquema de 
descrição proposto; como o suporte à consciência de contexto é fornecido; e como o esquema é utilizado em uma arquitetura de servidor de programas de TV Interativa baseada nos padrões MPEG-4 e MPEG-7.

Referência: GOULARTE, R.; MOREIRA, E. D. S. Representação de Objetos de Mídia para Aplicações Conscientes de Contexto em TV Interativa. In: SIMPÓSIO BRASILEIRO DE SISTEMAS MULTIMÍDIA E HIPERMÍDIA - SBMÍDIA. 8., 2002, Fortaleza. Anais. Fortaleza: SBC, 2002. p. 150-165.

Artigo 5: "Structuring Interactive TV Documents".

Abstract: Interactive video technology is meant to support user-interaction with video in scene objects associated with navigation in video segments and access to text-based metadata. Interactive TV is one of the most important applications of this area, which has required the development of standards, techniques and tools, such as MPEG-4 and MPEG7 , to create, to describe, to deliver and to present interactive content.

In this scenario, the structure and organization of documents containing multimedia metadata play an important role. However, the Interactive TV documents structuring and organization has not been properly explored during the development of advanced Interactive TV services.

This work presents a model to structure and to organize documents describing Interactive TV programs and its related media objects, as well as the links between them. This model gives support to represent contextual information, and makes possible to use relevant metadata information in order to implement advanced services like object-based searches, in- movie (scenes, frames, in-frame regions) navigation, and personalization. To demonstrate the functionalities of our model, we have developed an application which uses an Interactive TV program's documents descriptions to present information about in-frame video objects.

Referência: GOULARTE, R.; MOREIRA, E. D. S. Structuring Interactive TV Documents. In: ACM INTERNATIONAL SYMPOSIUM ON DOCUMENT ENGINEERING. 3., 2003, Grenoble. Proceedings. (artigo aceito para publicação em novembro de 2003). 


\section{Referências}

(ABERT, 2001)

ABERT/SET Grupo Técnico de TV Digital. Comentários à consulta pública 291/2001 - Televisão Digital, 2001. Disponível em:

$<$ http://www.anatel.gov.br/acontece_anatel/Consulta/2001/consu 1ta_291/CT_CP291_SETABERT.pdf $>$. Acesso em: 28 jul.2003.

(Abowd, 1999) ABOWD, G. D. Classroom 2000: an experiment with the instrumentation of a living educational environment. IBM Systems Journal, v. 38, n. 4, p. 508-530, 1999.

(Abowd \& Mynatt, ABOWD, G. D.; MYNATT, E. D. Charting past, present, and 2000) future research in ubiquitous computing. ACM Transactions on Computer-Human Interaction (TOCHI), v. 7, n. 1, p. 29-58, 2000.

(Abowd et al., 2002) ABOWD, G. D.; MYNATT, E. D.; RODDEN, T. The Human experience. IEEE Pervasive Computing, v. 1, n. 1, p. 48-57, 2002.

(ANATEL, 2001) Agência Nacional de Telecomunicações. Relatório Integrador dos Aspectos Técnicos e Mercadológicos da TV Digital, 2001. Disponível em:

$<$ http://www.anatel.gov.br/acontece_anatel/Consulta/2001/consu 1ta_291/R Relatorio_Integrador.exe $>$. Acesso em: 28 jul.2003.

(Apache, 2003) APACHE SOFTWARE FOUNDATION. Xerces2 Java Parser Readme, 2003. Disponível em <http://xml.apache.org/xerces2$\mathrm{j} /$ index.html>. Acesso em: 12 set. 2003.

(Apple, 2001) $\quad$ APPLE COMPUTERS, INC. QuickTime File Format, 2001. Disponível em:

$<$ http://developer.apple.com/documentation/QuickTime/QTFF/q tff.pdf $>$. Acesso em: 27 ago. 2003.

(ARIB, 1998) ARIB - Association of Radio Industries and Business. Terrestrial Integrated Services Digital Broadcast - ISDB-T: Specification of Channel Coding, Framing Structure and Modulation (ISDB-T), 2001. Disponível em: $<\mathrm{http} / / /$ www.dibeg.org/Documents/Isdb-t_spec.PDF $>$. Acesso em: 19 ago. 2003.

(Arruda Júnior, 2003) ARRUDA JÚNIOR, C. R. E. Context Kernel: Um Web Service Baseado nas Dimensões de Informação de Contexto. 2003. 85p. Dissertação (Mestrado) - Instituto de Ciências Matemáticas e de 
(ATS, 1995)

(ATS, 2001)

(ATVEF, 2000)

(Avaro \& Salembier, 2001)

(Avaro et al, 2000)

(Avaro et al., 2002)

(Battista et al., 1999)

(Benitez et al., 2000)

(Boll et al., 1999)

(Brown et al., 1997)

(Brown, 1998)

(Chang et al., 2001)

(Chalmers, 2002)
Computação, Universidade de São Paulo, São Carlos, 2003.

ATS - Advanced Television Systems I. Digital Audio Compression Standard (AC-3) - (A/52), 1995. Disponível em: < http://www.atsc.org/standards/a_52a.pdf $>$. Acesso em 27 ago. 2003.

ATS - Advanced Television Systems I. ATSC Standard A/53B with Amendments 1 and 2: ATSC Digital Television Standard, Rev. $B$, 2001. Disponível em:

$<\mathrm{http}$ ://www.atsc.org/standards/a_53b_with_amendment_12.pdf>. Acesso em: 19 ago. 2003.

ATVEF - Advanced Television Enhancement Forum. Enhanced Content Specification, 2000. Disponível em: $<$ http://www.atvef.com/library/spec1_1a.html $>$. Acesso em: 19 ago. 2003.

AVARO, O.; SALEMBIER, P. MPEG-7 Systems: Overview. IEEE Transactions on Circuits and Systems for Video Technology, v. 11, n. 6, p. 760-764, 2001.

AVARO, O.; ELEFTHERIADIS, A.; HERPEL, C.; RAJAN, G.; WARD, L. MPEG-4 Systems: Overview. Signal Processing: Image Communication, v. 15, n. 4-5, p. 281-298, 2000.

AVARO, O.; KOENEN, R.; PEREIRA, F. MPEG-4 Overview. In: PEREIRA, F.; EBRAHIMI, T. The MPEG-4 Book. Upper Saddle River: Prentice Hall PTR, 2002. p. 37-63.

BATTISTA, S.; CASALINO, F.; LANDE, C. MPEG-4: A Multimedia Standard for the Third Millennium - Part 1. IEEE MultiMedia, v. 6, n. 4, p. 74-83, 1999.

BENITEZ, A.B.; PAEK, S .; CHANG, S.; PURI, A.; HUANG, Q.; SMITH, J. R.; LI, C.; BERGMAN, L. D.; JUDICE, C. N. Object-based multimedia content description schemes and applications for MPEG-7. Signal Processing: Image Communication, v.16, n 1-2, p. 235-269, 2000

BOLL, S.; KLAS, W.; WANDEL, J. A Cross-Media Adaptation Strategy for Multimedia Presentations. In: ACM INTERNATIONAL CONFERENCE ON MULTIMEDIA. 7., 1999, Orlando. Proceedings. New York: ACM, 1999. p. 37-46.

BROWN, P. J.; BOVEY, J. D.; CHEN, X.: Context-Aware Applications: From the Laboratory to the Marketplace. IEEE Personal Communications, v. 4, n. 5, p. 58-64, 1997.

BROWN, P. J. Triggering Information by Context. Personal Technologies, v. 2, n. 1, p. 1-9, 1998.

CHANG, S.; SIKORA, T.; PURI, A. Overview of the MPEG-7 Standard. IEEE Transactions on Circuits and Systems for Video Technology, v. 11, n. 6, p. 668-695, 2001.

CHALMERS, D. Contextual Mediation to Support Ubiquitous Computing. 2002. 279p. Tese (Doutorado) - Imperial College of 
(Chorianopoulos

al., 2003)

(Cosmas et al., 1999)

(Crowley et al., 2002) CROWLEY, J. L.; COUTAZ, J.; REY, G.; REIGNIER, P. Perceptual Components for Context Aware Computing. In: BORRIELLO, G.; HOLMQUIST, L.E. UbiComp 2002: Ubiquitous Computing. Heidelberg: Springer-Verlag, 2002. p.117-134. (Lecture Notes in Computer Science, 2498)

(DeRose \& Durand, 1994)

(Dey \& Abowd, 1999)

(Dey, 2001)

(Digital, 2003)

(Dix et al., 2000)

(Dublin Core, 2003)

(Dufourd, 2002)

(DVB, 1999)

Science, Technology and Medicine, Universidade de Londres, Londres, 2002.

et CHORIANOPOULOS, K.; LEKAKOS, G.; SPINELLIS, D. Intelligent User Interfaces in the Living Room: Usability Design for Personalized Television Applications. In: ACM INTERNATIONAL CONFERENCE ON INTELLIGENT USER INTERFACES. 11., 2003, Miami. Proceedings. New York: ACM, 1999. p. 230-232.

COSMAS, E.; PARKER, Y.; SCHOONJAS, P.; VADUVA, A.; DOSCH, C.; SCHÄFER, R.; ERK, A.; MIES, R.; BAIS, M.; SCHÄFER, R.; STAMMNITZ, P.; SELINGER, T.; KLUNSOYR, G.; PEDERSEN, L.; BAUER, S.; ENGELSBERG, A.; KLOCK, B.; EVENSEN, G. CustomTV with MPEG-4 and MPEG-7. In: IEE COLLOQUIUM ON INTERACTIVE TELEVISION. Digest 99/200, 1999, Londres. Proceedings. Londres: IEE, 1999. p. 9/1-9/6.

DEROSE, S.; DURAND, D. Making Hypermedia Work: A User's Guide to HyTime. Boston: Kluwer, 1994.

DEY, A.K.; ABOWD, G.D. Towards a Better Understanding of Context and Context-Awareness. Atlanta, College of Computing, Georgia Institute of Technology, 1999. (Relatório Técnico)

DEY, A. K. Understanding and Using Context. ACM Personal and Ubiquitous Computing Journal, v. 5, n. 1, p. 4-7, 2001.

DIGITAL NETWORKS NORTH AMERICA, INC. ReplayTV, 2003. Disponível em: <http://www.replaytv.com>. Acesso em: 19 ago. 2003.

DIX, A.; RODDEN, T.; DAVIES, N.; TREVOR, J.; FRIDAY, A.; PALFREYMAN, K. Exploiting Space and Location as a Design Framework for Interactive Mobile Systems. ACM Transactions on Computer-Human Interaction, v. 7, n. 3, p. 285321, 2000.

DUBLIN CORE. Dublin Core Metadata Initiative. Disponível em: < http://dublincore.org $>$. Acesso em: 27 ago. 2003.

DUFOURD, J. BIFS: Scene Description. In: PEREIRA, F.; EBRAHIMI, T., The MPEG-4 Book. Upper Saddle River: Prentice Hall PTR, 2002. p. 103-147.

DVB - Digital Video Broadcasting. ETSI EN 300 74: Framing structure, channel coding and modulation for digital terrestrial television version 1.2.1, 1999. Disponível em: $<\mathrm{http}: / /$ www.etsi.org $>$. Acesso em: 19 ago. 2003. 
(DVB-MHP, 2001) DVB-MHP - Digital Video Broadcast-Multimedia Home Platform. Multimedia Home Platform (MHP) 1.1, 2001. Disponível em: $<$ http://www.mhp.org/technical_essen/>. Acesso em: 19 ago. 2003.

(Ebrahimi \& Horne, EBRAHIMI, T.; HORNE, C. MPEG-4 Natural Video Coding: 2000) an Overview. Signal Processing: Image Communication, v. 15, n. 4-5, p. 365-385, 2000.

(Envivio, 2003) ENVIVIO, INC. Envivio 4Coder SE MPEG-4 Offline Encoding Software - Overview, 2003. Diponível em: $<$ http://www.envivio.com/products/ees.html $>$. Acesso em 07 set. 2003.

(Envivio, 2003a) ENVIVIO, INC. 4Mation MPEG-4 Authoring System for Interactive Content and Applications - Overview, 2003. Diponível em: $<$ http://www.envivio.com/products/ebs.html $>$. Acesso em 07 set. 2003.

(Envivio, 2003b) ENVIVIO, INC. Envivio 4Caster ${ }^{\mathrm{TM}}$ SE Realtime MPEG-4 Encoder Software - Overview, 2003. Diponível em: $<$ http://www.envivio.com/products/elb.html $>$. Acesso em 07 set. 2003.

(Envivio, 2003c) ENVIVIO, INC. Envivio Coding Tools - Overview, 2003. Diponível em: $<\mathrm{http} / / /$ www.envivio.com/products/ect.html $>$. Acesso em 07 set. 2003.

(Envivio, 2003d) ENVIVIO, INC. EnvivioTV TM MPEG-4 Player-Overview, 2003. Diponível em:

$<$ http://www.envivio.com/products/etv/index.html $>$. Acesso em 07 set. 2003.

(Faria, 2001) FARIA, G. B. O Uso de MPEG-7 na Personalização da TV Interativa. 2001. 101p. Dissertação (Mestrado) - Instituto de Ciências Matemáticas e de Computação, Universidade de São Paulo, São Carlos, 2001.

(Faria et al., 2001) FARIA, G. B.; SANTOS JÚNIOR, J. B.; GOULARTE, R.; MOREIRA, E. D. S. Uso de perfis em aplicações de televisão interativa conscientes de contexto. In: SIMPÓSIO BRASILEIRO DE SISTEMAS MULTIMÍDIA E HIPERMÍDIA - SBMÍDIA. 7., 2001, Florianópolis. Anais. Florianópolis:SBC, 2001. p. 139-154.

(Gray \& Salber, GRAY, P.; SALBER, D. Modelling and Using Sensed Context 2001) Information in the Design of Interactive Applications. In: LITTLE, M.R.; NIGAY, L. EHCI 2001: 8th IFIP International Conference on Engineering for Human-Computer Interaction,. Heidelberg: Springer-Verlag, 2001. p.317-335. (Lecture Notes in Computer Science, 2254)

(Goularte \& Moreira, GOULARTE, R.; MOREIRA, E. D. S. Managing Access to a 2001)

Video Server Through a Metadata Base. International Journal of Computres \& Applications, v. 23, n. 1, p. 25 - 29, 2001. 
(Goularte \& Moreira, 2002)

(Goularte \& Moreira, 2003)

(Harisson et al., HARRISON, B. L.; FISHKIN, K. P.; GUJAR, A.; MOCHON, 1998)

(Harter et al., 1999)

(van Herwijenen,

(Herpel

Eleftheriadis, 2000)

(Herpel, 2002)

(Herpel et al., 2002)

(Hjelsvold et al., 2001)

(Hu \& Ye, 1999)

(Hull et al., 1997)

GOULARTE, R.; MOREIRA, E. D. S. Representação de Objetos de Mídia para Aplicações Conscientes de Contexto em TV Interativa. In: SIMPÓSIO BRASILEIRO DE SISTEMAS MULTIMÍDIA E HIPERMÍDIA - SBMÍDIA. 8., 2002, Fortaleza. Anais. Fortaleza: SBC, 2002. p. 150-165.

GOULARTE, R.; MOREIRA, E. D. S. Structuring Interactive TV Documents. In: ACM SYMPOSIUM ON DOCUMENT ENGINEERING. 3., 2003, Grenoble. Proceedings. (a ser publicado).

C.; WANT, R. Squeeze me, hold me, tilt me! An exploration of manipulative user interfaces. In: ACM CONFERENCE ON HUMAN FACTORS IN COMPUTING SYSTEMS - CHI'98, 16., 1998, Los Angeles. Proceedings. New York: ACM/Addison-Wesley, 1998. p. 17-24.

HARTER, A.; HOPPER, A.; STEGGLES, P.; WARD, A.; WEBSTER, P. The anatomy of a context-aware application. In: ACM/IEEE INTERNATIONAL CONFERENCE ON MOBILE COMPUTING AND NETWORKING. 5., 1999, Seatle. Proceedings. New York: ACM, 1999. p. 59-68.

VAN HERWIJENEN, E. Practical SGML. 2. ed. Boston: Kluwer, 1994.

\& HERPEL, C.; ELEFTHERIADIS, A. MPEG-4 Systems: Elementary Stream Management. Signal Processing: Image Communication, v. 15, n. 4-5, p. 299-320, 2000.

HERPEL, C. Object Description and Synchronization. In: PEREIRA, F. and EBRAHIMI, T., The MPEG-4 Book. Upper Saddle River: Prentice Hall PTR, 2002. p. 65-101.

HERPEL, C.; FRANCESCHINI, G.; SINGER D. Transporting and Storing MPEG-4 Content. In: PEREIRA, F. and EBRAHIMI, T., The MPEG-4 Book. Upper Saddle River: Prentice Hall PTR, 2002. p.227-291.

HJELSVOLD, R.; VDAYGIRI, S.; LÉAUTÉ, Y. Web-based Personalization and Management of Interactive Video. In: ACM INTERNATIONAL WORLD WIDE WEB CONFERECE, 10., 2001, Ottawa. Proceedings. New York: ACM, 2001. p. 129-139. HU, M.J.; YE, J. MD2L: content description of multimedia documents for efficient process and search/retrieval. In: IEEE FORUM ON RESEARCH AND TECHNOLOGY ADVANCES IN DIGITAL LIBRARIES. 6., 1999, Baltimore. Proceedings. Los Alamitos: IEEE, 1999. p. 200-213.

HULL, R.; NEAVES, P.; BEDFORD-ROBERTS, J. Towards Situated Computing. In: IEEE INTERNATIONAL SYMPOSIUM ON WEARABLE COMPUTERS, 1., 1997, Cambridge. Proceedings. Los Alamitos: IEEE, 1997. p. 146- 
(Hunter, 2001)

(Ishii \& Ullmer, 1997)

(ISO, 1999)

(ISO, 2001)

(ISO, 2002)

(ISO, 2002a)

(ISO, 2003)

(Jang et al., 2002)

(Johnson, 1999)

(Kim \& Wood, 2002)

(Kindberg et al., 2000)

(Koenen \& Pereira, 2002)
153.

HUNTER, J. An Overview of the MPEG-7 Definition Language (DDL). IEEE Transactions on Circuits and Systems for Video Technology, v. 11, n. 6, p. 765-772, 2001.

SHII, H.; ULLMER, B. Tangible bits: Towards seamless interfaces between people, bits and atoms. In: ACM CONFERENCE ON HUMAN FACTORS IN COMPUTING SYSTEMS - CHI'97, 15., 1997, Atlanta. Proceedings. New York: ACM, 1997. p.234-241.

ISO/IEC. MHEG. Disponível em: <http://www.mheg.org>. Acesso em 31 ago. 2003.

ISO/IEC. ISO/IEC 15938-5 Final Committee Draft, Information Technology - Multimedia Content Description Interface - Part 5: Multimedia Description Schemes, 2001. Disponível em: $<$ http://intermidia.icmc.usp.br/ rudinei/mds_fcd_W3966.pdf $>$ Acesso em: 21 ago. 2003.

ISO/IEC. Overview of the MPEG-4 Standard (ISO/IEC JTC1/SC29/WG11 N4668). Disponível em:

$<\mathrm{http}$ ://www.chiariglione.org/mpeg/standards/mpeg-4/mpeg4.htm>. Acesso em 20 ago. 2003.

ISO/IEC. MPEG-7 Overview (ISO/IEC JTC1/SC29/WG11 N4980). Disponível em: $<$ http://www.chiariglione.org/mpeg/standards/mpeg-7/mpeg7.htm>. Acesso em: 20 ago. 2003.

ISO/IEC. The Mpeg Home Page. Disponível em: $<\mathrm{http}$ ://www.chiariglione.org/mpeg/index.htm>. Acesso em: 31 ago. 2003.

JANG, E. S.; CAPIN, T.; OSTERMANN, J. Visual SNHC Tools. In: PEREIRA, F.; EBRAHIMI, T. The MPEG-4 Book. Upper Saddle River: Prentice Hall PTR, 2002. p. 383-450.

JOHNSON, M. XML for the Absolute Beginner. Disponível em: $<$ http://www.javaworld.com/javaworld/jw-04-1999/jw-04xml.html>. Acesso em: 19 ago. 2003.

KIM, M.; WOOD, S. Extensible MPEG-4 Textual Format. In: PEREIRA, F.; EBRAHIMI, T., The MPEG-4 Book. Upper Saddle River: Prentice Hall PTR, 2002. p.187-225.

KINDBERG, T.; BARTON, J.; MORGAN, J.; BECKER, G.; CASWELL, D.; DEBATY, P.; GOPAL, G.; FRID, M.; KRISHNAN, V.; MORRIS, H.; SCHETTINO, J.; SERRA, B.; SPASOJEVIC, M. People, places, things: Web presence for the real world. In: IEEE WORKSHOP ON MOBILE COMPUTING SYSTEMS AND APPLICATIONS - WMCSA'00, 3., 2000, Monterey. Proceedings. Los Alamitos: IEEE, 2000. p.19-30.

KOENEN, R.; PEREIRA, F. Profiling and Conformance: Approach and Overview. In: PEREIRA, F.; EBRAHIMI, T., The 
MPEG-4 Book. Upper Saddle River: Prentice Hall PTR, 2002. p.583-621.

(Korteum et al., KORTEUM, G.; SEGSLL, Z.; BAUER, M. Context-Aware, 1998) Adaptive Wearable Computers as Remote Interfaces to "Intelligent" Environments. In: IEEE INTERNATIONAL SYMPOSIUM ON WEARABLE COMPUTERS, 2., 1998, Pittsburgh. Proceedings. Los Alamitos: IEEE, 1998. p.58-65.

(Lagoze \& Hunter, LAGOZE, C.; HUNTER, J. The ABC Ontology and Model. 2001) Journal of Digital Information, v. 2 , n. 2, 2001. Disponível em: $<$ http://jodi.ecs.soton.ac.uk/articles/v02/i02/lagoze/>. Acesso em: 27 ago. 2003.

(Liberate, 2003) LIBERATE TECHNOLOGIES. Liberate, 2003. Disponível em: $<$ http://www.liberate.com>. Acesso em: 19 ago. 2003.

(Liberty, 2003) LIBERTY BROADBAND INTERACTIVE TELEVISION, INC. OpenTV, 2003. Disponível em: <http://www.opentv.com>. Acesso em 19 ago. 2003.

(Lum \& Lau, 2002) LUM, W. Y.; LAU, F. C. M. A Context-Aware Decision Engine for Context Adaptation. IEEE Pervasive Computing, v. 1, n. 3, p. 41-49, 2002.

(Macedo et al., 2002) MACEDO, A. A.; PIMENTEL, M. G.; GUERRERO, J. A. C. An Infrastructure for Open Latent Semantic Link. In: ACM INTERNATIONAL CONFERENCE ON HYPERTEXT AND HYPERMEDIA, 13., 2002, College Park. Proceedings. New York: ACM, 2002. p. 107-116.

(Macromedia, 2003) MACROMEDIA, INC. Flash MX, 2003. Disponível em: $<$ http://www.macromedia.com/software/flash/>. Acesso em: 19 ago. 2003.

(Matsushita, 2003) MATSUSHITA ELECTRIC CORPORATION OF AMERICA. Panasonic USA, 2003. Disponível em: $<\mathrm{http} / / /$ www.panasonic.com>. Acesso em: 19 ago. 2003.

(Merialdo et al., MERIALDO, B.; LEE, K. T.; LUPARELLO, D. Automatic 1999) Construction of Personalized TV News Programs. In: ACM INTERNATIONAL CONFERENCE ON MULTIMEDIA, 7., 1999, Orlando. Proceedings. New York: ACM, 1999. p. 323331.

(Microsoft, 2003) MICROSOFT CORPORATION. MSN TV, 2003 Disponível em: $<$ http://www.webtv.com>. Acesso em: 19 ago, 2003.

(Microsoft, 2003a) MICROSOFT CORPORATION. Ultimate TV, 2003. Disponível em: $<$ http://www.ultimatetv.com>. Acesso em 19 ago. 2003.

(Microsoft, 2003b) MICROSOFT CORPORATION. Ultimate TV, 2003. Disponível em: <http://www.ultimatetv.com/morefeatures.asp $>$. Acesso em: 19 ago. 2003.

(Markus et al., 2000) MARKUS, L. F.; BOWEN, M. G.; POST, A. J.; SHAUGHNESSY, K. L. Broadband E-Battle: Enhanced TV Challenges the PC for Interactive Services and E-media 
Supremacy, 2000. Disponível em: $<\mathrm{http}: / / \mathrm{www}$.itvmarketer.com/mktres/itvindustry/mritv01.htm>. Acesso em: 20 ago. 2003.

(Minneman et al., MINNEMAN, S.; HARRISON, S.; JANSSEN, B.; 1995) KURTENBACH, G.; MORAN, T.; SMITH, I.; VAN MELLE, B. A confederation of tools for capturing and accessing collaborative activity. In: ACM INTERNATIONAL CONFERENCE ON MULTIMEDIA, 3., 1995, San Francisco. Proceedings. New York: ACM, 1995. p. 523-534.

(Nack \& Lindsay, NACK, F.; LINDSAY, A. T. Everything You Wanted to Know 1999) About MPEG-7: Part 2. IEEE MultiMedia, v. 6, n. 4, p. 64-73, 1999.

(O'Driscoll, 2000) O'DRISCOLL, G. The Essential Guide to Digital Set-top Boxes and Interactive TV. Upper Saddle River: Prentice Hall, 2000.

(Oracle, 2003) ORACLE CORPORATION. Oracle9i Database Online

Documentation, Release 2 (9.2), 2003. Disponível em:

$<$ http://otn.oracle.com/docs/products/oracle9i/doc_library/releas e2/index.htm>. Acesso em: 12 set. 2003.

(Oracle, 2003a) ORACLE CORPORATION. Oracle XML DB An Oracle Technical White Paper, 2003. Disponível em: $<$ http://otn.oracle.com/tech/xml/xmldb/pdf/XMLDB_Technical_ Whitepaper.pdf $>$. Acesso em: 12 set. 2003.

(Pascoe, 1998) PASCOE, J. Adding Generic Contextual Capabilities to Wearable Computers. In: INTERNATIONAL SYMPOSIUM ON WEARABLE COMPUTERS, 2., 1998, Pittsburgh. Proceedings. Los Alamitos: IEEE, 1998. p. 92-99.

(Patel \& Moss, 1996) PATEL, P.; MOSS, K. Java Database Programming with $J D B C$. Scottsdale: Coriolis Group Books, 1996.

(Pereira, 2002) PEREIRA, F. Context, Objectives and Process. In: PEREIRA, F. and EBRAHIMI, T., The MPEG-4 Book. Upper Saddle River: Prentice Hall PTR, 2002. p. 1-35.

(Quakenbush

\& QUACKENBUSH, S.; LINDSAY, A. Overview of the MPEG-7

Lindsay, 2001)

Audio. IEEE Transactions on Circuits and Systems for Video Technology, v. 11, n. 6, p. 725-729, 2001.

(Royal, 2003)

ROYAL PHILIPS ELECTRONICS. Hard Disk Recorders, 2003. Disponível em: <http://www.consumer.philips.com>. Acesso em: 27 ago. 2003.

(Ryan et al., 1997) RYAN, N.; PASCOE, J.; MORSE, D.R. Enhanced reality

fieldwork: the context-aware archaeologist assistant. In:

DINGWALL, L.; EXON, S.; GAFFNEY, V.; LAFLIN, S.; VAN

LEUSEN, M. Archaeology in the age of the Internet:

Computer Applications \& Quantitative Methods in Archaeology. Oxford: Archaeopress, 1999. p. 269-274.

(Santos Júnior et al., SANTOS JÚNIOR, J. B.; GOULARTE, R.; MOREIRA, E. D. 2001)

S.; FARIA, G. B. The Modeling of Structured Context-Aware 
Interactive Environments. Transactions of the SDPS - Journal of Integrated Design and Process Science, v. 5, n. 4, p. 77-93, 2001.

(Santos Júnior, 2002) SANTOS JÚNIOR, J. B. Modelagem de ambientes interativos conscientes de contexto: uma abordagem baseada nos padrões MPEG-4 e MPEG-7. 2002. 252p. Tese (Doutorado) - Instituto de Ciências Matemáticas e de Computação, Universidade de São Paulo, São Carlos, 2002.

(Salber et al., 1998) SALBER, D.A.; DEY, A. K.; ABOWD, G. D. Ubiquitous Computing: Defining an HCI Research Agenda for an Emerging Interaction Paradigm, Atlanta, College of Computing, Georgia Institute of Technology, 1998. (Relatório Técnico)

(Salber et al., 1999) SALBER, D.; DEY, A.K.; ABOWD, G.D. The Context Toolkit: Aiding the Development of Context-Enabled Applications. In: CONFERENCE ON HUMAN FACTORS AND COMPUTING SYSTEMS - CHI'99, 17., 1999, Pittsburgh. Proceedings. New York: ACM, 1999. p. 434-441.

(Salembier \& Smith, SALEMBIER, P.; SMITH, R. MPEG-7 Multimedia Description 2001)

Schemes. IEEE Transactions on Circuits and Systems for Video Technology, v. 11, n. 6, p. 748-759, 2001.

(Schilit et al., 1994) SCHILIT, B. N.; ADAMS, N.; WANT, R. Context-Aware Computing Applications. In: IEEE WORKSHOP ON MOBILE COMPUTING SYSTEMS AND APPLICATIONS, 1., 1994, Santa Cruz. Proceedings. Los Alamitos: IEEE, 1994. p. 85-90.

(Schilit \& Theimer, SCHILIT, B. N.; THEIMER, M. Disseminating Active Map 1994)

Information to Mobile Hosts. IEEE Network, v. 8, n. 5, p. 22-32, 1994.

(Schilit, 1995) SCHILIT, W. N. A System Architecture for Context-Aware Mobile Computing, 1995. 144p. Tese (Doutorado) - Graduate School of Arts and Sciences, Columbia University, Columbia, 1995.

(Schilit et al., 1998) SCHILIT, B. N.; GOLOVCHINSKY, G.; PRICE, M. Beyond Paper: Supporting Active Reading with Free Form Digital Ink Annotations. In: ACM CONFERENCE ON HUMAN FACTORS IN COMPUTING SYSTEMS - CHI'98, 16., 1998, Los Angeles. Proceedings. New York: ACM/Addison-Wesley, 1998. p. 249-256.

(Schmidt et al., 1999) SCHMIDT, A.; AIDOO, K.A.; TAKALUOMA, A.; TUOMELA, U.; LAERHOVEN, K.V.; VELDE, W.V. Advanced Interaction in Context. In: GELLERSEN, H. W. HUC'99: International Symposium on Handheld and Ubiquitous Computing. Heidelberg: Springer-Verlag, 1999. p. 89-101. (Lecture Notes in Computer Science, 1707)

(Sikora, 2001) SIKORA, T. The MPEG-7 Visual Standard for Content Description - An Overview. IEEE Transactions on Circuits and 
(Sony, 2003)

(Srivastava, 2002)

(Swann, 2000)

(Swaminathan et al., 2002)

(TiVo, 2003)

(Truong et al., 2001)

(Tsinaraki et al., 2001)

(TV-Anytime, 2000)

(TV-Anytime, 2002)

(TV-Anytime, 2003)

(van Vilet \& van Stelten, 2001)
Systems for Video Technology, v. 11, n .6, p. 696-702, 2001.

SONY CORPORATION OF AMERICA. Sony, 2003. Disponível em: <http://www.sony.com>. Acesso em: 19 ago. 2003.

SRIVASTAVA, H. O. Interactive TV Technology and Markets. Norwood: Artech House, 2002.

SWANN, P. TV dot COM: The Future of Interactive Television. New York: TV Books, 2000.

SWAMINATHAN, V.; MACAULAY, A.; DE PETRIS, G. MPEG-J: MPEG-4 and Java. In: PEREIRA, F.; EBRAHIMI, T. The MPEG-4 Book. Upper Saddle River: Prentice Hall PTR, 2002. p. 149-185.

TIVO, INC. Tivo, 2003. Disponível em: <http://www.tivo.com>. Acesso em: 19 ago. 2003.

TRUONG, K. N.; ABOWD, G. D.; BROTHERTON, J. A. Who, What, When, Where, How: Design Issues of Capture \& Access Applications. In: ABOWD, G.D.; BRUMITT, B.; SHAFER, S. Ubicomp 2001: International Conference in Ubiquitous Computing. Heidelberg: Springer-Verlag, 2001. p. 209-224. (Lecture Notes in Computer Science, 2201)

TSINARAKI, C.; PAPADOMANOLAKIS, S.; CHRISTODOULAKIS, S. Towards a two-layered video metadata model. In: IEEE INTERNATIONAL WORKSHOP ON DATABASE AND EXPERT SYSTEMS APPLICATIONS, 12, 2001, Munique. Proceedings. Los Alamitos: IEEE, 2001. p. 937-941.

TV-ANYTIME FORUM. Requirements Series: R1 on: TVAnytime Environment, ago. 2000. Disponível em: <ftp://tva:tva@ftp.bbc.co.uk/Plenary/TV035r6.zip>. Acesso em: 28 jul. 2003.

TV-ANYTIME FORUM. Specification Series: S3 on: Metadata, Final Specification - Part A: Metadata Schemas, dez. 2002.

Disponível em:

<ftp://tva:tva@ftp.bbc.co.uk/Specifications/SP003v13.zip>. Acesso em: 28 jul. 2003.

TV-ANYTIME FORUM. Specification Series: S2 on: Systems Description, Final Specification, fev. 2003. Disponível em: <ftp://tva:tva@ftp.bbc.co.uk/Specifications/SP002v13.zip>. Acesso em: 19 ago. 2003.

(TV-Anytime, 2003a) TV-ANYTIME FORUM. Specification Series: S1 on: Phase 1 Benchmark Features, Final Specification, fev. 2003. Disponível em: <ftp://tva:tva@ftp.bbc.co.uk/Specifications/SP001v12.zip>. Acesso em: 19 ago. 2003.

VAN VILTEN, H.; VAN STELTEN, N. Next Generation Television. Telematica Institute, 2001. Disponível em: 
(W3C, 1999)

(W3C, 1999a)

(W3C, 2000)

(W3C, 2001)

(W3C, 2001a)

(W3C, 2001b)

(W3C, 2001c)

(W3C, 2001d)

(W3C, 2001e)

(W3C, 2002)

(W3C, 2003)

(Wactlar et al., 1996)

(Want et al., 1992)
$<$ https://doc.telin.nl/dscgi/ds.py/Get/File-

14793/D511 sotatv.pdf>. Acesso em: 19 ago. 2003.

W3C - World Wide Web Consortium. Resource Description Framework (RDF) Model and Syntax Specification, 1999 Disponível em: <http://www.w3.org/TR/1999/REC-rdf-syntax19990222/>. Acesso em: 19 ago. 2003.

W3C - World Wide Web Consortium. XML Path Language (XPath) Version 1.0, 1999. Disponível em: $<$ http://www.w3.org/TR/xpath >. Acesso em: 12 set. 2003.

W3C - World Wide Web Consortium. Extensible Markup Language (XML) 1.0 (Second Edition), 2000. Disponível em: $<$ http://www.w3.org/TR/REC-xml>. Acesso em: 19 ago. 2003.

W3C - World Wide Web Consortium. Synchronized Multimedia Integration Language (SMIL 2.0), 2001. Disponível em: $<$ http://www.w3.org/TR/smil20/>. Acesso em: 19 ago. 2003.

W3C - World Wide Web Consortium. Scalable Vector Graphics (SVG) 1.0 Specification, 2001. Disponível em: $<$ http://www.w3.org/TR/SVG/>. Acesso em: 19 ago. 2003.

W3C - World Wide Web Consortium. XML Schema Part 1:

Structures, 2001. Disponível em:

$<$ http://www.w3.org/TR/xmlschema-1/>. Acesso em: 19 ago. 2003.

W3C - World Wide Web Consortium. XML Schema Part 2:

Datatypes, 2001. Disponível em:

$<$ http://www.w3.org/TR/xmlschema-2/>. Acesso em: 19 ago. 2003.

W3C - World Wide Web Consortium. XML Schema Part 0:

Primer, 2001. Disponível em:

$<$ http://www.w3.org/TR/xmlschema-0/>. Acesso em: 19 ago.

2003.

W3C - World Wide Web Consortium. XML Linking Language (XLink) Version 1.0, 2001. Disponível em $<$ http://www.w3.org/TR/xlink/>. Acesso em: 27 ago. 2003.

W3C - World Wide Web Consortium. XML Pointer Language (XPointer) Version 1.0, 2002. Disponível em $<$ http://www.w3.org/TR/xptr/>. Acesso em: 27 ago. 2002.

W3C - World Wide Web Consortium. Composite Capability/Preference Profiles (CC/PP): Structure and Vocabularies, 2003. Disponível em: $<$ http://www.w3.org/TR/2003/WD-CCPP-struct-vocab20030325/>. Acesso em: 12 set. 2003.

WACTLAR, H.; KANADE, T.; SMITH, M.; STEVENS, S. Intelligent Access to Digital Video: The Informedia Project. IEEE Computer, v. 29, n. 5, p. 46-52, 1996.

WANT, R.; HOPPER, A.; FALCÃO V.; GIBBONS, J. The 
active badge location system. ACM Transactions on Information Systems, v. 10, n. 1, p. 91-102, jan. 1992.

(Ward et al., 1997) WARD, A.; JONES, A.; HOPPER, A. A. A New Location Technique for the Active Office. IEEE Personal Communications, v. 4, n. 5, p. 42-47, 1997.

(Watkinson, 1998) WATKINSON, J. MPEG-2. Editora Butterworth-Heinemann, 1998.

(Web3D, 1997) WEB3D CONSORTIUM. ISO/IEC 14772: The Virtual Reality Modeling Language (VRML), 1997. Disponível em: $<$ http://www.web3d.org/technicalinfo/specifications/ISO_IEC_1 4772-All/index.html >. Acesso em 19 ago. 2003.

(Web3D, 2001) WEB3D CONSORTIUM. Extensible 3D (X3D) - ISO/IEC FCD 19775:200x, 2001. Disponível em: : $<$ http://www.web3d.org/technicalinfo/specifications/ISO_IEC_1 9775/index.html>. Acesso em: 19 ago. 2003.

(Weiser, 1991) WEISER, M. The computer for the 21st century. Scientific American, v. 265, n. 3, p. 94-104. Disponível em: $<$ http://www.ubiq.com/hypertext/weiser/SciAmDraft3.html $>$. Acesso em: 19 ago. 2003.

(Weiser, 1993) WEISER M. Some Computer Science Issues in Ubiquitous Computing. Communications of the ACM, v. 36, n. 7, p. 75-84, jul. 1993.

(Wollborn et al., WOLLBORN, M.; MOCCAGATTA, I.; BENZLER, U. Natural 2002) Video Coding. In: PEREIRA, F.; EBRAHIMI, T. The MPEG-4 Book. Upper Saddle River: Prentice Hall, 2002. p. 293-381.

(Worldgate, 2003) WORLDGATE SERVICE, INC. WorldGate, 2003 Disponível em: <http://www.wgate.com>. Acesso em: 27 ago. 2003. 


\section{Apêndice A}

Este apêndice apresenta o código do esquema criado para representar informações de contexto, conforme explicado no capítulo seis.

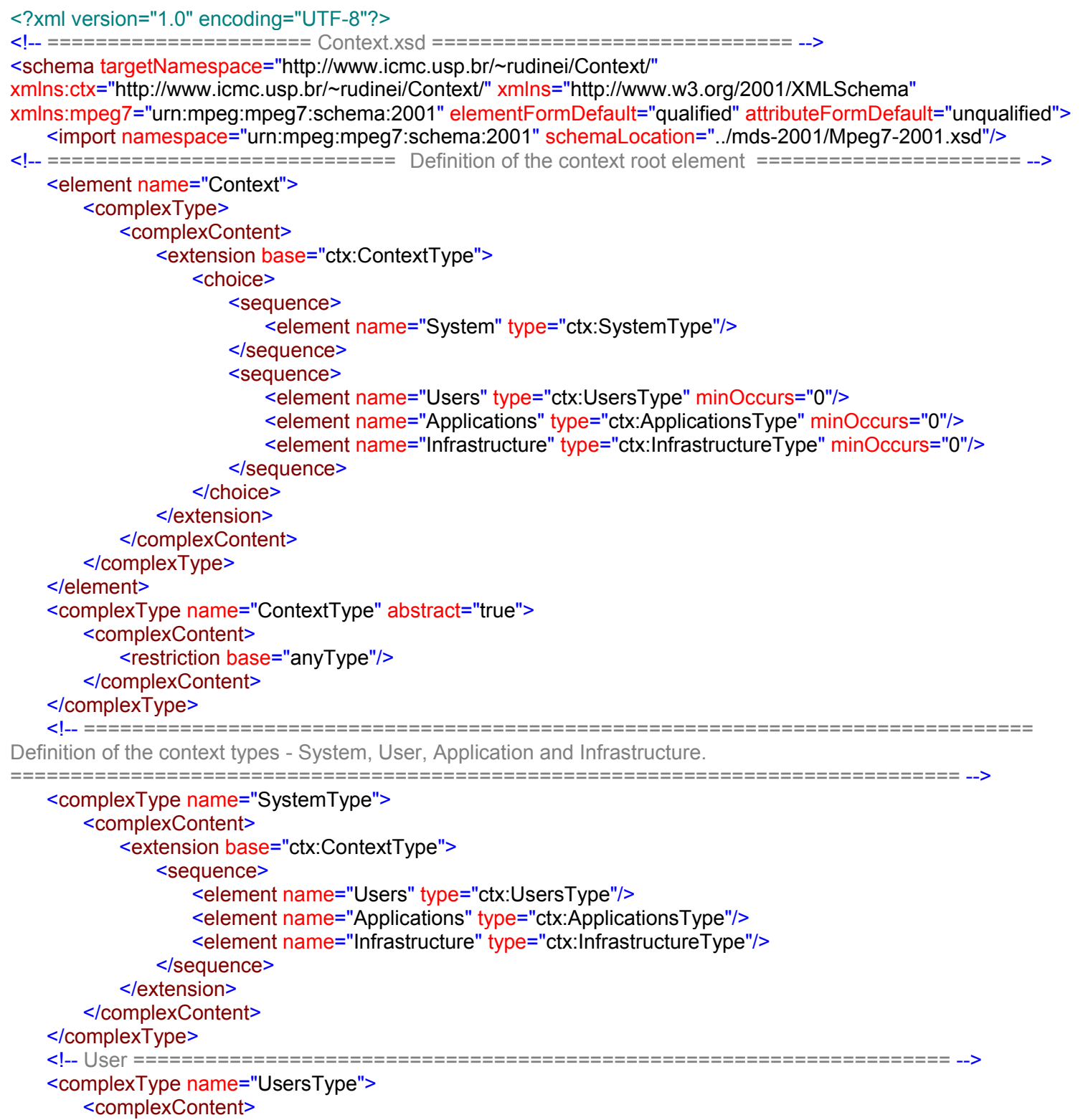




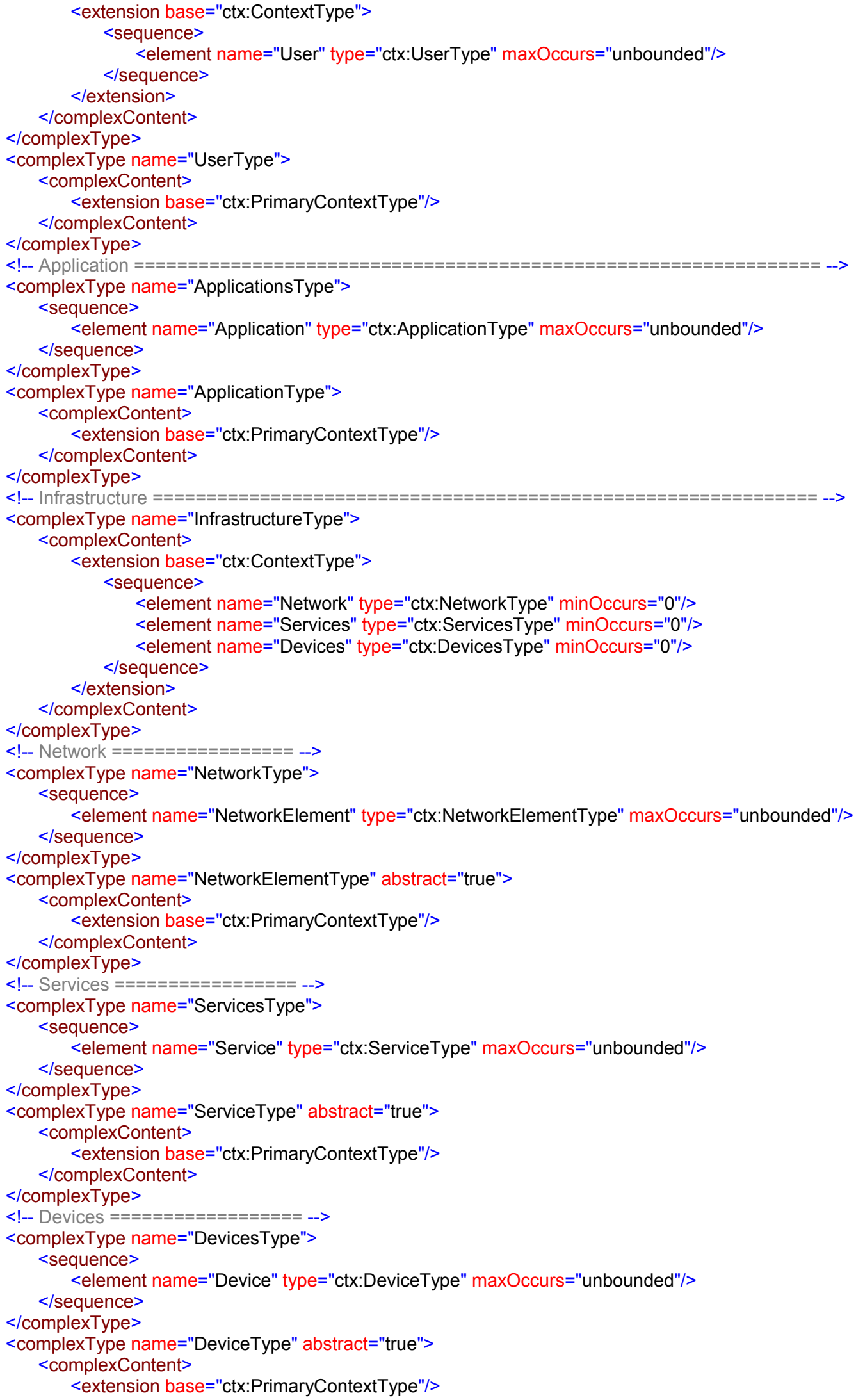


$</$ complexContent>

$<$ complexType>

Definition of the primary context - Identity, Location, Time, and Activity - in the form of XML Schema types.

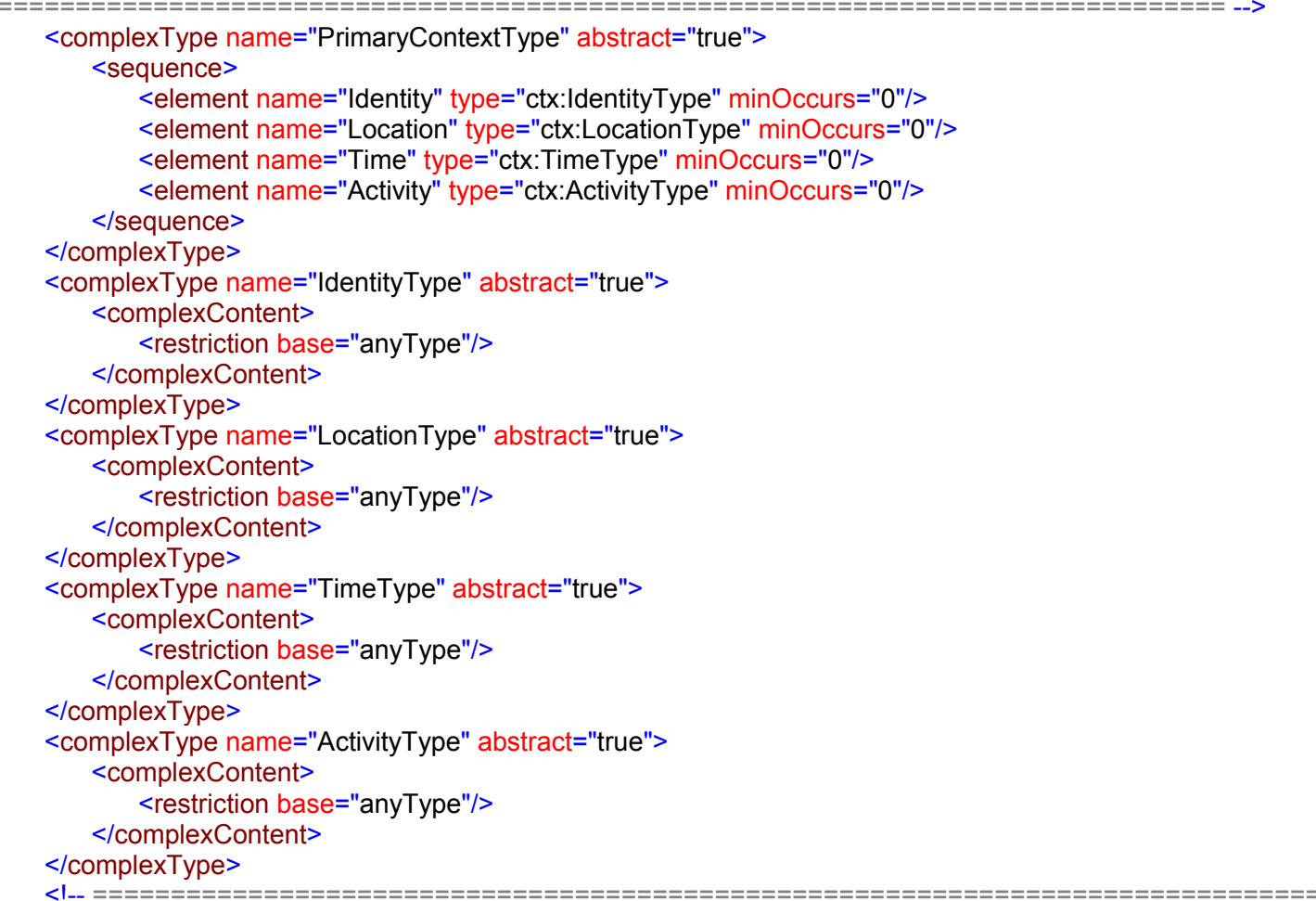

Examples of context pieces using the high level structures. These peices are used to characterize an entity. Some are contrext library built-in, but users can write theyr own in a similar way.

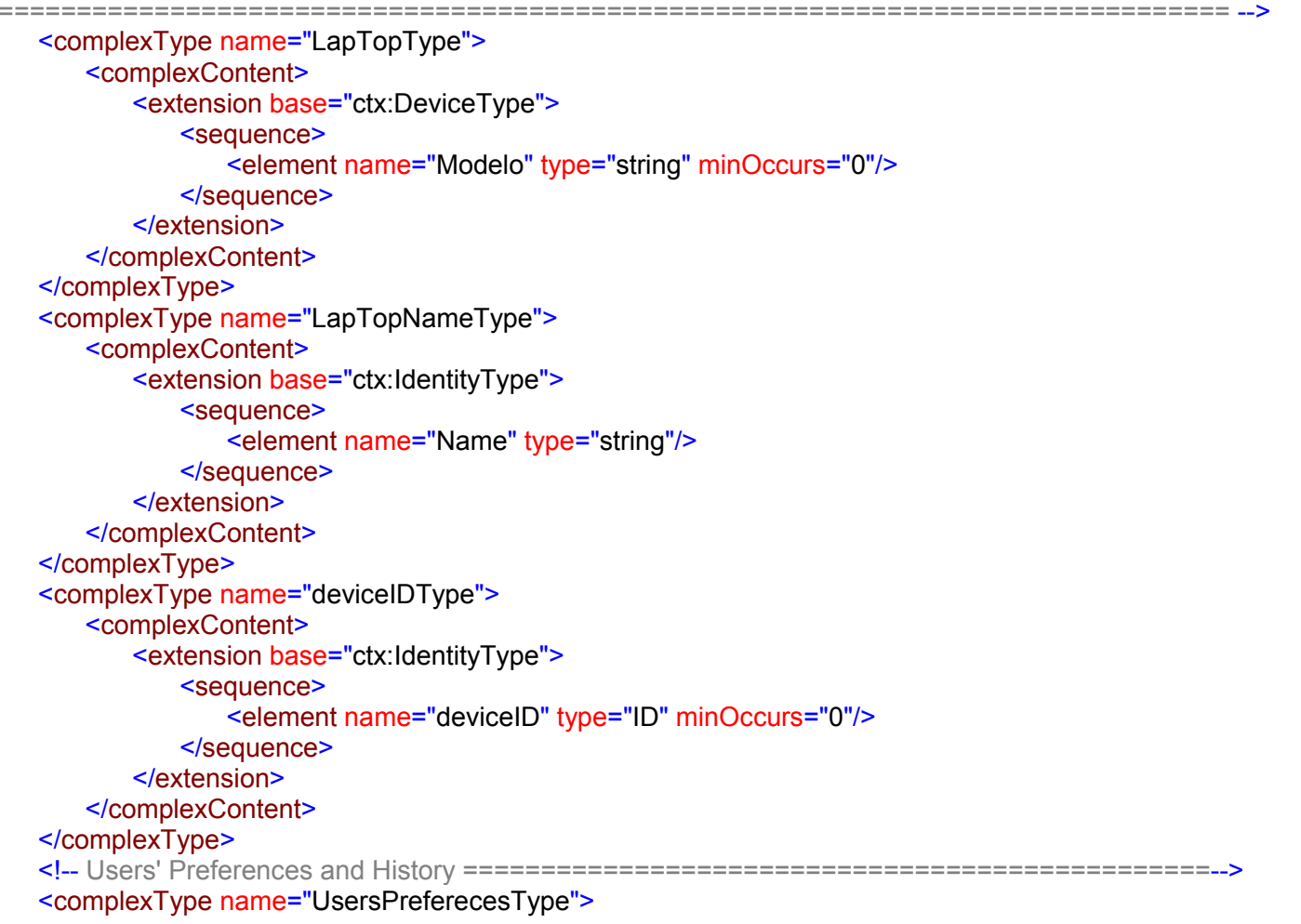




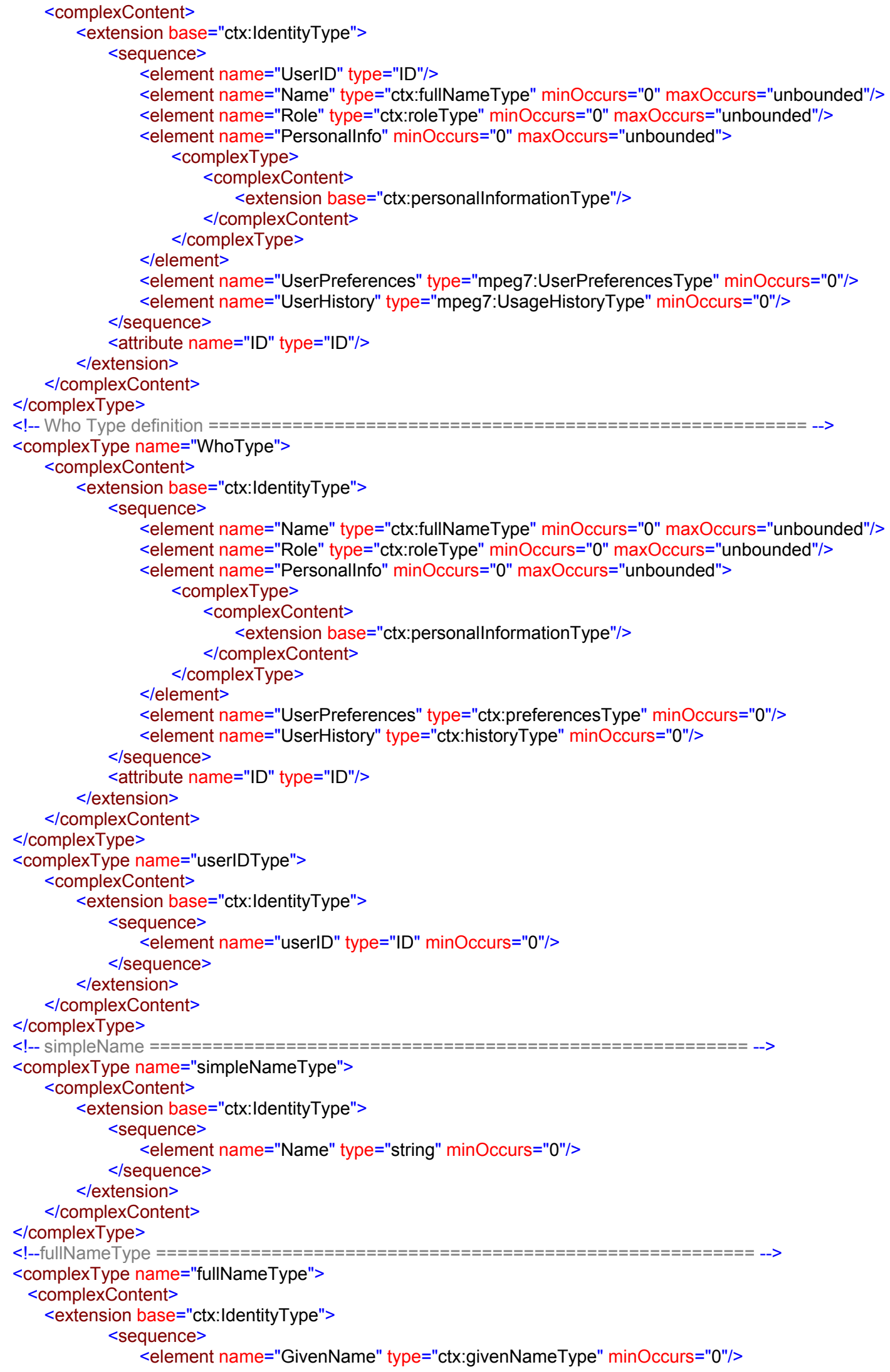



maxOccurs="unbounded"/>

<element name="FamilyName" type="ctx:familyNameType" minOccurs="0"/> $<$ element name="Title" type="ctx:personTitleType" minOccurs="0"/> $<$ /sequence $>$

$</$ extension>

$</$ complexContent>

$<$ complexType $>$

$<$ !-- givenName $=$

<simpleType name="givenNameType">

$<$ restriction base="string">

$<$ pattern value $="[\mathrm{~A}-\mathrm{Za}-\mathrm{z}]^{* " />}$

$<$ restriction>

$<$ /simpleType $>$

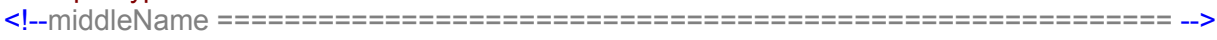

<simpleType name="middleNameType">

$<$ restriction base="string">

$<$ pattern value $="[\mathrm{~A}-\mathrm{Za}-\mathrm{z}]^{* "} />$

$</$ restriction>

$</$ simpleType $>$

$<!--$ familyName

$<$ simpleType name="familyNameType">

$<$ restriction base="string">

$<$ pattern value $="[\mathrm{~A}-\mathrm{Za}-\mathrm{z}]^{* "} />$

$<$ /restriction>

$</$ simpleType $>$

<simpleType name="personTitleType">

$<$ restriction base="string">

$<$ pattern value $="[A-Z a-z]\{5\} " />$

$</$ restriction>

$</$ simpleType $>$

<simpleType name="roleType">

$<$ restriction base="string">

$<$ enumeration value="user"/>

$<$ enumeration value="actor"/>

$<$ enumeration value $=$ "author"/>

$</$ restriction>

$</$ simpleType $>$

$<$ !-- pernsonallnformation $=$

$<$ complexType name="personallnformationType">

<sequence maxOccurs="unbounded">

<choice maxOccurs="unbounded">

<element name="Age" type="ctx:ageType" minOccurs="0"/>

<element name="Height" type="ctx:heightType" minOccurs="0"/>

$<$ element name="Weight" type="ctx:weightType" minOccurs="0"/>

$<$ element name="BirthDate" type="ctx:birthDateType" minOccurs="0"/>

$<$ element name="Eyes" type="ctx:eyesType" minOccurs="0"/>

$<$ element name="Hair" type="ctx:hairType" minOccurs="0"/>

$<$ /choice>

$</$ sequence $>$

$</$ complexType $>$

$<$ <impleType name="ageType">

$<$ restriction base="string">

$<$ pattern value $=" \mid d\{3\} " />$

$<$ restriction $>$

$</$ simpleType $>$

<simpleType name="heightType">

$<$ restriction base="string">

$<$ pattern value="Id $\{1\} . \mid \mathrm{I}\{2\} " />$

$</$ restriction $>$

$</$ simpleType $>$

$<$ simpleType name="weightType">

<restriction base="string">

$<$ pattern value="Id $\{3\} . \mid \mathrm{Id}\{3\} " />$

$<$ /restriction> 


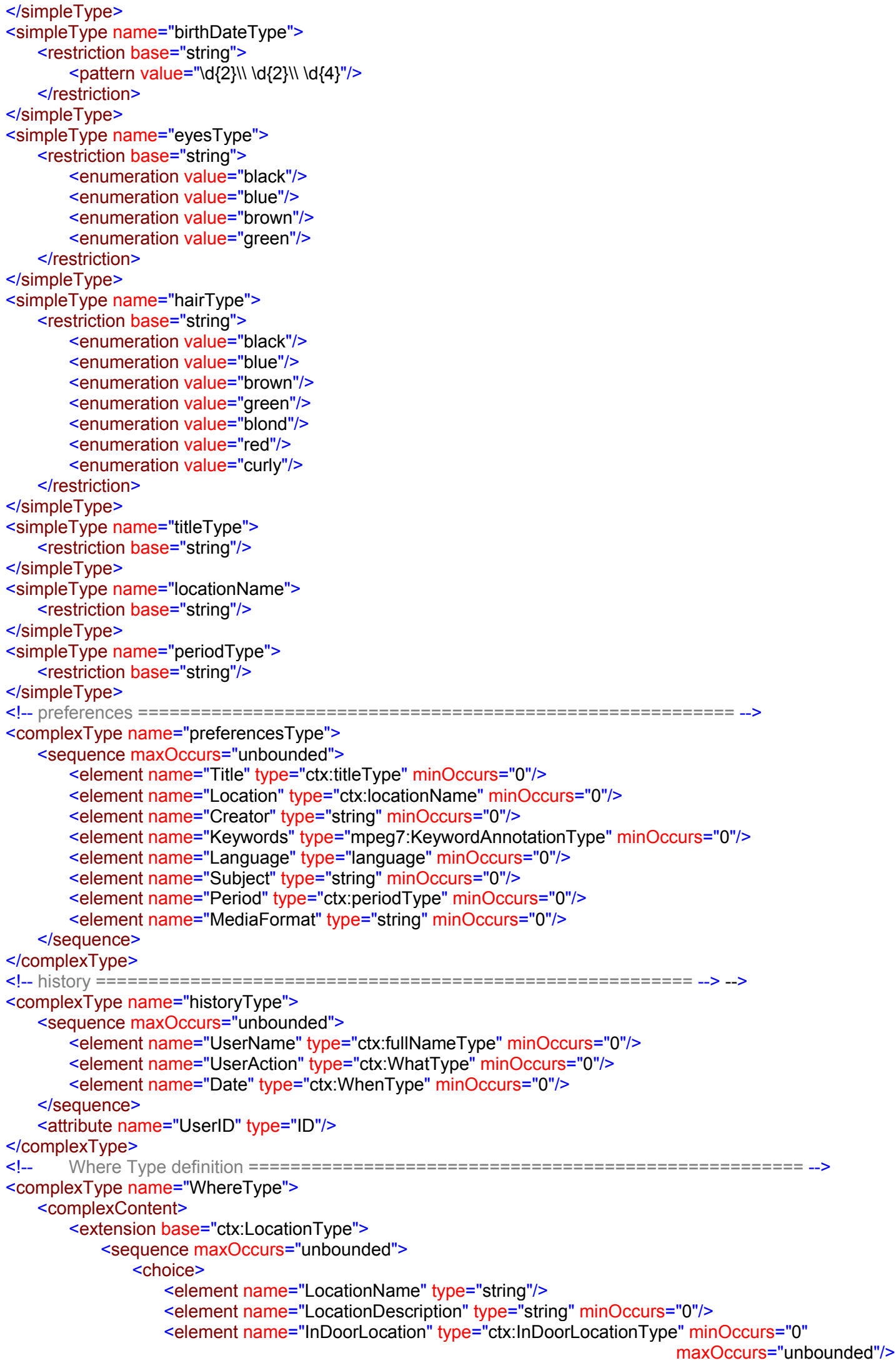


<element name="OutDoorLocation" type="ctx:OutDoorLocationType" minOccurs="0" maxOccurs="unbounded"/> <element name="ElectronicLocation" type="ctx:electronicLocationType" minOccurs="0" maxOccurs="unbounded"/>

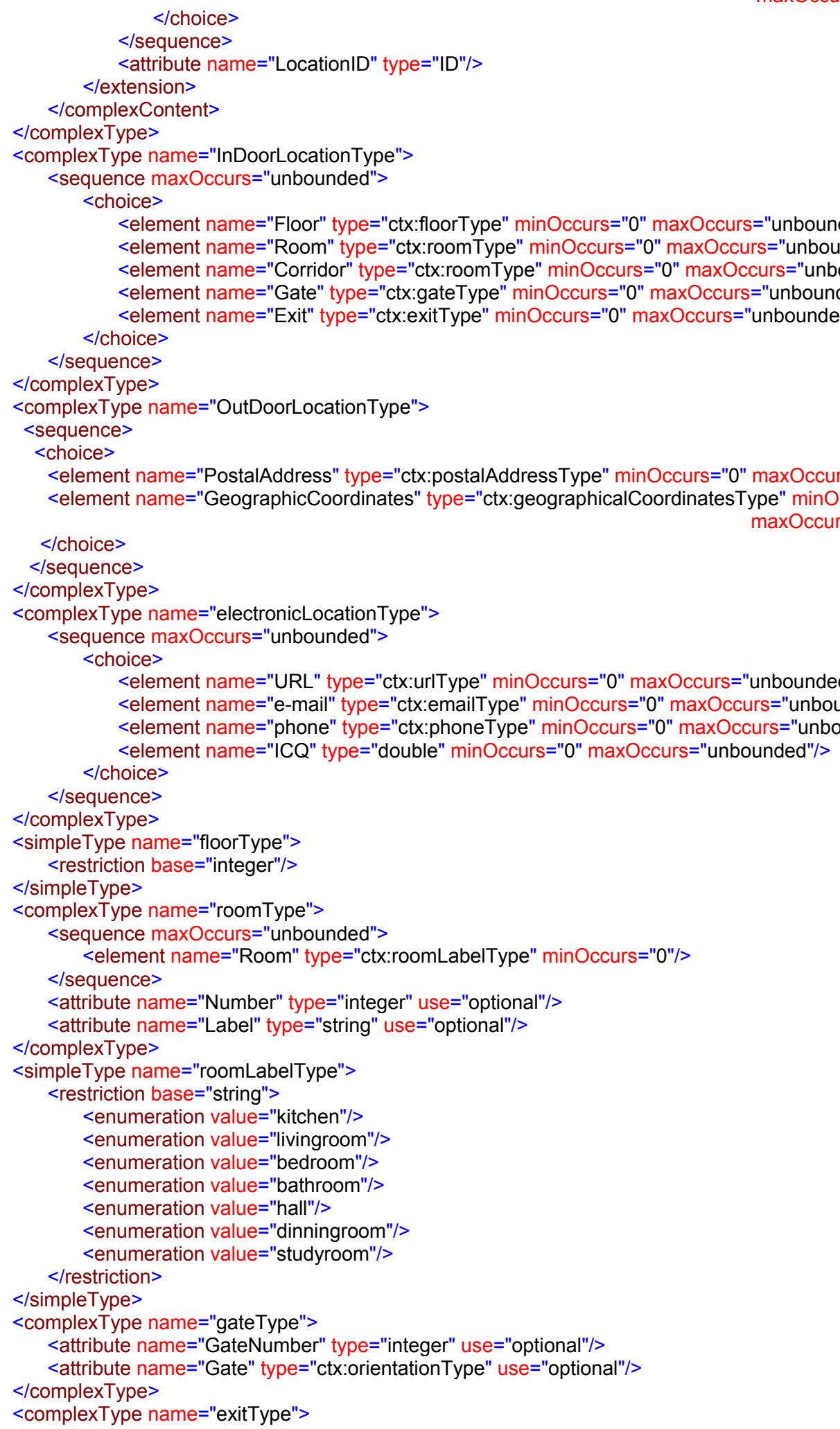


<attribute name="ExitNumber" type="integer" use="optional"/>

$<$ attribute name="Exit" type="ctx:orientationType" use="optional"/>

$</$ complexType $>$

$<$ complexType name="corridorType">

<attribute name="CorridorNumber" type="integer" use="optional"/>

$<$ attribute name="Corridor" type="ctx:orientationType" use="optional"/>

$<$ complexType $>$

$<$ simpleType name="orientationType">

<restriction base="string">

$<$ enumeration value $=" \mathrm{~N} " />$

$<$ enumeration value="S"/>

$<$ enumeration value $=" \mathrm{~W} " />$

$<$ enumeration value="E"/>

$<$ enumeration value $=" \mathrm{NE} " />$

$<$ enumeration value $=$ "NW"/>

$<$ enumeration value="SW"/>

$<$ enumeration value="SE"/>

$</$ restriction $>$

$</$ simpleType $>$

<simpleType name="StateType">

$<$ restriction base="string">

$<$ pattern value $="[\mathrm{~A}-\mathrm{Z}]\{2\} " />$

$</$ restriction $>$

$<$ /simpleType>

<simpleType name="zipCodeType">

<restriction base="string">

$<$ pattern value $=" / d\{2\} . \operatorname{Id}\{3\}-\mid d\{3\} " />$

$<$ restriction>

$<$ /simpleType $>$

$<$ simpleType name="streetType">

$<$ restriction base="string"/>

$<$ /simpleType $>$

<simpleType name="streetNumberType">

$<$ restriction base="positivelnteger"/>

$<$ /simpleType>

$<$ simpleType name="cityType">

$<$ restriction base="string"/>

$<$ /simpleType>

$<$ simpleType name="countryCodeType">

$<$ restriction base="string">

$<$ pattern value $="[A-Z]\{2\} " />$

$<$ restriction>

$</$ simpleType $>$

<complexType name="postalAddressType">

<sequence maxOccurs="unbounded">

$<$ choice>

<element name="Street" type="ctx:streetType"/>

<element name="Number" type="ctx:streetNumberType"/>

$<$ element name="Complement" type="string"/>

$<$ element name="City" type="ctx:cityType"/>

$<$ element name="State" type="ctx:StateType"/>

<element name="PostCode" type="ctx:zipCodeType"/>

$<$ element name="Country" type="ctx:countryCodeType"/>

$</$ choice $>$

$</$ sequence $>$

$</$ complexType $>$

$<$ complexType name="geographicalCoordinatesType">

$<$ sequence $>$

<element name="Longitute" type="ctx:longitudeType"/>

$<$ element name="Latitude" type="ctx:IongitudeType"/>

$<$ element name="Altitude" type="ctx:longitudeType"/>

$<$ /sequence $>$

$<$ complexType $>$

<simpleType name="longitudeType">

$<$ restriction base="double"/>

$<$ simpleType $>$ 


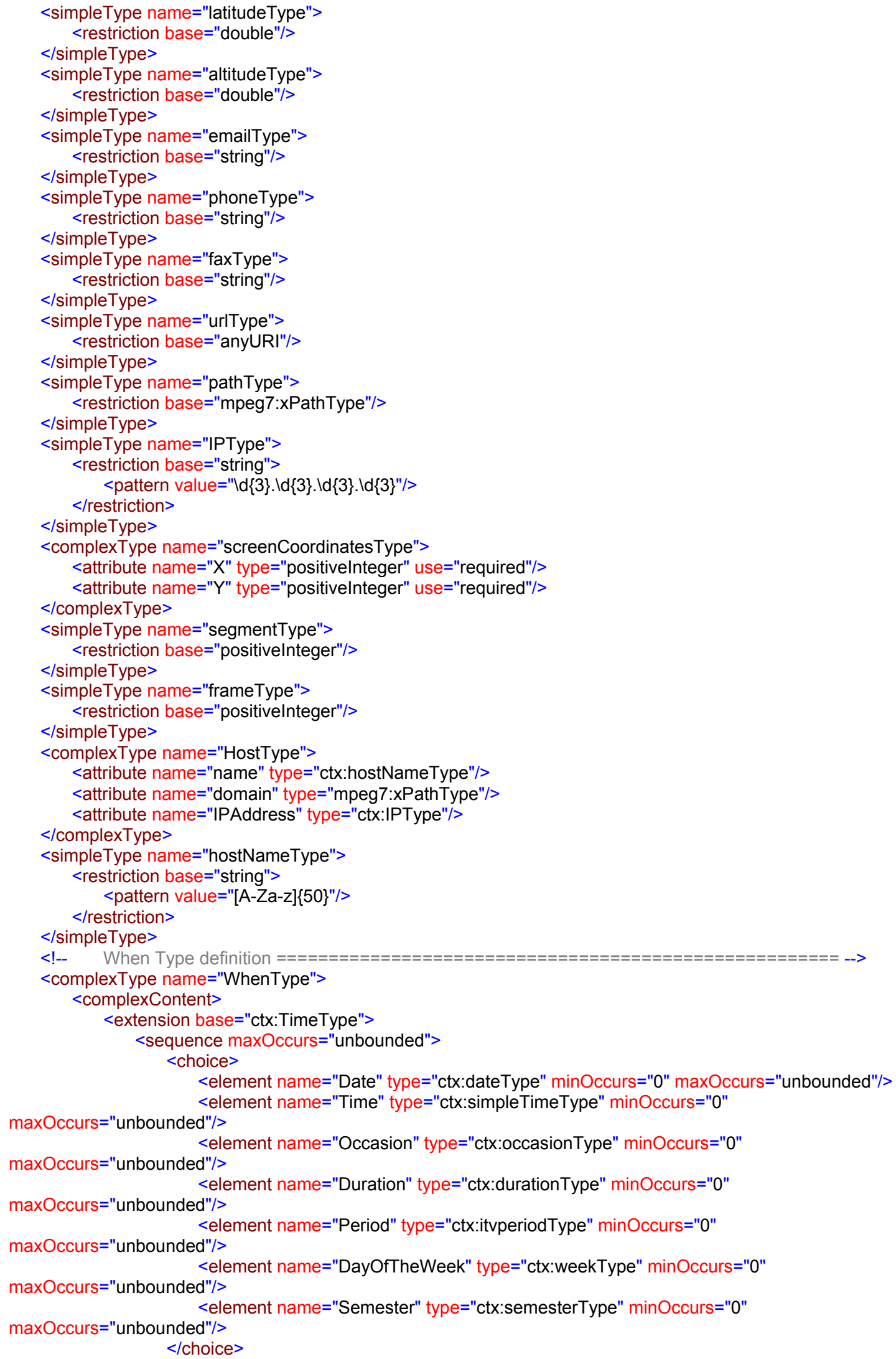




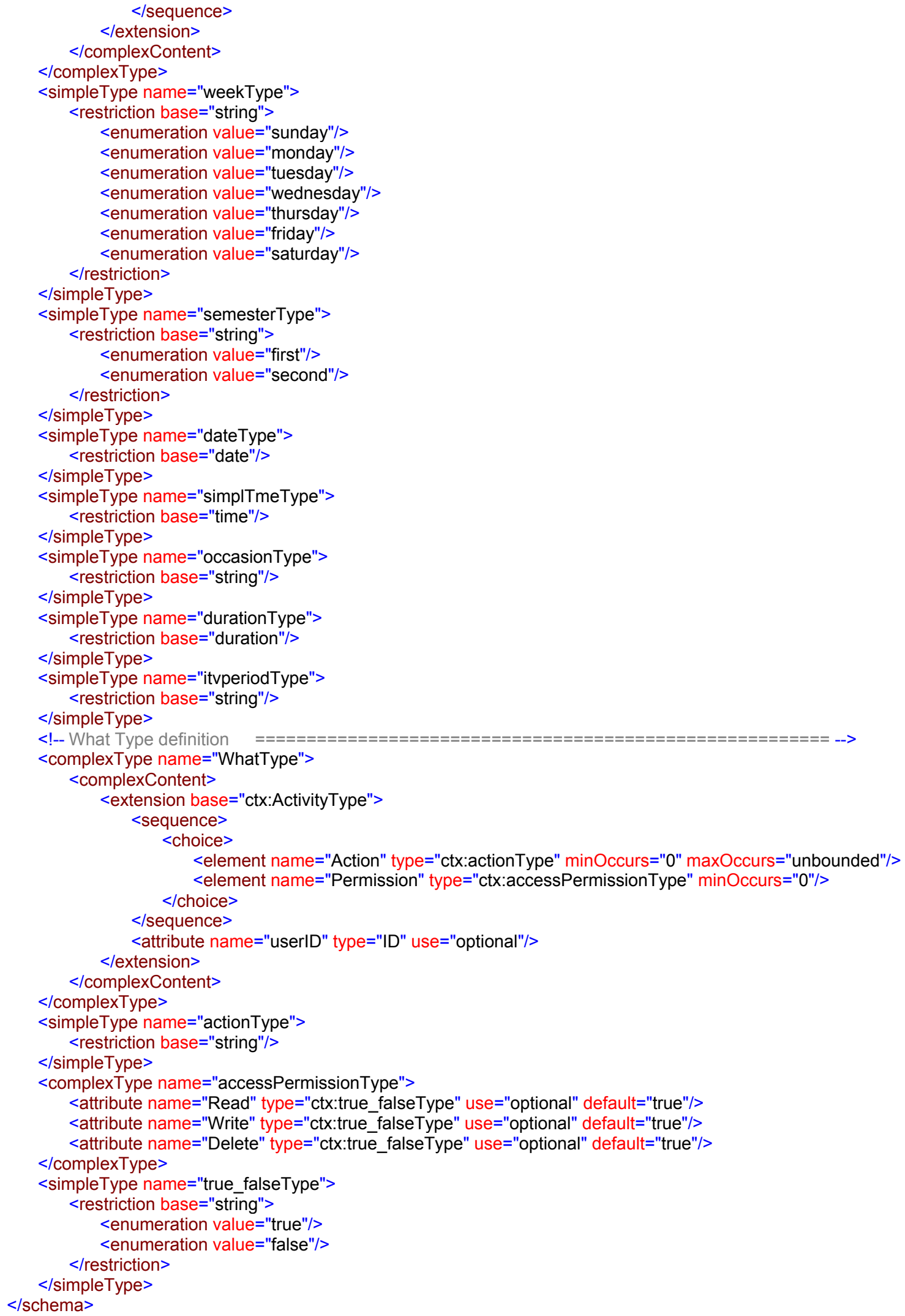




\section{Apêndice B}

Este apêndice apresenta o código dos esquemas criados para representar programas de TV Interativa, conforme exemplicado no capítulo sete. Os esquemas são baseados no trabalho de Faira (2001) e importam elementos dos esquemas padronizados pelo TVAnytime (2002) e pela parte MDS do padrão MPEG-7 (ISO, 2002a; Salembier \& Smith, 2001). Esses esquemas foram encapsulados em invólucros MPEG-7 de modo a torná-los compatíveis com esse padrão.

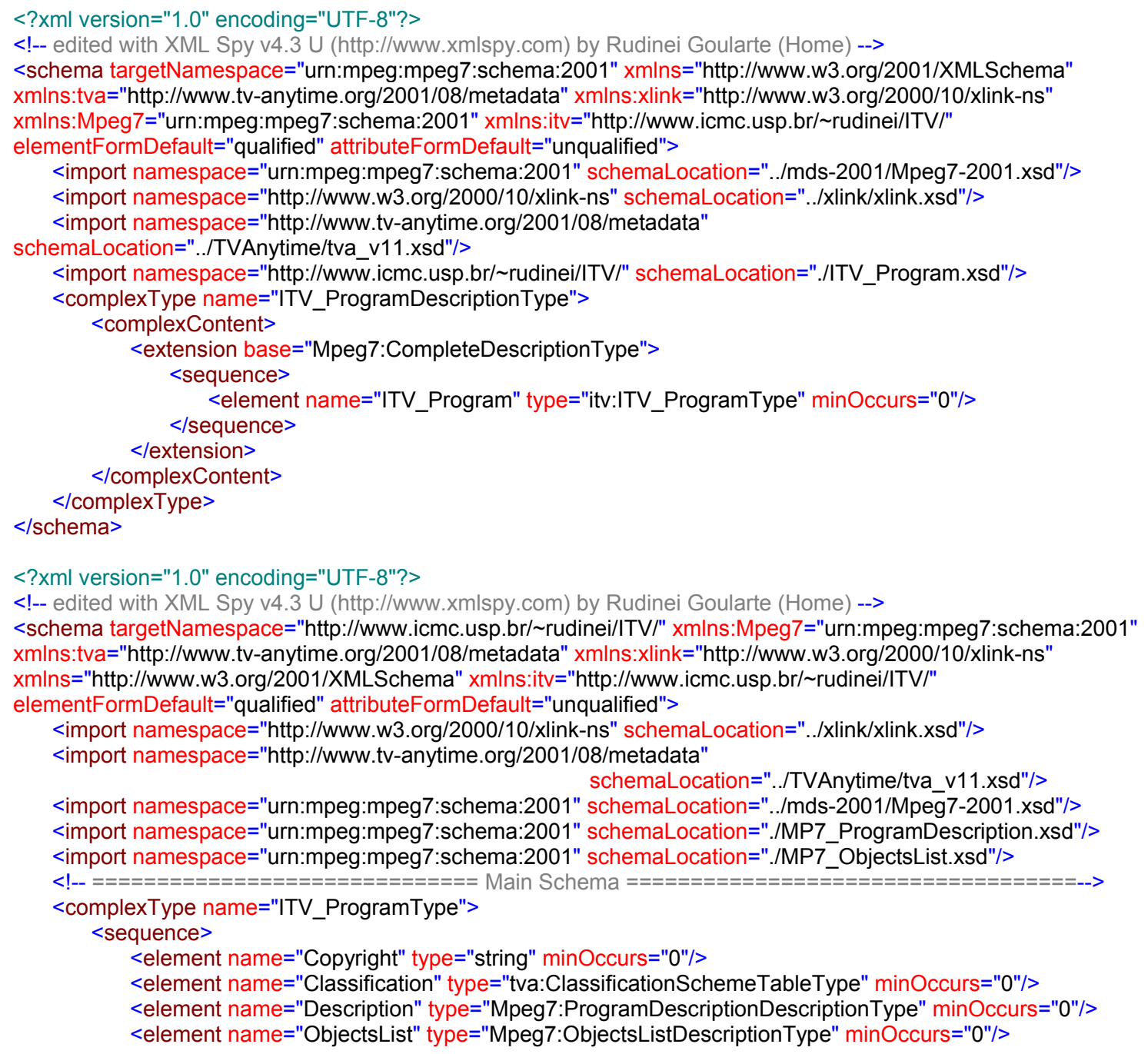




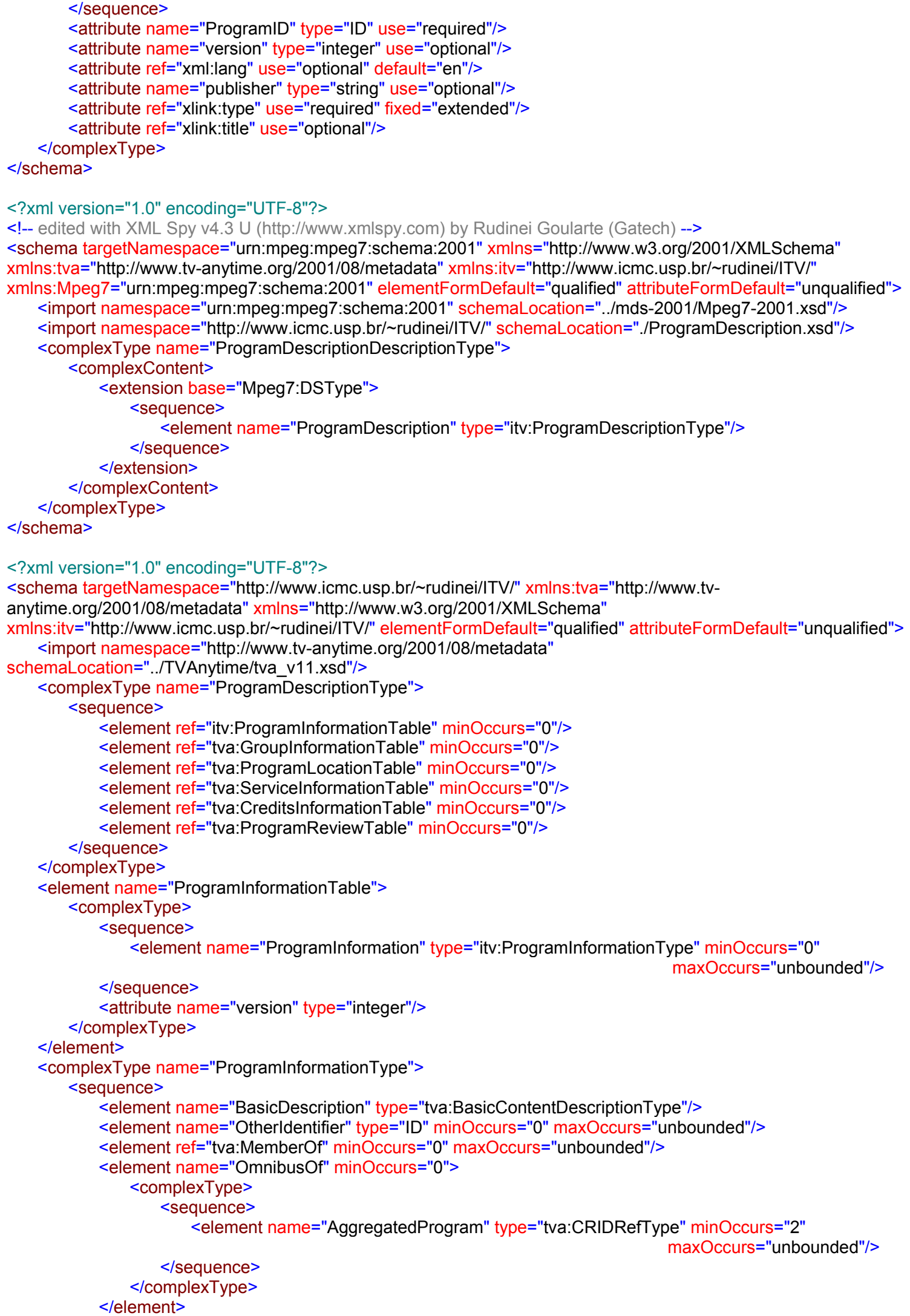




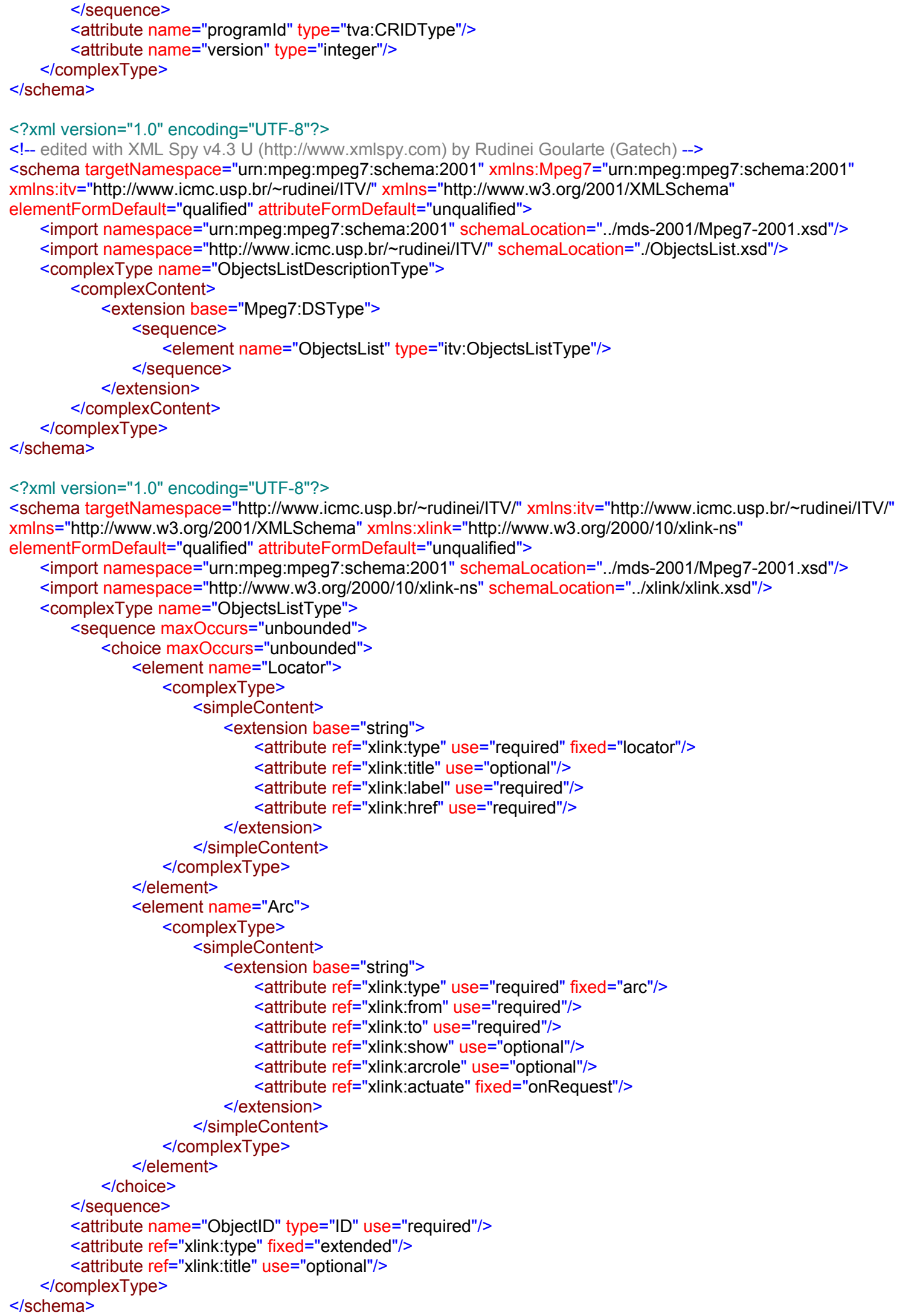


-14 - 


\section{Apêndice $C$}

Este apêndice apresenta o conjunto de esquemas MediaObject, criado para estruturar e representar objetos de mídia em TV Itnerativa, conforme explicado no capítulo sete. Esses esquemas foram encapsulados em invólucros MPEG-7 de modo torná-los compatíveis com esse padrão.

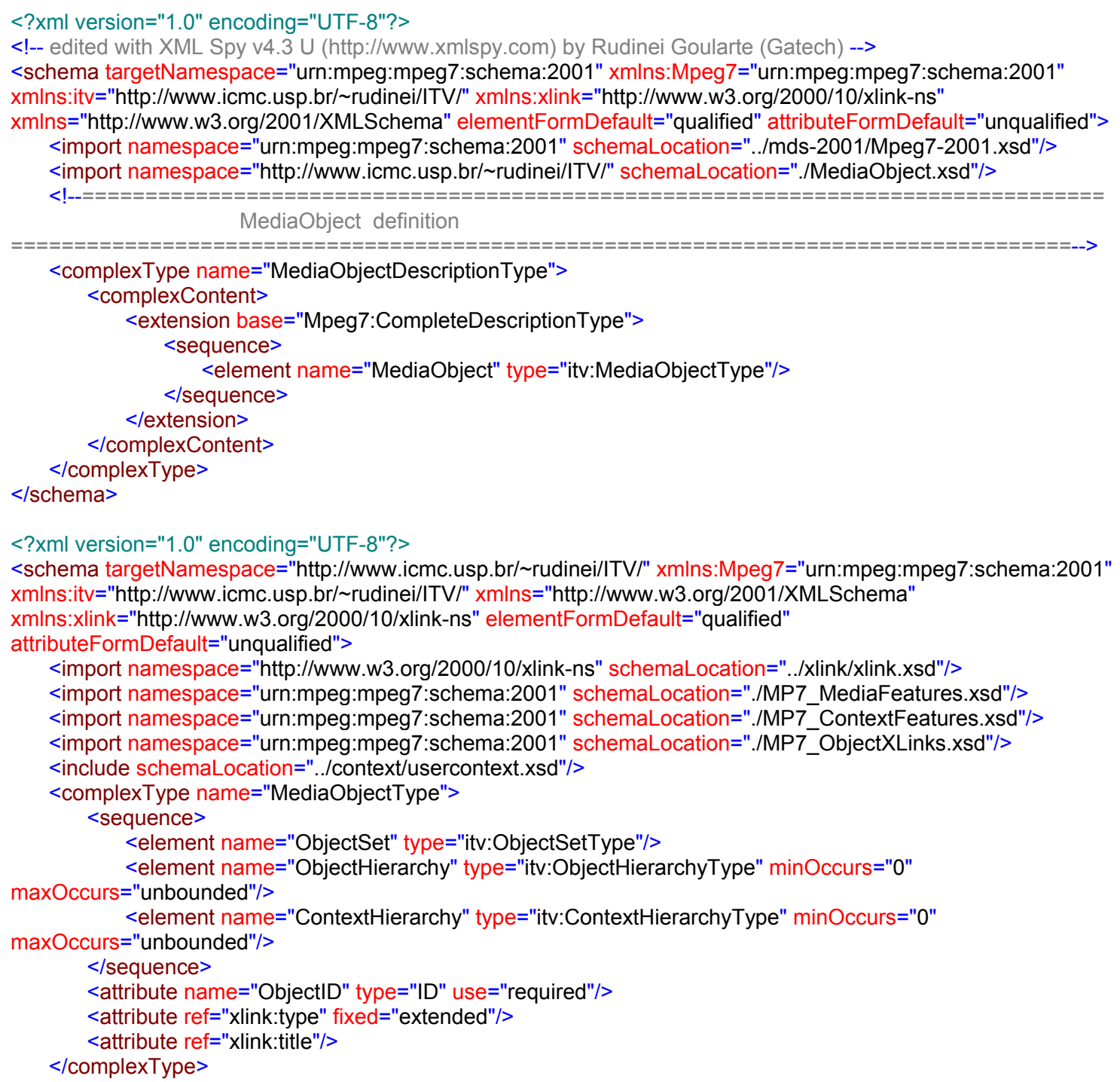




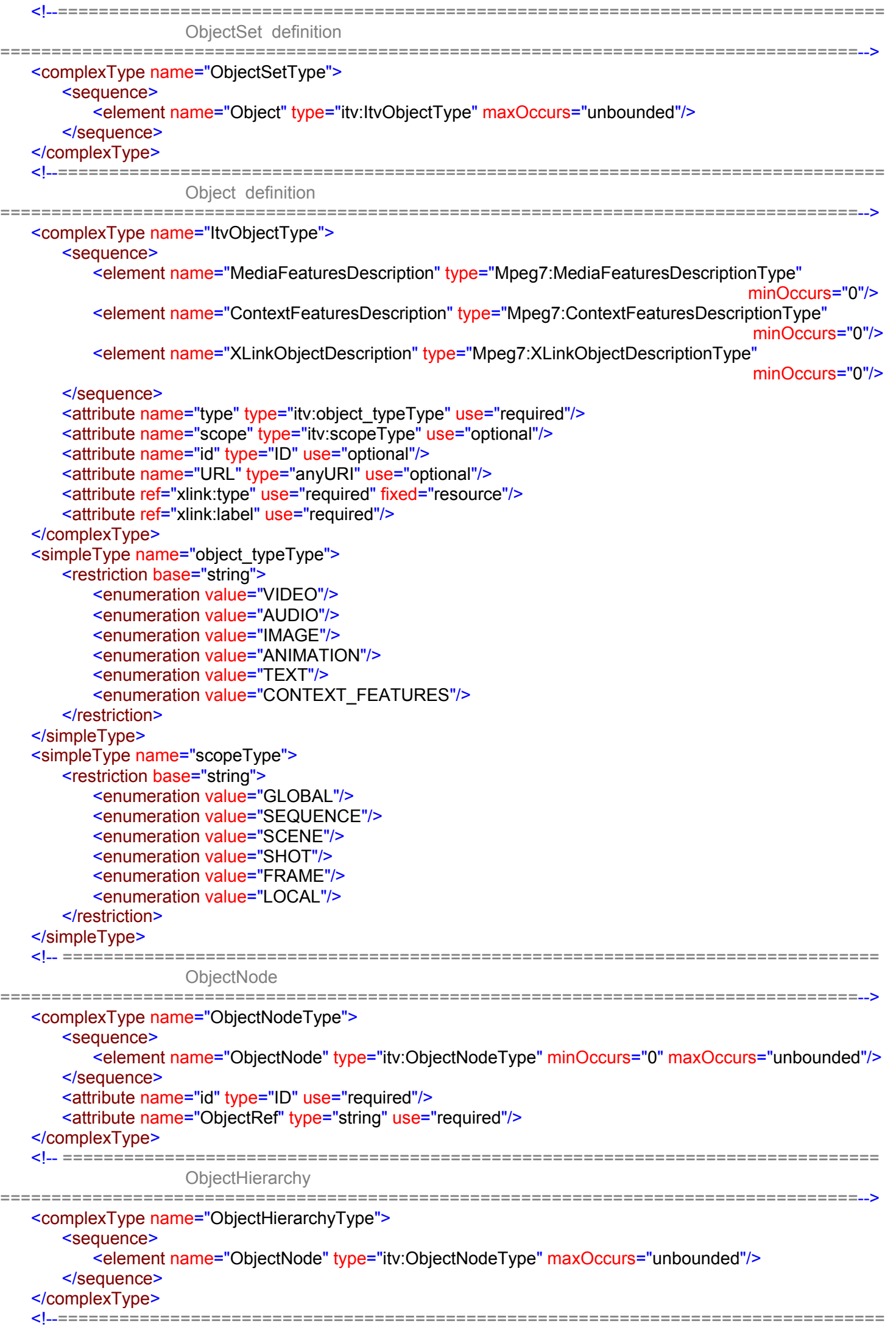




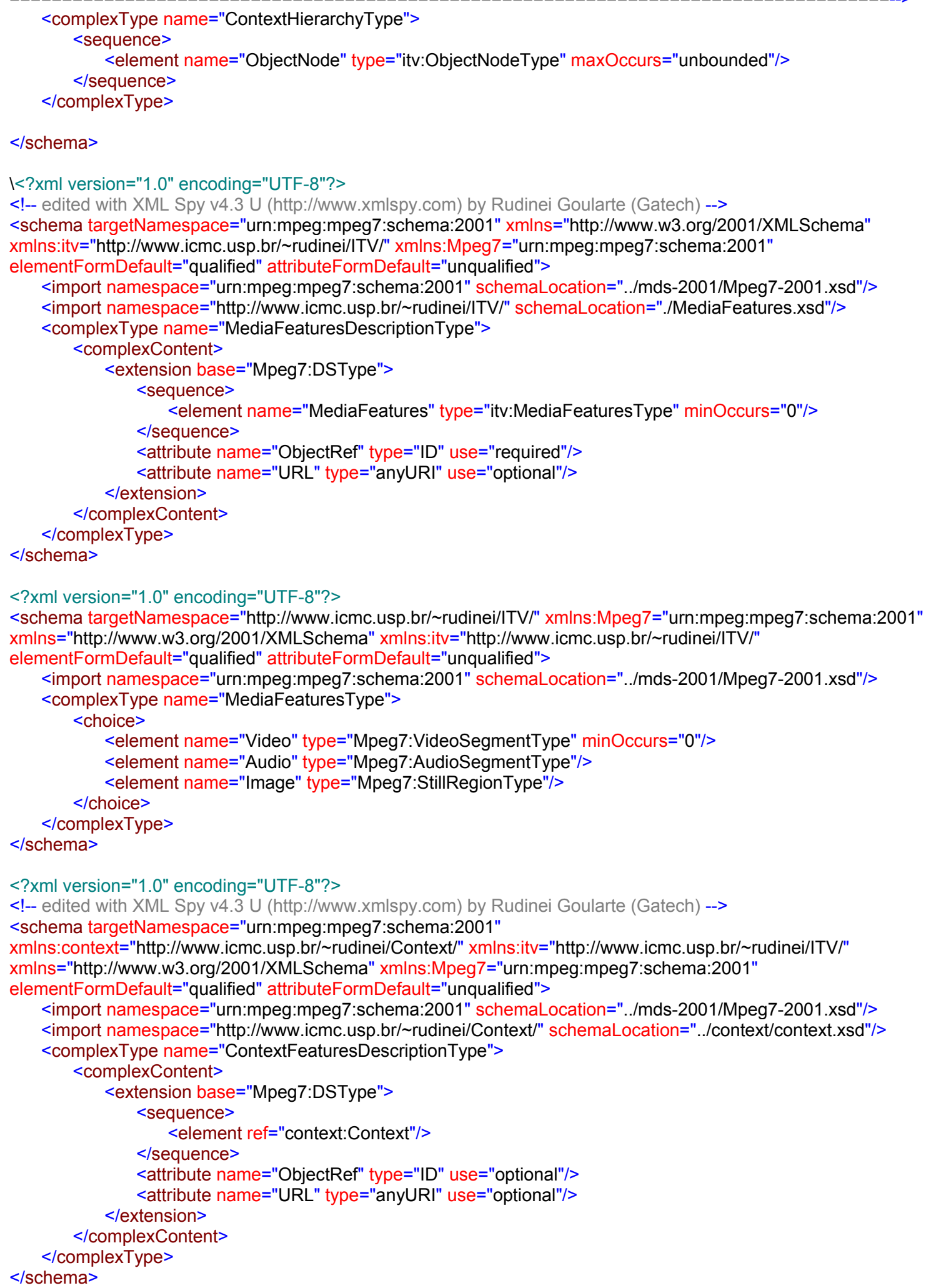




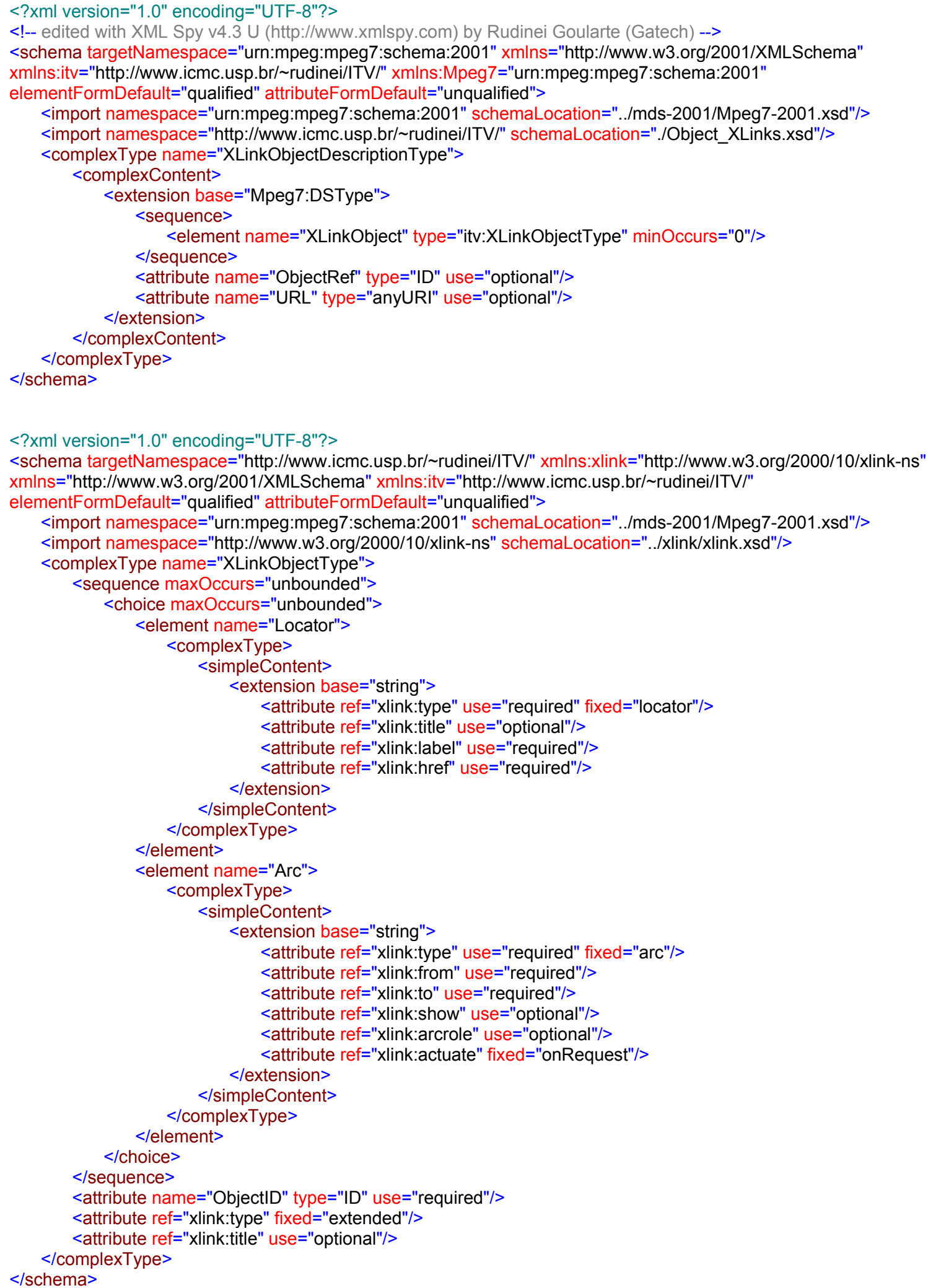




\section{Glossário}

Advanced simple. - É um perfil MPEG-4 que adiciona ao perfil simple ferramentas que melhoram a eficiência da compressão, como estimativa global de movimento e quadros de vídeo do tipo B (B-VOPs)

API - Application Programming Interface (Interface para Programação de Aplicação). Uma API é um padrão de interface para acesso a uma determinada aplicação, tornando a aplicação disponível em várias plataformas através de uma interface única.

Applet - É um pequeno programa (mais comumente em Java) embutido em uma página HTML executado pelo navegador do usuário. Applets se diferenciam de aplicações Java por não terem permissão de acesso a recursos como arquivos e dispositivos de rede, exceto se o acesso for feito ao computador de onde ele foi baixado. Essa é uma maneira de devolver aplicações locais ou funcionalidade baseada em serviço para um terminal de TV interativa.

ATM - Asynchronous Transfer Mode (Modo de Transferência Assíncrono). É um padrão emergente para redes de velocidades muito altas, normalmente usadas para transportar vídeo, áudio e dados integrados. ATM é considerado o padrão mais apropriado para sistemas avançados de TV interativa.

ATSC - Advanced Television Systems Committee (Comitê para o desenvolvimento de Sistemas Avançados para Televisão). É um comitê formado nos Estados Unidos para estabelecer padrões técnicos para sistemas avançados de TV, incluindo HDTV digital.

ATVEF - Advanced Television Enhancement Forum (Fórum para Melhoria de Televisão Avançada). É uma aliança de companhias de redes a cabo e por difusão, companhias eletrônicas e companhias de computadores pessoais. $O$ objetivo da aliança é o desenvolvimento de protocolos que permitam a criadores de conteúdo entregar programação de televisão interativa ou de televisão melhorada (enhanced TV).

Banda larga (do inglês broadband) - Um sistema combanda larga possui uma largura de banda muito alta. Em TV Interativa, o melhor exemplo é a TV a cabo, que pode devolver múltiplos canais e serviços.

BIFS - Binary Format for Scenes (Formato Binário para Cenas). É a representação binária de uma cena MPEG-4. 
Bitstream - É uma seqüência de bits transmitida através de um canal de comunicação digital. Um bitstream ocorre quando certa quantidade de dados é transmitida bit após bit.

Broadcast - ver difusão.

B-VOP - Bidirectional VOP. São VOPs codificados bidirecionalmente, usando as diferenças entre VOPs anteriores e posteriores

Canal de retorno (do inglês Return Path) - É a parte de um sistema de distribuição bidirecional sobre o qual os dados fluem do consumidor para o provedor de serviço.

CIF - Common Intermediate Format (Formato Intermediário Comum). É um formato padrão imagem definindo tamanho de quadro como $352 \times 288$ a taxa de 30 quadros por segundo (1 Megabit por segundo).

Codificador (do inglês encoder) - É um dispositivo que codifica ou mistura a informação antes da transmissão.

Comércio eletrônico (do inglês e-commerce) - $\mathrm{O}$ comércio eletrônico acontece quando uma firma vende algo pela Internet, utilizando alguma forma para o pagamento, tal como transações on-line com cartão de crédito.

Conteúdo - É um objeto de mídia e seu metadado.

Core - É um superconjunto do perfil MPEG-4 Simple, fornecendo melhor qualidade através de interpolação bidirecional de quadros (B-VOPs) e de codificação binária de formas. Tem suporte à escalabilidade temporal por meio do envio de P-VOPs extras.

Criador de conteúdo - É o produtor do conteúdo.

Crominância - É a parte de um sinal de TV ou vídeo que carrega a informação de cor. Há dois elementos de informação de crominância.

D - Descriptor (Descritor). No padrão MPEG-7 um descritor é a representação de uma característica, definindo a sintaxe e a semântica da representação da característica. Um descritor define de forma precisa a semântica da característica, os tipos de dados associados, os valores permitidos e uma interpretação dos valores do descritor. Descritores em MPEG-7 são definidos em DDL.

DAB - Digital Audio Broadcast (Difusão de Áudio Digital). Ver TV Digital.

DDL - Description Definition Language (Linguagem de definição de descrição). É a linguagem MPEG-7 que permite a criação de novos esquemas de descrição e de novos 
descritores. Também permite a extensão dos esquemas de descrição padrões . A DDL é baseada na linguagem XML Schema.

Decodificador (do inglês Decoder) - Em compressão digital, o decodificador é um dispositivo eletrônico usado para converter um sinal de TV encriptado ou comprimido em uma figura visível.

Difusão (do inglês broadcast) - Nome dado à prática de distribuir um sinal de uma fonte para vários destinos.

Downstream - O downstream acontece quando os dados fluem no sentido servidor-cliente.

Dublin core - É um conjunto de elementos de metadado que abrange 15 elementos básicos (tais como título, criador e formato) para descrição de recursos Web.

DVB - Digital Video Broadcasting (Distribuição de Vídeo Digital). Fórum da União Européia de Difusão (European Broadcasting Union) que desenvolve padrões e especificações de sistemas para difusão em televisão digital - DVB-S por satélite, DVB-C por cabo e DVB-T para o modo terrestre.

EBS - Envivio Broadcast Studio. É um software da empresa Envivio que permite a autoria e codificação de cenas MPEG-4.

ECT - Envivio Coding Tools. É um software da empresa Envivio que permite a codificação de cenas MPEG-4, incluindo MPEGlets, a partir de arquivos XMT.

EES - Envivio Encoding Station. É um software da empresa Envivio que permite codificar vídeos em formatos variados para vídeos em formato MPEG-4.

ELB - Envivio Live Broadcaster. É um software da empresa Envivio que permite capturar vídeo ao vivo codificando-o para o formato MPEG-4.

EPG - Electronic Program Guide (Guia de Porgramação Eletrônico). É um software que permite navegar por listas de programas de TV.

ES - Elementary Stream (Fluxo Elementar). No padrão MPEG-4 corresponde à forma codificada de um único objeto.

ESS - Envivio Streaming Server. É um software da empresa Envivio que permite transmitir vídeo no formato MPEG-4 utilizando a técnica de streaming.

ETV - Envivio TV. É uma implementação de um terminal MPEG-4 produzaida pela empresa Envivio. Funciona como um plug-in para os players RealOne ${ }^{\mathrm{TM}}$, QuickTime ${ }^{\mathrm{TM}} \mathrm{e}$ Windows Media ${ }^{\mathrm{TM}}$.

Fluxo (do inglês stream) - Em computação refere-se a um fluxo de dados. 
HDTV - High Definition Television (Televisão de Alta Definição). Refere-se à tecnologia de TV com qualidade superior a da TV por difusão convencional. Possui 1920 pixels/linha, 1080 linhas/quadro, e exibe 60 quadros por segundo.

HTML - Hypertext Markup Language (Linguagem para Marcação de Hipertexto). Linguagem de marcação de texto utilizada para a apresentação de hiperdocumentos na WWW.

Hiperligação (do inglês hiperlink) - São elementos dentro de uma página Web que podem ser clicados e, assim, levar o usuário a uma outra página ou área dentro da mesma página.

Hipermídia - É a união do hipertexto com a multimídia, isto é, é a utilização de documentos com ligações para diversos tipos de mídia, podendo estas mídias serem exibidas simultaneamente.

Hipertexto - É uma maneira de representar informações textuais de forma não-linear, permitindo que, a partir de um documento, usuários acessem outros documentos.

I-VOP - Intracoded VOP. É uma imagem intracodificada autocontida similar às usadas na compressão JPEG

JPEG - Joint Picture Experts Group (Grupo de Especialistas em Imagens). Padrão internacional para codificação de imagens estáticas.

Largura de banda (do inglês bandwidth) - Intervalo do espectro de freqüências disponível ou necessário para transmitir dados (imagens, áudio, pacotes digitais) sobre um meio, tal como cabo ou ar, ou sobre um dispositivo eletrônico. Quanto maior é a largura de banda disponível, maior é a quantidade de dados que pode ser transferida por segundo.

Luminância - É o componente de brilho no sinal de uma TV colorida.

Metadado - Metadados são os dados sobre o conteúdo. Considerando um programa de TV digital, por exemplo, a informação de metadado do programa poderia ser o título, o gênero e o sumário.

MPEGlet - O termo MPEGlet é uma alusão aos applets Java. É um programa Java desenvolvido por meio da API MPEG-J, a qual permite a um teminal MPEG-4 acessar e modificar o grafo da cena. MPEGlets são transmitidos em um fluxo elementar MPEG-4 para serem executados em um terminal no cliente.

Multimídia - É a utilização simultânea de vários tipos de mídia (texto, sons, imagens, gráficos, vídeos e animações).

Navegador (do inglês browser) - É um aplicativo para a apresentação de hiperdocumentos. A maioria dos navegadores disponíveis trabalha com hiperdocumentos HTML, e são utilizados na navegação pela Internet para a visualização das informações (textos, gráficos, imagens, sons, animações e vídeos) disponíveis. 
NTSC - National Television Systems Committee (Comitê Nacional para Sistemas de Televisão). Padrão de cores da televisão analógica dos Estados Unidos.

PAL - Phase Alternating Line (Linha de Alternância de Fase). Nome do sistema de transmissão de cores usado na Alemanha, parte da África, parte da Ásia e no Brasil. Possui vários padrões, no Brasil adota-se o padrão $\mathrm{M}$.

Pay-per-view - É um sistema onde o consumidor paga apenas pelos programas que ele assiste em um determinado canal de TV, ao invés de pagar por todo canal.

PDA - Personal Digital Assistant (Assistente Pessoal Digital). É um dispositivo do tamanho de um bolso usado para gravar mensagens digitadas ou escritas, que podem ser transportadas para um computador.

PDR - Personal Digital Recorder (Gravador Digital Pessoal). Um PDR é uma espécie de videocassete digital. É composto por uma placa de captura de vídeo, permitindo receber vídeo analógico dos programas de TV e transforma-los em vídeo digital. Um PDR também contém um disco rígido, para gravar os vídeos digitais, que pode variar de tamanho de acordo com o modelo. PDRs são utilizados no desenvolvimento de serviços avançados em TV Interativa como pausas, avanços e retrocessos em programas ao vivo.

Perfil - O perfil consiste de todas as informações que estão disponíveis sobre um usuário/grupo/sistema/terminal/serviço que pode ser usado para personalizar informações ou serviços.

Personalização - É o processo no qual um sistema se adapta a fim de satisfazer os requisitos de determinado usuário.

Programa - Nesta tese, o termo programa é usado como um sinônimo para uma apresentação de TV Interativa.

Provedor de conteúdo - É uma entidade que age como o agente para o conteúdo. Por exemplo, uma editora poder ser considerada um provedor do conteúdo.

Provedor de serviço - É uma entidade que age como explorador do serviço orientado a conteúdo.

P-VOP - Previous VOP. É uma imagem onde apenas a diferença entre o VOP atual e um conjunto de VOPs anteriores é codificada.

Q-CIF - Quarter CIF. É um formato padrão imagem definido com um quarto do tamanho CIF. O tamanho de quadro Q-CIF é de 176x144 e a taxa de quadors é de 15 quadros por segundo (250 Kilobits por segundo).

Razão de aspecto - É a razão entre a largura e a altura da imagem da TV. Nos vídeos PAL e NTSC o padrão é 4 por 3 (4:3). Para HDTV, o padrão é 16 por 9 (16:9). 
SECAM - Sequential Couleur Avec Memoire. Sistema de cor para TV usado na França, Rússia, etc.

Mecanismo de busca (do inglês search engine) - É um software que procura por strings (palavras), dadas pelo usuário, em um conjunto de informações. São normalmente usadas na Internet para encontrar documentos contendo certas palavras.

Segmentação - É o processo de identificar porções distintas de um documento, tais como cabeçalho, seções, parágrafos e figuras. Em multimídia porções podem ser seqüências, cenas e quadros, por exemplo,

Set-top box - ver URD.

Simple - É um perfil MPEG-4 que define um objeto de vídeo natural e retangular, tolerante a erros, com razão largura-altura arbitrária. É baseado em VOPs dos tipos I e P.

Stream - ver fluxo.

Streaming - É um bitstream em tempo real contendo informação de áudio ou vídeo, que torna possível apresentar a informação antes que a transmissão tenha se completado. Pode ser contrastado ao processo de downloading, que espera todos os dados chegarem para realizar a apresentação.

Taxa de amostragem - É a freqüência com a qual as amostras são obtidas em operações de digitalização. Taxas de amostragens para áudio variam de 11 até $48 \mathrm{kHz}$ e para vídeo variam de 13.5 até $75 \mathrm{MHz}$.

TV Digital - É quando sinais de televisão são devolvidos em uma forma digital. As vantagens da TV digital são o aumento da qualidade e a largura de banda reduzida. Além disso, difusão digital permite o desenvolvimento de serviços de TV interativa.

Upstream - O upstream acontece quando os dados fluem no sentido cliente-cliente.

URD - Unidade Receptora-Decodificadora. É um dispositivo eletrônico do consumidor que serve como um elo de ligação entre a TV e a rede.

URI - Uniform Resource Identifier (Identificador Uniforme de Recursos). É o conjunto genérico de todos os nomes/endereços (strings) que fazem referência a recursos na WWW.

Vídeo sob demanda - É um serviço para entretenimento e informação que permite aos consumidores comprarem programas em qualquer momento que eles desejarem. Sistemas de vídeo sob demanda requerem que servidores de vídeo sejam capazes de mandar vários fluxos de vídeo simultaneamente para consumidores diferentes. Serviços de pay-per-view com vídeo sob demanda prometem ser a maior fonte de renda da TV Interativa. 
VO - Video Object (Objeto de Vídeo). Um objeto de vídeo corresponde a um objeto 2D particular na cena. No caso mais simples ele pode ser um quadro retangular - um quadro de vídeo. Um objeto de vídeo pode ser também um objeto de forma arbitrária, correspondendo a um objeto intraquadro ou a um recorte correspondendo apenas ao fundo (background) da cena.

VOL - Video Object Layer (Camada de Objeto de Vídeo). Cada objeto de vídeo pode ser codificado de modo escalável (múltiplas camadas) ou não escalável (uma única camada), dependendo da aplicação. Cada camada é representada por uma VOL e cada VOL é composta por uma seqüência de VOPs.

VOP - Video Object Plane (Plano do Objeto de Vídeo). Um VOP é uma amostra no tempo de um objeto de vídeo. VOPs podem ser codificados tanto de modo independente quanto de modo dependente uns dos outros, usando compensação de movimento. Um quadro de vídeo convencional pode ser representado por um VOP com forma retangular, assim como o contorno da imgem de uma pessoa pode ser codificado com um VOP com forma arbitrária.

VRML - Virtual Reality Modeling Language (Linguagem de Modelagem para Realidade Virtual). É o padrão da Internet para animações tridimensionais. É uma linguagem, similar à HTML, que permite que projetistas de web sites criem formas primitivas de realidade virtual na Internet.

Wide-screen - TV com imagem mais larga, que usa razão de aspecto de 16:9 ao invés de 4:3 das TVs convencionais. 